Florida International University

FIU Digital Commons

$11-12-2020$

\title{
A Structural Equation Model Analysis of Computing Identity Sub- Constructs and Student Academic Persistence
}

\author{
Mohsen Taheri \\ Florida International University, mtahe006@fiu.edu
}

Follow this and additional works at: https://digitalcommons.fiu.edu/etd

Part of the Engineering Education Commons, and the Other Computer Engineering Commons

\section{Recommended Citation}

Taheri, Mohsen, "A Structural Equation Model Analysis of Computing Identity Sub-Constructs and Student Academic Persistence" (2020). FIU Electronic Theses and Dissertations. 4575.

https://digitalcommons.fiu.edu/etd/4575

This work is brought to you for free and open access by the University Graduate School at FIU Digital Commons. It has been accepted for inclusion in FIU Electronic Theses and Dissertations by an authorized administrator of FIU Digital Commons. For more information, please contact dcc@fiu.edu. 


\title{
FLORIDA INTERNATIONAL UNIVERSITY
}

Miami, Florida

\section{A STRUCTURAL EQUATION MODEL ANALYSIS OF COMPUTING IDENTITY SUB-CONSTRUCTS AND STUDENT ACADEMIC PERSISTENCE}

\author{
A dissertation submitted in partial fulfillment of \\ the requirements for the degree of \\ DOCTOR OF PHILOSOPHY \\ in \\ COMPUTER SCIENCE \\ by
}

Mohsen Taheri 
To: Dean John L. Volakis

College of Engineering and Computing

This dissertation, written by Mohsen Taheri, and entitled A Structural Equation Model Analysis of Computing Identity Sub-Constructs and Student Academic Persistence, having been approved in respect to style and intellectual content, is referred to you for judgment.

We have read this dissertation and recommend that it be approved.

Zahra Hazari

Mark Allen Weiss

Peter J Clarke

Nagarajan Prabakar

Monique Ross, Major Professor

Date of Defense: November 12, 2020

The dissertation of Mohsen Taheri is approved.

Dean John L. Volakis

College of Engineering and Computing

Andrés G. Gil

Vice President for Research and Economic Development and Dean of the University Graduate School

Florida International University, 2020 
C Copyright 2020 by Mohsen Taheri

All rights reserved. 


\title{
ABSTRACT OF THE DISSERTATION
}

\section{A STRUCTURAL EQUATION MODEL ANALYSIS OF COMPUTING IDENTITY SUB-CONSTRUCTS AND STUDENT ACADEMIC PERSISTENCE}

\author{
by \\ Mohsen Taheri \\ Florida International University, 2020 \\ Miami, Florida

\section{Professor Monique Ross, Major Professor}

This dissertation explores the impact of computing identity sub-constructs on the academic persistence of computing students. This research provides models, quantified relationships, and insights to increase the number of graduates with the intention of pursuing a career in computing. Despite the growing significance of computer science and all the projected new jobs in computer science, many university and college programs suffer from low student persistence rates. One theoretical framework used to better understand persistence in other STEM disciplines is disciplinary identity. Disciplinary identity refers to how students see themselves with respect to a discipline. This study examines the effects of computing identity sub-constructs (performance/competence, recognition, interest, and sense of belonging) on the academic persistence of computing students. A quantitative analysis with three phases was performed for this study. First, confirmatory factor analysis (CFA) and structural equation model (SEM) analysis were performed to validate and explore the relationship between sub-constructs in the computing identity model. Second, a multigroup SEM was performed to estimate the impact of the identity sub-constructs on persistence for students with diverse demographics in this case by gender and level of education. Third, 
a time-series SEM were used to investigate the impact of identity development on computing persistence over time. The findings indicated that students' academic persistence was directly influenced by their interest as the most significant factor. In addition, performance, competence, recognition, and sense of belonging contributed to students' identity development and academic persistence. Results of the second analysis indicated identity sub-constructs contributed differently to academic persistence among freshman and senior students; however, no significant differences were found between male and female students. Ultimately, the last analysis with time-series data indicated that interest and competence/performance, as individual factors had the strongest direct impacts on persistence over time. Considering student identity in understanding academic persistence in computing programs may provide a meaningful lens of analysis for institutes and their curriculum and extracurricular planning methods. In addition, the development of students' self-beliefs provides ways for increasing the number of graduates with increased likelihood of pursuing computing careers. 


\section{ACKNOWLEDGMENTS}

This dissertation is based upon work supported by the National Science Foundation [Collaborative Research: Florida IT Pathways to Success (Flit-Path) NSF\# 1643965, 1643931, 1643835]. Any findings, conclusions, and recommendations expressed in this work do not necessarily reflect the views of the National Science Foundation. 


\section{TABLE OF CONTENTS}

CHAPTER

PAGE

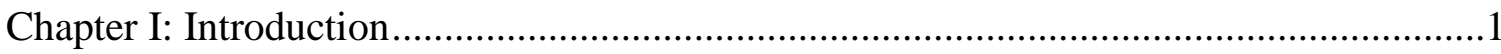

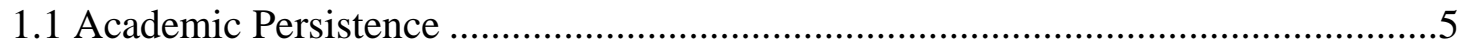

1.1.1 STEM, Engineering and Computing Persistence......................................16

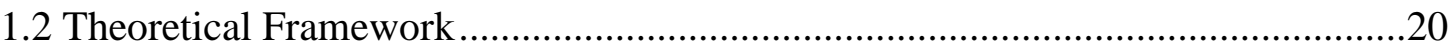

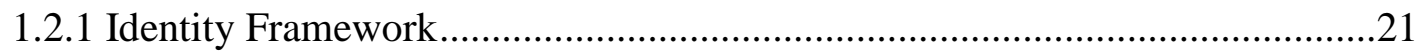

1.2.2 Social Cognitive Career Theory .............................................................25

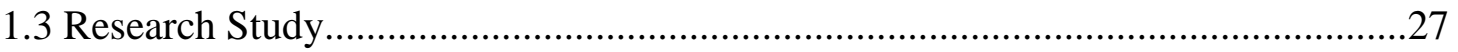

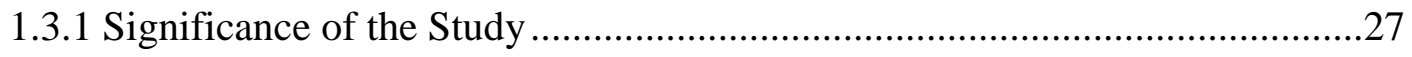

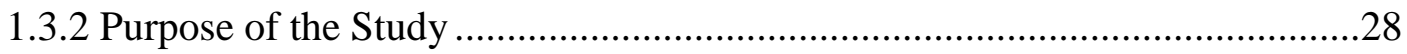

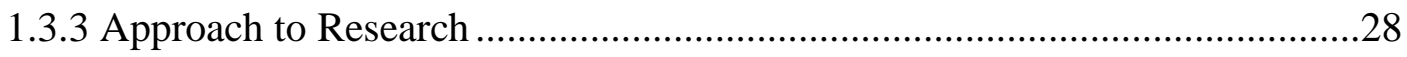

1.3.4 Research Questions and Explanation of Research Design .........................29

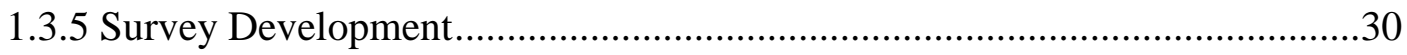

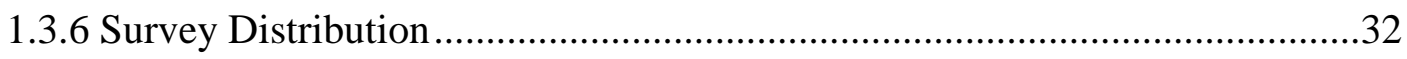

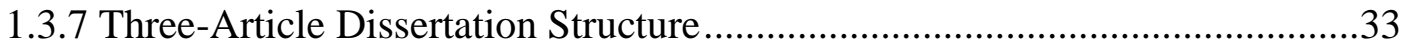

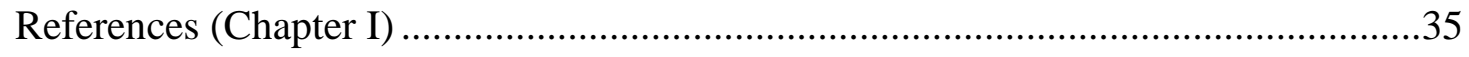

Chapter II: Article I: A Structural Equation Model Analysis of Computing Identity Sub-

Constructs and Student Academic Persistence ..............................................................43

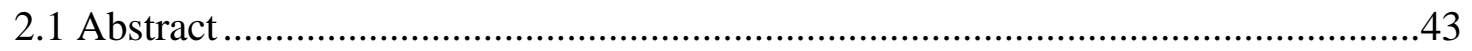

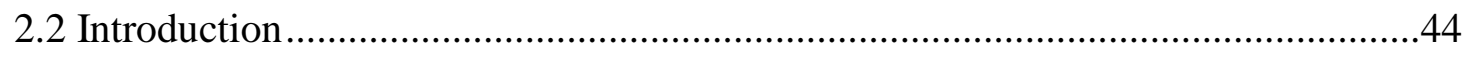

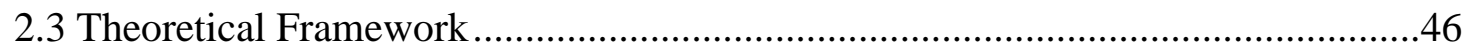




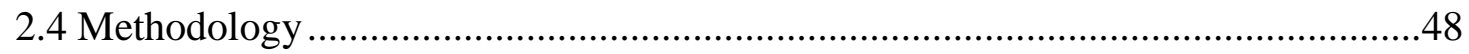

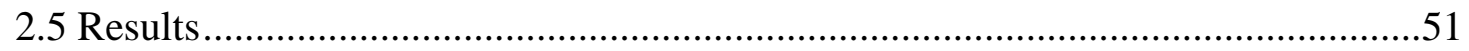

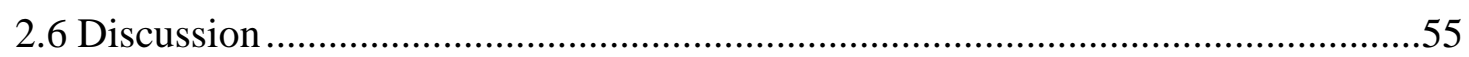

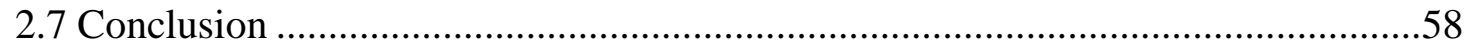

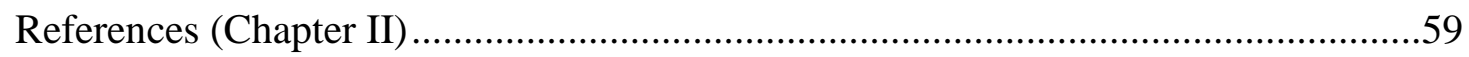

Chapter III: Article II: Exploring Computing Identity and Persistence Across Multiple Groups Using Structural Equation Modeling ……………............................................64

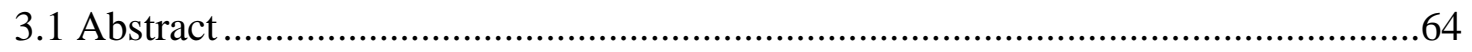

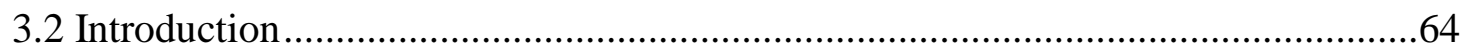

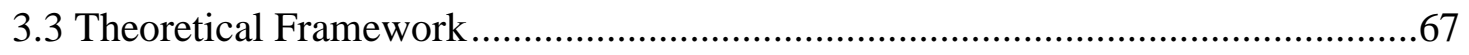

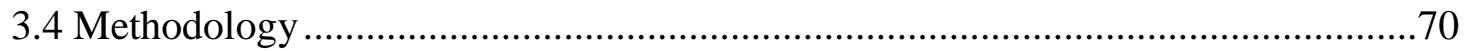

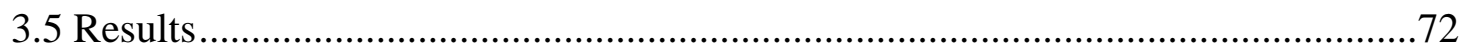

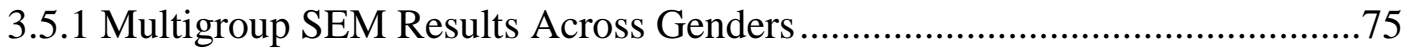

3.5.2 Multigroup SEM Results Across Level of Education......................................78

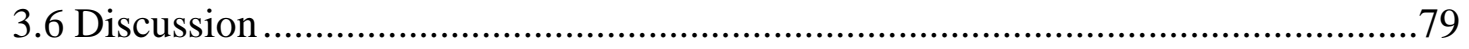

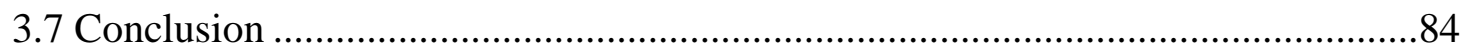

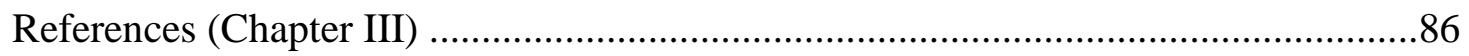

Chapter IV: Article III: Understanding Computing Persistence and Identity Through Structural Equation Modeling with Time Series Data ......................................................90

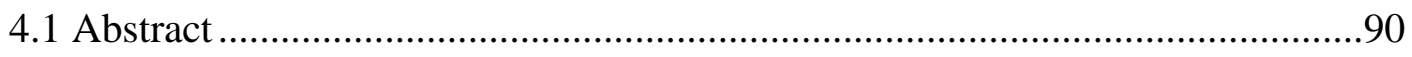

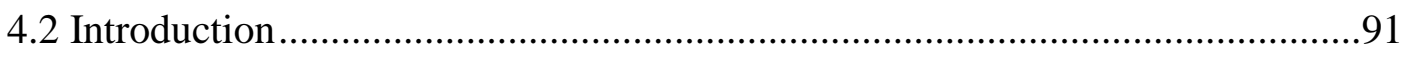




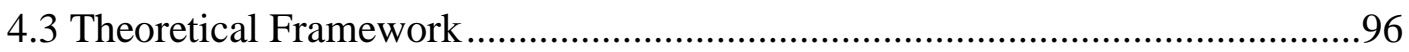

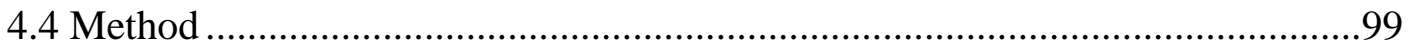

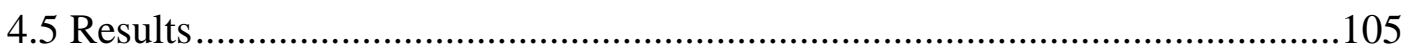

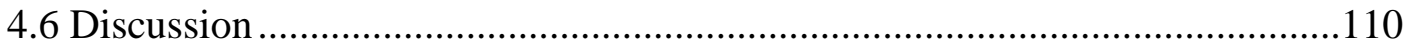

4.6.1 Implications for Practice ............................................................115

4.6.2 Limitations and Future Work ............................................................118

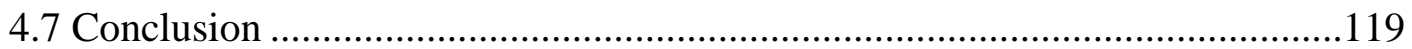

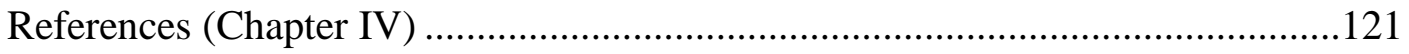

Chapter V: Discussion and Conclusion ..........................................................126

5.1 Synthesizing the Three-Article Dissertation ............................................126

5.1.1 Addressing the Research Questions ................................................127

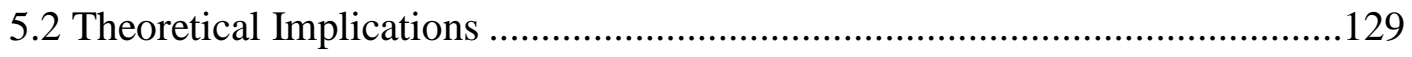

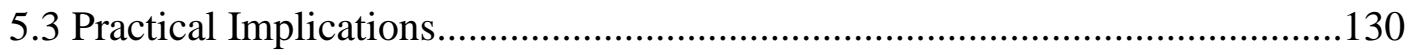

5.4 Limitations and Recommendations for Future Research............................132

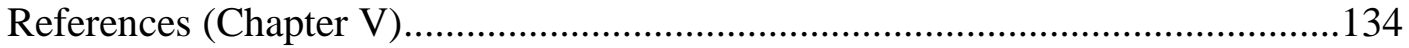

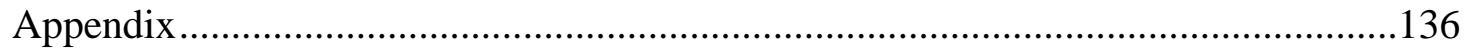

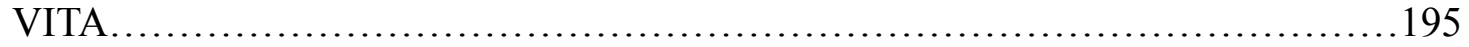




\section{LIST OF TABLES}

TABLE

PAGE

\section{Chapter II}

Table 1 - Confirmatory Factor Analysis Estimates and Fit Indices

\section{Chapter III}

Table 1 - Confirmatory Factor Analysis and List of Variables

\section{Chapter IV}

Table 1.a - Level of Education. These tables show that our target population represents the larger population

Table 1.b - Gender 103

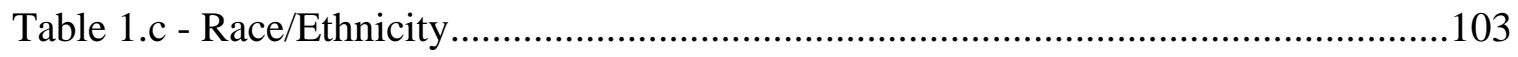

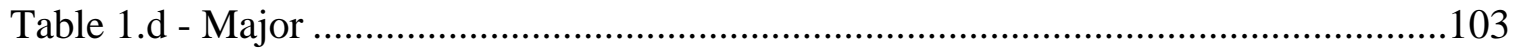

Table 2 - List of Variables for 2017 (T1) and 2019 (T2), and Confirmatory Factor Analysis (CFA) Results. 


\section{LIST OF FIGURES}

\section{FIGURE}

PAGE

\section{Chapter I:}

Figure 1 - Spady’s Dropout Process Model 1971 ........................................................

Figure 2 - Tinto's Integration Model 1975 ..............................................................

Figure 3 - Tinto's Institutional Departure Model 1993 ...............................................10

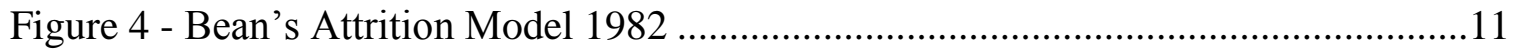

Figure 5 - Bean and Metzner's Model of Student Dropout 1985 ..................................12

Figure 6 - Bean and Eaton's Model of College Student Retention 2001........................13

Figure 7 - Student-Faculty Informal Contact Model 1980 .........................................13

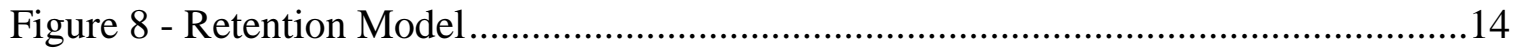

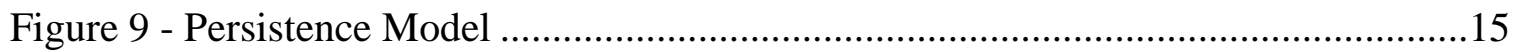

Figure 10 - Carlone and Johnson's Initial Science Identity Model 2007 ........................22

Figure 11 - Hazari, Sonnert, Sadler, and Shanahan's Disciplinary Identity Framework

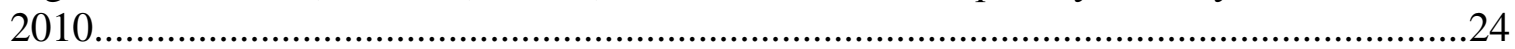

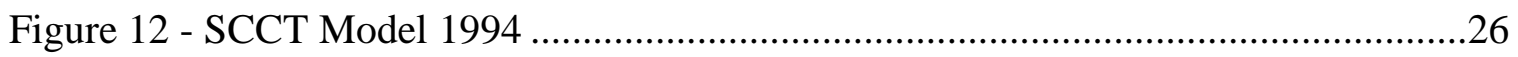

Figure 13 - Demographics of Flit-Path Survey Participants ..........................................33

\section{Chapter II}

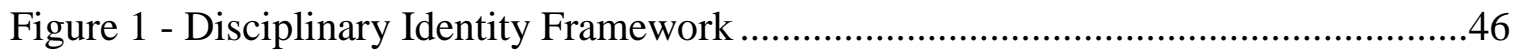

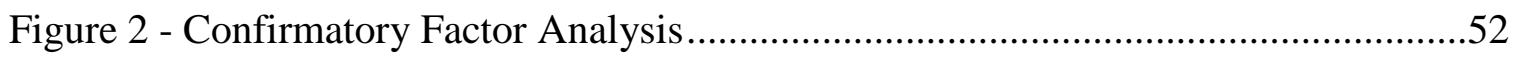

Figure 3 - Structural Equation Modeling Results .................................................54 


\section{Chapter III}

Figure 1 - Disciplinary Identity Framework

Figure 2 - Multigroup Structural Equation Modeling Results among Male and Female

Students

Figure 3 - Multigroup Structural Equation Modeling Results among Freshman and Senior Students ................................................................ 77

\section{Chapter IV}

Figure 1 - Computing Identity Framework

Figure 2 - Path Analysis Model

Figure 3 - Confirmatory Factor Analysis Indicators

Figure 4 - Structural Equation Modeling with Time Series Data

Figure 5 - The Importance of Individual Factors on Computing Persistence Over Time.....

Figure 6 - The Importance of Interest over Time in Computing Identity Development .111

Figure 7 - The Importance of The Development of Competence/Performance Over Time......

Figure 8 - Correlations among Identity Sub-constructs and the Importance of Competence/Performance Role as a Mediator Over Time 


\section{ABBREVIATIONS AND ACRONYMS}

Confirmatory Factor Analysis. CFA

Exploratory Factor Analysis ……………………….............................................EFA

Structural Equation Modeling ............................................................................. SEM

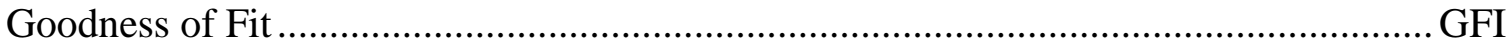

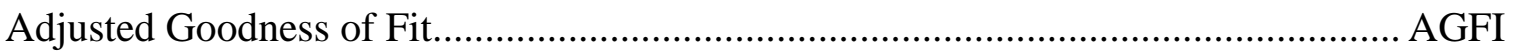

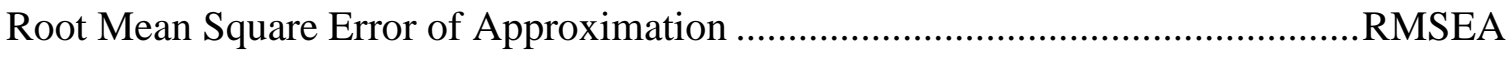

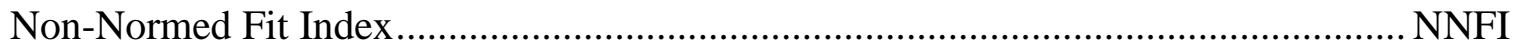

Standardized Root Mean Square Residual..................................................... SRMR

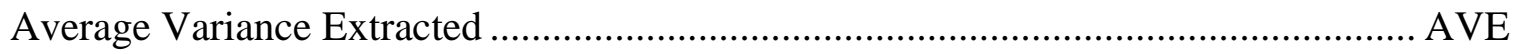

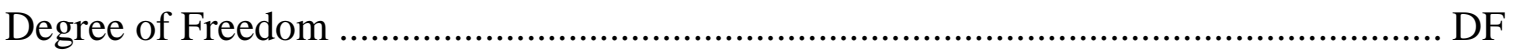




\section{Chapter I: Introduction}

Computing graduates are among the most in-demand on the job market. Employment in computing occupations is projected to grow 11 percent by 2029 by adding 531,200 new jobs in the United States (U.S. Bureau of Labor Statistics, 2020). The employment rate and median annual wage for computing is much higher than the average for all occupations (U.S. Bureau of Labor Statistics, 2020) (Fayer et al., 2017). In a nutshell, computing jobs provide many affordances including high wages, fast growth, and many openings (U.S. Bureau of Labor Statistics, 2020). However, the attrition rate in computer science is the highest among STEM disciplines (Chen, 2013). Academic persistence in computing majors continues to be a concern for schools and a top priority amongst faculty and administrators (Association for Computing Machinery, 2018). As such, schools, colleges, computing organizations, and even families are looking for solutions to retain students to graduation.

Persistence is important to CS students because completing a degree and learning computing skills increases the chance of getting a job. Likewise, students who do not persist are burdened with academic financial debt without the reward of a high paying position. Student persistence and graduation are both highly impactful factors in an institute's ranking and reputation (U.S. News \& World Report, 2020), resulting in schools spending a lot of campus resources on educational programs. Increasing persistence rates helps institutions yield a return on their investments. Persistence is also important to parents as it keeps them hopeful about their children's future regarding career opportunities and making a 
positive contribution to society (Tinto, 1987). It is also important to industry and government since both have identified employment gaps in these fields (Association for Computing Machinery, 2018).

Many students in higher education programs do not complete a degree and achieve their academic and career goals. In spite of efforts to retain students, some students drop out prior to their graduation. The U.S. Department of Education and the Center for Educational Statistics (National Center for Education Statistics, 2020) have reported that almost 40 percent of the undergraduates do not complete a degree due to various factors. Meeting the needs of students with diverse backgrounds has always been a complex problem. The literature on academic persistence is rich in theoretical models, strategies, and techniques that help to deal with common problems for college persistence. In this dissertation, some of the known models and important factors contributing to academic persistence are introduced. Some of these factors might not be easily controllable by schools. However, other factors could be influenced by school programs. For instance, it is much easier to help students develop interest rather than their socioeconomic status. Studying students' self-beliefs and their impact on academic persistence has been identified as an effective means of understanding the challenges in persistence (Hazari et al., 2010; Cass et al., 2011; Cribbs et al. 2016).

The impact of students' self-beliefs as a separate factor for persistence and choice of career has not been explored thoroughly in computing. This dissertation aims to fill this gap by studying the impact of students 'self-beliefs such as 
interest, recognition, performance, competence, and sense of belonging on their academic persistence. One theoretical framework used to better understand students' persistence is disciplinary identity (Hazari et al., 2010). Disciplinary identity refers to how students see themselves with respect to a discipline, and it is related to long-term membership in a disciplinary community (Hazari et al., 2010). For this study, construct and sub-construct are the building blocks of the models and theories that help to explain why and how specific phenomena behave. For instance, disciplinary identity has been theorized as being shaped by several sub-constructs such as interest, recognition, performance/competence and sense of belonging (Hazari et al., 2010). These types of constructs/sub-constructs are latent variables which cannot be observed and directly measured (latent variables) (Everett, 2013). However, each construct/sub-construct can be captured and represented to some extent by measurable variables (observable variables). In other words, to measure the impact of identity on persistence, I created proxies for the identity sub constructs (interest, recognition, performance, competence, and sense of belonging), and using observable variables to directly represent each sub-construct (latent variables). The structural equation modeling (SEM) used in this dissertation examines the impact of all sub-constructs on each other and on persistence.

Persistence for the purpose of this study refers to the willingness and the continuation of an effort to graduate with career intentions in the same/related area. In this section, I explore the academic persistence frameworks and theories and introduce previous studies on STEM, engineering, and computing persistence. 


\section{Problem}

The United States is facing a crisis regarding filling job vacancies related to computer science and information technology. Computing jobs are in demand in many different working environments from research and academia to industry and government (U.S. Bureau of Labor Statistics, 2020; National Science Board, 2018). Although computing graduates are still the primary preferred workforce sector for these environments, schools suffer from low persistence rates in computer science, computer engineering, and information technology programs (National Center for Science and Engineering Statistics [NCSES], 2017). To fill the gap between the number of graduates and job demands, to find ways to help students, and to provide insights to institutes, this study concentrates on students' self-beliefs and their relationship with academic persistence.

\section{Research Questions}

The research questions for this dissertation are as follows:

1) How do the theorized identity sub-constructs (performance/competence, recognition, interest, and sense of belonging) contribute to the academic persistence of computer science students?

2) How do the theorized identity sub-constructs contribute to the academic persistence of computer science first-year students versus senior undergraduate students?

3) How do the theorized identity sub-constructs contribute to the academic persistence of computer science male students versus female students? 
4) How do the identity sub-constructs contribute to the academic persistence of computer science students over time?

Manuscript one answers the first question. Manuscript two addresses the second and third research questions. The third manuscript answers the fourth research question.

\subsection{Academic Persistence}

To understand the impact of different constructs on academic persistence, this section introduces some of the known models and theories. The goal is to provide a high-level picture of all different factors contributing to a student's persistence, and highlighting the well-known models and persistence factors that are related to self-beliefs such as interest and self-efficacy. After introducing these models and studies, the two main theories used for the framing and SEM analysis will be thoroughly described. In this section, I explore the academic persistence frameworks and theories and introduce previous studies on persistence in STEM, engineering, and computing.

As mentioned earlier, computing persistence in this dissertation refers to graduation with career intentions in computer science. However, persistence and other terms such as retention have been used in the past with slightly different definitions. The earliest research of undergraduate persistence in the U.S. was performed in the 1930s (Berger et al., 2005). Since then, there have been several terms interchangeably used in academic and non-academic studies to describe students' departure. In the next section, some of these terms will be introduced when the related theories and models are discussed. These terms include 
persistence, retention, attrition, dropout, and withdrawal. Persistence in prior studies refers to students continued enrollment and their interest and action to complete their degree and returning to college within the higher education system (at any institution). However, retention refers to the continued enrollment and students' desire and action to stay with a specific college to complete a degree (Demetriou et al., 2011). Attrition refers to students who leave a particular school and do not enroll in consecutive terms (Berger et al., 2005). Dropout refers to students who have initial goals to complete a degree, but they do not or cannot (Aljohani, 2016). Withdrawal refers to students' departure from a school (Berger et al., 2005). It is worth mentioning that I have leveraged the definition of traditional persistence (intent to degree completion at any institution) and extended this construct by considering the student's career intentions in the same/related area. The next sections cover both persistence theory and practice from the perspective of researchers and practitioners. It describes the most important factors for academic persistence and their development over time.

Student persistence has been a critical concern since the beginning of the formal education system (Habley et al., 2012; Seidman, 2005; Tinto, 1975; Tinto 1987; Tinto 1988). Before 1970, many scholars studied academic persistence (Panos et al., 1968; Bayer, 1968; Marks, 1967). These researchers mainly focused on students and students' characteristics such as race, gender, and GPA. They did not concentrate on the students' interaction with the school environment (Tinto, 1993; Spady, 1971). Theoretical frameworks on persistence from systematic research were established in the 1970s (Astin et al., 2012). In the 1970s, 
researchers established some theoretical frameworks and systematic studies on students' interaction with schools (Tinto, 1975; Pascarella et al., 1979; Bean, 1980). Spady (1971) published his model and study on student dropout in higher education (Spady, 1971). He described the dropout process by exploring the student-school relationship. He believed students' persistence decision was dependent on two different systems: academic system including their intellectual development and academic performance, and social system including friendship support. Since then, many other models that leveraged the student-school relationship were proposed. For instance, Tinto $(1975,1993)$ proposed a model for institutional departure. Bean $(1980,1982)$ proposed a model for attrition. Pascarella (Pascarella et al., 1980) proposed a model for interaction between students and faculty. Astin (Astin, 1984) proposed a model for student involvement. Bean (Bean et al., 1985) proposed another model for student attrition. Cabrera and his colleagues (Cabrera et al., 1993) proposed a model for student persistence. Some of these models will be described to show how different constructs impact persistence, and how self-beliefs are involved.

The models developed by Tinto and Spady were derived from a theory that explored suicide (Durkheim, 1951). Durkheim's suicide model was based on social and intellectual integration into an individual's social life. He concluded that the less socially integrated and connected people are, the more likely they are to commit suicide. Models in the early 1970 such as Tinto's model and Spady's model used this key point for student behavior in persistence. Further research found that the suicide phenomenon was not completely equivalent to dropout 
(Tinto, 1993). They looked at the similarities like the voluntary withdrawal from a particular community or society. In Spady's model (dropout process model)

(Figure 1), several factors affect student decisions including family background, academic potential, friendship support, normative congruence, intellectual development, grade performance, social integration, satisfaction, and intellectual commitment.

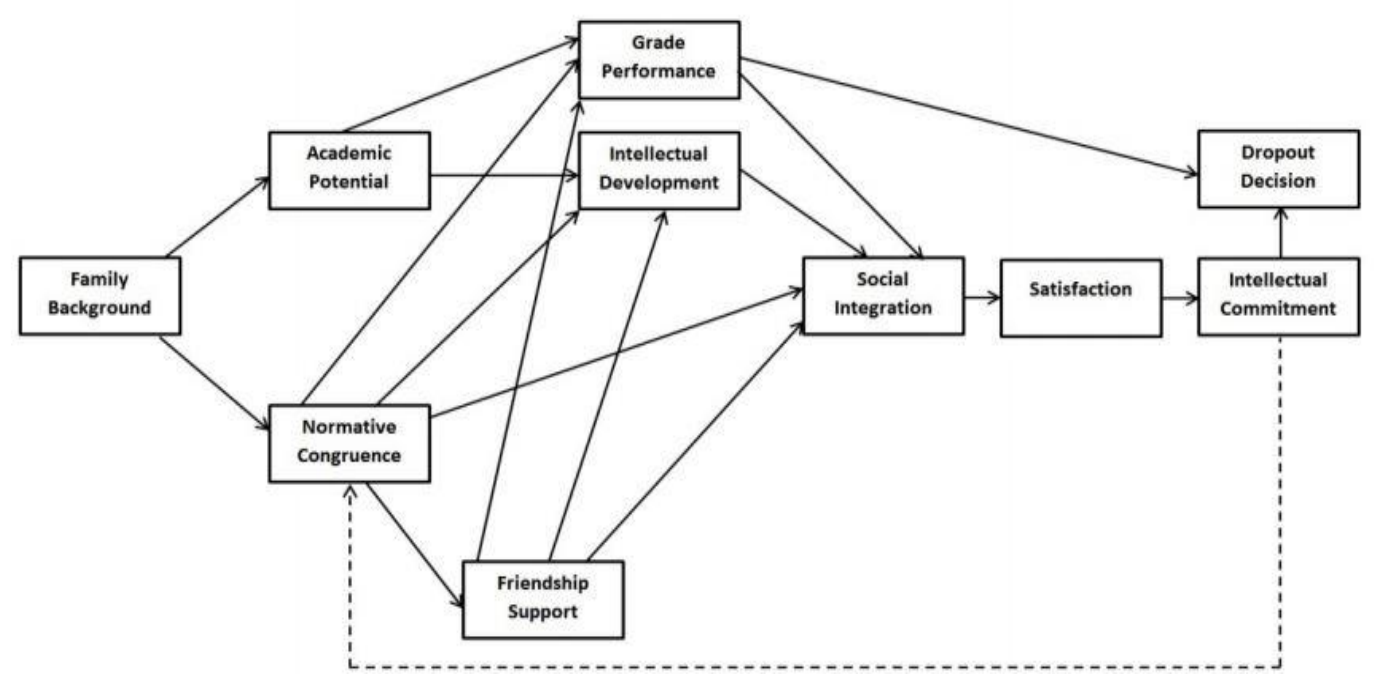

Figure 1- Spady's Dropout Process Model 1971. Note: Adapted from "Dropouts from higher education: Toward an empirical model" by WG. Spady, 1971, Interchange, 2(3), 38-62.

The other significant study was Tinto's integration model (Tinto, 1975)

(Figure 2). Tinto's model was one of the most known frameworks which had three phases including students' separation from their old community, transition, and integration in the new college community. This work was partially adopted from Van Gennep's rite of passage model (Van Gennep, 1960, 2019). Tinto’s original integration model was later revised by himself and other researchers (Pascarella et al., 1979; Tinto, 1988; Cabrera et al., 1992). He published the 
revised model (institutional departure model) in 1993 (Figure 3) which was similar to Spady's model of student-institution interaction.

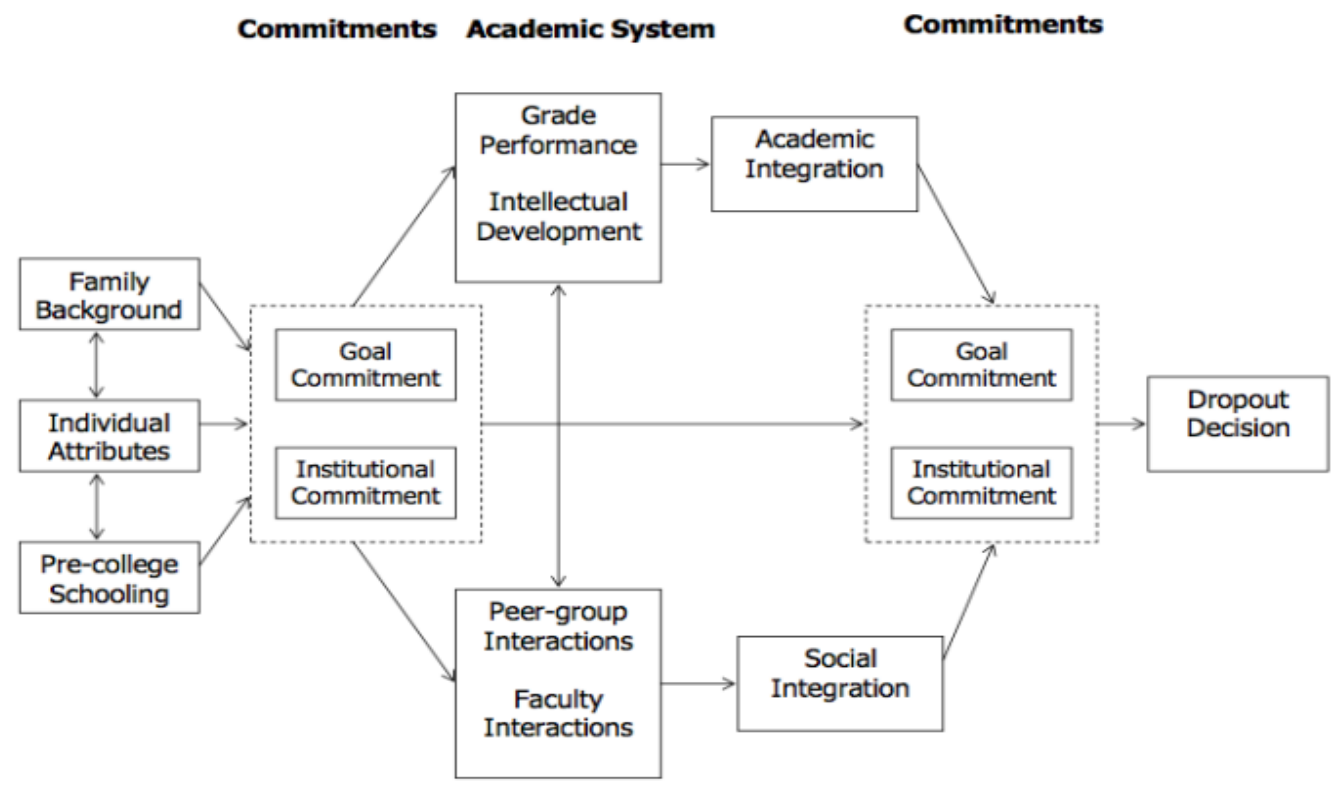

Figure 2 - Tinto's Integration Model 1975. Note: Adapted from "Dropout from higher education: A theoretical synthesis of recent research" by V. Tinto, 1975, Review of educational research.

Tinto's new model stated that a student needed to be integrated into both academic and social systems to be able to persist. Tinto's institutional departure model included four categories. The first category consisted of pre-entry attributes such as skills, family background, prior schooling, and abilities. The second category included goals and commitments. The third category was defined as institutional experience that included extracurricular activities, academic performance, peer group interactions, and faculty-staff interactions. The fourth category included academic integration and social integration. In this model, goal and institutional commitments had a direct impact on students' decisions. Tinto's model indicated that campus relationships and networks are vital in students' 
persistence. Later in the next section, the importance of sense of belonging in an academic environment, and the impact of educational and social communities will be discussed.

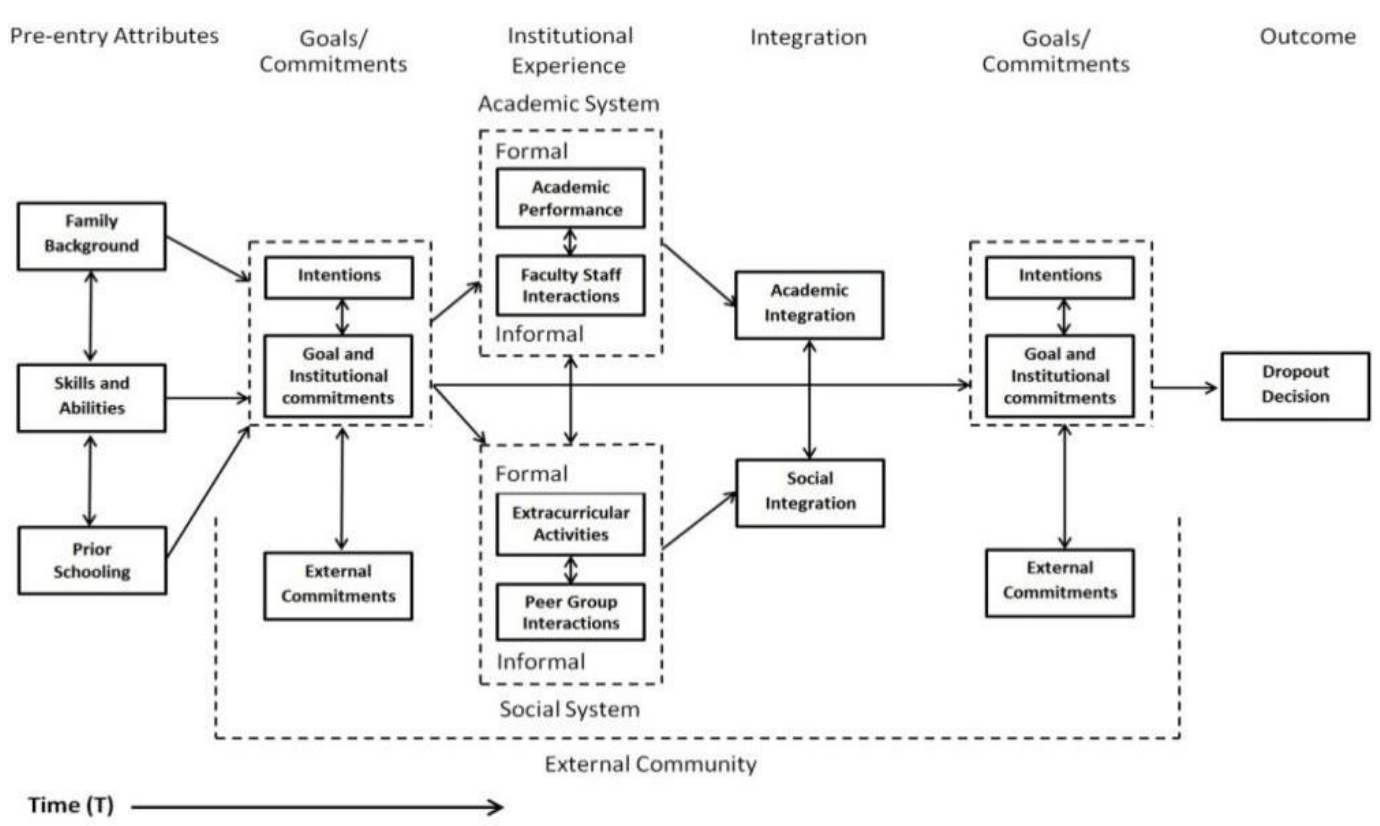

Figure 3 - Tinto's Institutional Departure Model 1993. Note: Adapted from "Building community by V. Tinto, 1993, Liberal Education.

Bean (Bean, 1980, 1982) proposed a model (attrition model) (Figure 4) based on turnover in work organizations conducted by Price (1977). Bean identified similarities in patterns of departure between students in an educational institution and employees of an organization. He replaced the pay variable with other factors like GPA, school quality, and practical value that were critical to a student in an education environment. He criticized Spady and Tinto's model for lack of analytical explanation about student withdrawal reasons (Figure $4 \&$ Figure 5). He published his revised model later (Price, 1989) based on Price, Tinto and Spady's studies. 


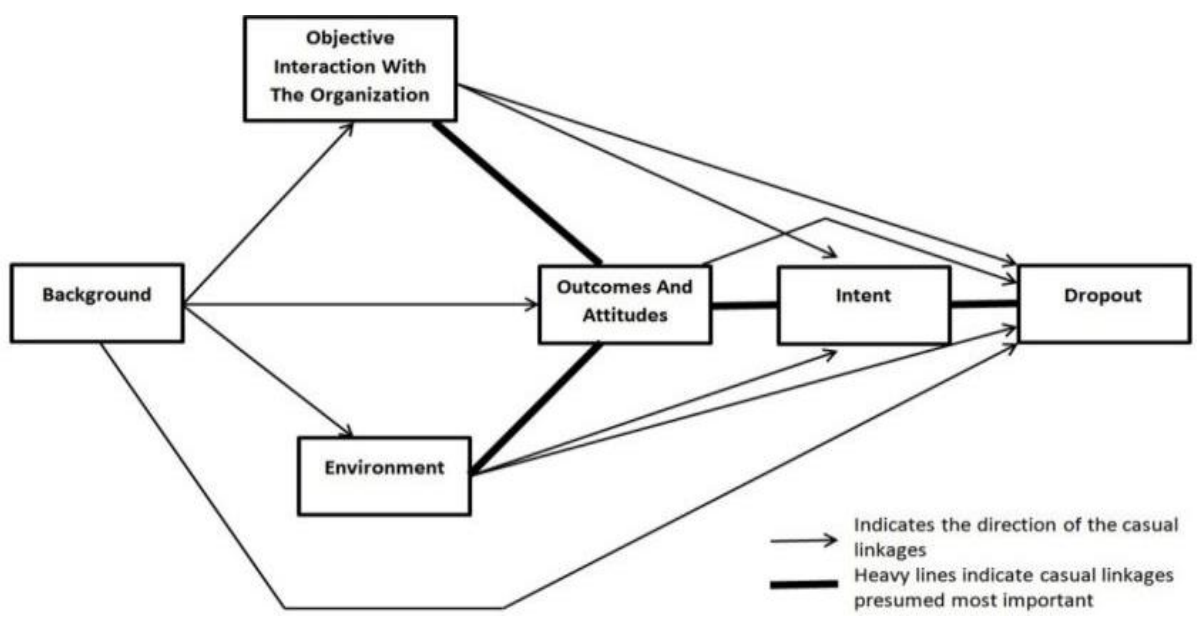

Figure 4 - Bean's Attrition Model 1982. Note: Adapted from "Student attrition, intentions, and confidence: Interaction effects in a path model" by JP. Bean, 1982. Research in higher education.

Bean and his colleague Metzner revised Bean's model on the basis of other theoretical studies such as Bentler's structural equation analysis (Bentler et al., 1981). These adaptations resulted in the dropout model (model of student dropout) (Figure 5) which revealed that external factors or environmental variables played an important role in the new model (Bean et al., 1985). They established that several factors affect the dropout decision such as 1) background variables (e.g., high school performance, age, educational goals, ethnicity, hours enrolled, and gender); 2) academic variables (e.g., major and job certainty, study hours and skills, absenteeism, academic advising, and course availability); 3) environmental variables (e.g., family responsibilities, finances, hours of employment, opportunity for transfer, and outside encouragement); 4) social integration (e.g., faculty contact, memberships, and school friends); 5) academic outcomes (i.e., GPA); 6) psychological outcomes (e.g., goal commitment, utility, stress, and satisfaction); and 7) intention for leaving school. 


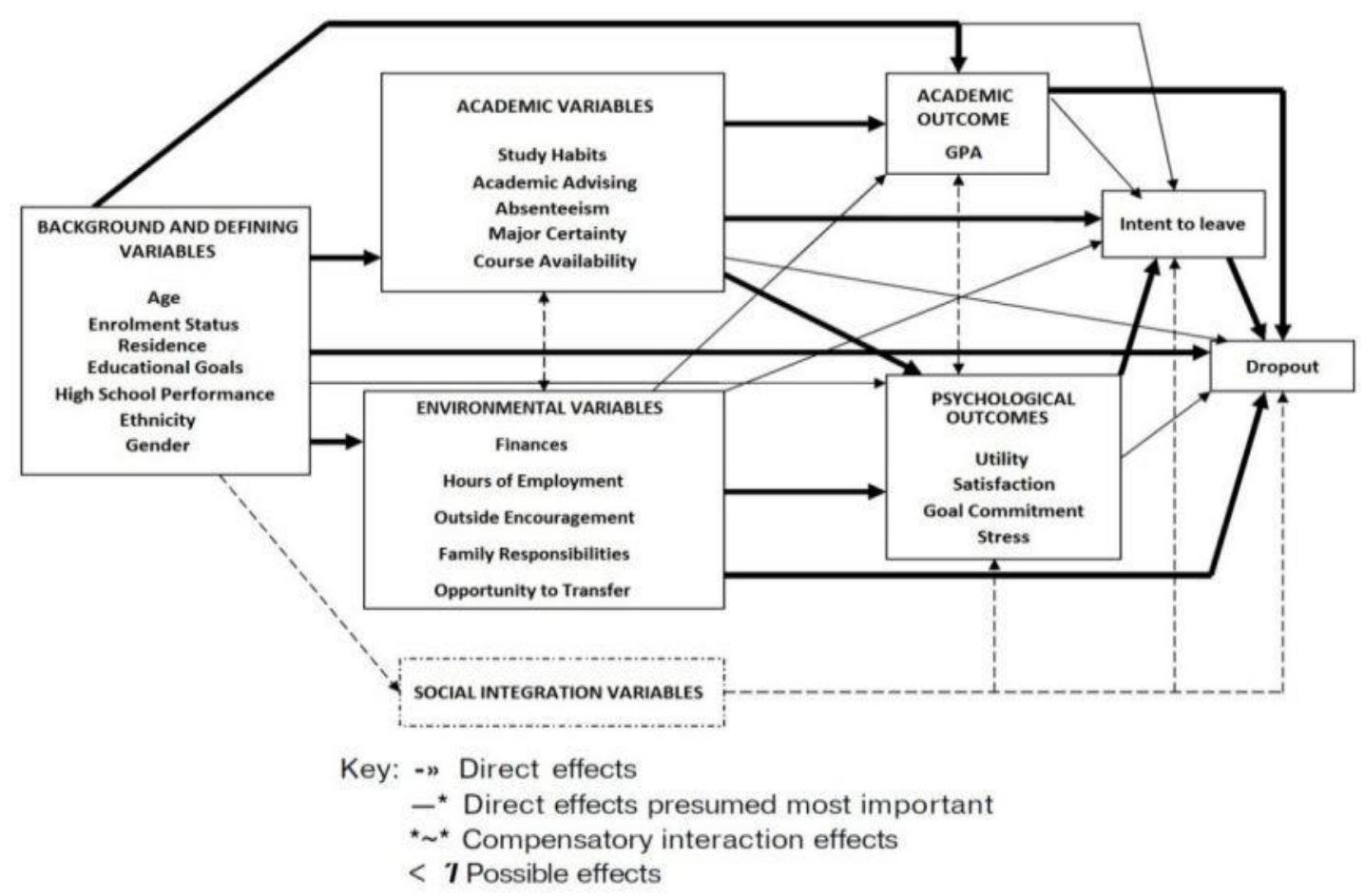

Figure 5 - Bean and Metzner's Model of Student Dropout 1985. Note: Adapted from "A conceptual model of nontraditional undergraduate student attrition" by JP. Bean \& BS. Metzner, 1985, Review of Educational Research.

In 2000, Bean and Eaton proposed another retention model (model of college student retention) (Figure 6) (Bean et al., 2000, 2001). In this model selfefficacy (a students' beliefs in their ability to perform a course of action) played an important role. The model indicated that students with high self-efficacy beliefs are likely to persist. In addition, self-efficacy had an impact on student's integration in their campus community.

Pascarella in 1980 proposed a persistence model (student-faculty informal contact model) (Figure 7) (Pascarella et al., 1980) on the basis of some of the assumptions from previous works of Tinto' institutional departure model and Spady's dropout process model. 


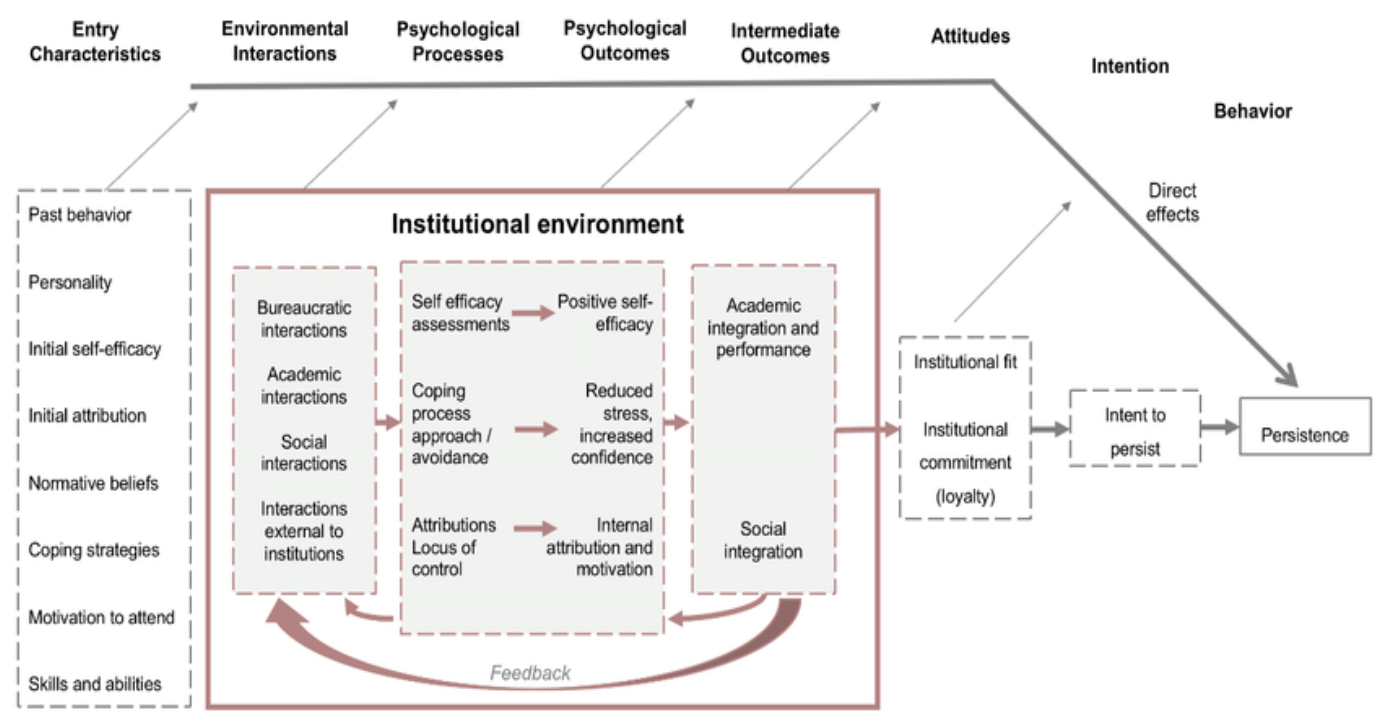

Figure 6 - Bean and Eaton's Model of College Student Retention 2001. Note: Adapted from "The psychology underlying successful retention practices" by JP. Bean \& SB. Eaton, 2001, Journal of College Student Retention: Research, Theory $\&$ Practice.

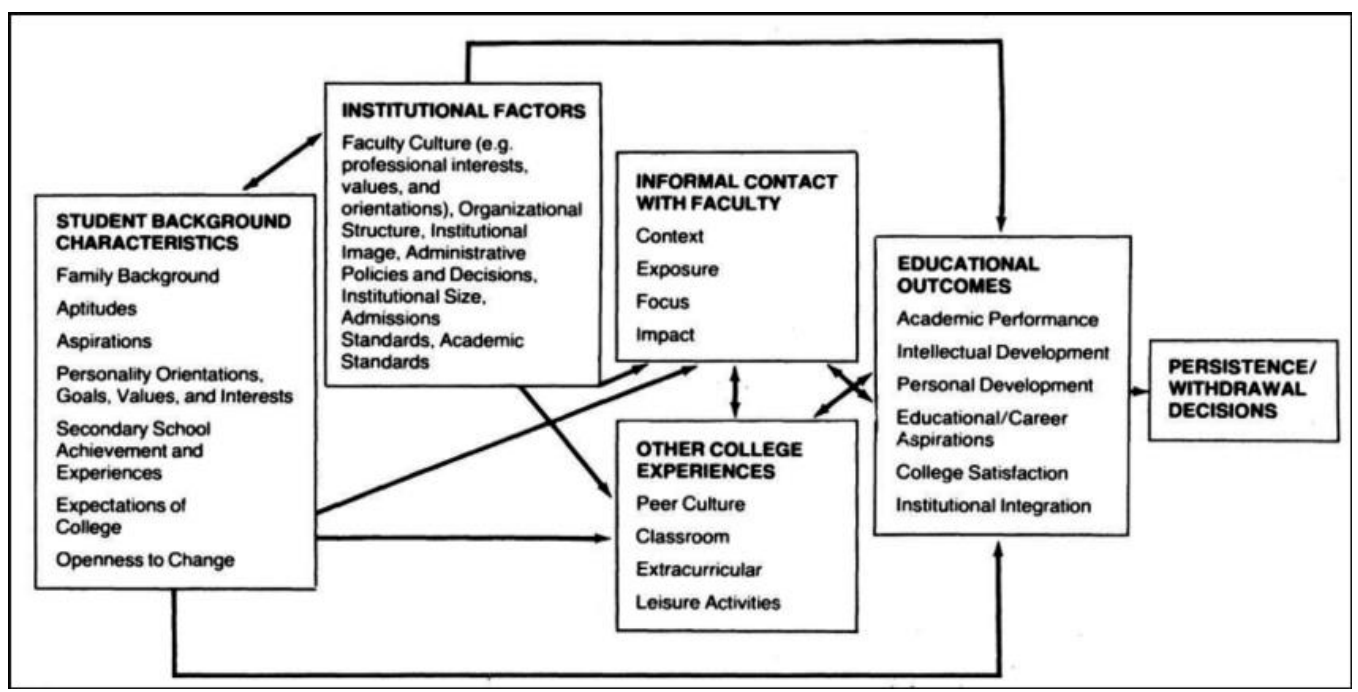

Figure 7 - Student-Faculty Informal Contact Model. Note: Adapted from "Predicting freshman persistence and voluntary dropout decisions from a theoretical model" by ET. Pascarella \& PT. Terenzini, 1980, Journal of higher education. 
In this model, the interaction between students and faculty had a high impact. He believed that faculty's informal interaction with students can increase students' commitments and decrease dropouts. He took into account five different factors: college experiences, background characteristics, informal contact with faculty, institutional factors, and educational outcomes. This model indicated the influence of students' self-beliefs such as interest and aspiration on persistence decisions.

Cabrera and his colleagues proposed a model (retention model) (Figure 8) (Cabrera et al., 1992, 1993) based on all the variables in Tinto and Bean models that were confirmed statistically along with other factors from the Cabrera's initial research. This model consisted of financial attitude, GPA, encouragement from friends and family, goal commitment, social integration, academic integration, institutional commitment, and intent to persist.

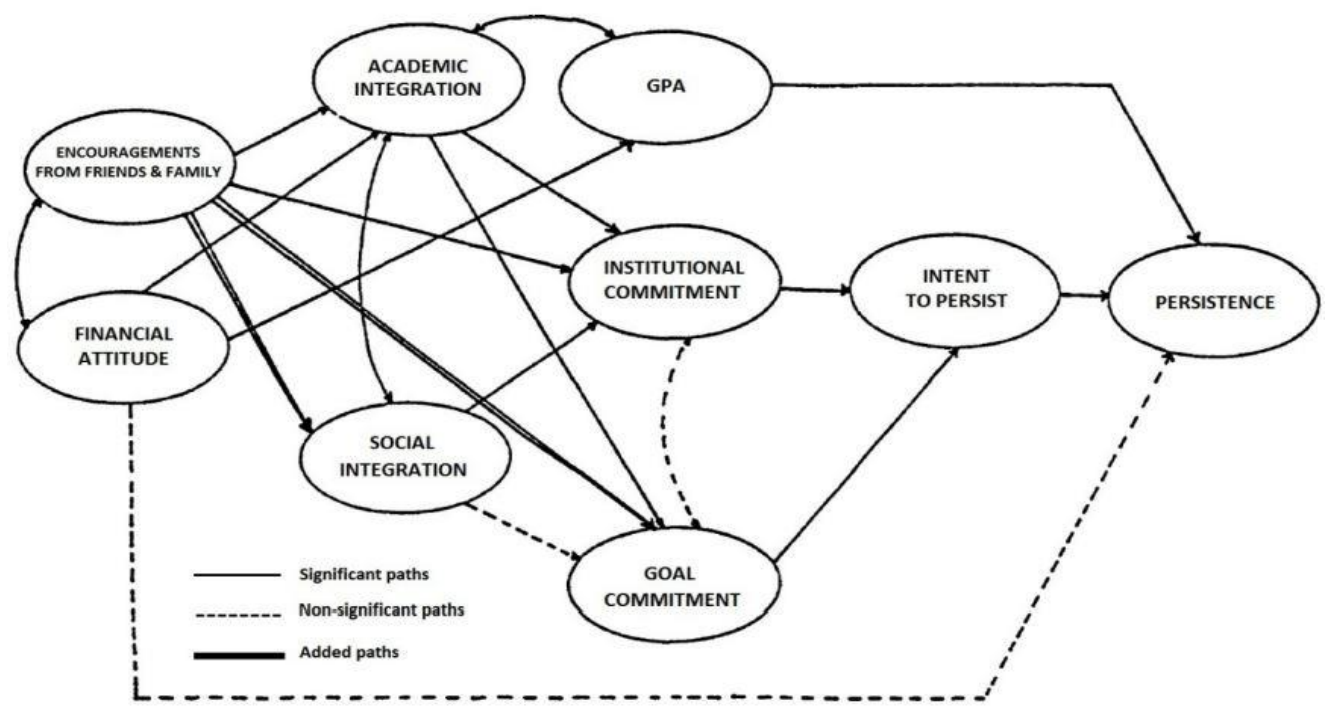

Figure 8 - Retention Model. Note: Adapted from "College persistence: Structural equations modeling test of an integrated model of student retention" by AF. Cabrera, A. Nora, \& MB. Castaneda, 1993, Journal of higher education. 
Braxton and his team proposed a new model (persistence model) (Figure 9) (Braxton et al., 2004, 2011, 2013). In their model, academic activities and learning communities had a positive impact on persistence. The model consisted of student characteristics including motivation, empathy, control issues, anticipatory socialization, self-efficacy, parental education, and affiliation needs; external environment including family, finances, work, support, and community; internal campus environment including active learning, institutional integrity, academic communities, learning communities, institutional environment, and intuitional commitment to student welfare; and initial institutional commitments and subsequent institutional commitment. This model highlighted many of the students' characteristics including motivation and self-efficacy that directly impacted persistence and also influenced institutional commitments.

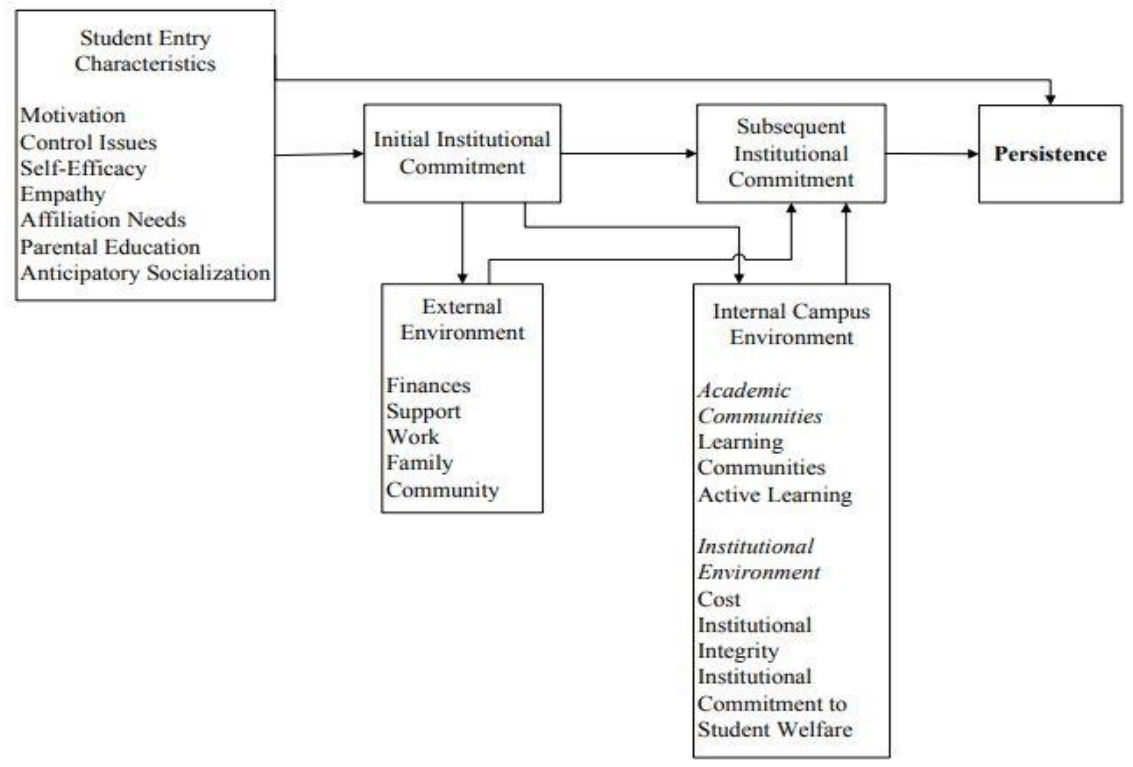

Figure 9 - Persistence Model. Note: Adapted from "Modifying Tinto's theory of college student departure using constructs derived from inductive theory revision" by J. Braxton, A. Hirschy, \& S. McClendon, 2004, Retention and student success in higher education. 
In addition to the frameworks and studies mentioned above, there are more models developed by researchers to address the higher education persistence issue. Astin (Astin, 1977, 1985) proposed a model for student involvement that indicated persistence is affected by students' interactions with peers, teachers, faculty, and staff. In summary, the early pioneer studies of student persistence were impacted by conceptual theories of three groups of researchers (Spady et al., Bean et al., and Tinto et. al.). In the next section, persistence in STEM, and engineering are described and some of the studies with a focus on students' selfbeliefs are highlighted.

\subsubsection{STEM, Engineering, and Computing Persistence}

Many interventions in recent years have been proposed to increase the number of qualified students for STEM majors. For instance, to increase college enrollment in computing and technology, "hour of code" (code.org) as a global movement was designed to help students learn the computing basics, and to broaden their contribution to computer science. Despite growing enrollment over the last few years, schools are still suffering from low persistence rates (Chen, 2013). This finding indicates that some work is needed in higher education to increase the persistence of students who were interested in STEM in the first place (Chen, 2013).

Drawing from known models and theories, scholars have identified effective strategies to boost persistence in STEM and engineering. Teaching quality and the relationship between students and faculty (Watkins \& Mazur, 2013, Seymour et al., 1997) have shown impact on STEM persistence. Likewise, 
advising students, student's involvement in research and sense of belonging were some of the constructive factors in engineering persistence (Marra et al., 2012). Other prior studies highlighted the importance of first-year persistence (Seymour et al., 1997; Almatrafi et al., 2017). Helping students in math, and building communities have been mentioned in STEM retention studies as effective approaches (Olson, et al., 2012). Additional studies provided recommendations such as providing support for discovery-based research courses and diversifying pathways to STEM (Elgin et al., 2016). Scholars (Green et al., 2018) indicated that empowering high school students with math preparation is an effective way to increase persistence in STEM. Others pointed to some factors like SAT math scores (Crisp et al., 2009; Le et al., 2014), math self-efficacy (Chen et al., 2013), high GPA, and first-year grades as important factors in STEM persistence (Thompson et al., 2011).

Other factors that have been identified as significant indicators in STEM persistence included race, ethnicity, and gender (National Science Board, 2008), self-interest to STEM (Rogers et al., 1997), teaching style, institutional support (Cheryan et al., 2015), study habits, peer mentoring programs (Colvin et al., 2010), time management skills, and motivation (Hershner et al., 2014). Scholars found that STEM students who have opportunities to interact in class are more likely to persist (Watkins et al., 2013). Studies have shown STEM students with high self-efficacy are likely to finish their program and graduate (Rittmayer et al., 2009). Researchers (Graham et al., 2013) proposed a framework for increasing the persistence of college students in STEM that is focused on students' confidence, 
self-efficacy, and motivation. This framework also indicated that professional identification and learning as persistence determinants can affect STEM confidence and motivation. Other studies identified that students' persistence is affected by their self-concept, and sense of community (Stets et al., 2017).

During the last decade, there have been multiple studies on engineering persistence. Burtner (Burtner, 2005) using quantitative analysis investigated noncognitive factors including confidence and intrinsic motivation, and their impact on engineering persistence. Researchers (French et al., 2005; Capobianco et al., 2012) also explored engineering cognitive and non-cognitive factors and their influence on persistence. They found motivation, high school GPA, SAT math, and high school rank had a significant impact. Bernold and his colleagues (Bernold et al, 2007) examined the learning styles and their relation with engineering retention. Their finding indicated that learning styles affect engineering student success and persistence. Nicholls (Nicholls et al., 2007) study showed that self-reporting math and computer ability are impactful factors in STEM retention. When scholars (Veenstra et al., 2008, 2009) investigated critical predictors of engineering and non-engineering students' persistence using factor analysis and regression analysis, they found math and computer self-ratings, ACT math, and science scores are some of the significant predictors. Moses (Moses et al., 2011) explored the first-year retention in engineering programs and indicated that high school GPA score is an impactful predictor. Scholars (Marra et al., 2012) that conducted an exploratory factor analysis and explored engineering 
dropout indicated curriculum, teaching style, and sense of belonging were significant factors in engineering retention.

Other researchers (Alkhasawneh et al., 2014) used ML-based approaches to investigate retention for underrepresented minorities in engineering. They indicated race, first-year grades, gender, and high school math and science as significant factors. Calcagno and his colleagues (Calcagno et al., 2008) investigated institutional factors such as the size of the institution, faculty relation, leadership, and local politics. They found individual factors were more correlated to student persistence than institutional factors. Wang (Wang, 2013) used the social cognitive career theory and structural equation modeling to explore STEM persistence sub-constructs. This work found math self-efficacy, and STEM interest were significant predictors. Luke (Luke et al., 2015) explored the connections between students' intention to pursue a career and academic persistence. Other studies in engineering, have shown career planning courses were critical in persistence to graduation and pursuing STEM careers (Belser et al., 2018). They indicated that the decision-making process and transitions related to a career were tightly linked to academic persistence.

Prior research in computer science persistence follows STEM and engineering studies. Scholars explored intervention programs, disparities in computing fields (Cohoon, 2001), student perceptions of computer science (CS) (Biggers et al., 2008), CS retention through orientation and research programs (Talton, 2006, Sithole, 2017), and pair programming for CS students' retention (Carver et al., 2007). Some of the studies also directly or indirectly highlighted 
the impact of students' self-beliefs, interest, self-efficacy, and motivation on persistence. These studies investigated in the CS self-efficacy and interest relationship (Miura, 1987), and improving interest and persistence for female students (DuBow, 2016). Recent scholars (Mahadeo et al., 2020) examined the impact of performance/competence, interest, and recognition in computing on persistence and career choice.

In general, many of the prior studies on persistence, directly or indirectly pointed out to the impact of students self-beliefs on their success, performance, and persistence. In addition, there are many other studies that used these theories to recommend programs and interventions. In the next section, I introduce the two models that are used in this dissertation to show the relationship between students' self-beliefs and persistence. The impact of self-beliefs are more highlighted in these two frameworks.

\subsection{Theoretical Framework}

Prior work has discussed students' self-beliefs as critical to persistence; however, none of the frameworks focused on building a model of computing persistence and students' computing identity. This study is focused on students' computing identity and its impact on persistence in computer science using previously established disciplinary identity framing. Understanding students' computing identity can influence how we examine students' choices toward graduation and pursuing a career in the same/related field. In the next section, two theoretical frameworks will be introduced and discussed: disciplinary identity as 
the driving framework, and social cognitive career theory (SCCT) for building the identity-persistence model and interpreting the results.

\subsubsection{Identity Framework}

The disciplinary identity model used for this dissertation is based on four sub-constructs that have been validated through prior studies for other science disciplines (Carlone et al., 2007). These sub-constructs are students' perceived beliefs of their interest, recognition, performance and competence. Interest in this context refers to a student's feeling of wanting to know and learn. Interest also refers to being concerned or having curiosity about something. Recognition refers to a students' feelings of being identified, acknowledged, accepted, and praised by others such as parents, teachers, and friends. The recognition may be a formal acknowledgment or any admiration and respect for a student's achievements. This sub-construct also includes an individual's recognition of themself. Performance is a student's feelings about their capability to perform academic tasks.

Competence is the students' feeling of understanding the concepts in a specific subject. Performance and competence are considered as one integrated subconstruct, as in the previous studies students had difficulty distinguishing the differences between understanding a subject and performing the tasks related to that subject. To measure each sub-construct I used a survey to ask each student about their feelings of interest, being recognized, and capability in computing. Survey development for capturing these constructs for this dissertation are described in the next section. 
The concept of disciplinary identity framework used in this dissertation was originally introduced in a qualitative study in 2007 by Carlone and Johnson (Figure 10) (Carlone \& Johnson, 2007). Carlone and Johnson clarified theoretical conceptions of science identity and examined identity in their original work by looking into competence, performance, and recognition of self and recognition by others. Their study characterized the identity of successful women of color over the course of their education and career. In their study, they proposed a model of science identity. They worked with 15 successful women to understand their science identity. They conducted ethnographic interviews when these women were undergraduate students. Then they interviewed the women six years later and continued with member checking.

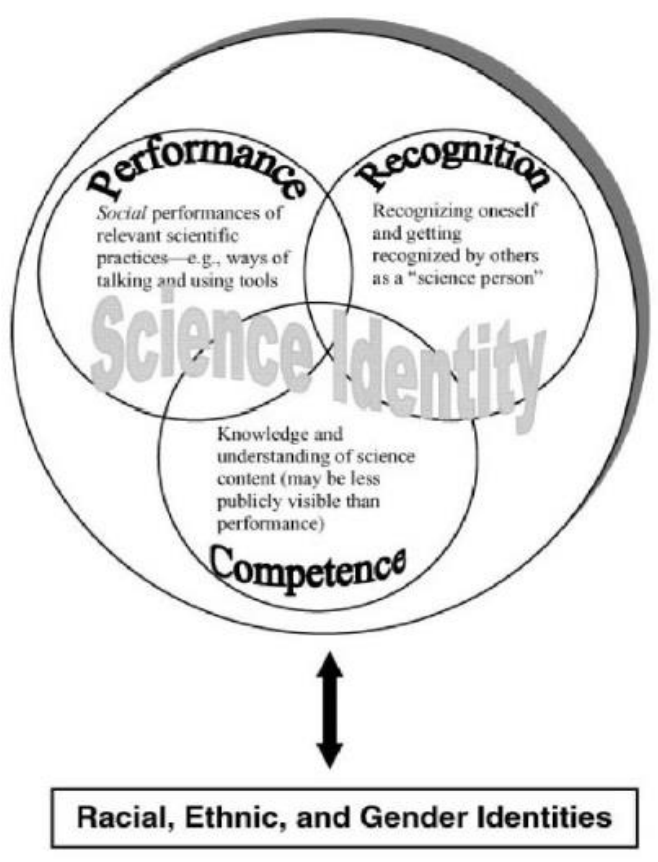

Figure 10 - Carlone and Johnson's Initial Science Identity Model 2007. Note: Adapted from "Understanding the science experiences of successful women of color: Science identity as an analytic lens" by HB. Carlone \& A. Johnson, 2007, Journal of Research in Science Teaching. 
Their results highlighted the significance of recognition especially recognition by others. For their prototype, they identified the essential characteristics of a person with a strong science identity. These factors included understanding science, being knowledgeable and skillful in scientific practices, high motivation for science, and working with scientific tools. They indicated a person with a strong science identity not only recognizes themself but also gets recognized by friends, teachers, and other people as a science person.

Carlone and Johnson's model highlighted the importance of performance, competence, and recognition. It also indicated these three constructs overlap to some extent. Performance in their work referred to the ability to perform scientific practices such as using tools, applications, and methods. Competence referred to a meaningful and deep understanding of the content within relevant scientific norms. To have a strong identity all three factors need to be present, otherwise the science identity may not develop over time. Some studies indicated that students can be highly recognized even when they do not have a deep understanding of their field and sometimes are not great performers of science practices; on the contrary, there can be students with the high competency who understand the science content and can do scientific practices, but are not being recognized or rarely recognized as legitimate scientists (Tonso, 2006). Science identity includes being highly recognized by people who matter to students, in addition to feelings of competency and ability to perform. 
Hazari, Sonnert, Sadler, and Shanahan in 2010 (Hazari et al., 2010)

explored how students' physics identity is formed by their experiences and by expectations of their career outcome (Figure 11). They conceptualized a framework for physics students based on what Carlone and Johnson built previously based on their qualitative study. Their framework concentrated on the three prior dimensions along with interest. They drew their data from a project called "Persistence Research in Science and Engineering (PRiSE)". The PRiSE survey was a national survey of U.S. university/college students about their science experiences and attitudes.

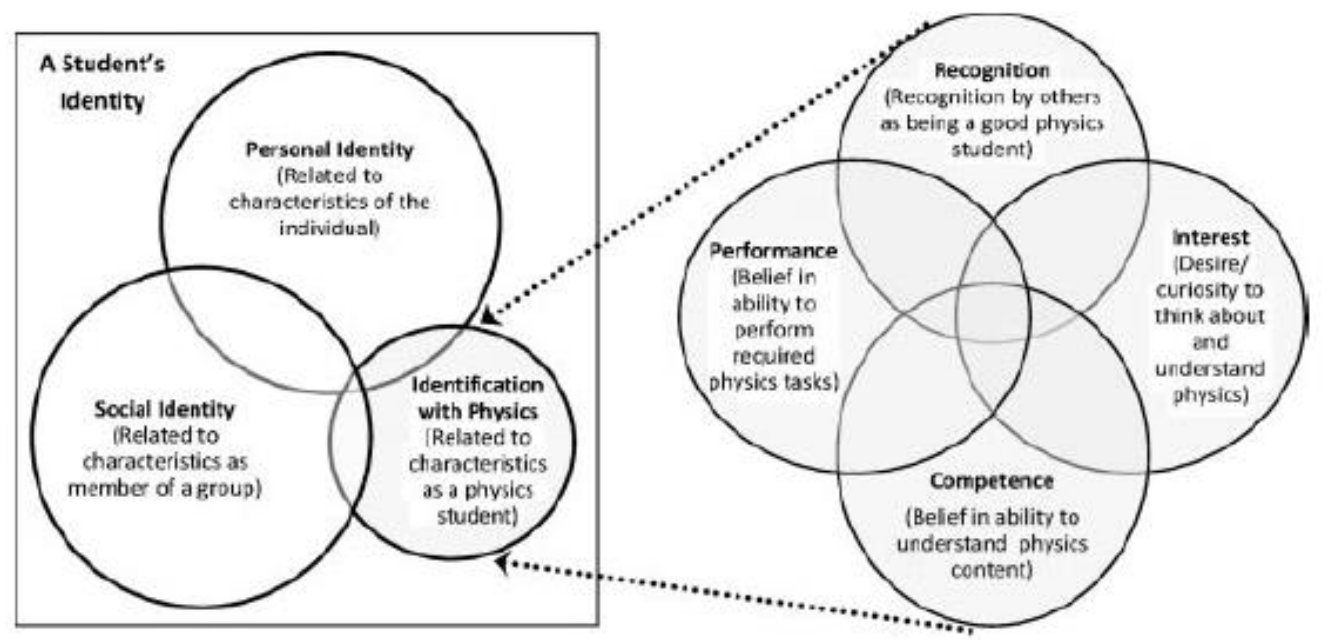

Figure 11 - Hazari, Sonnert, Sadler, and Shanahan's Disciplinary Identity Framework 2010. Note: Adapted from "Connecting high school physics experiences, outcome expectations, physics identity, and physics career choice: A gender study" by Z. Hazari, G. Sonnert, PM. Sadler, \& MC. Shanahan, 2010, Journal of research in science teaching.

The problem that they aimed to resolve was the lack of enough growth in physics bachelor graduates, especially female participation. Hazari and her coauthors found that physics identity is correlated positively with the choice of career. Their study further advanced the framework for disciplinary identity in 
science. They believed their model would provide a meaningful measure that can help to identify students' long-term relation to physics. In their study, they highlighted the role of self-beliefs and their impact on persistence and science participation. The importance of sense of belonging in an academic environment, and the impact of educational and social communities will be discussed in the next chapter; however, it is worth mentioning that sense of belonging is the recent sub-construct that we added to the model.

\subsubsection{Social Cognitive Career Theory}

Social cognitive career theory (SCCT) (Figure 12) (Lent et al., 1994) was established to explain outcome expectations, career choice, and performance. This theory has been extended to the study of many areas including psychosocial functioning, academic performance, and choice of engineering as a career. This theory incorporated different concepts such as self-efficacy, interest, learning experiences, person inputs, and environmental factors. SCCT was based on social cognitive theory (SCT) by Bandura (Bandura, 1986). Bandura's SCT was an extension of his social learning theory (SLT) (Bandura, 1977). SCT and SLT, in short, explain how people learn from watching the behavior of others. Selfefficacy in SCCT refers to people's self-beliefs about their capabilities to perform a particular task. The performance and competence sub-constructs in identity theory broadly encompass self-efficacy. However, performance and competence cover a wider range of tasks related to a subject. Self-efficacy (as shown in figure 12) impacts outcome expectations, interest, choice goals, choice actions, performance domains, and attainments. According to SCCT, people with a higher 
self-efficacy belief are more likely to develop interest and choose to pursue their goals. Interest in SCCT impacts choice goals, and choice actions. The choice goals could be intentions to pursue a specific major or career path. The choice goals and the choice actions are the closest concepts to my definition of persistence. SCCT as a well-established theory highlights different phases of career development: the selection of career options, career interest formation, and educational/occupational persistence.

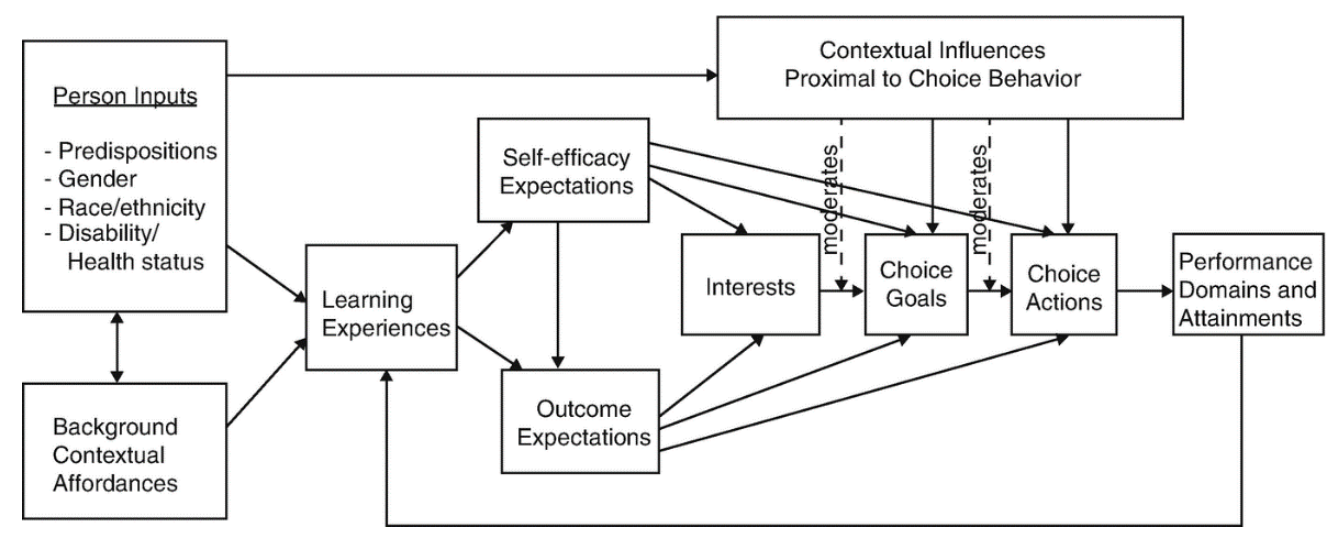

Figure 12 - SCCT Model. Note: Adapted from "Toward a unifying social cognitive theory of career and academic interest, choice, and performance" by RW. Lent, SD. Brown \& G. Hackett, 1994, Journal of vocational behavior.

Hazari and her colleagues leveraged SCCT and identified the correlation of self-beliefs, especially interest on persistence and career choice. The correlations between sub-constructs in SCCT is utilized for this dissertation to couple identity and persistence together and interpret the results of my final model. Interest and self-efficacy are reflected in the disciplinary identity model through interest, performance, and competence. In other words, the disciplinary identity model is used along with Lent's model for connecting some of the dots between identity and career choice. Likewise, this dissertation takes advantage of 
both theories for building the structural equation model. In addition, to compare the outcome of my analysis with previous well-known studies, and to show validation and contradiction, SCCT plays an important role. For instance, in terms of the impact of interest, a large body of SSCT-based studies identified the great influence of interest on persistence and career choices (Lent, et al., 1994). Furthermore, other researchers later expanded the model of identity to engineering disciplines (Cribbs 2016; Godwin et al., 2013, 2016) and took advantage of SCCT in interpreting the results.

\subsection{Research Study}

In this section, the significance and the purpose of this study, research design and survey development/distribution are described.

\subsubsection{Significance of the Study}

This study extends prior findings of persistence and identity in STEM and engineering to computing. In addition, I have added sense of belonging as a new sub-construct to the disciplinary identity theory. My model of computing persistence and identity provides an analytical lens for future research in computing. This analytical lens might have practical impacts on educating staff, educators, parents, and even students to increase persistence at schools. Demonstrations of the relationship between computing identity and persistence, specifically through the analysis of the theorized sub-constructs, would have implications for college administration. This includes implications for constructing curricular and extracurricular activities that will potentially increase 
academic persistence in computer science programs. Likewise, academic counselors who assist and advise students can leverage the results.

\subsubsection{Purpose of the Study}

The purpose of this study is to understand the impact of the identity subconstructs on computing persistence. This dissertation explores the relationship between students' self-beliefs and persistence in computer science and quantifies the correlations between computing identity sub-constructs. The ultimate goal is to capture a snapshot of all the relationships and then provide a model of identity development over time. For this purpose, the first phase was building the basic model for computing identity, including understanding the identity model and applying the prior frameworks. This phase included the development of a survey, its validation, and its distribution for the purpose of collecting data. The second step was data analysis, interpretation of results, and understanding the contribution of identity sub-constructs to persistence. The goal of this step was to quantitatively examine and measure how students' computing identity contribute to their computing persistence. Further analysis is performed to compare different demographics and levels of education for a better understanding of differences among students. Finally, for a comprehensive exploration of identity development over time and its impact on persistence a time-series analysis was conducted.

\subsubsection{Approach to Research}

A quantitative method is used to examine the relationship between variables using measurable data to formulate facts and uncover patterns in my research. This includes several steps such as framing a theory, hypothesis 
generation, data collection, data analysis, and result interpretation. This study

aims to capture a quantified contribution of each identity sub-construct on persistence.

\subsubsection{Research Questions and Explanation of Research Design}

As I outlined in the previous section, academic institutions suffer from low overall persistence. To address this problem, a quantitative research study is proposed and a structural model are used to describe the causal mechanisms of our system (Ullman et al., 2003). This model is an abstract quantitative representation of real-world dynamics. Structural equation modeling (SEM) is the best-known form of causal modeling (Hoyle, 1995). In this dissertation, the SEM method is used 1) to measure the factors which impact computing persistence from the computing identity sub-constructs; 2) to measure the relationships between the computing identity sub-constructs and persistence for male and female and senior and freshmen students; 3) to evaluate the model over time. This quantitative method draws on data collected as part of an NSF grant (Flit-Path) and is used to address the following research questions:

1) How do the theorized identity sub-constructs (performance, competence, recognition, interest, and sense of belonging) contribute to the academic persistence of undergraduate computing students?

2) How do the identity sub-constructs contribute to the academic persistence of computer science students who are male versus female?

3) How do the identity sub-constructs contribute to the academic persistence of computer science freshman versus upper-level undergraduate students? 
4) How do the identity sub-constructs contribute to the academic persistence of computer science students over time?

To address the research questions, I conducted a survey and performed an SEM, a multigroup SEM, and a time-series SEM.

\subsubsection{Survey Development}

The Florida IT Pathways to Success (Flit-Path) survey (Appendix A) was developed to capture information to understand students' experiences, background/demographics, and attitudes including students' self-beliefs. The creation and development of the Flit-Path survey included three main parts: 1) an extensive literature review of identity sub-constructs and persistence factors; 2) extraction of different items related to this work from other national surveys; 3 ) administering a pilot survey to test validity and reliability with students as well as validating with other educators and researchers. This pilot test was a pre-survey on 95 students from the computer science department at Florida International University during fall 2017 (Garcia et al., 2017). The pilot test helped this study in ascertaining the reliability and validity of survey items such as understanding the interpretation of the questions by students. The pre-survey questions were checked by several researchers and faculty from computer science. The survey was modified based on their feedback. Finally, the modified questions from the above-mentioned steps were used in the final survey. The modification included the wording of item questions and answer choices, adding more details and explanations, and removing extra options and questions. To determine if the 
measurement of identity constructs was valid, the survey responses were analyzed through exploratory factor analysis (EFA).

The final survey (Appendix A) consisted of 25 items including common demographic questions (gender, ethnicity, race), institution name, year in college, major, the field students wanted to pursue in middle school, high school and college, the likelihood of career choice, the likelihood of finishing bachelor, selfbeliefs (identity sub-constructs measured by interest, performance/competence, recognition, sense of belonging), area of interest, institution experiences, GPA overall, GPA in computing courses, English and math high school grade, parents education, students advocate, home being supportive, the number of friends in computing, and work hours outside of college.

One of the main instruments driving the survey development was the Persistence Research in Science and Engineering (PRiSE) survey. This survey was administered by Harvard researchers and was validated through several studies in STEM/engineering and was revised and modified over time. The PRiSE survey collected data nationally from college English students about their college and high school experiences, characteristics, and attitudes. Researchers used it to explore physics identity and career outcome expectations in high school physics classes (Hazari et al., 2010). The focus of PRiSE was on the persistence of women in STEM. It was funded by NSF and administrated by the Science Education Department of the Harvard-Smithsonian Center for Astrophysics. This survey was based on 1) a literature review of persistence and contributing factors on persistence; 2) asking more than 400 scientists and high-school teachers about 
the key factors on persistence through an open-ended questionnaire and text analysis; 3) Using prior valid national surveys such as Factors Influencing College Science Success — FICSS (Tai et al., 2006; Hazari et al., 2010).

To frame the Flit-Path survey questions, I concentrated on multiple subconstructs that were highlighted in prior studies; interest, performance, competence, recognition, and sense of belonging. Interest was one of the key factors found to impact persistence in different areas of science. For instance, in a national longitudinal data analysis, researchers found that interest was a strong predictor of persistence and graduation (Tai et al., 2006).

\subsubsection{Survey Distribution}

In order to obtain a wide representative sample of Florida students, online surveys were dispensed to students at three large metropolitan public schools. Students were selected in order to capture the experiences of Flitpath students as well as other students in the same programs. Students were in all levels of their undergraduate programs from first-year to four-years and more. The online survey was distributed in each school to undergraduate students in IT, CE, and CS either as part of an initial assignment for all students or within IT, CE, and CS courses taken by Flit-Path students.. In 2017, follow-up and reminder emails were sent as needed to professors to ensure the survey was being distributed in classes. On average the requests were sent to almost 50 professors and 110 classes, and more than 1600 students were included. The surveys were completed by students both in-class and outside of class. Respondents reported different demographics

(Figure 13). The second survey for the purpose of time-series analysis was 
conducted one year later and included the same identity questions. The details of the demographics for the time-series survey will be discussed in chapter four.

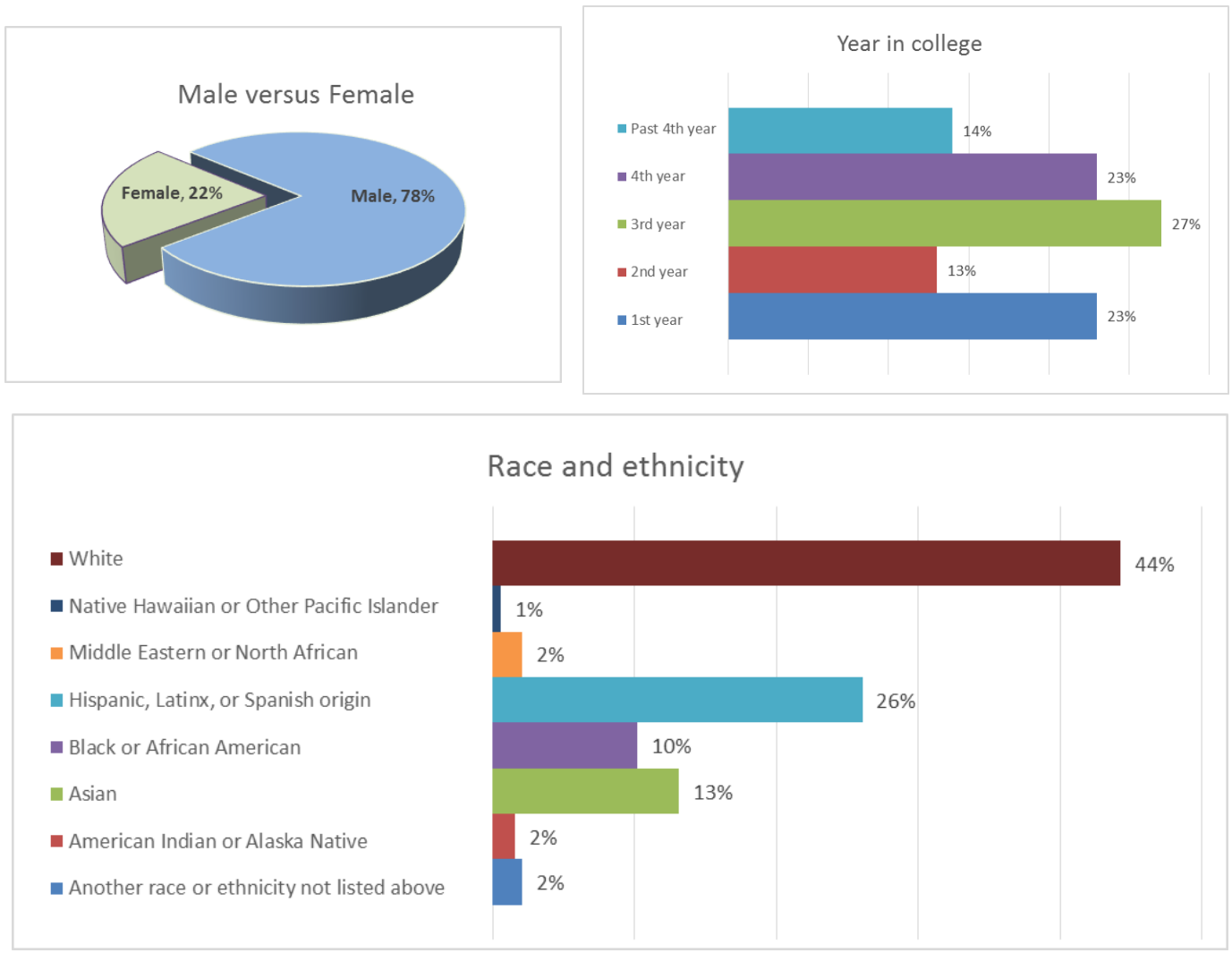

Figure 13 - Demographics of Flit-Path Survey Participants

\subsubsection{Three-Article Dissertation Structure}

The three articles for this dissertation will address the four research questions. The first paper provides a basic understanding of the model, the CFA, and SEM models. It indicates that the identity sub-constructs including interest, performance/competence, recognition, and sense of belonging all contribute to students' academic persistence to some degree. The second article provides further analysis for a better understanding of the model, and persistence, and it addresses the second and third research questions. This article compares the 
model between freshman and senior students and then between male and female students. A multi-group SEM is used to analyze the interesting paths between females and males, and senior students and first-year students. The third article addresses the fourth research question with a time-series SEM analysis by exploring the impact of identity development on academic persistence over time. 


\section{References (Chapter I)}

Aljohani, O. (2016). A Comprehensive Review of the Major Studies and Theoretical Models of Student Retention in Higher Education. Higher education studies, 6(2), 1-18.

Alkhasawneh, R., \& Hargraves, R. H. (2014). Developing a hybrid model to predict student first year retention in STEM disciplines using machine learning techniques. Journal of STEM Education: Innovations and Research, 15(3).

Almatrafi, O., Johri, A., Rangwala, H., \& Lester, J. (2017). Retention and persistence among STEM students: A comparison of direct admit and transfer students across engineering and science. In Proceedings of ASEE Annual Meeting.

Association for Computing Machinery. (2018, December 3). Tackling the challenge of undergraduate retention in computing: Interventions to improve engagement and retention of all students.

Astin, A. W. (1977). Four Critical Years. Effects of College on Beliefs, Attitudes, and Knowledge.

Astin, A. W. (1985). Achieving educational excellence. Jossey-Bass.

Bandura, A. (1986). Social foundations of thought and action. Englewood Cliffs, NJ, 1986, 23-28.

Bandura, A., \& Walters, R. H. (1977). Social learning theory (Vol. 1). Englewood Cliffs, NJ: Prentice-hall.

Bayer, A. E. (1968). The college drop-out: Factors affecting senior college completion. Sociology of Education, 305-316.

Bean, J. P. (1980). Dropouts and turnover: The synthesis and test of a causal model of student attrition. Research in higher education, 12(2), 155-187.

Bean, J. P. (1982). Student attrition, intentions, and confidence: Interaction effects in a path model. Research in higher education, 17(4), 291-320.

Bean, J. P., \& Eaton, S. B. (2000). A psychological model of college student retention. Reworking the student departure puzzle, 1, 48-61.

Bean, J. P., \& Metzner, B. S. (1985). A conceptual model of nontraditional undergraduate student attrition. Review of educational Research, 55(4), 485-540. 
Bean, J., \& Eaton, S. B. (2001). The psychology underlying successful retention practices. Journal of College Student Retention: Research, Theory \& Practice, 3(1), 73-89.

Belser, C. T., Prescod, D. J., Daire, A. P., Dagley, M. A., \& Young, C. Y. (2018). The Influence of Career Planning on Career Thoughts in STEM-Interested Undergraduates. The Career Development Quarterly, 66(2), 176-181.

Bentler, P. M., \& Speckart, G. (1981). Attitudes" cause" behaviors: A structural equation analysis. Journal of personality and social psychology, 40(2), 226.

Berger, J. B., Ramirez, G. B., \& Lyons, S. (2005). Past to present. College student retention: Formula for student success, 1.

Bernold, L. E., Spurlin, J. E., \& Anson, C. M. (2007). Understanding our students: A longitudinal-study of success and failure in engineering with implications for increased retention. Journal of Engineering Education, 96(3), 263-274.

Biggers, M., Brauer, A., \& Yilmaz, T. (2008). Student perceptions of computer science: a retention study comparing graduating seniors with cs leavers. ACM SIGCSE Bulletin, 40(1), 402-406.

Braxton, J. M., Doyle, W. R., Hartley III, H. V., Hirschy, A. S., Jones, W. A., \& McLendon, M. K. (2013). Rethinking college student retention. John Wiley \& Sons.

Braxton, J. M., Hirschy, A. S., \& McClendon, S. A. (2011). Understanding and reducing college student departure: ASHE-ERIC higher education report, volume 30, number 3 (Vol. 16). John Wiley \& Sons.

Braxton, J., Hirschy, A., \& McClendon, S. (2004). Modifying Tinto's theory of college student departure using constructs derived from inductive theory revision. Retention and student success in higher education, 201-245.

Burtner, J. (2005). The use of discriminant analysis to investigate the influence of non-cognitive factors on engineering school persistence. Journal of Engineering Education, 94(3), 335-338.

Cabrera, A. F., Castaneda, M. B., Nora, A., \& Hengstler, D. (1992). The convergence between two theories of college persistence. The journal of higher education, 63(2), 143-164.

Cabrera, A. F., Nora, A., \& Castaneda, M. B. (1993). College persistence:

Structural equations modeling test of an integrated model of student retention. The journal of higher education, 64(2), 123-139. 
Calcagno, J. C., Bailey, T., Jenkins, D., Kienzl, G., \& Leinbach, T. (2008). Community college student success: What institutional characteristics make a difference?. Economics of Education review, 27(6), 632-645.

Capobianco, B. M., French, B. F., \& DIEFES-DU, H. A. (2012). Engineering identity development among pre-adolescent learners. Journal of Engineering Education, 101(4), 698-716.

Carver, J. C., Henderson, L., He, L., Hodges, J., \& Reese, D. (2007, July). Increased retention of early computer science and software engineering students using pair programming. In 20th Conference on Software Engineering Education \& Training (CSEET'07) (pp. 115-122). IEEE.

Cass, C. A., Hazari, Z., Cribbs, J., Sadler, P. M., \& Sonnert, G. (2011, October). Examining the impact of mathematics identity on the choice of engineering careers for male and female students. In 2011 Frontiers in Education Conference (FIE) (pp. F2H-1). IEEE.

Chen, X. (2013). STEM Attrition: College Students' Paths into and out of STEM Fields. Statistical Analysis Report. NCES 2014-001. National Center for Education Statistics.

Cheryan, S., Master, A., \& Meltzoff, A. N. (2015). Cultural stereotypes as gatekeepers: Increasing girls' interest in computer science and engineering by diversifying stereotypes. Frontiers in psychology, 6, 49.

Cohoon, J. M. (2001). Toward improving female retention in the computer science major. Communications of the ACM, 44(5), 108-114.

Colvin, J. W., \& Ashman, M. (2010). Roles, risks, and benefits of peer mentoring relationships in higher education. Mentoring \& Tutoring: Partnership in Learning, 18(2), 121-134.

Computer and Information Technology Occupations. (n.d.). U.S. Bureau of Labor Statistics. Retrieved September 15, 2020, from https://www.bls.gov/ooh/computer-and-information-technology/home.htm

Cribbs, J. D., Cass, C., Hazari, Z., Sadler, P. M., \& Sonnert, G. (2016). Mathematics identity and student persistence in engineering. The International journal of engineering education, 32(1), 163-171.

Crisp, G., Nora, A., \& Taggart, A. (2009). Student characteristics, pre-college, college, and environmental factors as predictors of majoring in and earning a STEM degree: An analysis of students attending a Hispanic serving institution. 
Demetriou, C., \& Schmitz-Sciborski, A. (2011, November). Integration, motivation, strengths and optimism: Retention theories past, present and future. In Proceedings of the 7th National Symposium on student retention (Vol. 201).

DuBow, W. M., \& James-Hawkins, L. (2016). What influences female interest and persistence in computing?: Preliminary findings from a multiyear study. Computing in Science \& Engineering, 18(2), 58-67.

Durkheim, E. (1951). Suicide: a study in sociology [1897]. Translated by JA Spaulding and G. Simpson (Glencoe, Illinois: The Free Press, 1951).

Elgin, S. C., Bangera, G., Decatur, S. M., Dolan, E. L., Guertin, L., Newstetter, W. C., ... \& Brenner, K. A. (2016). Insights from a convocation: integrating discovery-based research into the undergraduate curriculum. CBE-Life Sciences Education, 15(2), fe2.

Everett, B. (2013). An introduction to latent variable models. Springer Science \& Business Media.

Fayer, S., Lacey, A., \& Watson, A. (2017). STEM occupations: Past, present, and future. Spotlight on Statistics, 1-35.

French, B. F., Immekus, J. C., \& Oakes, W. C. (2005). An examination of indicators of engineering students' success and persistence. Journal of Engineering Education, 94(4), 419-425.

Garcia, A., Ross, M., Hazari, Z., Weiss, M., Christensen, K., \& Georgiopoulos, M. (2018). Examining the Computing Identity of High-Achieving Underserved Computing Students on the Basis of Gender, Field, and Year in School. Collaborative Network for Engineering and Computing Diversity (CoNECD).

Godwin, A. (2016, January). The development of a measure of engineering identity. In ASEE Annual Conference \& Exposition.

Godwin, A., Potvin, G., Hazari, Z., \& Lock, R. (2013, October). Understanding engineering identity through structural equation modeling. In 2013 IEEE Frontiers in Education Conference (FIE) (pp. 50-56). IEEE.

Godwin, A., Potvin, G., Hazari, Z., \& Lock, R. (2016). Identity, critical agency, and engineering: An affective model for predicting engineering as a career choice. Journal of Engineering Education, 105(2), 312-340.

Graham, M. J., Frederick, J., Byars-Winston, A., Hunter, A. B., \& Handelsman, J. (2013). Increasing persistence of college students in STEM. Science, 341(6153), 1455-1456. 
Green, A., \& Sanderson, D. (2018). The roots of STEM achievement: An analysis of persistence and attainment in STEM majors. The American Economist, 63(1), 79-93.

Habley, W. R., Bloom, J. L., \& Robbins, S. (2012). Increasing persistence: Research-based strategies for college student success. John Wiley \& Sons.

Hazari, Z., Sonnert, G., Sadler, P. M., \& Shanahan, M. C. (2010). Connecting high school physics experiences, outcome expectations, physics identity, and physics career choice: A gender study. Journal of research in science teaching, 47(8), 978-1003.

Hershner, S. D., \& Chervin, R. D. (2014). Causes and consequences of sleepiness among college students. Nature and science of sleep, 6, 73.

Hoyle, R. H. (1995). Structural equation modeling: Concepts, issues, and applications. Sage.

Le, H., Robbins, S. B., \& Westrick, P. (2014). Predicting student enrollment and persistence in college STEM fields using an expanded PE fit framework: A largescale multilevel study. Journal of Applied Psychology, 99(5), 915.

Education leads to higher wages, lower unemployment. (2020, May 1). U.S. Bureau of Labor Statistics. https://www.bls.gov/careeroutlook/2020/data-ondisplay/education-pays.htm

Lent, R. W., Brown, S. D., \& Hackett, G. (1994). Toward a unifying social cognitive theory of career and academic interest, choice, and performance. Journal of vocational behavior, 45(1), 79-122.

Lent, R. W., Brown, S. D., \& Hackett, G. (1996). Career development from a social cognitive perspective. Career choice and development, 3, 373-421.

Luke, C., Redekop, F., \& Burgin, C. (2015). Psychological factors in community college student retention. Community college journal of research and practice, 39(3), 222-234.

Mahadeo, J., Hazari, Z., \& Potvin, G. (2020). Developing a Computing Identity Framework: Understanding Computer Science and Information Technology Career Choice. ACM Transactions on Computing Education (TOCE), 20(1), 1-14.

Marks, E. (1967). Student perceptions of college persistence, and their intellective, personality and performance correlates. Journal of Educational Psychology, 58(4), 210. 
Marra, R. M., Rodgers, K. A., Shen, D., \& Bogue, B. (2012). Leaving engineering: A multi-year single institution study. Journal of Engineering Education, 101(1), 6-27.

Miura, I. T. (1987). The relationship of computer self-efficacy expectations to computer interest and course enrollment in college. Sex roles, 16(5-6), 303-311.

Morse, R., \& Brooks, E. (2020, September 13). A More Detailed Look at the Ranking Factors. U.S. News. https://www.usnews.com/education/bestcolleges/articles/ranking-criteria-and-weights

Moses, L., Hall, C., Wuensch, K., De Urquidi, K., Kauffmann, P., Swart, W., ... \& Dixon, G. (2011). Are math readiness and personality predictive of first-year retention in engineering?. The Journal of psychology, 145(3), 229-245.

National Science Board (US). (2008). Research and Development: Essential Foundation for US Competitiveness in a Global Economy: a Companion to Science and Engineering Indicators 2008. National Science Foundation.

Nicholls, G. M., Wolfe, H., Besterfield-Sacre, M., Shuman, L. J., \& Larpkiattaworn, S. (2007). A method for identifying variables for predicting STEM enrollment. Journal of Engineering Education, 96(1), 33-44.

Occupations that have it all: Many openings, fast growth, and high wages. (2020, September 1). U.S. Bureau of Labor Statistics.

https://www.bls.gov/careeroutlook/2020/data-on-display/occupations-that-have-itall.htm

Olson, S., \& Riordan, D. G. (2012). Engage to Excel: Producing One Million Additional College Graduates with Degrees in Science, Technology, Engineering, and Mathematics. Report to the President. Executive Office of the President.

Panos, R. J., \& Astin, A. W. (1968). Attrition among college students. American Educational Research Journal, 5(1), 57-72.

Pascarella, E. T., \& Terenzini, P. T. (1979). Interaction effects in Spady and Tinto's conceptual models of college attrition. Sociology of education, 197-210.

Pascarella, E. T., \& Terenzini, P. T. (1980). Predicting freshman persistence and voluntary dropout decisions from a theoretical model. The journal of higher education, 51(1), 60-75.

Price, J. L. (1977). The study of turnover. Iowa State Press.

Price, J. L. (1989). The impact of turnover on the organization. Work and occupations, 16(4), 461-473. 
Rittmayer, M. A., \& Beier, M. E. (2009). Self-efficacy in STEM. Applying research to practice (ARP) resources, 2-12.

Rogers, W. D., \& Ford, R. (1997). Factors that affect student attitude toward biology. Bioscene, 23(2), 3-5.

Seidman, A. (2005). Minority student retention: Resources for practitioners. New directions for institutional research, 2005(125), 7-24.

Seymour, E., \& Hewitt, N. M. (1997). Talking about leaving (p. 134). Westview Press, Boulder, CO.

Sithole, A., Chiyaka, E. T., McCarthy, P., Mupinga, D. M., Bucklein, B. K., \& Kibirige, J. (2017). Student Attraction, Persistence and Retention in STEM Programs: Successes and Continuing Challenges. Higher Education Studies, 7(1), 46-59.

Spady, W. G. (1971). Dropouts from higher education: Toward an empirical model. Interchange, 2(3), 38-62.

Stephenson, C., Derbenwick Miller, A., Alvarado, C., Barker, L., Barr, V., Camp, T., Frieze, C., Lewis, C., Cannon Mindell, E., Limbird, L., Richardson, D., Sahami, M., Villa, E., Walker, H., and Zweben, S. (2018). Retention in Computer Science Undergraduate Programs in the U.S.: Data Challenges and Promising Interventions. New York, NY. ACM.

Stets, J. E., Brenner, P. S., Burke, P. J., \& Serpe, R. T. (2017). The science identity and entering a science occupation. Social science research, 64, 1-14.

Tai, R. H., Sadler, P. M., \& Mintzes, J. J. (2006). Factors influencing college science success. Journal of College Science Teaching, 36(1), 52.

Talton, J. O., Peterson, D. L., Kamin, S., Israel, D., \& Al-Muhtadi, J. (2006, March). Scavenger hunt: computer science retention through orientation. In Proceedings of the 37th SIGCSE technical symposium on Computer science education (pp. 443-447).

Thompson, R., \& Bolin, G. (2011). Indicators of Success in STEM Majors: A Cohort Study. Journal of College Admission, 212, 18-24.

Tinto, V. (1975). Dropout from higher education: A theoretical synthesis of recent research. Review of educational research, 45(1), 89-125.

Tinto, V. (1987). Leaving college: Rethinking the causes and cures of student attrition. University of Chicago Press, 5801 S. Ellis Avenue, Chicago, IL 60637. 
Tinto, V. (1988). Stages of student departure: Reflections on the longitudinal character of student leaving. The journal of higher education, 59(4), 438-455.

Tinto, V. (1993). Building community. Liberal Education, 79(4), 16-21.

Tonso, K. L. (2006). Student engineers and engineer identity: Campus engineer identities as figured world. Cultural studies of science education, 1(2), 273-307.

U.S. Department of Education, National Center for Education Statistics. (2020). The Condition of Education 2020: Undergraduate Retention and Graduation Rates. NCES. https://nces.ed.gov/pubs2020/2020144.pdf

Ullman, J. B., \& Bentler, P. M. (2003). Structural equation modeling. Handbook of psychology, 607-634.

Van Gennep, A. (1960). The rites of passage (MB Vizedom \& GL Caffee, trans.). Chicago: University of Chicago.(Original work published 1908).

Van Gennep, A. (2019). The rites of passage. University of Chicago Press.

Veenstra, C. P., Dey, E. L., \& Herrin, G. D. (2008). Is modeling of freshman engineering success different from modeling of non-engineering success?. Journal of Engineering Education, 97(4), 467-479.

Veenstra, C. P., Dey, E. L., \& Herrin, G. D. (2009). A Model for Freshman Engineering Retention. Advances in Engineering Education, 1(3), n3.

Wang, X. (2013). Why students choose STEM majors: Motivation, high school learning, and postsecondary context of support. American Educational Research Journal, 50(5), 1081-1121.

Watkins, J., \& Mazur, E. (2013). Retaining students in science, technology, engineering, and mathematics (STEM) majors. Journal of College Science Teaching, 42(5), 36-41. 


\section{Chapter II: Article I: A Structural Equation Model Analysis of Computing Identity Sub-Constructs and Student Academic Persistence}

\subsection{Abstract - This Research Full Paper presents the effects of}

computing identity sub-constructs on the persistence of computer science students. Computer science (CS) is one of the fastest-growing disciplines in the world and an emerging critical field for all students to obtain vital skills to be successful in the 21 st century. Despite the growing importance of computer science, many university and college programs suffer from low student persistence rates. Disciplinary identity is a theoretical framework that refers to how students see themselves with respect to a discipline and is related to longterm membership in a disciplinary community. The theory has been effectively applied in Science, Technology, Engineering, and Mathematics (STEM) to understand students' success and persistence. This study examines the effects of performance/competence, recognition, interest, and sense of belonging on the academic persistence of computer science students. A survey of approximately 1,640 computing students as part of a National Science Foundation (NSF) funded project was developed and administered at three metropolitan public institutions. Confirmatory Factor Analysis (CFA) was performed to validate the subconstructs of identity for use in a computing identity model. Then, a structural equation model (SEM) was constructed as a snapshot of the structural relationships for describing and quantifying the impact of the identity subconstructs on persistence. The results indicated that our model for CS aligns with prior research on disciplinary identity but also adds the importance of sense of 
belonging. In addition, the findings indicate that students' academic persistence is directly influenced by their interest. A better understanding of these factors may leverage insight into students' academic persistence in computer science/engineering programs as well as a meaningful lens of analysis for further curriculum and extracurricular activities.

Keywords — computer science education; computing identity; academic persistence; structural equation modeling; engineering education.

\subsection{Introduction}

Computer technology and computing is part of everything we do from the daily work with cellphones, to the movies we watch. CS is one of the fastestgrowing disciplines and highest paying career paths in the world which enables us to make a positive difference in the world by driving innovation in the other sciences (Schneider et al., 2018). Despite the increasing popularity and demand for computer science, many university programs suffer from low student persistence rates. The number of undergraduate students who leave Science, Technology, Engineering, and Mathematics (STEM) programs before completion is the highest for computer science majors (59\%) compared to all other STEM disciplines (Chen et al., 2013). Numerous students who leave computer science programs switch to other majors or drop out of school without earning an academic degree (Chen et al., 2013).

Literature specifies that academic persistence depends on a combination of factors such as the academic system, social system, family background, prior schooling (Tinto, 1975, 1985, 1997; Bean et al., 2000, 2001, 2003), career 
interests (Astin, 1993), academic motivation (French et al., 2005), communities of practice (Lave et al., 1991), interest, self-efficacy (Lent et al., 1994; Gist et al., 1992; Cabrera et al., 1992), and many more. Social cognitive theory (SCT) (Bandura, 1986) and social cognitive career theory (SCCT) (Lent et al., 2002) have also been prominent in STEM and engineering in the past decade emphasizing that self-beliefs explain students' academic choice behavior and influence students' performance, and career aspirations (Godwin, 2013, 2016; Cribbs et al., 2015). Other studies (Hazari et al., 2010; Cass et al., 2011) show that a disciplinary identity or a student's self-perception of his/her performance, competence, interest, and recognition are notably related to his/her goals, institutional commitments, choice of career and persistence with respect to a discipline (Figure 1). This disciplinary identity refers to how students see themselves with respect to a discipline. The disciplinary identity theory has been effectively applied in STEM to understand students' success, and persistence (Godwin, 2013, 2016; Cribbs et al., 2015; Hazari et al., 2010; Cass et al., 2011). Although there has been extensive work in science and engineering there is a dearth of literature on the implications of computer science identity on persistence.

To address the persistence issue, this study examines the effects of performance, competence, recognition, and sense of belonging which for the purpose of this study are defined as "identity sub-constructs" on the academic persistence of computer science students. A sub-construct is an attribute, ability, or skill that exists in the human brain, and is not directly observable. For this 
study, a survey was developed and administered at three metropolitan public institutions consisting of 1,640 computer science (CS), computer engineering (CE) and information technology (IT) students as part of a National Science Foundation (NSF) funded project [Collaborative Research: Florida IT Pathways to Success (Flit-Path) NSF\# 1643965]. A Confirmatory Factor Analysis (CFA) was performed first; then the structural equation model (SEM) was constructed to demonstrate and quantify the structural relationships of identity sub-constructs and persistence.

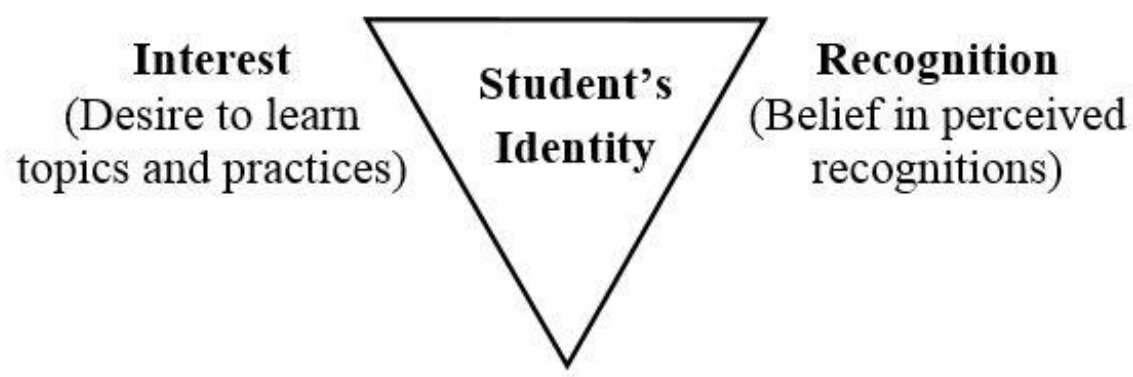

Competence/Performance

(Belief in ability to understand and accomplish tasks)

Figure 1 - Disciplinary Identity Framework

The research question guiding the study was how the theorized identity sub-constructs (performance, competence, recognition, interest, and sense of belonging) contribute to the academic persistence of undergraduate computer students?

\subsection{Theoretical Framework}

Identity development in STEM: Identity is an essential analytical instrument in education research for understanding students (Gee, 2000). There 
has been increasing attention to identity development in STEM (Tytler, 2014) due to a growing concern of the lack of interest in science among students. Identity has been defined as an individual's lens of experience and performances in society and the world around them (Tytler, 2014) or at the present time or even future envisioning (Shnahan, 2009; Barton et al., 2013). In 2007, a framework for science identity was proposed that emphasized performance, recognition, and competence (Carlone et al., 2007). The authors developed a model of science identity to investigate the science experiences of students throughout their education in science and science-related careers. Later, interest was introduced as another interrelated sub-construct that contributed to the framework (Hazari, 2010) (Figure 1). This framework has been validated for examining identity in the fields of math, physics, science, and engineering (Godwin et al., 2013, 2016; Cribbs et al., 2015; Hazari et al., 2010; Cass et al., 2011). A student's desire to learn and study, perceived competence/performance, and his/her beliefs of being recognized by others have been identified to be predictive of his/her persistence in education and career in that discipline (Godwin et al., 2013). Sense of belonging (belief in fitting into a community) on the other hand, has been identified as an additional construct contributing to student identity and persistence (Tinto, 1997; Lewis et al., 2016; Trujillo et al., 2014) which in this work is applied to the framework and examined as an identity sub-construct.

Although the STEM identity literature highlights the significance of selfbelief in academic persistence and success (Godwin et al., 2013, 2016; Cribbs et al., 2015; Hazari et al., 2010; Carlone et al., 2007; Aschbacher et al., 2010; 
Boaler, 2002; Capobianco et al., 2012; Cobb et al., 2010; Varelas et al., 2012;

Tonso, 1997), the research on computing identity has not been studied and framed widely. Researchers explored several areas as related to computing identity such as self-perception of performance/competence, students' expectation and values

(Bell-Watkins et al., 2009; DiSalvo et al., 2011; Mercier et al., 2006; Smith et al., 2005). The computing identity literature is lacking rigorous studies and still demands a more in-depth inquiry to indicate whether CS identity aligns with prior studies but also how the interrelated sub-constructs of computing identity influence CS students' persistence.

\subsection{Methodology}

A quantitative research method was used for this study. A survey exploring computing identity was developed and disseminated. The structural equation modeling (SEM) was used to determine whether the identity model was valid and how the theorized identity sub-constructs contribute to the academic persistence of computer science students (Godwin et al., 2018). After the institutional review board (IRB) approval, we first conducted a pre-survey on 95 students in three rounds. We revised some of the questions after the central tendency measurement, CFA analysis, and follow-up conversation with some of the students. Then, we conducted the main Flit-Path survey which was given to 1640 undergraduate students ranging from freshmen to seniors at three metropolitan public institutions, Florida International University (FIU), University of Central Florida (UCF), and University of South Florida (USF). The final version of the survey included 22 questions that covered the theorized sub- 
constructs of computing identity, persistence likelihood, and career likelihood and consisted of multiple-choice, Likert-scale, and categorical questions. The survey responses included a wide range of students: $22 \%$ female, $78 \%$ male, $23 \% 1$ st year, $13 \%$ 2nd year, $27 \%$ 3rd year, 23\% 4th year, 14\% past 4th year. Also, respondents included 31 American Indian or Alaska Native, 254 Asian, 198 Black or African American, 505 Hispanic, Latin, or Spanish origin, 40 Middle Eastern or North African, 11 Native Hawaiian or Other Pacific Islander, 857 White, and 41 other race or ethnicity.

SEM is a quantitative multivariate statistical analysis technique consisting of multiple regression and factor analysis which utilizes measured variables and latent variables in complex relationships (Wright et al, 2012). Measured variables such as our survey items can be observed and are measurable, while, latent variables such as persistence and identity sub-constructs cannot be observed directly, but their values can be implied by their relationships to observed variables. SEM builds on correlational research by adding theoretical perspectives of an explanatory nature that provides more insight into potential causation. The main reason for using SEM in this study is that SEM can measure latent variables and assesses the validity and reliability of the measurement model. Also, it enables us to evaluate a model of relationships among constructs and subconstructs simultaneously (Wright et al, 2012). The SEM first uses factor analysis to evaluate how well the items measure the underlying theoretical construct or latent variables. Then uses path analysis to evaluate the relationships among the 
latent variables and the validation of the model fit (Godwin et al., 2016; Cribbs et al., 2015; Hazari et al., 2010).

In this study, different aspects of reliability and validity were utilized.

Face, content, and construct validity were performed to determine whether the survey measures what it intended to measure. A pre-survey was designed and developed by leveraging valid and reliable instruments in engineering and science (Hazari et al., 2010; Cass et al., 2011) to provide feedback and establish face and content validity (Haynes et al., 1995). We performed several changes incrementally to examine and modify some of the questions. We piloted the survey to ensure that it was formatted correctly, worded correctly and that the questions were valid. In terms of construct validity, a Confirmatory Factor Analysis (CFA) was applied to the survey to validate whether the suitable measures were loaded on the four separate sub-constructs. In the construct validity, we compared the test elements of sub-constructs to determine how correlated the measures were and how well our tool measured the sub-constructs. We set a minimum factor loading of 0.5 (Godwin et al., 2013; Fox, 2006; Schumacker et al., 2012) and the results showed a high correlation on our fourfactor design. In terms of reliability, an internal consistency test was performed on the items used to build the four identity sub-constructs. Cronbach's alpha for the interest and recognition, performance/competence, and sense of belonging items were above the acceptable level of reliability of 0.7 (Godwin et al., 2013; Schumacker et al., 2012). 


\subsection{Results}

CFA was performed to identify the number and nature of underlying latent factors and examine the survey responses to confirm the factorial structure. We loaded questions into five factors. CFA confirmed three items for interest, three items for recognition, two items for performance/competence, and two items for sense of belonging. Each item of the sub-constructs had a loading factor of 0.5 or greater (Wright et al., 2012; Schumacker et al., 2012). The CFA model was tested based on our theoretical understanding of prior qualitative work (Carlone, 2007). Question 7 (Please rate the current likelihood of choosing a career in the computing field) (Appendix 1) and question 8 (How likely is it that you will finish a bachelor's degree in your current major (or intended major)?) were initially used for measuring computing persistence. However, when we performed more analysis, we narrowed it down to question 7 due to a high correlation between question 8 and interest questions.

Measurement Model: The confirmatory factor analysis was performed using R open-source software version 1.1.442. The SEM and Lavaan packages were used for measurement and the structural model. Bootstrapping and maximum likelihood estimation were used for our data to moderate the potential biasing effects for missingness (Godwin et al., 2013; Fox, 2006). Due to the large data sample size, the chi-square is significant (Schumacker et al., 2012). All of the fit indices of the model including GFI, AGFI, RMSEA, NNFI, and SRMR were within the recommended range of SEM and engineering education scholars 
(Godwin et al., 2016; Cribbs et al., 2015; Schumacker et al., 2012). Figure 2

shows the initial measurement model and fit indices.

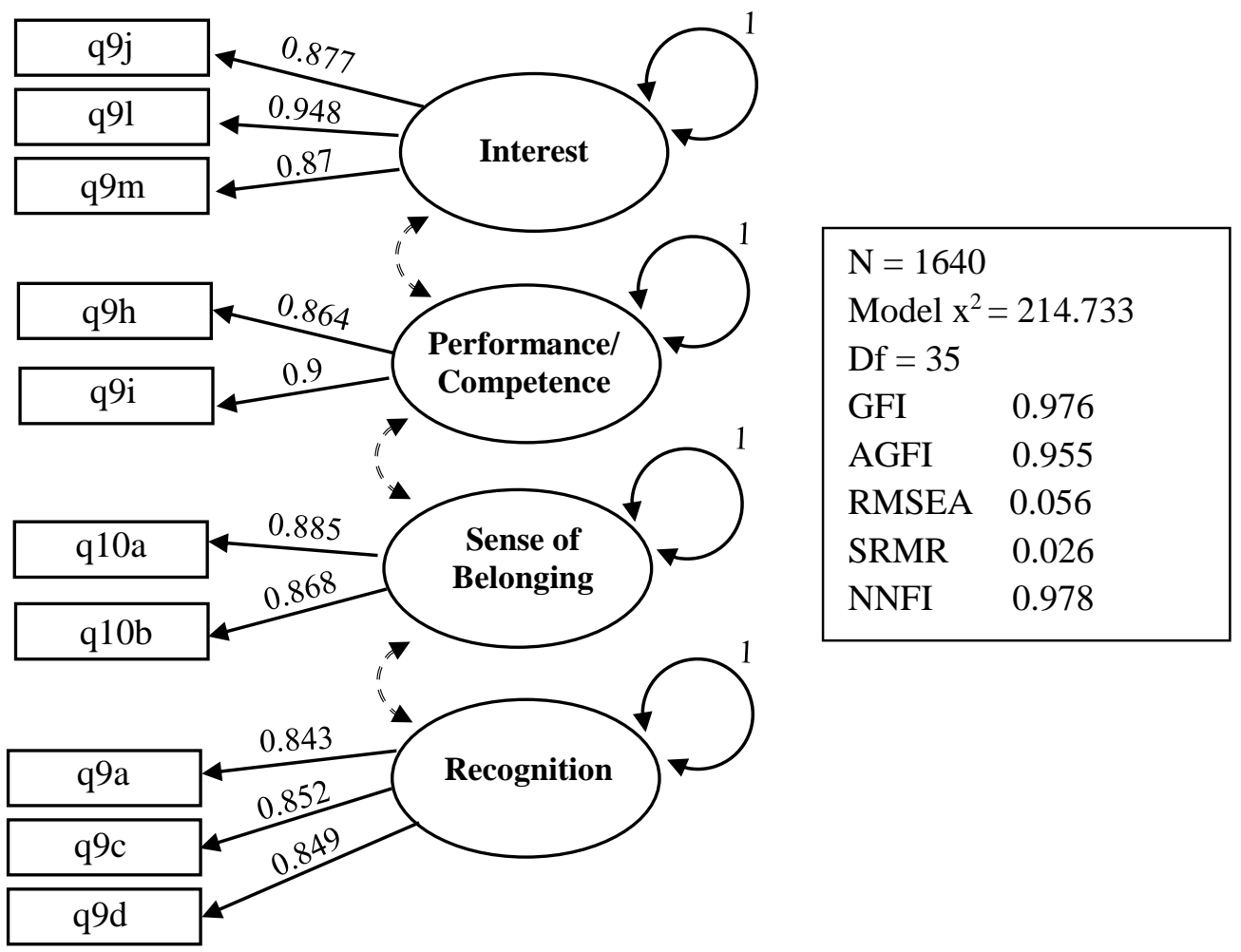
$\mathbf{q 9} \mathbf{a}=$ I see myself as an exemplary student in computing fields
$\mathbf{q 9 c}=$ Other students see me as an exemplary student in computing fields q9d = My teachers see me as an exemplary student in computing fields $\mathbf{q 9 h}=$ I can do well on computing tasks $\mathbf{q 9} \mathbf{i}=$ I understand concepts underlying computer processes
$\mathbf{q} \mathbf{9} \mathbf{j}=$ Topics in computing excite my curiosity
$\mathbf{q 9 1}=$ I enjoy learning about computing
$\mathbf{q 9} \mathbf{m}=$ I like to know what is going on in computing
$\mathbf{q 1 0 a}=$ I feel like you are part of the community
$\mathbf{q 1 0 b}=$ I feel valued and respected

Figure 2 - Confirmatory Factor Analysis (Acceptable values: GFI ( $p>0.90)$, AGFI $(p>0.90)$, RMSEA ( $p<0.08)$, NNFI $(p>0.90)$, SRMR $(p<0.08))$ 
Table 1 shows the results of the initial measurement model and fit indices. It includes the factor loadings, item reliability, construct reliability, and average invariance of variables. The range of standardized factor loading was from 0.84 to 1 which is acceptable (Godwin et al., 2016; Schumacker et al., 2012).

Table 1 - Confirmatory Factor Analysis Estimates and Fit Indices. Acceptable values: Item reliability $>0.50$, Construct reliability $>0.70$, Average variance extracted $>0.50$

\begin{tabular}{|c|c|c|c|c|c|c|}
\hline $\begin{array}{l}\text { Latent } \\
\text { variable }\end{array}$ & Indicator variable & $\begin{array}{l}\text { Standardi } \\
\text { zed factor } \\
\text { loading }\end{array}$ & $\begin{array}{l}\text { Standard } \\
\text { error }\end{array}$ & $\begin{array}{l}\text { Item } \\
\text { reliabilit } \\
\mathbf{y} \\
\left(\mathbf{R}^{2}\right) \\
\end{array}$ & $\begin{array}{l}\text { Construct } \\
\text { reliability }\end{array}$ & $\begin{array}{l}\text { Average } \\
\text { variance } \\
\text { extracted }\end{array}$ \\
\hline Interest & $\begin{array}{l}\text { q9j } \\
\text { q91 } \\
\mathbf{q 9 m}\end{array}$ & $\begin{array}{l}0.877 \\
0.948 \\
0.87\end{array}$ & $\begin{array}{l}0.020 \\
0.017 \\
0.019\end{array}$ & $\begin{array}{l}0.769 \\
0.899 \\
0.757\end{array}$ & 0.927 & 0.808 \\
\hline $\begin{array}{l}\text { Performance/ } \\
\text { Competence }\end{array}$ & $\begin{array}{l}\text { q9h } \\
q 9 i\end{array}$ & $\begin{array}{l}0.864 \\
0.9\end{array}$ & $\begin{array}{l}0.025 \\
0.024\end{array}$ & $\begin{array}{l}0.746 \\
0.810\end{array}$ & 0.875 & 0.778 \\
\hline Recognition & $\begin{array}{l}\text { q9a } \\
\text { q9c } \\
\text { q9d }\end{array}$ & $\begin{array}{l}0.843 \\
0.852 \\
0.849\end{array}$ & $\begin{array}{l}0.021 \\
0.021 \\
0.021\end{array}$ & $\begin{array}{l}0.711 \\
0.726 \\
0.721\end{array}$ & 0.885 & 0.719 \\
\hline $\begin{array}{l}\text { Sense of } \\
\text { Belonging }\end{array}$ & $\begin{array}{l}\text { q10a } \\
\text { q10b }\end{array}$ & $\begin{array}{l}0.885 \\
0.868\end{array}$ & $\begin{array}{l}0.026 \\
0.025\end{array}$ & $\begin{array}{l}0.783 \\
0.753\end{array}$ & 0.869 & 0.768 \\
\hline
\end{tabular}

Structural Model: We hypothesized a structural model for identity subconstructs and persistence. Figure 3 shows the model which was built using a 
correlation matrix. The goal of SEM is to find the best model fit. We tested and hypothesized different combinations of sub-constructs based on the previous work on identity theory and social cognitive careers (Lent et al., 1994, 2002; Godwin et al., 2013, 2016; Carlone et al., 2007). The reference variable for computing persistence was fixed in the model to 1 . All pathways were significant $(p<0.001)$ and fit indices were within the recommended range (Godwin, 2016; Cribbs et al., 2015, Schumacker et al., 2012).

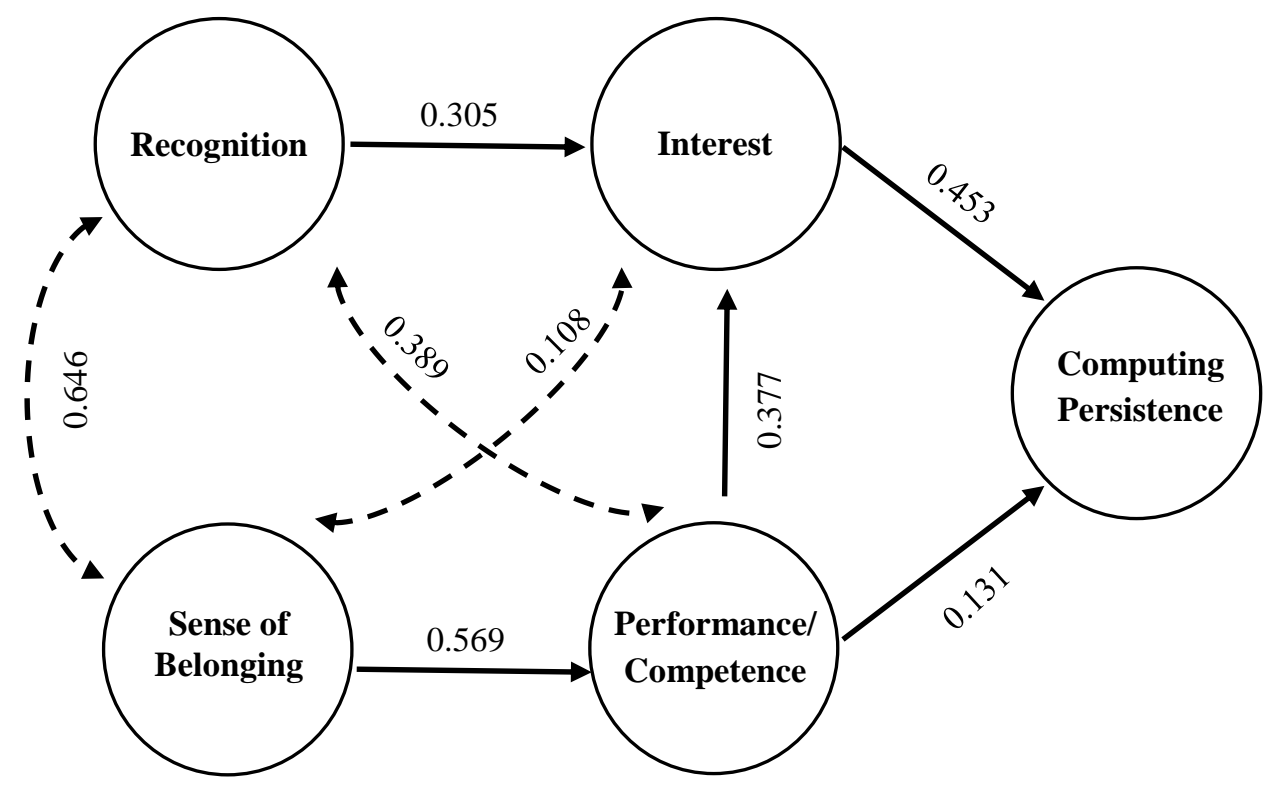

$$
\begin{array}{lclc}
\text { N }=1640 & & \multicolumn{3}{l}{\text { Df }=38} \\
\text { Model } x^{2}=234.903 & \text { GFI } & 0.973 \\
\text { AGFI } & 0.954 & \text { RMSEA } & 0.056 \\
\text { SRMR } & 0.031 & \text { NNFI } & 0.977
\end{array}
$$

Figure 3 - Structural Equation Modeling Results. GFI: goodness of fit; AGFI: adjusted goodness of fit; RMSEA: root mean square error of approximation; SRMR: standardized root mean square residual; NNFI: non-normed fit. (Acceptable values: GFI ( $p>0.90)$, AGFI ( $p>0.90)$, RMSEA ( $p<0.08)$, NNFI $(p>0.90)$, SRMR $(p<0.08))$ 


\subsection{Discussion}

While computing identity sub-constructs contributed to persistence, their effects were varied with both direct and indirect pathways. Since the theoretical structure does not explain the nuance in how the sub-constructs affect each other and identity, we tested several direct and indirect models for the effect of the subconstruct. The interest had the strongest direct effect on persistence $(\mathrm{p}<0.001)$ which indicates that the more students are interested in computing, the more likely they would be to persist. There is rich literature (Lent et al., 2008; Biggers et al., 2008) that emphasizes student's desire to learn computing and curiosity about computing topics are linked with student's persistence, engagement, and motivation in computing.

Student's self-competence beliefs also had a significant pathway to persistence $(\mathrm{p}<0.001)$. Students' beliefs about their ability to understand and perform in computing affect students' activities (Bandura, 1986). The direct effect of interest and competency is supported by SCCT and self-efficacy theory (Bandura et al., 1981). Students with higher self-competence beliefs are more likely to persist in learning, education, and occupation (Ferla et al, 2010). The effects of interest and self-efficacy on student's persistence and performance have been studied in many studies (Lent et al, 1987, 2006, 2016; Navarro et al., 2014; Lee et al., 2014). Recognition had both direct and indirect effects ( $\mathrm{p}<0.001)$. Recognition had a direct effect on interest $(\mathrm{p}<0.001)$ which indicates that the more a student believes that their friends and family members view him/her as a computing person, the more likely he/she feels interested in computing (Lent et al, 
1994). The indirect influence of recognition on persistence went through interest. It indicates that recognition may increase student's persistence by influencing interest. For instance, being recognized by friends and teachers as a software developer for a computing student positively affects his/her interest and consecutively his/her persistence in academia and career intentions. Recognition and performance/competence have been studied as predictive of positively impacting students' persistence (Godwin et al., 2016).

Sense of belonging had a direct effect on competence and performance $(\mathrm{p}<0.001)$. It indicates that the more students feel a belonging to the computing community, groups, and organizations, the more likely they feel they are capable to understand computer science and perform in computing. The strong correlation among recognition, sense of belonging, and performance /competence revealed that there are bidirectional effects among them. If school administrators and teachers encourage students to be part of computing organizations like ACM and IEEE, it allows students to feel a sense of belonging in computing sciences. The difference in our results to the expected identity framework (Godwin et al., 2013, 2016; Cribbs et al., 2015; Cass et al., 2011) may potentially be caused by multiple reasons. For example, the variation in CS interest for the students who study computing across IT, CS, and CE might suggest that interest level distinguishes their likelihood of persisting in CS-related careers. Students may be interested initially in CS careers for many reasons that are not related to the core interest in the subject. Thus, their original interest once in the programs may serve to distinguish them in ways that affect their persistence. For instance, a student 
who enters CS because he/she is interested initially in a career related to gaming may realize once in the program that actual CS tasks are less interesting and therefore be less likely to persist. In contrast, the model for students in engineering (Godwin et al., 2013, 2016) may be different because they initially major in those subjects with similar interests in the content itself. Second, in this study, the focus was on persistence as an outcome rather than an overall measure for a student's disciplinary identity. Thus, we did not expect identical results from earlier work in physics, math, and science.

Interest in this model has been identified as the most effective subconstruct with a direct pathway to persistence. The other sub-constructs have an indirect effect on the interest sub-construct. For instance, if a student feels less recognized, he/she is more likely to drop out or choose an unrelated career due to the fact of not being interested in computing. It would be beneficial to investigate the theory in action and do a further study about student's feelings and beliefs on their persistence.

Our findings is slightly different from some of the previous findings in other disciplines especially in engineering (Godwin et al., 2013, 2016). In our model interest and competence/performance directly influenced persistence; however in previous studies interest and recognition directly influenced persistence and performance/competence was mediated through interest and recognition. The key difference in these studies is the negative direct impact of performance/competence on persistence when is not mediated. Computing's nature might be slightly different from other STEM disciplines. Computing topics 
and software/hardware technology are being updated every day and this might be the reason that computing students need a higher performance/competence feelings compared to other STEM disciplines.

\subsection{Conclusion}

The purpose of this study was to investigate how computing identity subconstructs contribute to the academic persistence of CS students. In addition, it aimed to examine whether the theorized sub-constructs aligns with the prior work on identity. For this purpose, we designed a conceptual model, developed a hypothesis, designed a questionnaire, conducted a survey, and used multiple statistical techniques including CFA and SEM to accomplish our goal and answer our research question. The results showed CS persistence is influenced by the computing identity sub-constructs. Structural equation modeling analysis quantified the impact of these pathways.

It is important to understand that investigating students' disciplinary identity is one way to explore students' persistence. The model proposed in this paper will help researchers to understand students' persistence in computing through further exploring their identity sub-constructs. Also, constructing curricular and extracurricular activities based on these findings potentially increase the academic persistence in computer science programs. Furthermore, students, instructors, and faculty members, as well as academic counselors who assist and advise students can leverage the results. The future work includes a further assessment of our structural equation model for diverse demographics such as gender dynamics and level of education. 


\section{References (Chapter II)}

Aschbacher, P. R., Li, E., \& Roth, E. J. (2010). Is science me? High school students' identities, participation and aspirations in science, engineering, and medicine. Journal of Research in Science Teaching, 47(5), 564-582.

Astin, A. W. (1993). What matters in college?: Four critical years revisited (Vol. 1). San Francisco: Jossey-Bass.

Bandura, A. (1986). Social foundations of thought and action: A social cognitive theory. Englewood Cliffs, NJ, US: Prentice-Hall, Inc.

Bandura, A., \& Schunk, D. H. (1981). Cultivating competence, self-efficacy, and intrinsic interest through proximal self-motivation. Journal of personality and social psychology, 41(3), 586.

Bean, J. P. (2003). College student retention. Encyclopedia of education, 1, 401407.

Bean, J. P., \& Eaton, S. B. (2000). A psychological model of college student retention. Reworking the student departure puzzle, 1, 48-61.

Bean, J., \& Eaton, S. B. (2001). The psychology underlying successful retention practices. Journal of College Student Retention: Research, Theory \& Practice, 3(1), 73-89.

Bell-Watkins, K., Barnes, T., \& Thomas, N. (2009). Developing computing identity as a model for prioritizing dynamic K-12 computing curricular standards. Journal of Computing Sciences in Colleges, 24(3), 125-131.

Biggers, M., Brauer, A., \& Yilmaz, T. (2008, March). Student perceptions of computer science: a retention study comparing graduating seniors with cs leavers. In ACM SIGCSE Bulletin (Vol. 40, No. 1, pp. 402-406). ACM.

Boaler, J. (2002). Experiencing school mathematics: Traditional and reform approaches to teaching and their impact on student learning. Routledge.

Cabrera, A. F., Nora, A., \& Castaneda, M. B. (1992). The role of finances in the persistence process: A structural model. Research in higher education, 33(5), 571593.

Calabrese Barton, A., Kang, H., Tan, E., O’Neill, T. B., Bautista-Guerra, J., \& Brecklin, C. (2013). Crafting a future in science: Tracing middle school girls' identity work over time and space. American Educational Research Journal, 50(1), 37-75. 
Capobianco, B. M., French, B. F., \& DIEFES-DU, H. A. (2012). Engineering identity development among pre-adolescent learners. Journal of Engineering Education, 101(4), 698-716.

Carlone, H. B., \& Johnson, A. (2007). Understanding the science experiences of successful women of color: Science identity as an analytic lens. Journal of research in science teaching, 44(8), 1187-1218.

Cass, C. A., Hazari, Z., Cribbs, J., Sadler, P. M., \& Sonnert, G. (2011, October). Examining the impact of mathematics identity on the choice of engineering careers for male and female students. In Frontiers in Education Conference (FIE), 2011 (pp. F2H-1). IEEE.

Cobb, P., \& Hodge, L. L. (2010). Culture, identity, and equity in the mathematics classroom. In A journey in mathematics education research (pp. 179-195). Springer, Dordrecht.

Cribbs, J. D., Hazari, Z., Sonnert, G., \& Sadler, P. M. (2015). Establishing an explanatory model for Mathematics Identity. Child development, 86(4), 10481062.)

Enyedy, N., Goldberg, J., \& Welsh, K. M. (2006). Complex dilemmas of identity and practice. Science Education, 90(1), 68-93.

Ferla, J., Valcke, M., \& Schuyten, G. (2010). Judgments of self-perceived academic competence and their differential impact on students' achievement motivation, learning approach, and academic performance. European Journal of Psychology of Education, 25(4), 519-536.

Fox, J. (2006). Teacher's corner: structural equation modeling with the sem package in R. Structural equation modeling, 13(3), 465-486.

French, B. F., Immekus, J. C., \& Oakes, W. C. (2005). An examination of indicators of engineering students' success and persistence. Journal of Engineering Education, 94(4), 419-425.

G. Chen, X. (2013). STEM Attrition: College Students' Paths into and out of STEM Fields. Statistical Analysis Report. NCES 2014-001. National Center for Education Statistics.

Gee, J. P. (2000). Chapter 3: Identity as an analytic lens for research in education. Review of research in education, 25(1), 99-125.

Gist, M. E., \& Mitchell, T. R. (1992). Self-efficacy: A theoretical analysis of its determinants and malleability. Academy of Management review, 17(2), 183-211. 
Godwin, A., Potvin, G., Hazari, Z., \& Lock, R. (2013, October). Understanding engineering identity through structural equation modeling. In Frontiers in Education Conference, 2013 IEEE (pp. 50-56). IEEE.

Godwin, A., Potvin, G., Hazari, Z., \& Lock, R. (2016). Identity, critical agency, and engineering: An affective model for predicting engineering as a career choice. Journal of Engineering Education, 105(2), 312-340.

Haynes, S. N., Richard, D., \& Kubany, E. S. (1995). Content validity in psychological assessment: A functional approach to concepts and methods. Psychological assessment, 7(3), 238.

Hazari, Z., Sonnert, G., Sadler, P. M., \& Shanahan, M. C. (2010). Connecting high school physics experiences, outcome expectations, physics identity, and physics career choice: A gender study. Journal of research in science teaching, 47(8), 978-1003.

Hilton, T. L., \& Lee, V. E. (1988). Student interest and persistence in science: Changes in the educational pipeline in the last decade. The Journal of Higher Education, 59(5), 510-526.

James DiSalvo, B., Yardi, S., Guzdial, M., McKlin, T., Meadows, C., Perry, K., \& Bruckman, A. (2011, May). African American men constructing computing identity. In Proceedings of the SIGCHI Conference on Human Factors in Computing Systems (pp. 2967-2970). ACM.

Lave, J., Wenger, E., \& Wenger, E. (1991). Situated learning: Legitimate peripheral participation (Vol. 521423740). Cambridge: Cambridge university press.

Lee, W., Lee, M. J., \& Bong, M. (2014). Testing interest and self-efficacy as predictors of academic self-regulation and achievement. Contemporary Educational Psychology, 39(2), 86-99.

Lent, R. W., \& Brown, S. D. (2006). On conceptualizing and assessing social cognitive constructs in career research: A measurement guide. Journal of career assessment, 14(1), 12-35.

Lent, R. W., Brown, S. D., \& Hackett, G. (1994). Toward a unifying social cognitive theory of career and academic interest, choice, and performance. Journal of vocational behavior, 45(1), 79-122.

Lent, R. W., Brown, S. D., \& Hackett, G. (2002). Social cognitive career theory. Career choice and development, 4, 255-311. 
Lent, R. W., Brown, S. D., \& Larkin, K. C. (1987). Comparison of three theoretically derived variables in predicting career and academic behavior: Selfefficacy, interest congruence, and consequence thinking. Journal of counseling psychology, 34(3), 293.

Lent, R. W., Lopez Jr, A. M., Lopez, F. G., \& Sheu, H. B. (2008). Social cognitive career theory and the prediction of interests and choice goals in the computing disciplines. Journal of Vocational Behavior, 73(1), 52-62.

Lent, R. W., Miller, M. J., Smith, P. E., Watford, B. A., Lim, R. H., \& Hui, K. (2016). Social cognitive predictors of academic persistence and performance in engineering: Applicability across gender and race/ethnicity. Journal of Vocational Behavior, 94, 79-88.

Lewis, K. L., Stout, J. G., Pollock, S. J., Finkelstein, N. D., \& Ito, T. A. (2016). Fitting in or opting out: A review of key social-psychological factors influencing a sense of belonging for women in physics. Physical Review Physics Education Research, 12(2), 020110.

Mercier, E. M., Barron, B., \& O'connor, K. M. (2006). Images of self and others as computer users: The role of gender and experience. Journal of computer assisted learning, 22(5), 335-348.

Navarro, R. L., Flores, L. Y., Lee, H. S., \& Gonzalez, R. (2014). Testing a longitudinal social cognitive model of intended persistence with engineering students across gender and race/ethnicity. Journal of Vocational Behavior, 85(1), 146-1.

Schneider, G. M., \& Gersting, J. (2018). Invitation to computer science. Cengage Learning.

Schumacker, R. E., \& Lomax, R. G. (2012). A beginner's guide to structural equation modeling. Routledge.

Shanahan, M. C. (2009). Identity in science learning: Exploring the attention given to agency and structure in studies of identity. Studies in Science Education, 45(1), 43-64.

Smith, J. L., Morgan, C. L., \& White, P. H. (2005). Investigating a measure of computer technology domain identification: A tool for understanding gender differences and stereotypes. Educational and Psychological Measurement, 65(2), $336-355$.

Tinto, V. (1975). Dropout from higher education: A theoretical synthesis of recent research. Review of educational research, 45(1), 89-125. 
Tinto, V. (1985). Dropping out and other forms of withdrawal from college. Increasing student retention, 2, 28-43.

Tinto, V. (1997). Classrooms as communities: Exploring the educational character of student persistence. The Journal of higher education, 68(6), 599-623.

Tonso, K. L. (1997). Constructing engineers through practice: Gendered features of learning and identity development.

Trujillo, G., \& Tanner, K. D. (2014). Considering the role of affect in learning: Monitoring students' self-efficacy, sense of belonging, and science identity. CBELife Sciences Education, 13(1), 6-15.

Tytler, R. (2014). Attitudes, identity, and aspirations toward science. Handbook of research on science education, 82-103.

Varelas, M., Martin, D. B., \& Kane, J. M. (2012). Content learning and identity construction: A framework to strengthen African American students' mathematics and science learning in urban elementary schools. Human Development, 55(5-6), 319-339.

Wright, R. T., Campbell, D. E., Thatcher, J. B., \& Roberts, N. H. (2012). Operationalizing Multidimensional Constructs in Structural Equation Modeling: Recommendations for IS Research. CAIS, 30, 23. 


\section{Chapter III: Article II: Exploring Computing Identity and Persistence Across Multiple Groups Using Structural Equation Modeling}

\subsection{Abstract}

Despite the projected growth of computer and information technology occupations, many computing students fail to graduate. Studying students'selfbeliefs is one way to understand persistence in a school setting. This paper explores how students' disciplinary identity sub-constructs including competence/performance, recognition, interest, and sense of belonging contribute to academic persistence. A survey of 1,640 students as part of an NSF grant was conducted at three South Florida metropolitan public universities. A quantitative analysis was performed which included a structural equation model (SEM) and a multigroup SEM. The study examined different groups of students such as male versus female, and freshman versus senior students. Results suggest identity subconstructs contribute differently to academic persistence among freshman and senior students; however, no significant differences were found between male and female students. The findings, such as the significance of particular aspects of computing identity on academic persistence, can have implications for educators and college administration.

\subsection{Introduction}

Computer science and modern technologies empower individuals and undoubtedly have a monumental impact on many areas of society. According to national statistical projections, computing employment is estimated to increase in the future (Hogan et al., 2015), and will continue to be one of the most lucrative 
fields. University education in computer science, computer engineering, and information technology is providing students with abundant future job opportunities. Although the lack of a formal computing degree cannot stop young people from securing a lucrative job in technology, an academic computing degree can be a big advantage for a candidate. Industry statistics suggest companies and startups are more likely to recruit someone skilled with a bachelor's degree (Hogan et al., 2017; Bureau of Labor Statistics, 2019). In spite of the increasing demand for computing jobs, computer science dropouts are still the highest among STEM disciplines (Chen, 2013). In addition, despite the emphasis on diversity in technology, the gender gap in computing education and jobs has worsened over the past 30 years (Hogan et al., 2015; Bureau of Labor Statistics, 2019; Snyder et al., 2012).

Prior studies showed that there are many factors involved in students' academic retention and persistence such as family background, vision for a career, demographic characteristics, institutional type, curriculum (Tinto, 1975, 1987), classroom-related factors, grade performance (Tinto, 1987), friendship support, academic engagement, attitudes, and satisfaction, as well as many more (Lent et al., 1984, 1994). Early studies (Feldman, 1994) examined the effect of students' characteristics and their interactions on their persistence. Other researchers (Tinto, 1975) studied other factors like career goals and commitments. These studies are framed using many theoretical frameworks. One such framework is the social cognitive career theory (SCCT) (Lent et al., 1994; 2002). SCCT was developed to explain how some educational and career choices are made. SCCT shows the 
impact of interest and self-efficacy, learning experiences, personal inputs, and environmental influences on choice actions, persistence, and satisfaction.

Likewise, disciplinary identity theory (Carlone et al., 2007; Hazari et al., 2010) describes how students' perceived feelings of their competence/performance, recognition, interest, and sense of belonging form their identities. In this framework (Figure 1), identity has been defined using four subconstructs including competence/performance, recognition, interest, and sense of belonging (Taheri et al., 2019). Student interest is defined by their engagement with respect to a topic. Competence/performance refers to a student's selfconfidence in understanding a particular topic and feeling accomplished (or able to become accomplished) in that topic. Recognition is defined by measuring the internalized feelings of recognition of a student when he/she communicates with his/her teacher, family members, or friends. Sense of belonging relates to a student's feelings of belonging to a community or group related to the topic and discipline. In the past, researchers studied identity theory and its impact on various disciplines including mathematics, physics, and general science students (Hazari et al., 2015; Cass et al., 2011). They also examined the effect of identity sub-constructs on choice of careers (Hazari et al., 2010; Cass et al., 2011). In general, computing identity is not defined as just being good at a computingrelated test or homework; it is defined by a student's interest, and the other previously mentioned self-beliefs in computing. 


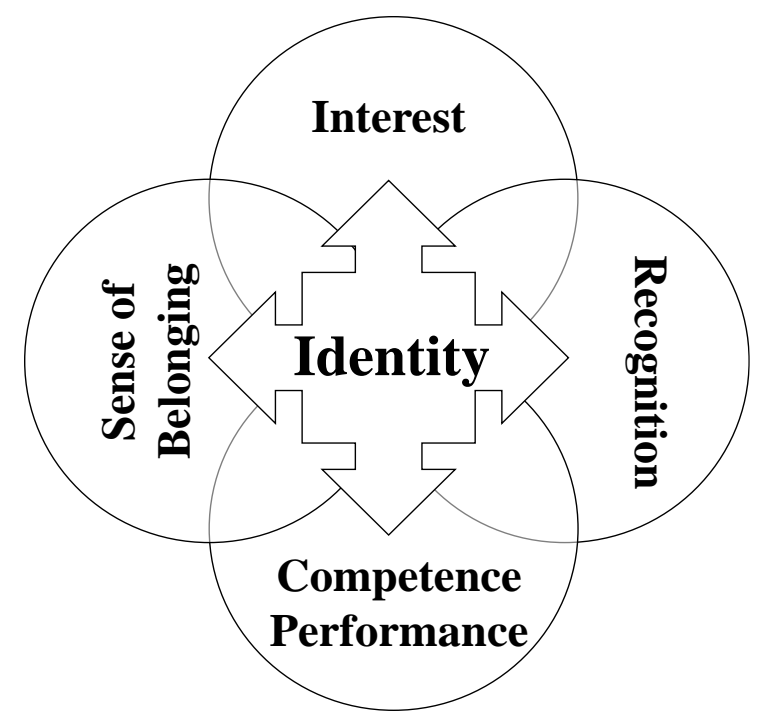

Figure 1 - Disciplinary Identity Framework

Due to the lack of rigorous research on the identity sub-constructs in computing education, in this paper, we concentrated on students' disciplinary identity, self-beliefs and their impacts on persistence. For this purpose, we designed a survey and a quantitative research study as part of the Florida IT Pathways to Success (Flit-Path) NSF grant. The Flit-Path grant supports student scholarships, curricular/co-curricular activities, and research studies on evidencebased practices on persistence, success, and graduation in IT-related and computing disciplines. A survey was designed and conducted, and a multi-group SEM was performed to further investigate diverse demographics and contexts such as gender and level of school education.

\subsection{Theoretical Framework}

This study is guided by two theoretical frameworks. Disciplinary Identity theory was the main driving theory, and social cognitive career theory was used to 
understand some of the results. Identity has been a topic of particular interest in psychology, philosophy, and social science since the 1900s (Stets et al., 2000, 2013). Identity has been defined in many different ways but it is usually closely tied with a simple, yet complicated question: "who are you?" (Jenkins, 2014; Erikson, 1970). A person may identify in a variety of ways and hold several different roles in his/her daily life such as female, student, sister, and wife. In 2000 (Gee, 2000), identity was framed as an analytic lens for research in education and was defined by Gee as "being recognized as a certain kind of person in a given context" (p.99). Gee described the characteristics of identity based on social and cultural views.

In 2007, Carlone and Johnson (Carlone et al., 2007) conducted a qualitative research study and developed a framework for STEM and science education. This model included performance, competence, recognition of self, and recognition by others. They provided evidence that identities are formed and developed in practice and that identity is not solely constructed by an individual. They did not have interest as a sub-construct since they studied scientists who already were successful and interested in science. When we consider students in a classroom, their interest level may vary and play a vital role in their identities.

In 2010, researchers (Hazari et al., 2010) developed a theoretical framework that measured identity across physics and mathematics students. They followed up with several case studies trying to understand how identity development occurs, how students conceptualize identity and how to quantify thinking around identity (Godwin, 2016; Shanahan, 2009). They defined 
disciplinary identity as how a student identifies himself/herself with respect to a specific discipline, for example, when a student mentions he/she sees himself/herself as a "computer person." Also, they theorized that the competence/performance sub-construct was a more appropriate sub-construct for identity compared to self-efficacy since it covers a broader range of students' beliefs in accomplishing things, and is not limited to a specific task (Hazari et al., 2010; Cass et al., 2011).

What prior scholars developed as a model allowed other researchers to predict students' choices. Choices can include taking a class in the next semester, decisions to persist, and even future career intentions. Other researchers (Hazari et al., 2015; Cribbs et al., 2015; Cass et al., 2011; Godwin, 2016) conducted additional identity studies to further explore the identity development for different genders. They examined gender as a specific identity to investigate the intersection of having a physics identity and an identity as a female. They also found that students' math and physics identities are significant factors and predictors of their engineering identity (Godwin et al., 2013).

The research questions guiding this work are: 1) how do the identity subconstructs contribute to the academic persistence of computer science students who are male versus female? 2) how do the identity sub-constructs contribute to the academic persistence of computer science freshman versus upper-level undergraduate students? To address the research questions, we conducted a survey and performed a multigroup SEM. 


\subsection{Methodology}

To answer the research questions, a quantitative research method was utilized for this study. After the IRB approval, a survey was administered to students in information technology (IT), computer science (CS), and computer engineering (CE) at three South Florida metropolitan public universities (Florida International University (FIU), University of Central Florida (UCF), and University of South Florida (USF)). The survey consisted of 22 questions that included demographics, students' intention to pursue a CS career, students' intentions to persist to a bachelor's degree in computing, as well as items measuring constructs related to their identities. For this study, persistence refers to the willingness and the continuation of an effort to graduate with career intentions in computing-related areas.

The constructs included computing competence/performance beliefs (two items), computing recognition (three items), computing interest (two items), and sense of belonging (two items) (factor loadings >0.5) (Table1) (Schumacker et al., 2012). These items were drawn from previously validated and reliable instruments in engineering and science. However, the reliability and validity of the constructs were further tested including establishing face, content, and construct validity. Face and content validity were established through pilot testing with 95 students and focus groups. Construct validity was established through factor analysis. Internal consistency (reliability) was assessed using Cronbach's alpha with all constructs having reliability greater than 0.7 (Godwin, 
2016; Schumacker et al., 2012). Survey questions consisted of Likert scale, multiple-choice, and categorical questions.

In total, 1640 survey responses were collected in Fall 2017 including 78\% male and $22 \%$ female respondents. In terms of year in college, $37 \%$ were 4 th year or more, $27 \%$ were 3 rd year, $13 \%$ were 2 nd year, and $23 \%$ were 1 st year. For students' race and ethnic identities, there were 31 students who identified as American Indian/Alaska Native, 254 Asian students, 198 Black/African American students, 505 Hispanic students, 40 Middle Eastern/North African students, 11 Native Hawaiian/Other Pacific Islander students, 857 White students, and 41 other race/ethnicity students.

To examine the contribution of the identity sub-constructs on computing persistence we utilized a structural equation model analysis. In SEM both latent and observed variables can be evaluated simultaneously (Kline, 2015). The final SEM model was based on a theoretical understanding of identity and persistence. In addition, our experiences of working in a computing academic setting and working with computing students for several years added more perspective and insight into our analysis. For running the SEM analysis, we first performed a confirmatory factor analysis (CFA) to assure the measurements for this model were valid. All factor loadings were within the acceptable range $(>0.5)$ (Schumacker et al., 2012; Rosseel, 2012). After factor analysis, the relationships among latent variables including competence/performance, recognition, interest, sense of belonging, and computing persistence were evaluated. The model fit was measured and validated accordingly. We handled the missing data using the 
maximum likelihood approach (Schumacker et al., 2012) which utilizes all the information into the analysis and provides an unbiased parameter estimation (Schumacker et al., 2012). The whole analysis was performed in R using the SEM and Lavaan package (Rosseel, 2012, 2018).

After we completed the basic SEM analysis, we compared the model for different groups including male and female students, and freshman and senior students (multigroup SEM). For this purpose, we performed the model invariance test to identify significant differences between groups. For the invariance measurement testing, all of the factor loadings and regression coefficients in our measurement/structural model were constrained to be equal. Then, we unconstrained one path at a time to determine which paths are significantly different. First, we focused on gender differences across all paths including measurement and structural coefficients. A Chi-square difference test was established to see if the difference was significant $(\mathrm{p}<0.05)$ (Schumacker et al., 2012; Rosseel, 2018). After comparing the model between males and females, we analyzed senior students versus freshman students with the same approach to investigate the differences.

\subsection{Results}

Our results include a CFA, an SEM analysis, and multigroup SEM across groups. We first describe the CFA results, and then we focus on the SEM and multigroup SEM. The CFA results (Table 1) show that our measurement model fits the data. 
Table 1 - Confirmatory Factor Analysis and List of Variables. Acceptable values: Item reliability $>0.50$, Construct reliability $>0.70$, Average variance extracted $>$ 0.50

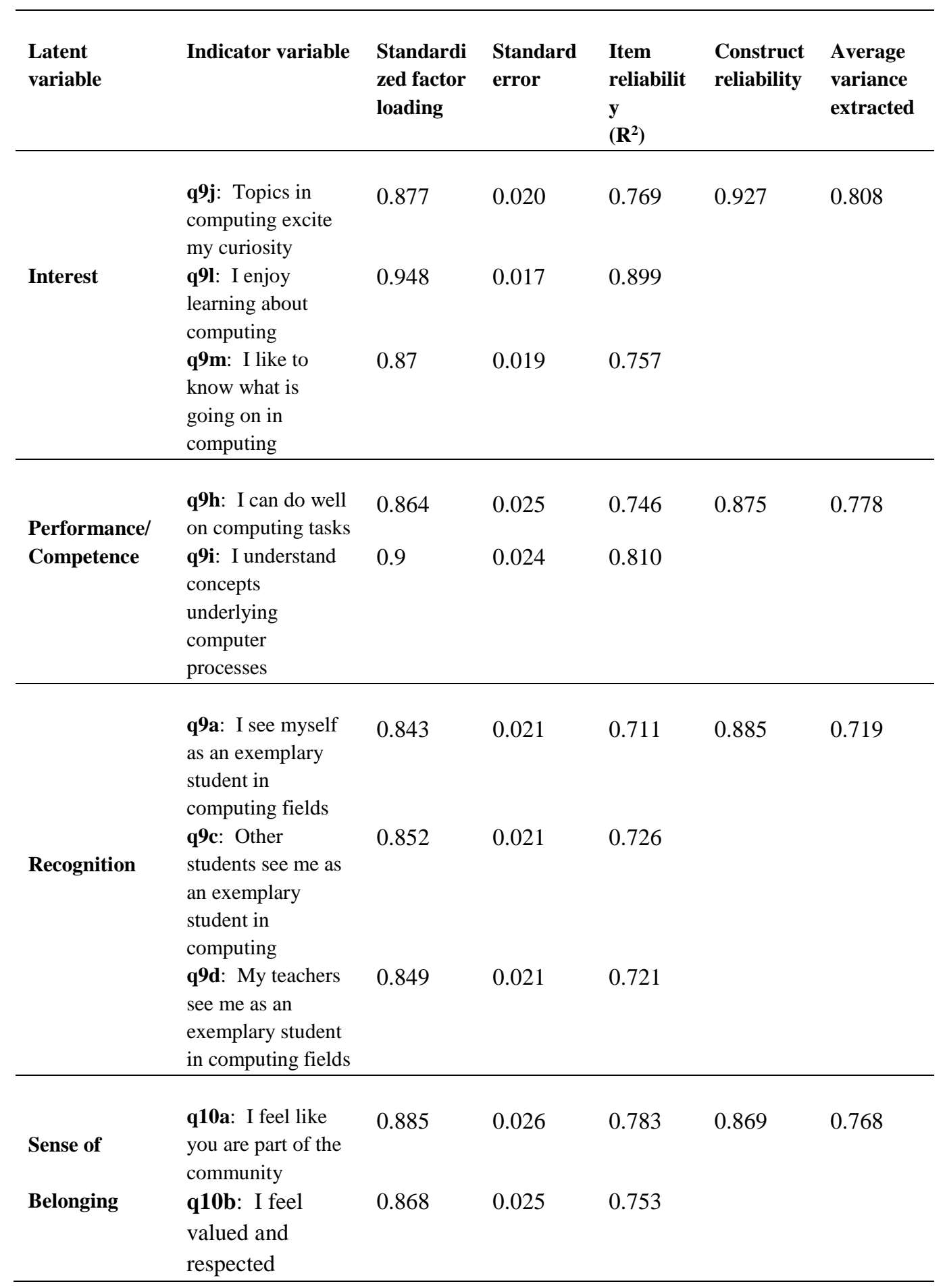


It indicates that the theorized sub-constructs are well-measured and our measurement model shows that the selected measurement variables represent the latent variables. The RMSEA or the "root mean square error of approximation" value was 0.056 . The GFI or "Goodness of fit index" value was 0.976 . The AGFI or "adjusted goodness of fit index" value was 0.955 . SRMR or "standardized root mean square residual" value was 0.026 . The NNFI or "non-normed fit index" value was 0.978 . All the relevant fit indices were within the acceptable ranges which indicates that the measurement model (i.e. survey items indicating latent identity sub-constructs) was well fit. While the Chi-square was significant (214.733, $\mathrm{df}=35$ ), this is not an issue since a significant Chi-square for a large sample size does not indicate a weak fit (Schumacker et al., 2012).

Furthermore, the CFA results confirm that individual and overall reliability of our underlying constructs are within the acceptable ranges (Schumacker et al., 2012; Dillon et al., 1984). The squared multiple correlations represent the reliability of an individual measure. The average variance extracted (AVE) values were within acceptable ranges (Schumacker et al., 2012; Dillon et al., 1984). Also, this measure is used for convergent and discriminant validity. Convergent validity and discriminant validity are subtypes of the construct validity. Convergent validity along with factor loading is used to show that two items measuring a construct are related. To assess convergent validity with construct reliabilities, the threshold is greater than 0.7 for good reliability (Hair et al., 2014). AVE is used for discriminant validity. Discriminant validity is used to show that there is no relation between two items that are not from the same 
construct. Question 7 (Please rate the current likelihood of choosing a career in the computing field) (Appendix 1) and question 8 (How likely is it that you will finish a bachelor's degree in your current major (or intended major)?) were initially used for measuring computing persistence. However, when we performed more analysis, we narrowed it down to question 7 due to a high correlation between question 8 and interest questions.

\subsubsection{Multigroup SEM Results Across Genders}

As we described, 1) we performed the CFA, and we built the SEM model based on the prior literature, our experience and understanding of the computing students' self-beliefs on persistence. 2) Then, we validated the model with the fit indices. 3) Next, to answer the research questions, we established the multigroup SEM (Figures 2, 3) to validate the model for different groups. 4) Finally, we performed an invariance measurement test to examine the statistically significant difference between groups. The measurement invariance test was based on the modification indices. We built the model by allowing all the factors and regression coefficients to be constrained equally. We released each path one at a time and examined the Chi-squared distribution. Due to a non-significant difference across genders, we concluded that the equally constrained model is similar to the unconstrained model. Therefore, there was not a significant difference between males and females on the path coefficients. In general, interest and competence/performance beliefs each had a substantial direct effect on persistence. This indicates that maintaining interest is likely the most crucial factor in computing persistence (factor loading of male $=0.438$ and female $=0.494$ ). 


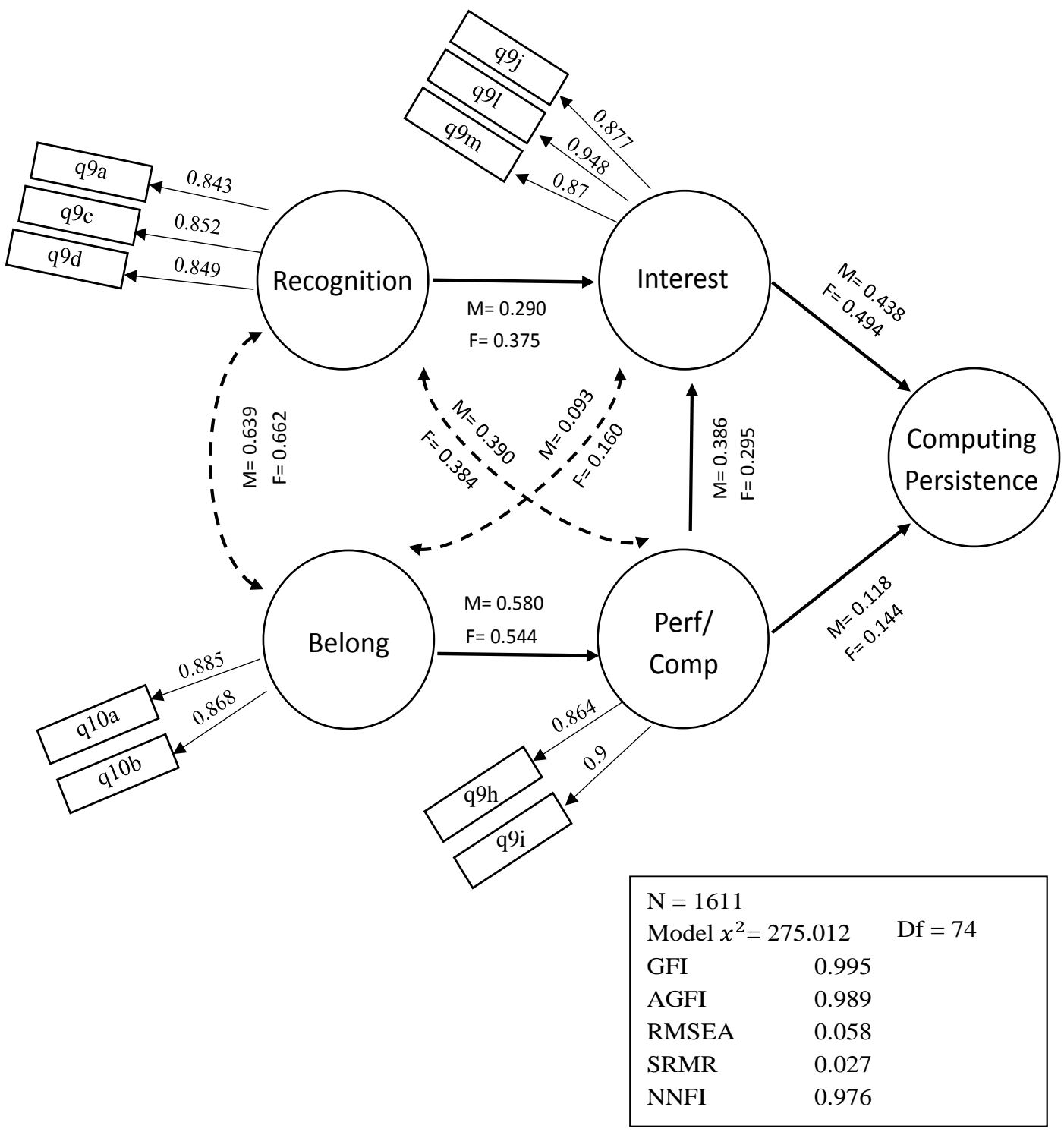

$*$ indicates $\mathrm{p}$-values $>0.05$.

All other path are significant $\mathrm{p}<0.001$.

$\mathrm{M}=$ Male, $\mathrm{F}=$ Female

Figure 2 - Multigroup Structural Equation Modeling Results among Male and Female Students. GFI: goodness of fit; AGFI: adjusted goodness of fit; RMSEA: root mean square error of approximation; SRMR: standardized root mean square residual; NNFI: non-normed fit. (Acceptable values: GFI ( $p>0.90)$, AGFI $(p>0.90)$, RMSEA ( $p<0.08)$, NNFI ( $>>0.90)$, SRMR $(p<0.08))$. No significant difference was found between male and female students. 


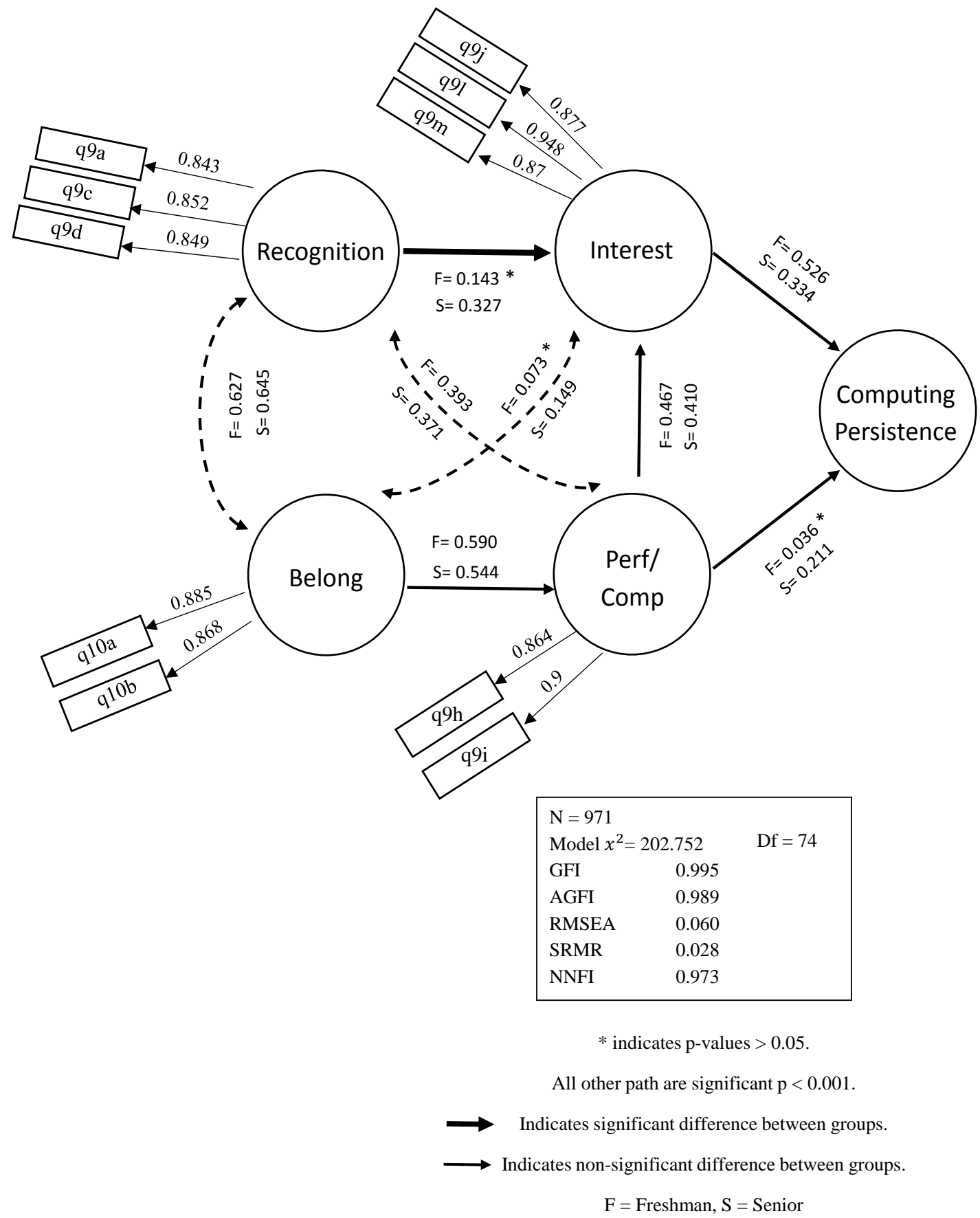

Figure 3 - Multigroup Structural Equation Modeling Results among Freshman and Senior Students. GFI: goodness of fit; AGFI: adjusted goodness of fit; RMSEA: root mean square error of approximation; SRMR: standardized root mean square residual; NNFI: non-normed fit. (Acceptable values: GFI ( $p>0.90)$, AGFI $(p>0.90), \operatorname{RMSEA}(p<0.08)$, NNFI $(p>0.90)$, SRMR $(p<0.08))$. 
Competence/performance had a substantial impact on persistence both directly and indirectly through interest (factor loading of male $=0.386$ and female $=0.295$ ). The structural model also indicated the importance of recognition on persistence indirectly through interest (factor loading of male $=0.290$ and female $=0.375$ ). This means recognition predicted interest and impacted persistence through interest. Finally, the model also showed the importance of a sense of belonging on persistence which is mediated by indirect paths through competence/performance (factor loading of male $=0.580$ and female $=0.544$ ). This shows that feeling a sense of belonging may increase one's competency beliefs.

\subsubsection{Multigroup SEM Results Across Level of Education}

For senior students versus first-year students, we performed the same analysis. We discovered some interesting paths and then conducted the measurement invariance test to determine whether the paths were significantly different between groups. Due to the significant difference between the constrained and the unconstrained model, we concluded that the model was not equivalent for both groups, and there is a significant difference (Figure 3). The difference between freshmen and seniors was for the path between recognition and interest $(\mathrm{F}=0.143, \mathrm{~S}=0.327)$. There was not a significant difference in the other paths between freshman and senior.

The influence of interest on persistence was strong for both groups $(\mathrm{p}<0.001)(\mathrm{F}=0.526, \mathrm{~S}=0.334)$. The other interesting paths were the path between a sense of belonging and competence/performance $(\mathrm{p}<0.001)(\mathrm{F}=0.590$, $\mathrm{S}=0.544)$, and the path between competence/performance and interest $(\mathrm{p}<0.001)$ 
$(\mathrm{F}=0.467, \mathrm{~S}=0.410)$. Although all sub-contracts directly or indirectly predict persistence, for both freshman and senior students, interest was the most critical contributor to their persistence.

\subsection{Discussion}

Our SEM analysis showed that interest had the most direct impact on computing students' persistence for all categories including male, female, freshman, and senior students $(\mathrm{p}<0.001)$. After interest, competence/performance had the most direct effect on persistence $(\mathrm{p}<0.001)$. The impact of interest and competence/performance on persistence and the relation between interest and competence/performance have been shown in prior studies (Lent et al., 2002; Hazari et al., 2010; Godwin, 2016). Our results confirm the findings of prior research studies. Recognition also had an impact on persistence through interest but significantly less so for freshmen students. As an example, if a student is recognized and conceptualizes a feeling of recognition, he/she is more likely to develop or maintain an interest in computing and persist throughout their degree program. The result indicated that when freshmen are recognized, it is less impactful for their interest than it is for seniors. The culture of computing might be breeding a performative culture where students become more interested only if they are recognized externally. This seems to be fostering extrinsic motivations for interest. We would be less concerned if recognition drove self-perceptions directly. Our results are different from prior studies in STEM where recognition had a direct effect. This might originate from the fast-paced nature of computing and the necessity of catching up with new technology. Students need to 
understand the new computing topics and perform well on the newest tasks and tools every day.

Sense of belonging had a significant impact on competence/performance. This path is exciting as it is the strongest path in this model. In 2012, a study (Marra et al., 2012) indicated a lack of belonging had been identified as an essential reason for engineering dropouts. Tinto also mentioned that sense of belonging was one of the impactful factors on academic persistence (Tinto, 1987). As an instance, when a student joins to a computing group/community, he/she may start communicating with peers and friends, and realize that his/her own skills and struggles are comparable to others, thus, lending to his/her own competency beliefs. In addition, by participating in computing communities and clubs, not only can students learn new computing tools and methods, but he/she also develops a feeling of support which consequently may increase his/her competency beliefs.

The male/female multigroup SEM analysis showed that the model was equivalent for both males and females and there was no significant difference. Thus, we addressed the first research question which was the identity subconstructs contribution to academic persistence among male and female students. These results indicated that women in computer science at the target universities may have developed their interest, competence/ performance, and consequently identity, similar to the men in their respective programs.

The freshman/senior multigroup SEM analysis in addressing the second research question showed that there was a significant difference between these 
two groups. The measurement invariance test showed a significant difference in the path between recognition and interest. The other structural paths were not statistically different. The relationship between recognition and interest indicates that providing sources of recognition is an effective way to increase interest and persistence. Students' interest is a good predictor of persistence for both groups. This outcome also explains the importance of extra activities, and engaging courses in their degree programs (Lent et al., 2005; Schiefele, 1991).

In general, the analysis showed that although male and female students have developed the same beliefs, students in different levels of their college education may have different predictors. For university staff and professors in computing who are involved in teaching and organizing events or managing programs, understanding the importance of developing self-beliefs is valuable. They can help students as soon as a student starts his/her degree program. This may increase students' persistence toward graduation in university and consecutively toward a successful career in computing.

In our model, considering some specific relationships are vital; for example, interest, sense of belonging, and recognition can be considered priorities. Instructors can engage students and help them by recognizing them as a programmer, computer engineer, computer scientist, software engineer, and so on (Allen, 2014; White et al., 2006). They can use any opportunity to recognize students by celebrating a student who has worked hard in gaining more knowledge and experience. This can be verbal, or by writing a note or email, or even by awarding a certificate of achievement (Hepplestone et al., 2011; Kitchen, 
2012). It is essential that students internalize the recognition that ultimately reinforces and shapes their own identity (Wentzel et al., 1998). Educators also can increase interest as the intrinsic motivation for learning in class or at school by making topics relevant to real-life problems and future careers (Lent et al., 2008). They can make the classroom a space of engagement with gamification (Amiriani et al., 2013; Stott et al., 2013), competitions, teamwork, and having fun in a way that encourages meaningful learning and students' participation (Reyes et al., 2012). One practical approach may be to realize what students are already interested in and then connecting the teaching material to topics that already build upon existing interests (Reyes et al., 2012; Pekrun et al., 2012).

In our model sense of belonging only has an indirect path through competency beliefs. This raises questions such as "are students relying too heavily on the approval of others in order to feel competent? Do faculty not recognize student competency enough?" To answer these type of questions, let's imagine some students with high competency/performance beliefs who don't feel recognized versus students with high competency/performance beliefs that are constantly being recognized. Based on our model the chance of persisting in computing for the second category is higher. This might be due to the fact that computing faculty is more focused on student's skills and performance than boosting recognition feelings. In this case when an exemplary student in computing is being recognized, it is considered a big win to student. This type of recognition might be higher in other STEM disciplines than computer science. 
Furthermore, administrators and staff can positively help students by organizing computing events and clubs like the Association for Computing Machinery (ACM), Upsilon Pi Epsilon (UPE) to promote the sense of belonging at school. Communities that often organize hackathons, coding bootcamps, and programming/engineering competitions are useful in increasing the sense of belonging and persistence in computing programs. Sense of belonging not only has an impact on identity and persistence, but it also helps students feel happier, and it encourages them to have a positive relationship with both friends and teachers (Goodenow, 1991; Osterman, 2000). Instructors and professors can also play an important role in improving the sense of belonging in the classroom by being respectful, creating a supportive learning environment, creating mutual respect among classmates, and fair treatment (Ma, 2003; Freeman et al., 2007; Meeuwisse et al., 2010).

What a student experiences in an academic setting impacts his or her behavior and choices, in particular, if those choices enable students to build a feeling of identity or belonging to the community. We confirmed that developing computing identity has a positive impact on persistence; however, understanding the persistence factors in computing across time has not been well studied. A future longitudinal research study may help us to discover new insights. Our future work seeks to perform a time-series SEM analysis to evaluate how the identity sub-constructs and persistence interact over a prolonged period of time. Also, there are many factors that affect a student's persistence such as prior academic performance, family support, and education level of parents which are 
not included in this study since this research is focused on the identity subconstructs' contributions to persistence.

Ultimately, while there may not be difference by gender in predictive ability, there may be differences based on prevalence such as the differences between males and females (or freshmen and seniors) on their averages for each sub-construct. For example the average identity among females might be lower than males as we found out in our pre-survey analysis (Garcia et al., 2017). In addition, the results might be different if we were looking not just at computing students. Computing is slightly different from other majors and the impact of individualistic factors is much higher in our model. Also, there might be a selection effect where the female students and male students with similar characteristics are the ones who choose computing in the first place.

\subsection{Conclusion}

While approximately sixty percent of all available STEM jobs are in computing, the total numbers of computing graduates are among the lowest. Many students drop out or switch to other majors due to a lack of interest or other self-belief factors. The issue is more critical for gender diversity and students at different levels of education. Students' computing identity or the way students see themselves with regards to computing is directly related to their choice of actions. Studying students' self-beliefs is one way to better understand what leads students to persist. This paper presents a multigroup structural equation model to examine the contribution of identity sub-constructs that include competence/performance, recognition, interest, and sense of belonging to the persistence across groups. 
In answering the first research question, we reviewed and analyzed the interesting paths between females and males. There was not a significant difference across male and female students. To address the second research question, we found that there was only one different path.

Finally, our results showed that all the sub-constructs to some extent have a significant impact on increasing persistence. Interest in this model is a vital component for increasing computing persistence. Fostering the activities that contribute positively to self-beliefs of competence/performance, recognition and a sense of belonging directly/indirectly have an impact on both interest and persistence. We also had two full mediation paths including the sense of belonging through competence/performance and recognition through interest. These correlations indicate that if students do not feel competent or interested at first, feeling recognized or like they belong could be a first step to their becoming interested and feeling capable. Measuring the quantitative impact of the identity sub-constructs on persistence among genders and college levels in computing may have some implications in better understanding a students' identity. This may increase the likelihood of their persistence in their degree program. Finally, the analysis across groups helps to explore the diversity gap in tech and computing education. 


\section{References Chapter III}

Allen, B. R. (2014). An analysis of student success predictors for technical college persistence. Edgewood College.

Amriani, A., Aji, A. F., Utomo, A. Y., \& Junus, K. M. (2013, October). An empirical study of gamification impact on e-Learning environment. In Proceedings of 2013 3rd International Conference on Computer Science and Network Technology (pp. 265-269). IEEE.

Carlone, H. B., \& Johnson, A. (2007). Understanding the science experiences of successful women of color: Science identity as an analytic lens. Journal of Research in Science Teaching: The Official Journal of the National Association for Research in Science Teaching, 44(8), 1187-1218.

Cass, C. A., Hazari, Z., Cribbs, J., Sadler, P. M., \& Sonnert, G. (2011, October). Examining the impact of mathematics identity on the choice of engineering careers for male and female students. In 2011 Frontiers in Education Conference (FIE) (pp. F2H-1). IEEE.

Chen, X. (2013). STEM Attrition: College Students' Paths into and out of STEM Fields. Statistical Analysis Report. NCES 2014-001. National Center for Education Statistics.

Cribbs, J. D., Hazari, Z., Sonnert, G., \& Sadler, P. M. (2015). Establishing an explanatory model for mathematics identity. Child development, 86(4), 10481062.

Dillon, W. R., \& Goldstein, M. (1984). Multivariate analysis methods and applications (No. 519.535 D5).

Erikson, E. H. (1970). Autobiographic notes on the identity crisis. Daedalus, 730759 .

Felder, R. M., Felder, G. N., \& Dietz, E. J. (1998). A longitudinal study of engineering student performance and retention. V. Comparisons with traditionally-taught students. Journal of Engineering Education, 87(4), 469-480.

Feldman, K. A. (1994). What matters in college? Four critical years revisited. Journal of Higher Education, 65(5), 615-623.

Freeman, T. M., Anderman, L. H., \& Jensen, J. M. (2007). Sense of belonging in college freshmen at the classroom and campus levels. The Journal of Experimental Education, 75(3), 203-220. 
Gee, J. P. (2000). Chapter 3: Identity as an analytic lens for research in education. Review of research in education, 25(1), 99-125.

Godwin, A. (2016, January). The development of a measure of engineering identity. In ASEE Annual Conference \& Exposition.

Godwin, A., Potvin, G., Hazari, Z., \& Lock, R. (2016). Identity, critical agency, and engineering: An effective model for predicting engineering as a career choice. Journal of Engineering Education, 105(2), 312-340.

Goodenow, C. (1991). The Sense of Belonging and Its Relationship to Academic Motivation among Pre-and Early Adolescent Students.

Hazari, Z., Brewe, E., Goertzen, R. M., \& Hodapp, T. (2017). The importance of high school physics teachers for female students' physics identity and persistence. The Physics Teacher, 55(2), 96-99.

Hazari, Z., Cass, C., \& Beattie, C. (2015). Obscuring power structures in the physics classroom: Linking teacher positioning, student engagement, and physics identity development. Journal of Research in Science Teaching, 52(6), 735-762.

Hazari, Z., Sonnert, G., Sadler, P. M., \& Shanahan, M. C. (2010). Connecting high school physics experiences, outcome expectations, physics identity, and physics career choice: A gender study. Journal of research in science teaching, 47(8), 978-1003.

Hepplestone, S., Holden, G., Irwin, B., Parkin, H., \& Thorpe, L. P. (2011). Using technology to encourage student engagement with feedback: a literature review. Research in Learning Technology, 19(2), 117-127.

Hogan, A., \& Roberts, B. (2015). Occupational employment projections to 2024. Monthly Lab. Rev., 138, 1.

Jenkins, R. (2014). Social identity. Routledge.

Kitchen, M. (2012). Facilitating small groups: how to encourage student learning. The clinical teacher, 9(1), 3-8.

Kline, R. B. (2015). Principles and practice of structural equation modeling. Guilford publications.

Lent, R. W., Brown, S. D., \& Hackett, G. (1994). Toward a unifying social cognitive theory of career and academic interest, choice, and performance. Journal of vocational behavior, 45(1), 79-122. 
Lent, R. W., Brown, S. D., \& Hackett, G. (2002). Social cognitive career theory. Career choice and development. Journal of vocational behavior, 45(1), 79-122.

Lent, R. W., Brown, S. D., \& Larkin, K. C. (1984). Relation of self-efficacy expectations to academic achievement and persistence. Journal of counseling psychology, 31(3), 356.

Lent, R. W., Brown, S. D., Sheu, H. B., Schmidt, J., Brenner, B. R., Gloster, C. S., ... \& Treistman, D. (2005). Social cognitive predictors of academic interests and goals in engineering: Utility for women and students at historically black universities. Journal of counseling psychology, 52(1), 84.

Lent, R. W., Lopez Jr, A. M., Lopez, F. G., \& Sheu, H. B. (2008). Social cognitive career theory and the prediction of interests and choice goals in the computing disciplines. Journal of Vocational Behavior, 73(1), 52-62.

Ma, X. (2003). Sense of belonging to school: Can schools make a difference?. The Journal of Educational Research, 96(6), 340-349.

Marra, R. M., Rodgers, K. A., Shen, D., \& Bogue, B. (2012). Leaving engineering: A multi-year single institution study. Journal of Engineering Education, 101(1), 6-27.

Meeuwisse, M., Severiens, S. E., \& Born, M. P. (2010). Learning environment, interaction, sense of belonging and study success in ethnically diverse student groups. Research in Higher Education, 51(6), 528-545.

Osterman, K. F. (2000). Students' need for belonging in the school community. Review of educational research, 70(3), 323-367.

Pekrun, R., \& Linnenbrink-Garcia, L. (2012). Academic emotions and student engagement. In Handbook of research on student engagement (pp. 259-282). Springer, Boston, MA.

Reyes, M. R., Brackett, M. A., Rivers, S. E., White, M., \& Salovey, P. (2012). Classroom emotional climate, student engagement, and academic achievement. Journal of educational psychology, 104(3), 700.

Rosseel, Y. (2012). Lavaan: An R package for structural equation modeling and more. Version 0.5-12 (BETA). Journal of statistical software, 48(2), 1-36.

Rosseel, Y. (2018). The lavaan tutorial. Belgium: Department of Data Analysis, Ghent University.

Schiefele, U. (1991). Interest, learning, and motivation. Educational psychologist, 26(3-4), 299-323. 
Schumacker, R. E., \& Lomax, R. G. (2012). A Beginner's Guide to Structural Equation Modeling: New York.

Shanahan, M. C. (2009). Identity in science learning: Exploring the attention given to agency and structure in studies of identity. Studies in Science Education, 45(1), 43-64.

Snyder, T. D., \& Dillow, S. A. (2012). Digest of education statistics 2011. National Center for Education Statistics.

Stets, J. E., \& Burke, P. J. (2000). Identity theory and social identity theory. Social psychology quarterly, 224-237.

Stets, J. E., \& Serpe, R. T. (2013). Identity theory. In Handbook of social psychology (pp. 31-60). Springer, Dordrecht.

Stott, A., \& Neustaedter, C. (2013). Analysis of gamification in education. Surrey, BC, Canada, 8, 36.

Taheri, M., Ross, M., Hazari, Z., Weiss, M., Georgiopoulos, M., Christensen, K., ... \& Chari, D. (2018, October). A Structural Equation Model Analysis of Computing Identity Sub-Constructs and Student Academic Persistence. In 2018 IEEE Frontiers in Education Conference (FIE) (pp. 1-7). IEEE.

Tinto, V. (1975). Dropout from higher education: A theoretical synthesis of recent research. Review of educational research, 45(1), 89-125.

Tinto, V. (1987). Leaving college: Rethinking the causes and cures of student attrition. University of Chicago Press, 5801 S. Ellis Avenue, Chicago, IL 60637.

Tinto, V. (1997). Classrooms as communities: Exploring the educational character of student persistence. The Journal of higher education, 68(6), 599-623.

U.S. Bureau of Labor Statistics. (2019). Occupational Outlook Handbook, Computer Programmers. https://www.bls.gov/ooh/computer-and-informationtechnology/computer-programmers.htm

Wentzel, K. R., \& Wigfield, A. (1998). Academic and social motivational influences on students' academic performance. Educational Psychology Review, 10(2), 155-175.

White, J. L., Altschuld, J. W., \& Lee, Y. F. (2006). Persistence of interest in science, technology, engineering, and mathematics: A minority retention study. Journal of Women and Minorities in Science and Engineering, 12(1). 


\section{Chapter IV: Article III: Understanding Computing Persistence and Identity Through Structural Equation Modeling with Time Series Data}

\subsection{Abstract}

Computer science has become increasingly popular, and there has been an exploding interest in computing graduates. Academic persistence in computer science is a concern for many CS programs in the United States and become a growing issue over the past decade. Although there are some valid explanations, the low persistence rate is still problematic. Understanding students' self-beliefs or disciplinary identity has been shown as an effective way and a potential means to explore student persistence and choice of goals and careers in science.

However, computing identity and its impact on computing persistence have not been thoroughly explored. In this study, we examine and explore the contribution of identity sub-constructs on computing persistence through a quantitative analysis conducted as part of a multi-institutional study. The data was collected from two surveys from computing students at three Florida-based metropolitan universities over two years. Students' identity sub-constructs, including interest, competence/performance, recognition, and sense of belonging were explored through confirmatory factor analysis and structural equation modeling.

Results revealed direct and indirect positive impacts of identity subconstructs on persistence. Interest had the largest direct impact on computing persistence. Interest and competence/performance, as individual factors had the strongest direct impacts on persistence; while recognition and sense of belonging, as social factors had impacts on the individual factors and indirectly influenced 
persistence. Understanding the impact of computing students' self-beliefs or computing identity on their persistence may provide essential insights to academic administrators, instructors, and coordinators that plan and organize curricular and extracurricular activities. In addition, the development of students' self-beliefs provides ways for increasing the number of graduates with the high potential of pursuing computing careers.

\subsection{Introduction}

In modern societies, there are not many aspects of human life left untouched by technology. Computers are in our homes, our schools, and our workplaces. Our lives are built around computers and software. Computer science matters more than ever, and there is a bright future for computer science graduates. The U.S. Bureau of Labor projection shows that more than 60 percent of new jobs in STEM will be in computing by 2026 (U.S. Bureau of Labor Statistics, 2019). A skillful CS graduate may serve a number of computing occupations, including but not limited to web development, data science, software engineering, hardware engineering, and information technology (IT). Most of these computing jobs are in the greatest demand and are identified as the highest salaried occupations (U.S. Bureau of Labor Statistics, 2019; Hogan et al., 2015). Although school degrees are not the only way to pursue a career in computing fields, reports suggest that companies are still interested in hiring college graduates, and college graduates have considerable advantages in the job market (U.S. Bureau of Labor Statistics, 2019; Hogan et al., 2015). Since computing degrees from accredited institutions in the US are highly regarded by companies 
and employers (Hogan et al., 2015), enrollment in CS has trended upward over the past decade in the US. There has been a 74 percent growth between 2009 and 2015 (Snyder et al., 2012; Camp et al., 2017). Predictions show that the enrollment surge is expected to continue (U.S. Bureau of Labor Statistics, 2019; Zweben et al., 2018; Chen, 2013).

While the computing institutions took actions to handle the popularity of CS as a choice of major, schools still suffer from students' attrition and dropouts (Chen, 2013). The dropout rate in computing is the highest among all STEM disciplines (Chen, 2013). Low persistence rates have been a common problem faced by computing schools over the past decade, and empirical research and data for understanding and addressing this complex issue is limited. In addition, academic dropout cost is significant to students, parents, and schools, so that finding solutions to increase computing persistence is critical. One way to boost persistence in schools is by studying students' self-beliefs. There has been a gap in exploring students' self-beliefs in computing. Although scholars have explored the impact of self-beliefs in other majors using well-established frameworks, they have not extended their work on computing, especially when it comes to using time-series data. In the next paragraphs, some of the most critical contributors in academic persistence are introduced to have a better understanding of some of the challenges and have a high-level picture of academic persistence before we return to students' self-beliefs and computing identity.

Persistence has been challenging to define as it has not been consistent across schools, articles, and reports. (Bean et al., 1980, 1982, 1985; Spady, 1970; 
Tinto, 2006; Belch et al., 2001; Kerby, 2015). For the purpose of this study, we define computing persistence as the willingness and the continuation of an effort to graduate with career intentions in computing-related areas regardless of time and location. There is a wide range of factors that influence students' persistence. It is worth mentioning them before we focus on students' self-beliefs in particular. These factors include but not limited to goal commitment, interest, role models, cumulative knowledge, educational background, parents support, curriculum, financial situation, life stress, campus environment, health, motivation, curriculum, life challenges, academic expectations, learning experiences, and selfbeliefs (Tinto, 2006; Giannakos et al., 2017).

The literature is rich with theoretical frameworks on persistence. Astin (Astin 1997) showed students' interaction with peers and faculty is significant for their persistence. Tinto (Tinto, 1975) determined academic goals, career goals, commitment, community, and academic difficulty affect students' persistence. Rendon (Rendon, 1995) showed the importance of academic advising, orientation programs, and positive connection between students and staff/faculty. Bean (Bean et al., 1980, 1982, 1985) indicated background characteristics, institutional and psychological situation, and intention as the main influencing factors in persistence. Bean explored external contributing factors in student attrition at higher education institutions. Swail (Swail, 2004) focused on students' financial and economic situation and personal and family factors. Spady (Spady et al., 1970, 1971, 1991) identified social integration, satisfaction, and institutional commitment as the main impactful factors on persistence. In general, before 1970, 
the majority of persistence studies were focused on students' characteristics like gender, and race. After 1970, the impact of students' interaction with their institution was highlighted (Tinto, 1975; Swail, 2004; Spady et al., 1991). Persistence in engineering and computing has been also explored in several studies. Factors like personal values, degree usefulness, satisfaction with learning effectiveness, teaching quality, and many other factors have been examined (Levin et al., 1995; Giannakos et al., 2017).

In terms of self-beliefs' impact on persistence, scholars have shown that students' self-beliefs contribute to academic achievements and student's decision to succeed and persist (Lent et al., 1994, 1994). These beliefs are the primary explanation for motivation, choice of goals, performance, and persistence (Lent et al., 1994, 2008; Bandura, 1977). Bandura identified that personal factors such as cognitive factors, including beliefs and self-perceptions or behavioral factors, including self-efficacy, all interact with culture and environment and influence each other (Bandura, 1977). Self-efficacy, as a task-specific version of selfesteem, refers to individuals' judgments on their capability to perform a particular task, behavior, or course of action. Bandura's social cognitive theory (SCT) has been applied to other areas, such as career choice. Social cognitive career theory (SCCT) developed by Lent and his colleagues in 1994 (Lent et al., 1994) identified the impact of interest and self-efficacy in educational and career choices. Interest factor in SCCT is an outgrowth of outcome expectations and self-efficacy. In their model, educational and occupational interest, and selfefficacy influence choice goals and choice actions. Carlone and Johnson in 2007 
(Carlone et al., 2007) conceptualized the disciplinary identity framework and highlighted the impact of self-beliefs. Hazari, Sonnert, Sadler, and Shanahan in 2010 (Hazari et al., 2010) continued their work to complete the framework and looked into the quantified impact of students' identity on persistence and choice goals.

The social cognitive career theory and disciplinary identity theory are two main theories that have been used to show the relationships between self-beliefs and academic persistence. In the next section, identity theory will be discussed more, and some of the previous works on students' self-beliefs in science and STEM majors will be explored. In this study, the identity theory has been used as the driving theory, and SCCT has been used to interpret and understand the results. These two well-established theories are the most relevant theories to our research question: "How do the theorized identity sub-constructs contribute to academic persistence with time-series data?" The goal of this study is to use timeseries data to evaluate the development of identity sub-constructs over time. For this purpose, we used two different snapshot data (time series data) of students' self-beliefs and persistence to quantify how these self-beliefs influence persistence after being developed during the time. We conducted a survey and a diverse set of mathematical models to represent, estimate, and test the network of relationships between our variables. In the next sections, the theoretical framework, method, and then results will be discussed. 


\subsection{Theoretical Framework}

In 2007, Carlone \& Johnson (Carlone et al., 2007) conceptualized a grounded model of science identity to explore the science experiences of 15 women of color over their education and career. The model included three main sub-constructs, including performance, competence, and recognition. In their model, the performance represented social performances of scientific practices like using tools. Competence represented knowledge and understanding of the content of science and was considered less publicly visible than performance. Finally, recognition is referred to being recognized as a "science person." This model did not include interest as all interviewees were selected from a pool of successful populations who already developed an interest in their education and career.

Another group of scholars in 2010 (Hazari et al., 2010, 2015, 2016), drawing from earlier work of other scholars, including Carlone, Johnson, and Gee, explored identity as an analytic lens for research in education (Gee, 2000), to examine how students' physics identity is developed in high school physics classes. They conceptualized a framework for students' identification with a specific subject area. Their model included personal and social identity. Personal identity was related to an individuals' characteristics, and social identity was about characteristics as a member of a group. They conducted case studies to see how to measure students' self-beliefs and to find out when and how students disciplinary identity formed. They defined identity as the way students see themselves in regard to a specific discipline. This model or framework provided 
new insights as a predictive tool for measuring students' identity. This model aimed to understand students' choices based on their self-beliefs about their discipline. Although identity has a broad meaning, and it has been used in different spaces, scholars concentrated on fundamental students' beliefs and identity. This kind of identity was more like when a student says, "I think I'm a physics/math/science person.” This framework covered students' social performance, known as the recognition aspect. Their framework had three subconstructs: interest, recognition, and competence/performance. Interest referred to enthusiasm and passion in the field. Competence/performance referred to the feeling of capabilities in understanding and performing in a field like physics. Finally, recognition referred to students' beliefs on their perceived recognition by friends, parents, teachers, and themselves. They later expanded on this framework by examining the impact of mathematics identity on the choice of engineering careers and also used math and physics identity for engineering choice prediction (Cass et al., 2011).

More recently, researchers (Taheri et al., 2018) started to examine computing identity and persistence in 2018 . They built the computing identity framework by adding sense of belonging to the disciplinary identity framework (Figure 1); as they found in their research that computing students needed a community of practice (Taheri et al., 2018). Students tend to have an 'inherent' desire to belong and feel connected and accepted by others as a member of a computing group (Strayhorn et al., 2012). 


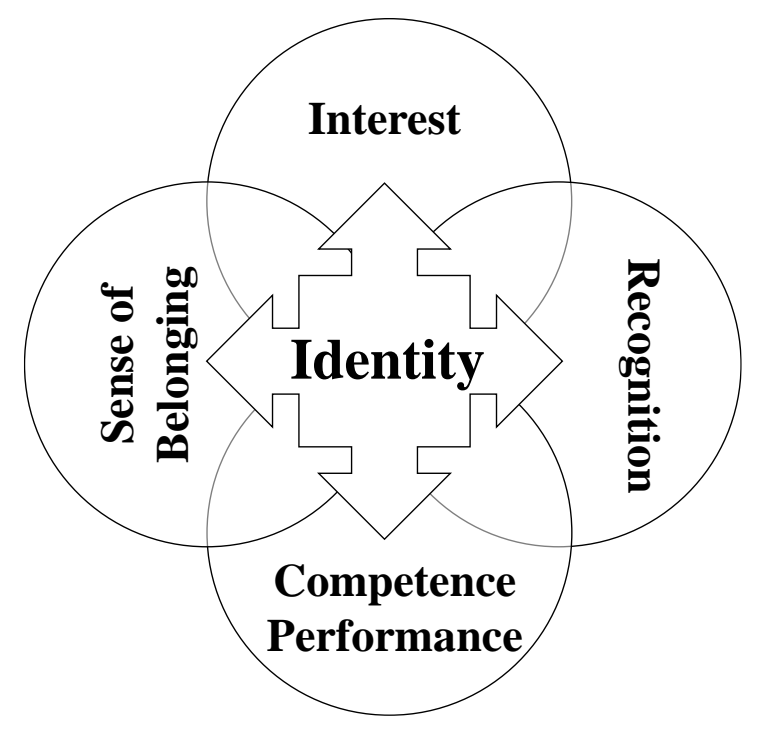

Figure 1 - Computing Identity Framework

In a cross-sectional study, they quantified all of the relationships between sub-constructs and identified the impact of interest as the main driving factor in computing persistence. They highlighted the supporting role of other factors, including recognition and sense of belonging in developing interest and increasing persistence (Figure 2). In their next study, they conducted a multigroup analysis among male/female and freshman/senior students (Taheri et al., 2019) to understand the differences among them better. Results suggested identity subconstructs contribute differently to academic persistence among freshman and senior students (one path); however, no significant differences were found between male and female students. In this study, we used the computing identity framework that is a developed version of the disciplinary identity framework. This framework considers both individual and social identity and the most critical self-belief factors that have been examined for academic persistence and choice of careers. 


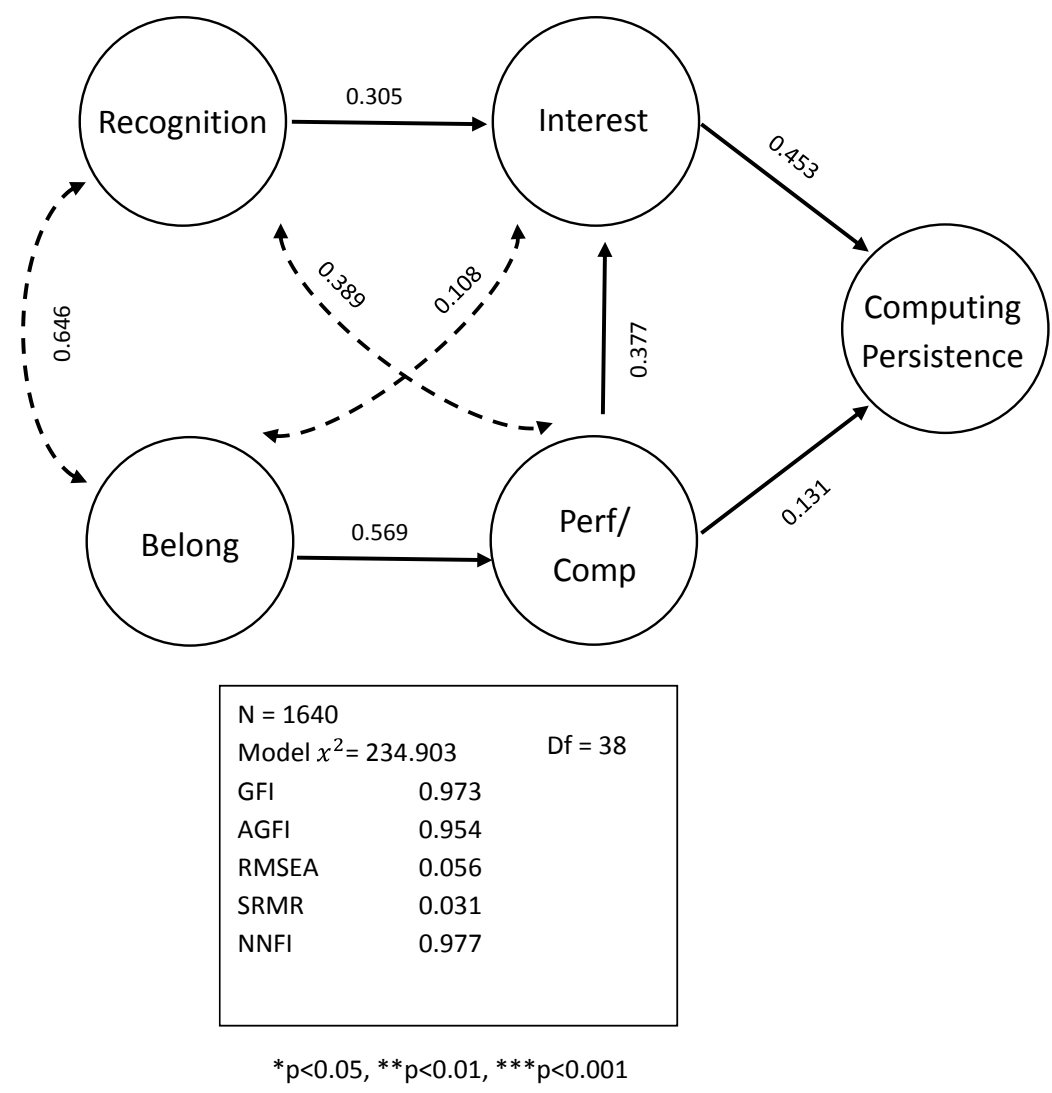

Figure 2 - Path Analysis Model. This model indicates the strong impact of interest on persistence and also the supporting role of other sub-constructs (solid lines)

\subsection{Method}

To answer the research question and estimate the quantified contribution of identity sub-constructs on each other and persistence over time, a quantitative approach was used for this study. A survey was designed based on our research question, the theoretical framework and leveraging existing surveys, and other validated works and questionnaires. The Persistence Research in Science and Engineering (PRiSE) survey (Hazari et al., 2010) was among the validated instruments guiding our survey development. This survey was used for the initial disciplinary identity framework in 2010 at Harvard (Hazari et al., 2010). Our literature review for identifying critical computing identity and persistence 
characteristics, and also conducting the pre-survey with open-ended questions helped us to tailor our survey to our target student population and universities.

To validate the survey, face and content validity were performed. We asked several scholars and practitioners in computing, education, and sociology to review the questions. The content validity was performed through focus groups, and we captured feedback from researchers and scientists in the computer science and education fields. We revised the questions based on the gathered comments. The pre-survey was piloted, and face validity was performed. We asked students to respond to questions, and we reflected their comments where needed. The presurvey enabled us to revisit some of the questions and follow up with students to make sure there were no ambiguities in the survey. Through the face and content validity, the survey format and questions were revised multiple times. The construct validity was performed in order to measure how well the test measures what it intends to measure. A Confirmatory Factor Analysis (CFA) with a minimum factor loading of 0.5 , and a four-factor design was performed for both times (Randal et al., 2004). In terms of reliability and consistency across items, and how closely a set of items are as a group, an internal consistency test by calculating the Cronbach's alpha. Cronbach's alpha was measured to assess this reliability, and it was less than the minimum level of 0.7 (Randal et al., 2004). Convergent validity that is a subtype of construct validity, was measured by conducting the CFA and examining the factor loadings. Convergent validity was used to assess the relation of construct variables as they claim. 
The final survey had 22 questions and was distributed to almost 1600 students in 2017 and 2019. The survey distribution was part of a multiinstitutional research study for an NSF-funded grant. The project aims to increase students' retention and success by providing scholarships to talented students with financial need. This program also provides students with curricular activities and co-curricular support. The project is a collaborative grant among three metropolitan universities. The survey was distributed online among all computing-related disciplines (computer science, information technology, and computer engineering) at these three universities through the administrators and instructors. Data collection was executed twice, once in 2017, and once in 2019. The respondents included 1,640 students to the first survey and 1,650 students to the second survey. The survey included questions on demographics, graduation likelihood, career likelihood, interest, competence/performance, recognition, sense of belonging, and many other questions including fields that students wanted to pursue in middle school, high school, and the beginning of college, students experiences with respect to computing (i.e., internship), research and job experience, GPA and mathematics grades, the highest level of education of their parents, number of friends in computing and finally whether their home environment is supportive towards computing.

In order to quantify the impact of all of our sub-constructs on each other and on persistence over time, we needed students who responded to both surveys. These students were mostly freshman and sophomore for our 2017 survey, which became junior and senior in 2019. To analyze the time-series data, we matched 
students from two surveys with unique student IDs. To handle the missing data, we used the full information maximum likelihood (FIML) technique (Schumacker et al., 2004). In this technique, missing data were handled within the analysis model rather than being replaced or imputed. This technique is widely used for structural equation modeling (SEM) (Enders et al., 2001, 2006; Schreiber et al., 2006). FIML leverages the available data to do unbiased estimation using maximum likelihood (ML). This ML value is the most likely estimate to have resulted in our observed data that maximizes the likelihood function. Table 1 shows the demographics and level of education before and after merging the data. The numbers indicated that the target population represents the larger populations in regards to distributions. For example, the total number of students who responded to the first survey and were in their second year was 223 in 2017 and 289 in 2019 with a ratio of 0.77 (before the merge); after filtering the population to select students who responded to both survey (after the merge), the numbers changed to 39 in 2017 and 50 in 2019 with a ratio of 0.78 . The ratio of 2017 students to 2019 students before and after the merge was reasonable in terms of the level of education, gender, race/ethnicity, and major. This comparison allowed us to use the final selected population for our analysis as a representative of our larger population. In other words, our final selected students were not only male or freshman. It was as diverse as our bigger population from survey one and two. 
Table 1.a - Level of Education. These tables show that our target population represents the larger population

\begin{tabular}{|l|l|l|l|l|l|l|}
\hline \multicolumn{2}{|c|}{} & $\begin{array}{l}\text { First } \\
\text { Year }\end{array}$ & $\begin{array}{l}\text { Second } \\
\text { Year }\end{array}$ & $\begin{array}{l}\text { Third } \\
\text { Year }\end{array}$ & $\begin{array}{l}\text { Fourth } \\
\text { Year }\end{array}$ & $\begin{array}{l}\text { Fifth } \\
\text { Year }\end{array}$ \\
\hline $\begin{array}{l}\text { Before } \\
\text { Merge }\end{array}$ & $\begin{array}{l}\text { Students in } \\
2017\end{array}$ & 393 & 223 & 459 & 380 & 236 \\
\cline { 2 - 7 } & $\begin{array}{l}\text { Students in } \\
2019\end{array}$ & 93 & 289 & 544 & 445 & 277 \\
\hline $\begin{array}{l}\text { After } \\
\text { Merge }\end{array}$ & $\begin{array}{l}\text { Students in } \\
2017\end{array}$ & 48 & 39 & 45 & 8 & 13 \\
\cline { 2 - 7 } & $\begin{array}{l}\text { Students in } \\
2019\end{array}$ & 1 & 50 & 55 & 27 & 20 \\
\hline
\end{tabular}

Table 1.b - Gender

\begin{tabular}{|l|l|l|l|}
\hline \multicolumn{2}{|c|}{} & Male & Female \\
\hline $\begin{array}{l}\text { Before } \\
\text { Merge }\end{array}$ & Students in 2017 & 1319 & 355 \\
\cline { 2 - 4 } $\begin{array}{l}\text { After } \\
\text { Merge }\end{array}$ & Students in 2019 & 1284 & 347 \\
\cline { 2 - 4 } & Students in 2017 & 105 & 47 \\
\hline
\end{tabular}

Table 1.c - Race/Ethnicity

\begin{tabular}{|l|l|l|l|l|l|l|l|l|l|}
\hline \multicolumn{2}{|c|}{} & $\begin{array}{l}\text { Amer } \\
\text { ican } \\
\text { India } \\
\text { n }\end{array}$ & Asian & Black & Hispanic & $\begin{array}{l}\text { Mid } \\
\text { dle } \\
\text { easte } \\
\text { rn }\end{array}$ & $\begin{array}{l}\text { Ha } \\
\text { wai } \\
\text { ian }\end{array}$ & White & Other \\
\hline $\begin{array}{l}\text { Before } \\
\text { Merge }\end{array}$ & $\begin{array}{l}\text { Students } \\
\text { in 2017 }\end{array}$ & 31 & 254 & 198 & 505 & 40 & 11 & 857 & 41 \\
\cline { 2 - 10 } & $\begin{array}{l}\text { Students } \\
\text { in 2019 }\end{array}$ & 23 & 272 & 196 & 593 & 51 & 17 & 738 & 37 \\
\hline $\begin{array}{l}\text { After } \\
\text { Merge }\end{array}$ & $\begin{array}{l}\text { Students } \\
\text { in 2017 }\end{array}$ & 3 & 35 & 16 & 40 & 3 & 2 & 70 & 3 \\
\cline { 2 - 10 } & $\begin{array}{l}\text { Students } \\
\text { in 2019 }\end{array}$ & 2 & 34 & 19 & 40 & 3 & 3 & 71 & 4 \\
\hline
\end{tabular}

Table 1.d - Major

\begin{tabular}{|l|l|l|l|l|l|}
\hline \multicolumn{2}{|c|}{} & $\begin{array}{l}\text { Computer } \\
\text { Science }\end{array}$ & $\begin{array}{l}\text { Information } \\
\text { Technology }\end{array}$ & $\begin{array}{l}\text { Computer } \\
\text { Engineering }\end{array}$ & Other \\
\hline $\begin{array}{l}\text { Before } \\
\text { Merge }\end{array}$ & $\begin{array}{l}\text { Students in } \\
2017\end{array}$ & 668 & 483 & 177 & 365 \\
\cline { 2 - 6 } & $\begin{array}{l}\text { Students in } \\
2019\end{array}$ & 722 & 342 & 324 & 261 \\
\hline $\begin{array}{l}\text { After } \\
\text { Merge }\end{array}$ & $\begin{array}{l}\text { Students in } \\
2017\end{array}$ & 74 & 31 & 34 & 14 \\
\cline { 2 - 6 } & $\begin{array}{l}\text { Students in } \\
2019\end{array}$ & 73 & 35 & 30 & 15 \\
\hline
\end{tabular}


For this study, we used the structural equation modeling (SEM) method. It enabled us to run a simultaneous analysis of all variables and paths and quantify the relationships between constructs over time. We used $\mathrm{R}$ as a tool for data analysis. Two main R packages were used, including SEM and Lavaan (Rosseel, 2012, 2018). The data analysis for this study had two main parts: measurement model and structural model. We used confirmatory factor analysis to build the measurement model and examine how well the variables measured our latent constructs (CFA table). CFA is a special form of factor analysis. It is a multivariate statistical method that is used to reject or confirm the measurement theory. For our CFA, we first developed a hypothesis of contributing variables that we believed it could measure the constructs based on literature, and then we evaluated the model fit. While exploratory factor analysis (EFA) allows data to identify the factor structure, CFA uses pre-selected variables to test the hypothesis. There were some assumptions for our CFA analysis in the research, including normality, and sufficient or fair sample size. CFA or measurement model validation is an integral part of SEM. CFA was also used for our measurement tool reliability and is widely used for a new population or any instrument refinement.

SEM is a powerful multivariate analysis method and was the best method for our research since it considers both structural and measurement models simultaneously, which is more similar to real-world scenarios. It tested the hypotheses on relationships among variables in our correlational study. SEM includes many other techniques like confirmatory factor analysis, multiple 
regression, path analysis, and analysis of variance (Schumacker et al., 2004;

Enders et al, 2001, 2006; Schreiber et al., 2006; Rosseel, 2012, 2018; Kline, 2011). SEM uses a set of covariance to regenerate an observed covariance matrix by measuring parameters in the model. The output of SEM consists of parameter estimates and data on the efficiency of reproducing the covariance matrix. SEM was used in our study to examine the contributions of latent variables on each other and computing persistence. From previous work on computing identity (Figure 2), the constructs of computing identity were deployed and hypothesized. Figure 3 indicates the impact of students' self-beliefs in 2017 (T1) on student selfbeliefs in 2019 (T2). Also, it shows the impact of all sub-constructs from different times on persistence. We estimated the model fit for both measurement and structural models. Fit refers to the likelihood of a model to regenerate the data. Some of the common fit indices are RMSEA, SRMR, and NNFI (Kline, 2015). Root Mean Square Error of Approximation (RMSEA) is one of the most widely reported measures for model fit. RMSEA estimates the value of misfit per degree of freedom. Standardized Root Mean Square Residual (SRMR) refers to the difference between the predicted correlation and observed correlation. NonNormed Fit Index (NNFI) resolves some of the problems of negative bias.

\subsection{Results:}

For the CFA results, four identity sub-constructs including interest, competence/performance, recognition, and sense of belonging were identified. The path values (factor loadings of latent variables), statistical significance, and CFA metrics helped us in the measurement model validation process. For our 
CFA analysis, the fit indices and convergent validity were assessed. CFA results are shown in Table 2. Meanwhile, Fig 3 shows some of the formula used for CFA table indicator measurements. All factor loadings, CFA metrics, model fit values were in the acceptable range. Construct reliability (composite reliability) measures the internal consistency of a measure and is under the internal consistency umbrella (Fornell et al., 1981). The average variance extracted (AVE) was used to measure convergent validity. AVE refers to the amount of construct variance in relation to the amount of variance caused by measurement error (Schreiber et al., 2006; Rosseel, 2012, 2018; Kline, 2015; Fornell et al., 1981; Sin, 2009). All fit indices were within an acceptable range indicated that the measurement model variables reflect the sub-constructs. 
Table 2 - List of Variables for 2017 (T1) and 2019 (T2), and Confirmatory Factor Analysis (CFA) Results. Acceptable values: Item reliability $>0.50$, Construct reliability $>0.70$, Average variance extracted $>0.50 . \mathrm{N}=147$, Model $x^{\wedge} 2=$ 275.864, Df = 154, RMSEA 0.073, SRMR 0.044, NNFI 0.929.

\begin{tabular}{|c|c|c|c|c|c|c|}
\hline $\begin{array}{l}\text { Latent } \\
\text { variable }\end{array}$ & $\begin{array}{l}\text { Indicator } \\
\text { variable }\end{array}$ & $\begin{array}{l}\text { Standardized } \\
\text { factor } \\
\text { loading }\end{array}$ & $\begin{array}{l}\text { Standard } \\
\text { error }\end{array}$ & $\begin{array}{l}\text { Item } \\
\text { reliability } \\
\left(\mathbf{R}^{2}\right)\end{array}$ & $\begin{array}{l}\text { Construct } \\
\text { reliability }\end{array}$ & $\begin{array}{l}\text { Average variance } \\
\text { extracted }\end{array}$ \\
\hline \multirow{3}{*}{ Interest T1/T2 } & $\begin{array}{l}\text { q9j: Topics in computing excite my } \\
\text { curiosity }\end{array}$ & $0.913 / 0.900$ & $0.053 / 0.058$ & $0.834 / 0.810$ & \multirow[t]{3}{*}{$0.907 / 0.929$} & \multirow[t]{3}{*}{$0.766 / 0.814$} \\
\hline & $\begin{array}{l}\text { q91: I enjoy learning about } \\
\text { computing }\end{array}$ & $0.911 / 0.926$ & $0.049 / 0.051$ & $0.830 / 0.857$ & & \\
\hline & $\begin{array}{l}\mathbf{q 9 m} \text { : I like to know what is going } \\
\text { on in computing }\end{array}$ & $0.796 / 0.880$ & $0.059 / 0.052$ & $0.634 / 0.774$ & & \\
\hline \multirow{2}{*}{$\begin{array}{l}\text { Performance/ } \\
\text { Competence } \\
\text { T1/T2 }\end{array}$} & $\begin{array}{l}\text { q9h: I can do well on computing } \\
\text { tasks }\end{array}$ & $0.879 / 0.844$ & $0.081 / 0.067$ & $0.773 / 0.712$ & \multirow[t]{2}{*}{$0.889 / 0.875$} & \multirow[t]{2}{*}{$0.800 / 0.778$} \\
\hline & $\begin{array}{l}\text { q9i: I understand concepts } \\
\text { underlying computer processes }\end{array}$ & $0.910 / 0.918$ & $0.075 / 0.063$ & $0.828 / 0.843$ & & \\
\hline \multirow{3}{*}{$\begin{array}{l}\text { Recognition } \\
\text { T1/T2 }\end{array}$} & $\begin{array}{l}\text { q9a: I see myself as an exemplary } \\
\text { student in computing fields }\end{array}$ & $0.807 / 0.879$ & $0.070 / 0.065$ & $0.651 / 0.773$ & \multirow[t]{3}{*}{$0.875 / 0.864$} & \multirow[t]{3}{*}{$0.701 / 0.680$} \\
\hline & $\begin{array}{l}\text { q9c: Other students see me as an } \\
\text { exemplary student in computing }\end{array}$ & $0.803 / 0.760$ & $0.074 / 0.068$ & $0.645 / 0.578$ & & \\
\hline & $\begin{array}{l}\text { q9d: My teachers see me as an } \\
\text { exemplary student in computing } \\
\text { fields }\end{array}$ & $0.899 / 0.830$ & $0.064 / 0.065$ & $0.808 / 0.689$ & & \\
\hline \multirow{2}{*}{$\begin{array}{l}\text { Sense of } \\
\text { Belonging } \\
\text { T1/T2 } \\
\end{array}$} & $\begin{array}{l}\text { q10a: I feel like you are part of the } \\
\text { community }\end{array}$ & $0.812 / 0.849$ & $0.080 / 0.079$ & $0.659 / 0.721$ & \multirow[t]{2}{*}{$0.876 / 0.842$} & \multirow[t]{2}{*}{$0.781 / 0.727$} \\
\hline & q10b: I feel valued and respected & $0.950 / 0.856$ & $0.067 / 0.073$ & $0.903 / 0.733$ & & \\
\hline
\end{tabular}




$$
\text { Construct relaibility }=\frac{\text { sum of standardized factor loading }{ }^{2}}{\text { sum of standardized factor loading }{ }^{2}+\text { sum of indicator measurement }}
$$

$$
\begin{gathered}
\text { Measurement error }=\left[1-\text { indicator's standardized loading }^{2}\right] \\
\text { Avergae Variance extracted }=\frac{\text { sum of squared standardized factor loading }}{\text { Total no of indicators }}
\end{gathered}
$$

Figure 3 - Confirmatory Factor Analysis Indicators. It includes construct reliability, measurement error, and average variance extracted.

Fig 4 shows the final SEM for all students who responded to both surveys. All paths are significant except the path between interest T1 and sense of belonging T2. Fit indices indicate an acceptable fit for the structural model. Answering the research question: "How do the theorized identity subconstructs contribute to academic persistence with time-series data?"

The structural model shown in fig 4 indicates that identity sub-constructs from time one affect time two, and both influence persistence. In our model, individual factors have the strongest direct effect on persistence. Interest has the strongest direct effect on persistence (factor loading 0.392, $\mathrm{p}<0.001$ ). This model indicates the significance of competence/performance on interest. It also highlights the importance of recognition and sense of belonging to individual factors and persistence over time. 


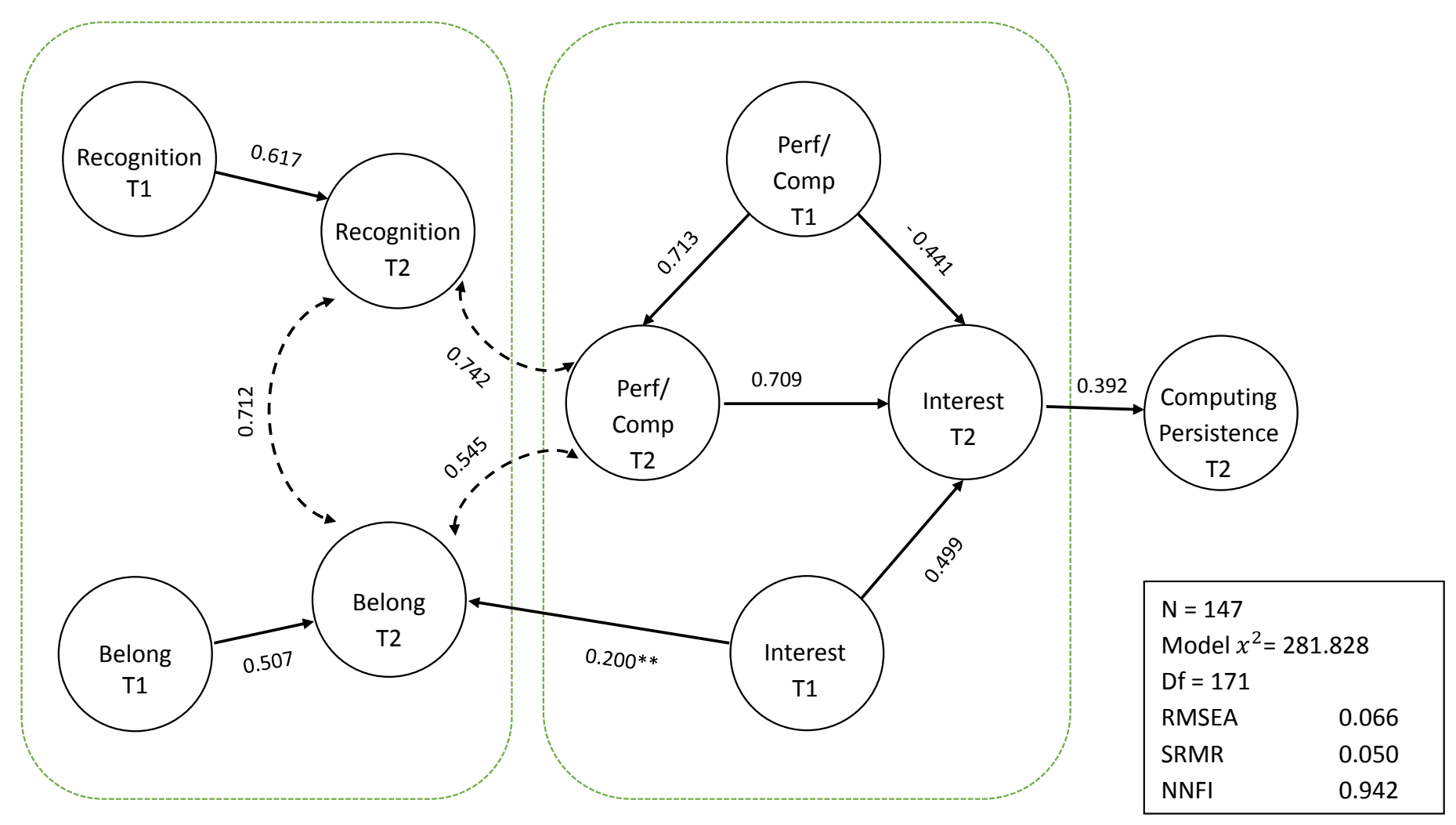

$* *$ indicates $\mathrm{p}$-values $<0.01$. All other paths are significant $p$-values $<0.001$

Figure 4 - Structural Equation Modeling with Time Series Data. RMSEA: root mean square error of approximation; SRMR: standardized root mean square residual; NNFI: non-normed fit. (Acceptable values: RMSEA ( $p<0.08$ ), NNFI $(\mathrm{p}>0.90)$, SRMR $(\mathrm{p}<0.08))$. 


\subsection{Discussion}

Our model demonstrates that, although social factors influence persistence, they are not sufficient to predict persistence alone over time. This helps us to develop better arguments for the different rotation of disciplinary identity sub-constructs for different majors. In our basic model, we found that interest and competence were two impactful factors on persistence with direct paths. The new findings align with our previous results and also show that over time interest is more dominant. As we aimed to examine the contribution of subconstructs on persistence over time, and how computing identity form, the focus of our structural model was not on the paths between old constructs. Our primary focus was on the paths between old and new constructs and also new constructs on persistence. Several useful key points were revealed in this study.

The first key point is how we separated interest and competence from recognition and sense of belonging. The two boxes with the dashed line in the structural model (Figure 4) show this separation. As figure 4 might be complicated, we broke it down to smaller modules (Figure 5) for better understanding. In fig 5, the boxes separate the individual factors from social factors. The impact of individual factors on persistence over time indicates students' self-beliefs on their interest and competence/performance are the main driving factors to persist (Interest: Direct path T2: factor loading 0.392, Indirect path T1: 0.499, p<0.001) (competence/performance: Indirect path T2: factor loading 0.799 , Indirect path T1: $0.713, \mathrm{p}<0.001$ ). The relationship of interest and 
competence/performance with persistence is well established (Lent et al., 1984, 1994, 2008). Our model shows how disciplinary identity may change and develop over time. Our findings not only indicate the importance of individual factors over time but also confirm the significance of social factors. It is really important that social factors indirectly impact persistence.

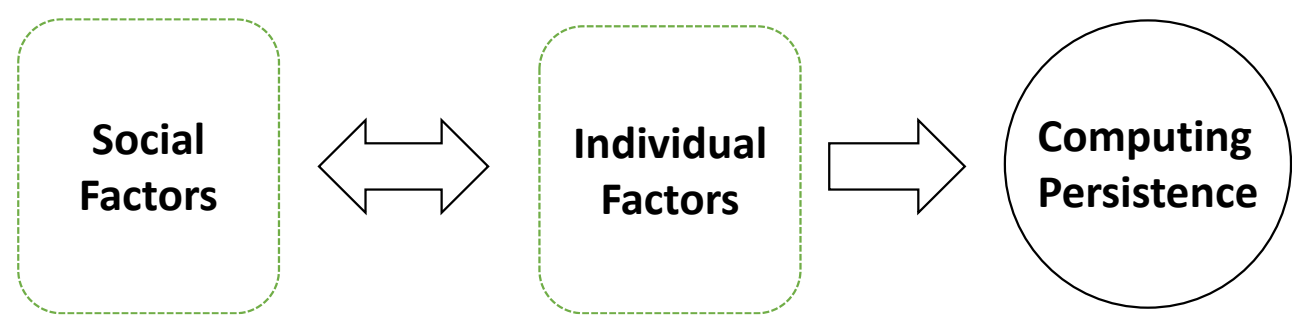

Figure 5 - The Importance of Individual Factors on Computing Persistence Over Time.

The second key point is the supportive role of social factors on both individual factors and persistence over time (Figure 5). Our model shows recognition (T2: factor loading 0.742, T1: $0.617, \mathrm{p}<0.001$ ) and sense of belonging (T2: factor loading $0.545, \mathrm{~T} 1: 0.507, \mathrm{p}<0.001$ ) affect both individual factors and persistence. Literature shows the influence of recognition and sense of belonging on persistence (Meyers et al., 2012; Cordell-McNulty, 2009; Strayhorn, 2012). The third key point is the impact of interest as the most important factor in persistence over time (factor loading 0.392, p<0.001) (fig6).

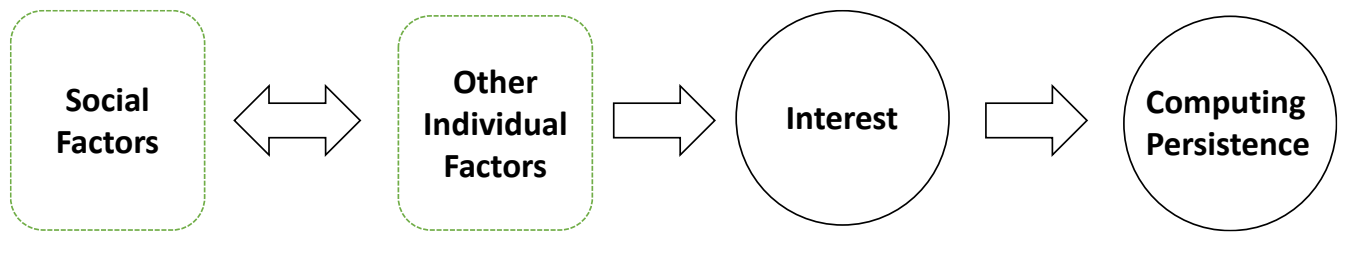

Figure 6 - The Importance of Interest over Time in Computing Identity Development 
Competence/performance in our basic model was one of the direct factors on persistence, but in this model, it does not have any direct impact. Previous work on disciplinary identity in math, and physics showed a direct negative path from competence/performance to identity (Godwin et al., 2013). This indicated that competence/performance beliefs were not adequate for identity development, and they needed to be mediated by interest and recognition. It is worth mentioning that in our study, we examined the impact of identity sub-constructs on persistence, not identity itself as a construct. The direct connection between interest and competence/performance is also well established (Meyers et al., 2012; Cordell-McNulty, 2009). Our study confirms SCCT on the relationship of interest and competence and their impacts on choice goals and actions.

Figure 7 indicates that if a student develops competency beliefs, he/she is more likely to establish interest. Another interesting finding in this model is the negative impact of competence/performance T1 on Interest T2 (factor loading $0.441, \mathrm{p}<0.001)$. There is a positive path from competence/performance T1 to competence/performance T2 (factor loading $0.713, \mathrm{p}<0.001$ ). This indicates if a student with an initial feeling of competency can not keep the competency feeling up over time, he/she is less likely to develop interest.

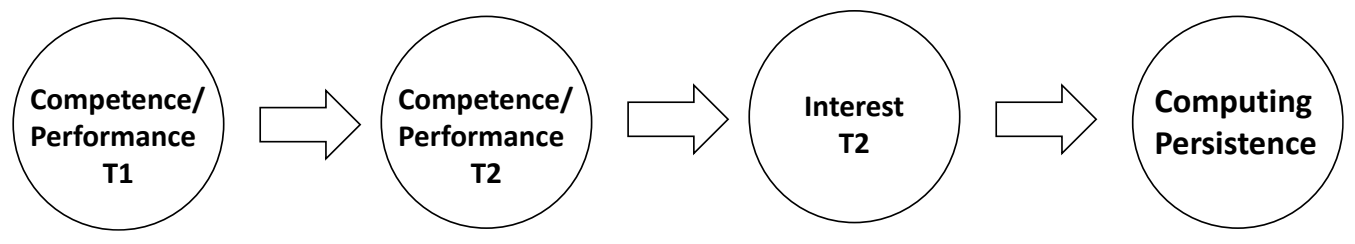

Figure 7 - The Importance of the Development of Competence/Performance over Time. 
In our new model, recognition does not have the same direct impact on interest compared to what we found before (Taheri et al., 2018). In the multigroup SEM cross-sectional analysis (Taheri et al., 2019), this path was the only path with significant differences between senior and first-year students. Although in the new model, there is no direct path to interest, there is still a correlation between recognition $\mathrm{T} 2$ and competence/performance. (T2: factor loading 0.742 , $\mathrm{p}<0.001)$.

Competence/performance plays an important role as a mediator for recognition and sense of belonging. Fig 8 shows that there are three significant zero-order correlations (non-causal or unexplained relation) in the model between competence/performance and recognition, competence/performance and sense of belonging, and recognition and sense of belonging $(\mathrm{p}<0.001)$.

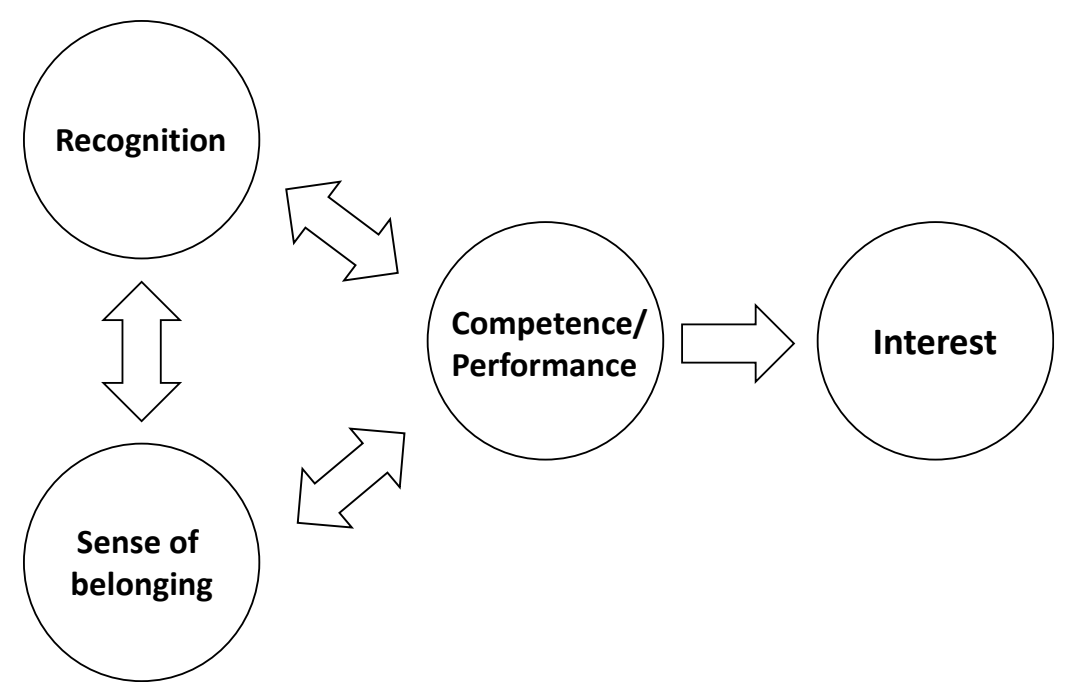

Figure 8 - Correlations among Identity Sub-constructs and the Importance of Competence/Performance Role as a Mediator over Time

The last key point is the significant impact of all sub-constructs at time1 on their same-type constructs at time 2. Interest (factor loading 0.499, $\mathrm{p}<0.001$ ), 
competence/performance (factor loading 0.713, $\mathrm{p}<0.001$ ), Recognition (factor loading $0.617, \mathrm{p}<0.001$ ), and sense of belonging competence/performance (factor loading $0.507, \mathrm{p}<0.001)$. Competence $\mathrm{T} 1 \mathrm{~T} 2$ path is the strongest direct path in the model. These values confirm identity develops over time, and self-beliefs need to be considered in an academic setting as soon as possible.

In our model recognition has correlation with competence/performance (factor loading 0.617, $\mathrm{p}<0.001$ ). Recognition can motivate students, and make them feel appreciated. Recognition has been cited in multiple studies of identity as being important (Carlone et al., 2007; Hazari et al., 2010; Gee, 200; Godwin et al., 2013, 2016).

Sense of belonging in our model has a significant impact (factor loading $0.507, \mathrm{p}<0.001)$. Lack of sense of belonging has been shown in many studies as one of the reasons for students to drop out (Marra et al., 2012). Building a safe learning culture and fostering positive communications between students, staff, and educators can increase sense of belonging in institutions (Frieze et al., 2015; Barker et al., 2014). Students who participate in co-curricular programs can earn many positive experiences such as learning skills to social interaction that may increase sense of belonging. Students who have a higher amount of sense of belonging feelings have better performance and higher persistence (Frieze et al., 2015; Barker et al., 2014; Massi et al., 2012).

Ultimately, it is worth mentioning that other disciplines (math, physics, and engineering) (Godwin et al., 2013, 2016) have found direct effects of the 
"social aspects" to persistence and therefore it is fully possible to critique the individualistic nature of computing identity development in programs. Computer science programs can leverage more communal social aspects for computing identity development so that it could have a direct effect in future.

\subsubsection{Implications for Practice:}

Understanding the development of students' identity over the years at schools is vital to address the persistence issue since different constructs influence each other and directly or indirectly affect persistence. Schools can improve these self-beliefs much easier than controlling some external factors like parents' education level or financial situation. We found that interest has the most substantial impact on students' persistence. For computing instructors and professors, understanding the effects of students' self-beliefs, especially interest, is valuable. There are overlaps between what fosters students' interest and other factors like recognition, sense of belonging, and competence/performance. There are several approaches in a classroom that might increase students' interest. Educators may increase interest by doing several activities such as concentrating on fundamental topics in computing, making the learning process more fun and interactive, better interaction with students (Barker et al., 2014), teamwork, and breaking down complex and tedious subjects to smaller modules to look more achievable. Lack of interest can be a significant challenge at school, and educators need to pick practical approaches that are effective in their setting. Project-based and hands-on learning help students to get involved in experiments, and solve 
real-world problems. It also empowers them to get familiar with job market roles and products. Agency beliefs also have been shown as an essential factor in increasing interest, identity, and persistence. When students are aware of the social impact of computer science and know that computing can have a positive impact and meaningful change in the world, they are more likely to develop interest around it (Godwin et al., 2016).

Parents can also play an essential role in student interest. Several studies show that computer science learning from childhood is an effective way to involve students in computing (Google education, 2015). Although there are still limitations for world-wide computer education for children, parents can provide computing tools and learning resources at home. Lack of exposure to CS and lack of opportunity to learn CS are some of the other reasons for lack of interest. Encouragement and recognition are some of the most important factors in interest. A study has shown students who have been encouraged by teachers or parents and received words like they can be good at computer science are almost three times more likely to develop interest in computer science (Google education, 2015).

Administrators and coordinators can also help students by providing more scholarships, and developing curricular structure with courses around compelling contexts that align with students' interest. Also, using role models, demonstrating the relevance of computing and courses to their future jobs, and demonstrating the growing role of CS in society and job market demand might be helpful. Finally, providing extra-curricular activities like bootcamps, hackathons, and workshops, 
providing tutoring for introductory courses, and offering elective courses might impact students' identity and increase their computing persistence (Barker et al., 2004).

Computing organizations (Stephenson et al., 2018) suggests some promising interventions to increase computing interest, such as helping students to have a better understanding of computer science (Fisher et al., 2003). Decreasing stereotypes and misconceptions can be performed by organizing some orientation sessions or using ambassadors for students. Performance and competence also have a significant influence on interest and persistence. If a student feels competent and able to perform well in computer science, it can develop interest in computing. The finding of this research also has implications for organizations like Google and ACM that are gathering data, forming retention committees, and generating reports on computer science retention (Stephenson et al., 2003).

Minority-serving Institutions that suffer from low persistence may also take advantage of our results or framework. While persistence is an essential estimate of institutional success, a number of them do not collect students' selfbeliefs. Computing celebrations/symposiums/conferences like the Richard Tapia Celebration of Diversity in Computing and Grace Hopper Celebration of Women in Computing (GHC) might leverage our findings to explore self-beliefs systematically and organize their events somehow to help students' self-beliefs to rise. While empowering students to reach to the point that they develop adequate 
interest, understand computer science, and perform well in computing goals and tasks can be challenging, it might help them with pursuing CS and computing occupation.

\subsubsection{Limitations and Future Work}

This study was limited by the fact that the survey's focus was on Florida metropolitan universities and, as such, is set within a particular cultural, social environment.

Another limitation was the amount of students' data that were used in the final SEM analysis. For this longitudinal study, on the contrary to our previous cross-sectional works that captured a snapshot of students' identity, we used the data from two different times. After matching students, the selected students were mostly from first-year and second-year students in 2017 who participated in 2019 when they were junior or senior students. The survey data did not include previous seniors as they already graduated and did not participate in the 2019 survey.

Another limitation was the concern of how well disciplinary identity or in particular computing identity, as a framework, describes students' persistence with no controls for additional external factors like level of family education and support, student academic background, socioeconomic status, and out-of-school experiences. For future work, we aim to expand our research to include other possible self-beliefs and some of the most critical factors on persistence. Our dataset let us explore additional questions that have not been examined in our 
study. These factors do not necessarily include self-beliefs, but they might be useful, like students' background or parents' background. In addition, we believe understanding the student situation of those that do not persist by after leaving the major and asking questions like what was the last class or teacher they took before leaving might help to explore their lack of persistence. A qualitative study with students who dropped out might answer many undiscovered areas of persistence. Finally, although the impact of identity on persistence is inevitable, it is not the only piece of the persistence puzzle, and there is no one-size-fits-all answer for all schools. Academic institutions need to plan strategic approaches based on their needs, goals, and their cultural/social situation to address the low rate of computing persistence.

\subsection{Conclusion}

Computer science jobs are in demand and are expected to grow faster than the average growth rate of other careers. Academic computing schools and institutions as the major centers for providing society with skillful computing graduates suffer from low retention. In this study, we explored the impact of computing identity over time on students' persistence. The results indicated that persistence is more directly impacted by students' interest as an individual factor. Competence/performance also influenced both interest and persistence. Social factors like recognition and sense of belonging played significant supporting roles for individual factors and persistence. Our model indicated that computing identity is formed and developed over time through students' experiences. 
Developing experiences that contribute positively to interest,

competence/performance, recognition beliefs, and sense of belonging in schools may be a vital component to retain students. 


\section{References Chapter IV}

Astin, A. W. (1977). Four Critical Years. Effects of College on Beliefs, Attitudes, and Knowledge.

Astin, A. W. (2000). Diversity and Multiculturalism on the Campus. Learning from Change: Landmarks in Teaching and Learning in Higher Education from Change Magazine, 1969-1999, 323.

Bandura, A. (1977). Self-efficacy: toward a unifying theory of behavioral change. Psychological review, 84(2), 191.

Barker, L. J., \& Garvin-Doxas, K. (2004). Making visible the behaviors that influence learning environment: A qualitative exploration of computer science classrooms. Computer Science Education, 14(2), 119-145.

Barker, L. J., O'Neill, M., \& Kazim, N. (2014, March). Framing classroom climate for student learning and retention in computer science. In Proceedings of the 45th ACM technical symposium on Computer science education (pp. 319324).

Barker, L., Hovey, C. L., \& Thompson, L. D. (2014, October). Results of a largescale, multi-institutional study of undergraduate retention in computing. In 2014 IEEE Frontiers in Education Conference (FIE) Proceedings (pp. 1-8). IEEE.

Bean, J. P. (1980). Dropouts and turnover: The synthesis and test of a causal model of student attrition. Research in higher education, 12(2), 155-187.

Bean, J. P. (1982). Student attrition, intentions, and confidence: Interaction effects in a path model. Research in higher education, 17(4), 291-320.

Bean, J. P., \& Metzner, B. S. (1985). A conceptual model of nontraditional undergraduate student attrition. Review of educational Research, 55(4), 485-540.

Belch, H. A., Gebel, M., \& Maas, G. M. (2001). Relationship between student recreation complex use, academic performance, and persistence of first-time freshmen. NASPA journal, 38(2), 254-268.

Camp, T., Adrion, W. R., Bizot, B., Davidson, S., Hall, M., Hambrusch, S., ... \& Zweben, S. (2017). Generation CS: the growth of computer science. ACM Inroads, 8(2), 44-50.

Carlone, H. B., \& Johnson, A. (2007). Understanding the science experiences of successful women of color: Science identity as an analytic lens. Journal of Research in Science Teaching: The Official Journal of the National Association for Research in Science Teaching, 44(8), 1187-1218. 
Cass, C. A., Hazari, Z., Cribbs, J., Sadler, P. M., \& Sonnert, G. (2011, October). Examining the impact of mathematics identity on the choice of engineering careers for male and female students. In 2011 Frontiers in Education Conference (FIE) (pp. F2H-1). IEEE.

Chen, X. (2013). STEM Attrition: College Students' Paths into and out of STEM Fields. Statistical Analysis Report. NCES 2014-001. National Center for Education Statistics.

Cordell-McNulty, K. L. (2009). Predictors of academic achievement, social adjustment, and intention to persist: A bioecological analysis of college retention. University of Florida.

Enders, C. K. (2006). Analyzing structural equation models with missing data. Structural equation modeling: A second course, 2, 493-519.

Enders, C. K., \& Bandalos, D. L. (2001). The relative performance of full information maximum likelihood estimation for missing data in structural equation models. Structural equation modeling, 8(3), 430-457.

Fornell, C., \& Larcker, D. F. Evaluating structural models with unobserved variables and measurement errors. Journal of Marketing Research. v18 i1, 39-50.

Frieze, C., \& Quesenberry, J. (2015). Kicking butt in computer science: Women in computing at Carnegie Mellon University. Dog Ear Publishing.

Gee, J. P. (2000). Chapter 3: Identity as an analytic lens for research in education. Review of research in education, 25(1), 99-125.

Giannakos, M. N., Pappas, I. O., Jaccheri, L., \& Sampson, D. G. (2017). Understanding student retention in computer science education: The role of environment, gains, barriers and usefulness. Education and Information Technologies, 22(5), 2365-2382.

Godwin, A. (2016, January). The development of a measure of engineering identity. In ASEE Annual Conference \& Exposition.

Godwin, A., Potvin, G., Hazari, Z., \& Lock, R. (2013, October). Understanding engineering identity through structural equation modeling. In 2013 IEEE Frontiers in Education Conference (FIE) (pp. 50-56). IEEE.

Godwin, A., Potvin, G., Hazari, Z., \& Lock, R. (2016). Identity, critical agency, and engineering: An affective model for predicting engineering as a career choice. Journal of Engineering Education, 105(2), 312-340. 
Google. (2015). Searching for Computer Science:

https://services.google.com/fh/files/misc/searching-for-computer-

science_report.pdf

Hazari, Z., Sonnert, G., Sadler, P. M., \& Shanahan, M. C. (2010). Connecting high school physics experiences, outcome expectations, physics identity, and physics career choice: A gender study. Journal of research in science teaching, 47(8), 978-1003.

Hogan, A., \& Roberts, B. (2015). Occupational employment projections to 2024. Monthly Lab. Rev., 138, 1.

Kerby, M. B. (2015). Toward a new predictive model of student retention in higher education: An application of classical sociological theory. Journal of College Student Retention: Research, Theory \& Practice, 17(2), 138-161.

Kline, R. B. (2015). Principles and practice of structural equation modeling. Guilford publications.

Lent, R. W., Brown, S. D., \& Hackett, G. (1994). Toward a unifying social cognitive theory of career and academic interest, choice, and performance. Journal of vocational behavior, 45(1), 79-122.

Lent, R. W., Brown, S. D., \& Larkin, K. C. (1984). Relation of self-efficacy expectations to academic achievement and persistence. Journal of counseling psychology, 31(3), 356.

Lent, R. W., Lopez Jr, A. M., Lopez, F. G., \& Sheu, H. B. (2008). Social cognitive career theory and the prediction of interests and choice goals in the computing disciplines. Journal of Vocational Behavior, 73(1), 52-62.

Levin, J., \& Wyckoff, J. H. (1995). Predictors of persistence and success in an engineering program. NACADA Journal, 15(1), 15-21.

Margolis, J., \& Fisher, A. (2002). Unlocking the clubhouse: Women in computing. MIT press.

Marra, R. M., Rodgers, K. A., Shen, D., \& Bogue, B. (2012). Leaving engineering: A multi-year single institution study. Journal of Engineering Education, 101(1), 6-27.

Massi, L., Lancey, P., Nair, U., Straney, R., Georgiopoulos, M., \& Young, C. (2012, October). Engineering and computer science community college transfers and native freshmen students: Relationships among participation in extracurricular and co-curricular activities, connecting to the university campus, and 
academic success. In 2012 Frontiers in Education Conference Proceedings (pp. 16). IEEE.

Meyers, K. L., Ohland, M. W., Pawley, A. L., Silliman, S. E., \& Smith, K. A. (2012). Factors relating to engineering identity. Global Journal of Engineering Education, 14(1), 119-131.

Rendon, L. I. (1995). Facilitating Retention and Transfer for First Generation Students in Community Colleges.

Rosseel, Y. (2012). Lavaan: An R package for structural equation modeling and more. Version 0.5-12 (BETA). Journal of statistical software, 48(2), 1-36.

Rosseel, Y. (2018). The lavaan tutorial. Belgium: Department of Data Analysis, Ghent University.

Schreiber, J. B., Nora, A., Stage, F. K., Barlow, E. A., \& King, J. (2006). Reporting structural equation modeling and confirmatory factor analysis results: A review. The Journal of educational research, 99(6), 323-338.

Schumacker, R. E., \& Lomax, R. G. (2004). A beginner's guide to structural equation modeling. psychology press.

Sin, S. C. J. (2009). Structural and individual influences on information behavior: A national study of adolescents' use of public libraries (Doctoral dissertation, University of Wisconsin--Madison).

Snyder, T. D., \& Dillow, S. A. (2012). Digest of education statistics 2011. National Center for Education Statistics.

Spady, W. G. (1970). Dropouts from higher education: An interdisciplinary review and synthesis. Interchange, 1(1), 64-85.

Spady, W. G. (1971). Dropouts from higher education: Toward an empirical model. Interchange, 2(3), 38-62.

Spady, W. G., \& Marshall, K. J. (1991). Beyond Traditional Outcome-Based Education. Educational leadership, 49(2), 67-72.

Stephenson, C., Derbenwick Miller, A., Alvarado, C., Barker, L., Barr, V., Camp, T., ... \& Richardson, D. (2018). Retention in computer science undergraduate programs in the US: Data challenges and promising interventions. New York, NY. ACM.

Strayhorn, T. L. (2018). College students' sense of belonging: A key to educational success for all students. Routledge. 
Swail, W. S. (2004, June). The art of student retention: A handbook for practitioners and administrators. In Educational Policy Institute. Texas Higher Education Coordinating Board 20th Annual Recruitment and Retention Conference Austin, TX June (Vol. 21, No. 877, pp. 1-39).

Taheri, M., Ross, M., Hazari, Z., Weiss, M., Georgiopoulos, M., Christensen, K., ... \& Chari, D. (2018, October). A Structural Equation Model Analysis of Computing Identity Sub-Constructs and Student Academic Persistence. In 2018 IEEE Frontiers in Education Conference (FIE) (pp. 1-7). IEEE.

Taheri, M., Ross, M., Hazari, Z., Weiss, W., Georgiopoulos, M., Christensen, K., ... \& Taheri, Z. (2019, January). Exploring Computing Identity and Persistence Across Multiple Groups Us-ing Structural Equation Modeling. In American Society for Engineering Education (ASEE) Conference Proceedings.

Tinto, V. (1975). Dropout from higher education: A theoretical synthesis of recent research. Review of educational research, 45(1), 89-125.

Tinto, V. (2006). Research and practice of student retention: What next? Journal of college student retention: Research, Theory \& Practice, 8(1), 1-19.

Tinto, V. (2017). Through the eyes of students. Journal of College Student Retention: Research, Theory \& Practice, 19(3), 254-269.

U.S. Bureau of Labor Statistics. (2019). Occupational Outlook Handbook, Computer Programmers. https://www.bls.gov/ooh/computer-and-informationtechnology/computer-programmers.htm

Zweben, S., Bizot, B., \& Computing Research Association. (2018). Taulbee survey: Undergrad enrollment continues upward; doctoral degree production declines but doctoral enrollment rises (Washington, DC, 2018). 


\section{Chapter V: Discussion and Conclusion}

Academic persistence has been one of the most significant topics in education over the past few decades. While demands for skilled computing workforce are on the rise, institutes suffer from low persistence rates in computing. Prior studies in STEM and engineering have indicated that students' self-beliefs (identity) is one of the vital factors in academic persistence. This dissertation presented a rigorous model for integrating students' self-beliefs and their persistence in computer science. In this study the aim was to study previous frameworks, validate the model for computing, and expand the proposed model by offering new sub-constructs. In addition to a better understanding of our model, different analyses for different groups were performed and the impact of identity on persistence over time was studied. This dissertation along with the published articles introduced studying disciplinary identity in computing, coupling identity and persistence, and utilizing SEM to quantify correlations of identity sub-constructs and persistence. This would fill a gap which was found in computing in terms of shortage of robust theories and scientific methods to consider students' identity in graduation, persistence, and career choice for computer science and computing students.

\subsection{Synthesizing the Three-Article Dissertation}

The three articles comprising this dissertation build upon one another to address the four research questions and provide a comprehensive view of computing identity and persistence framework. The first article provided a basic 
understanding of the model. The SEM analysis showed the relationships between identity sub-constructs and identity. This model complemented the prior research (Hazari et al., 2010; Cass et al., 2011; Cribbs et al. 2016; Godwin 2013, 2016) and expands on knowledge of disciplinary identity by building the computing identity model. The results of the first article revealed that the computing identity was a significant predictor of students' computing persistence and career choice as other scholar also indicated (Mahadeo et al., 2020). Furthermore, sense of belonging was added as a new sub-construct to the disciplinary identity.

The second and third articles provided further analysis of different groups and identity development over time. These studies added more insight into the computing identity model and enhanced the understanding of science and engineering identity (Hazari et al., 2010; Godwin 2013, 2016) using granular exploration and discovery.

\subsubsection{Addressing the Research Questions}

In the past three chapters, all research questions were addressed. The first paper indicated that all the identity sub-constructs contribute to students' academic persistence. The structural equation model was used to quantify the impacts. While interest directly had a major impact, performance and competence influenced persistence indirectly through interest. In addition, recognition and sense of belonging both played an important role in this model by influencing persistence indirectly through interest and performance/competence. 
The second paper compared the model among freshman and senior students and then among male and female students. After running the multigroup SEM, interesting paths between females and males were reviewed and analyzed. There was no significant difference between male and female students. Analyzing the paths for different undergraduate levels identified that there are differences between senior students and first-year students, and the differences are significant. In other words, the results of multigroup SEM analysis showed that the identity sub-constructs are equally predictive of their persistence among men and women, while not equally predictive for freshmen and seniors.

The third paper addressed the fourth research question. In a time-series SEM analysis, the impact of identity sub-constructs on academic persistence was evaluated over time. The results indicated that identity is more directly impacted by students' interest as an individual factor. Social factors like recognition and sense of belonging played significant supporting roles for individual factors and persistence. Results indicated that identity is formed and developed over time through students' experiences.

In general, the results of all three articles aligned with prior studies on identity (Hazari et al., 2010; Godwin et al., 2013, 2016) and persistence (Lent et al., 1994, 1996, 2002). Students interest was the critical sub-constructs in the model and performance/competence played an important role in the identity development and boosting persistence. Recognition and sense of belonging influenced persistence through interest and performance/competence. The results 
aligned with previous studies on the impact of social support and feelings of belonging and recognition on persistence (Hazari et al., 2010; Godwin et al., 2013, 2016, Lent et al., 1994, 2016).

\subsection{Theoretical Implications}

In this dissertation, identity theory was evaluated, and the importance of identity sub-constructs on persistence in computing were highlighted. The outcome of this research and the proposed model with quantified paths would have implications for other researchers. It provides an analytical lens to dive deep into students' self-beliefs, and to find solutions to increase computing interest and other perceived feelings of competency, recognition, and belonging. This dissertation expanded the original identity model by looking into the impact of sense of belonging on persistence. Also, it disaggregated the findings to male and female and also freshman and seniors for a better understanding of the nuances. This would provide insights for future studies with varied populations and multigroup analysis. For instance, the multigroup analysis for different genders might be helpful in gender gap in computer science. Ultimately, the time-series analysis showed the impact of identity development on persistence by capturing two snapshots of student's self-belief and building a model of SEM. This provides the significance of longitudinal analysis as opposed to cross-sectional studies for finding the correlations of sub-constructs over time. 


\subsection{Practical Implications}

This study provides insights into academic persistence not only for higher education institutes and communities, but also for parents, and the general public. Academic persistence is a complex issue in education and society. The findings have implications for educational institutions for the fulfillment of their mission and administrative practices such as boosting graduation rates for ranking purposes. Schools would leverage the results in educational short-term, long-term roadmap/vision development, building extra-curricular activities, planning orientations, and even defining strategies for hiring and training staff, faculty, and counselors (Bean 1987; Astin et al., 2012). Schools can promote the impact of students' identity through workshops and classes. They can also wisely reinforce and strengthen each sub-construct by different programs, encouragement and enforcements (Tinto, 2005). Well-designed curricular and extra-curricular activities, calculated decisions, and ad-hoc analysis of the outcome will gradually help to increase the persistence rate (Lee et al., 2009).

Understanding the impact of identity on persistence can be useful to students for personal and academic goal attainment. Schools can help this process by organizing orientations. Staff and administrators can educate students and highlight the impact of computing identity, so students and teachers can both take advantage of the findings and also contribute more effectively in programs or use any opportunity to foster the culture. For instance, teachers will be more likely to recognize students in the classroom if they are following a framework to develop 
students' identity and measure their success (Han et al., 2017; Hohne et al., 2019). Institutes can help to bring students together so they can get familiar with each other, meet other people at school, and find out how they can get involved in computing communities (Braxton et al., 2001).

Institutes can educate students on their academic journey and how to develop more interest or skills over time. By organizing orientation for parents, institutes can help families get more familiar with what their children experience at school, and how to better influence and support students' interest and recognition feelings. By organizing orientations for faculty and staff of these institutions and educating them, they would learn how to participate in students' self-beliefs development. For instance, schools can encourage them to interact with students even outside the formal classroom setting to boost engagement and interest (Soria et al., 2012).

There are multiple ways to impact each sub-construct positively at school. For instance, by organizing career orientation, including career exploration in weekly/monthly orientations or newsletters, inviting successful graduates or role models to talk and engage with students, they can help students to develop interest. By improving the computing curriculum and the quality of teaching, schools can prepare students for computing internships/jobs and improve their performance/competence feelings (Bean et al., 2001; Derby et al., 2004).

In general, while most of the universities, educators, and administrators have no control over some of the external factors, they could have more effective 
impacts on students' self-beliefs in the short-term or long-term. College awareness and understanding of these factors may help students persist despite other barriers that a student may face. Schools can plan an annual persistence program with senior management commitment. They can invite a committee of educators and researchers and prioritize the programs. Schools need to run powerful intervention programs to create and encourage change. Calculated decisions based on data along with monitoring the impact and learning from the process would help to increase the persistence rate (Escobedo, 2007).

\subsection{Limitations and Recommendations for Future Research}

This study was a multi-institutional study in Florida. The characteristics and circumstances of our research might not allow us to easily generalize the results and findings to a larger population such as the United States as a country or beyond. Another limitation of this study is the sample population. I focused on traditional academic four-year intuitions. I did not disaggregate data based on transfer students from colleges. Another multi-group analysis might provide more insight into these two groups. The other limitation is that our focus was only on students who already persisted in their education. I did not capture any information about people who already left to investigate their departure and the reasons behind their decisions. Another limitation is the lack of categorizing students into different demographic categories. For example, the most important persistence factors for African American students might not be the same as Hispanic students. Moreover, our model did not include external factors, as the 
focus of this study was only on academic identity isolated from other external factors; however, this dissertation provides a comprehensive list of models and constructs for future studies. Ultimately, questions (Q7 and 8) used to capture persistence is about intentions. Intentions are not the same as actual graduation and getting a job. This is a limitation of cross-sectional and short-term longitudinal designs.

All of the above-mentioned limitations indicate the importance of further research in this arena. This study built an identity-persistence model for computing with the hope of providing ways for further quantitative studies in this field. Conducting a national survey or analysis on extracted data from previously conducted national surveys is highly recommended. In addition, more multigroup analysis of demographics is recommended depending on the purpose of the study and the sample population. Another recommendation is conducting a qualitative study on students who could not persist in their computing education. This might be difficult to conduct since students who leave schools are not always willing to contribute to schools' programs. However, this might be useful to discover unknown factors especially self-belief sub-constructs related to persistence. In addition, it might help schools to anticipate departures and develop afterdeparture programs and plans. Moreover, another study is recommended for expanding the model and evaluating the impact of our sub-constructs along with other external factors. 


\section{References (Chapter V)}

Astin, A. W., Berger, J. B., Bibo, E. W., Burkum, K. R., Cabrera, A. F., Crisp, G., ... \& Mina, L. (2012). College student retention: Formula for student success. Rowman \& Littlefield Publishers.

Bean, J. P. (1987). Increasing student retention: Effective programs and practices for reducing the dropout rate.

Bean, J., \& Eaton, S. B. (2001). The psychology underlying successful retention practices. Journal of College Student Retention: Research, Theory \& Practice, 3(1), 73-89.

Boudreau, C. A., \& Kromrey, J. D. (1994). A longitudinal study of the retention and academic performance of participants in freshmen orientation course. Journal of College Student Development.

Braxton, J. M., \& McClendon, S. A. (2001). The fostering of social integration and retention through institutional practice. Journal of College Student Retention: Research, Theory \& Practice, 3(1), 57-71.

Cass, C. A., Hazari, Z., Cribbs, J., Sadler, P. M., \& Sonnert, G. (2011, October). Examining the impact of mathematics identity on the choice of engineering careers for male and female students. In 2011 Frontiers in Education Conference (FIE) (pp. F2H-1). IEEE.

Cribbs, J. D., Cass, C., Hazari, Z., Sadler, P. M., \& Sonnert, G. (2016).

Mathematics identity and student persistence in engineering. The International journal of engineering education, 32(1), 163-171.

Derby, D. C., \& Smith, T. (2004). An orientation course and community college retention. Community College Journal of Research and Practice, 28(9), 763-773.

Escobedo, G. (2007). A retention/persistence intervention model: Improving success across cultures. Journal of Developmental Education, 31(1), 12.

Godwin, A. (2016, January). The development of a measure of engineering identity. In ASEE Annual Conference \& Exposition.

Godwin, A., Potvin, G., Hazari, Z., \& Lock, R. (2013, October). Understanding engineering identity through structural equation modeling. In 2013 IEEE Frontiers in Education Conference (FIE) (pp. 50-56). IEEE.

Godwin, A., Potvin, G., Hazari, Z., \& Lock, R. (2016). Identity, critical agency, and engineering: An affective model for predicting engineering as a career choice. Journal of Engineering Education, 105(2), 312-340. 
Han, C. W., Farruggia, S. P., \& Moss, T. P. (2017). Effects of academic mindsets on college students' achievement and retention. Journal of College Student Development, 58(8), 1119-1134.

Hazari, Z., Sonnert, G., Sadler, P. M., \& Shanahan, M. C. (2010). Connecting high school physics experiences, outcome expectations, physics identity, and physics career choice: A gender study. Journal of research in science teaching, 47(8), 978-1003.

Höhne, E., \& Zander, L. (2019). Sources of male and female students' belonging uncertainty in the computer sciences. Frontiers in psychology, 10, 1740.

Lee, D., Olson, E. A., Locke, B., Michelson, S. T., \& Odes, E. (2009). The effects of college counseling services on academic performance and retention. Journal of College Student Development, 50(3), 305-319.

Lent, R. W., Brown, S. D., \& Hackett, G. (1994). Toward a unifying social cognitive theory of career and academic interest, choice, and performance. Journal of vocational behavior, 45(1), 79-122.

Lent, R. W., Brown, S. D., \& Hackett, G. (1996). Career development from a social cognitive perspective. Career choice and development, 3, 373-421.

Lent, R. W., Lopez Jr, A. M., Lopez, F. G., \& Sheu, H. B. (2008). Social cognitive career theory and the prediction of interests and choice goals in the computing disciplines. Journal of Vocational Behavior, 73(1), 52-62.

Lent, R. W., Miller, M. J., Smith, P. E., Watford, B. A., Lim, R. H., \& Hui, K. (2016). Social cognitive predictors of academic persistence and performance in engineering: Applicability across gender and race/ethnicity. Journal of Vocational Behavior, 94, 79-88.

Mahadeo, J., Hazari, Z., \& Potvin, G. (2020). Developing a Computing Identity Framework: Understanding Computer Science and Information Technology Career Choice. ACM Transactions on Computing Education (TOCE), 20(1), 1-14.

Soria, K. M., \& Stebleton, M. J. (2012). First-generation students' academic engagement and retention. Teaching in Higher Education, 17(6), 673-685.

Tinto, V. (2005). College student retention: Formula for student success. Greenwood Publishing Group. 


\section{Florida IT Pathways (Flit-Path) Survey}

Information Regarding Your Participation in this Survey

We are interested in your experiences, attitudes, beliefs, and career expectations with respect to computer science, information technology, and computer engineering. Please make your best estimate for each item and answer as many questions as possible. Describe yourself as you generally are now, not as you wish to be in the future. Describe yourself as you honestly see yourself.

Please note:

- You must be 18 years or older to participate.

- $\quad$ The survey will take approximately 5 minutes to complete.

- $\quad$ Participation is voluntary. You may withdraw at any time.

- $\quad$ Participation will NOT impact your grades or participation in the Flit-Path program.

- You will be asked for contact information (email) in case we want to follow-up on some of your survey responses. This information is voluntary and will not be shared with any third party.

Thank you for your time and insight. 
1. Please provide your student ID number.

2. What institution are you enrolled in?
O FIU
$\mathrm{O}$ UCF
O USF

3. What year are you in college?
$\mathrm{O} 1^{\text {st }}$ year
$\mathrm{O} 2^{\text {nd }}$ year
O $3^{\text {rd }}$ year
$\mathrm{O} 4^{\text {th }}$ year
O Past $4^{\text {th }}$ year

4. What is your major (or intended major)?

O Computer Science O Information TechnologyO Computer Engineering O Other

5. Which of the following best describes your participation in the Flit-Path Scholars Program?

O I have never heard of the Program

O I am considering applying to the Program

O I have applied to the Program

O I am currently in the Program (have received notification of award) 


\section{About Your Aspirations}

6. Which of the following options best describe what field(s) you wanted to pursue in middle school, the beginning of high school, the end of high school, the beginning of college, and currently. (Mark all that apply)

\begin{tabular}{|c|c|c|c|c|c|}
\hline & $\begin{array}{l}\text { Middle } \\
\text { school }\end{array}$ & $\begin{array}{l}\text { Beginning of } \\
\text { high school }\end{array}$ & $\begin{array}{l}\text { End of high } \\
\text { school }\end{array}$ & $\begin{array}{l}\text { Beginning of } \\
\text { college }\end{array}$ & $\begin{array}{l}\text { Currently } \\
\text { (Now) }\end{array}$ \\
\hline Computer Science & $\mathrm{O}$ & $\mathrm{O}$ & $\mathrm{O}$ & $\mathrm{O}$ & $\mathrm{O}$ \\
\hline Information Technology & $\mathrm{O}$ & $\mathrm{O}$ & $\mathrm{O}$ & $\mathrm{O}$ & $\mathrm{O}$ \\
\hline Computer Engineering & $\mathrm{O}$ & $\mathrm{O}$ & $\mathrm{O}$ & $\mathrm{O}$ & $\mathrm{O}$ \\
\hline Electrical Engineering & $\mathrm{O}$ & $\mathrm{O}$ & $\mathrm{O}$ & $\mathrm{O}$ & $\mathrm{O}$ \\
\hline Mechanical Engineering & $\mathrm{O}$ & $\mathrm{O}$ & $\mathrm{O}$ & $\mathrm{O}$ & $\mathrm{O}$ \\
\hline Other Engineering & $\mathrm{O}$ & $\mathrm{O}$ & $\mathrm{O}$ & $\mathrm{O}$ & $\mathrm{O}$ \\
\hline Other Technology-Related Field & $\mathrm{O}$ & $\mathrm{O}$ & $\mathrm{O}$ & $\mathrm{O}$ & $\mathrm{O}$ \\
\hline $\begin{array}{l}\text { Natural Science (e.g. Biology, Chemistry, } \\
\text { Physics, Earth Science) }\end{array}$ & $\mathrm{O}$ & $\mathrm{O}$ & $\mathrm{O}$ & $\mathrm{O}$ & $\mathrm{O}$ \\
\hline Mathematics & $\mathrm{O}$ & $\mathrm{O}$ & $\mathrm{O}$ & $\mathrm{O}$ & $\mathrm{O}$ \\
\hline Medicine/Health & $\mathrm{O}$ & $\mathrm{O}$ & $\mathrm{O}$ & $\mathrm{O}$ & $\mathrm{O}$ \\
\hline $\begin{array}{l}\text { Other STEM }{ }^{\dagger} \text {-related Field (e.g. Social Science, } \\
\text { Psychology) }\end{array}$ & $\mathrm{O}$ & $\mathrm{O}$ & $\mathrm{O}$ & $\mathrm{O}$ & $\mathrm{O}$ \\
\hline Business & $\mathrm{O}$ & $\mathrm{O}$ & $\mathrm{O}$ & $\mathrm{O}$ & $\mathrm{O}$ \\
\hline $\begin{array}{l}\text { Other Non-STEM }{ }^{\dagger} \text {-related Field (e.g. English, } \\
\text { Music, Law) }\end{array}$ & $\mathrm{O}$ & $\mathrm{O}$ & $\mathrm{O}$ & $\mathrm{O}$ & $\mathrm{O}$ \\
\hline
\end{tabular}

${ }^{\dagger}$ STEM stands for Science, Technology, Engineering, and Mathematics 
7. Please rate the current likelihood of your choosing a career in the following:

\begin{tabular}{lcl}
\hline & Not at all & Extremely \\
Computer Science & likely & likely $\mathbf{4}$ \\
Information Technology & $\mathrm{O}$ & $\mathrm{O}$ \\
Computer Engineering & $\mathrm{O}$ & $\mathrm{O}$ \\
\hline
\end{tabular}

8. How likely is it that you will finish a bachelor's degree in your current major (or intended major)?

Not at all likely 0

\section{Extremely likely}

$\mathrm{O}$ 


\section{About Your Attitudes}

9. Please rate the following statements as they apply to you.

I see myself as a computer savvy person

My family sees me as a computer savvy person

My friends/classmates see me as a computer savvy person

My instructors/teachers see me as a computer savvy

$$
\text { person }
$$

I am confident I can understand computing

Others ask me for help with computers

Others ask me for help with software (applications/programs)

I can do well on computing tasks (e.g. Programing and setting up servers

I understand concepts underlying computer processes

Topics in computing excite my curiosity

Computer programming is interesting to me

I enjoy learning about computing

I like to know what is going on in computing

$\begin{array}{ccccl}\text { Not at all } & \mathbf{1} & \mathbf{2} & \mathbf{3} & \mathbf{4} \text { Very much } \\ \mathrm{O} & \mathrm{O} & \mathrm{O} & \mathrm{O} & \mathrm{O} \\ \mathrm{O} & \mathrm{O} & \mathrm{O} & \mathrm{O} & \mathrm{O} \\ \mathrm{O} & \mathrm{O} & \mathrm{O} & \mathrm{O} & \mathrm{O} \\ \mathrm{O} & \mathrm{O} & \mathrm{O} & \mathrm{O} & \mathrm{O} \\ \mathrm{O} & \mathrm{O} & \mathrm{O} & \mathrm{O} & \mathrm{O} \\ \mathrm{O} & \mathrm{O} & \mathrm{O} & \mathrm{O} & \mathrm{O} \\ \mathrm{O} & \mathrm{O} & \mathrm{O} & \mathrm{O} & \mathrm{O} \\ \mathrm{O} & \mathrm{O} & \mathrm{O} & \mathrm{O} & \mathrm{O} \\ \mathrm{O} & \mathrm{O} & \mathrm{O} & \mathrm{O} & \mathrm{O} \\ \mathrm{O} & \mathrm{O} & \mathrm{O} & \mathrm{O} & \mathrm{O} \\ \mathrm{O} & \mathrm{O} & \mathrm{O} & \mathrm{O} & \mathrm{O} \\ \mathrm{O} & \mathrm{O} & \mathrm{O} & \mathrm{O} & \mathrm{O} \\ \mathrm{O} & \mathrm{O} & \mathrm{O} & \mathrm{O} & \mathrm{O}\end{array}$


10. With respect to the computing community, to what extent do you...

\begin{tabular}{|c|c|c|c|c|c|}
\hline & Not at all 0 & 1 & 2 & 3 & 4 Very much \\
\hline ...feel like you are part of the community & $\mathrm{O}$ & $\mathrm{O}$ & $\mathrm{O}$ & $\mathrm{O}$ & $\mathrm{O}$ \\
\hline ...feel different from others in the community & $\mathrm{O}$ & $\mathrm{O}$ & $\mathrm{O}$ & $\mathrm{O}$ & $\mathrm{O}$ \\
\hline ...feel valued and respected & $\mathrm{O}$ & $\mathrm{O}$ & $\mathrm{O}$ & $\mathrm{O}$ & $\mathrm{O}$ \\
\hline ...feel alone or isolated & $\mathrm{O}$ & $\mathrm{O}$ & $\mathrm{O}$ & $\mathrm{O}$ & $\mathrm{O}$ \\
\hline ...feel you can share your thoughts/ideas & $\mathrm{O}$ & $\mathrm{O}$ & $\mathrm{O}$ & $\mathrm{O}$ & $\mathrm{O}$ \\
\hline ...feel you can be heard & $\mathrm{O}$ & $\mathrm{O}$ & $\mathrm{O}$ & $\mathrm{O}$ & $\mathrm{O}$ \\
\hline ...feel inadequate as a member & $\mathrm{O}$ & $\mathrm{O}$ & $\mathrm{O}$ & $\mathrm{O}$ & $\mathrm{O}$ \\
\hline $\begin{array}{c}\text {...feel that others (students, faculty, etc.) are } \\
\text { accessible/available to help you }\end{array}$ & $\mathrm{O}$ & $\mathrm{O}$ & $\mathrm{O}$ & $\mathrm{O}$ & $\mathrm{O}$ \\
\hline ...ffeel you can help others & $\mathrm{O}$ & $\mathrm{O}$ & $\mathrm{O}$ & $\mathrm{O}$ & $\mathrm{O}$ \\
\hline
\end{tabular}


11. Which of the following areas are you interested in? Mark all that apply

O Advanced user support

O Database development

O Gaming

O Graphics/art

O Hardware/circuitry

O Networking

O Programming

O Robotics

O Web development

O User interface development

O None of the above

\section{About Your Prior Experiences}

12. Which of the following experiences have you had at your institution with respect to computing? Mark all that apply

O Internship

O Research experience

O Job experience

O Job offers

O Tutoring experience, being a Learning Assistant

O None of the above

13. What is your average GPA in your computing courses? _--

14. What is your average GPA overall? _.

15. What grade did you receive in your highest high school english course?
$\mathrm{OA}+\mathrm{OA}$
$\mathrm{OA}-\mathrm{OB}+\mathrm{OB}$
$\mathrm{O} B-$
$\mathrm{OC}+\mathrm{OC} \mathrm{OC}-\mathrm{OD}$
O F

16. What grade did you receive in your highest high school mathematics course?
$\mathrm{OA}+\mathrm{OA}$
$\mathrm{O}$ A-
$\mathrm{OB}+\mathrm{OB}$
$\mathrm{O}$ B
$\mathrm{OC}+\mathrm{OC} \quad \mathrm{OC}-$
O D O F

17. What grade did you receive in your highest college/university mathematics course?

$\mathrm{OA}+\mathrm{OA} \mathrm{OA}_{-} \mathrm{OB}+\mathrm{OB}^{\mathrm{OB}-} \mathrm{OC}+\mathrm{OC}_{-} \mathrm{OCD}_{-} \mathrm{OP}$

\section{About You}

18. With which racial and ethnic group(s) do you identify? Mark all that apply

O American Indian or Alaska Native

O Asian

O Black or African American

O Hispanic, Latinx, or Spanish origin

O Middle Eastern or North African

O Native Hawaiian or Other Pacific Islander

O White

O Another race or ethnicity not listed above 
19. How do you describe your gender identity? Mark all that apply

O Female O Male O Agender O Transgender O A gender not listed

20. What was the highest level of education for your parent(s) / guardian(s)?

\begin{tabular}{|c|c|c|c|c|c|c|c|}
\hline & $\begin{array}{l}\text { Gender of } \\
\text { parent }\end{array}$ & $\begin{array}{l}\text { Less than } \\
\text { high school } \\
\text { diploma }\end{array}$ & $\begin{array}{l}\text { High school } \\
\text { diploma } \\
\text { /GED }\end{array}$ & $\begin{array}{l}\text { Some } \\
\text { college or } \\
\text { associate } \\
\text { /trade } \\
\text { degree }\end{array}$ & $\begin{array}{l}\text { Bachelor's } \\
\text { degree }\end{array}$ & $\begin{array}{l}\text { Master's } \\
\text { degree or } \\
\text { higher }\end{array}$ & Don't know \\
\hline $\begin{array}{l}\text { Parent / } \\
\text { Guardian \#1 }\end{array}$ & $\begin{array}{l}\text { O Female } \\
\text { O Male }\end{array}$ & $\mathrm{O}$ & $\mathrm{O}$ & $\mathrm{O}$ & $\mathrm{O}$ & $\mathrm{O}$ & $\mathrm{O}$ \\
\hline $\begin{array}{l}\text { Parent / } \\
\text { Guardian \#2 }\end{array}$ & $\begin{array}{l}\text { O Female } \\
\text { O Male }\end{array}$ & $\mathrm{O}$ & $\mathrm{O}$ & $\mathrm{O}$ & $\mathrm{O}$ & $\mathrm{O}$ & $\mathrm{O}$ \\
\hline
\end{tabular}


21. Who encouraged you towards computing? Mark all that apply

O No one O ParentO Sibling O Other family member

O Friends O Teacher O Guidance counselor O Other:

22. How supportive is your home environment towards computing?

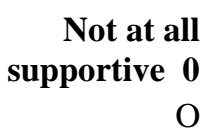

\section{Not at all}

$\mathrm{O}$

\section{Extremely supportive}

$\mathrm{O}$

23. How many friends do you have in computing?
O 0
O $1-2$
O 3-4
O 5-6
O 7-8
O 9-10

O More than 10

24. How many hour do you work outside the home?
$\mathrm{O} 0$
O 1-5
O 6-10
O 11-15
O 16-20
O More

than 20

25. Which of the following apply to your day-to-day life? Mark all that apply

O Caring for a child (e.g. sibling, your own child)

$O$ Caring for an adult (e.g. grandparent)

O Personal recurring health problem (not including common illnesses like a cold or flu)

O Other:

O None of the above

\section{Flit-Path Code Book:}

\section{GENERAL NOTES ON DATASET:}

Variables pertaining to a survey question start with an identifier of that question (e.g., q1 ... is a variable pertaining to Question 1).

Important variables:

ID = Form ID number (a unique identifier for each individual student)

Missing values are coded as '.' throughout.

Q1.

$\mathrm{q} 1=$ Student's ID number

Q2.

$\mathrm{q} 2=$ What institution are you enrolled in?

VALUES: 1 = "FIU", 2 = "UCF", 3 = "USF", . =Missing data .

Q3.

q3 = What year are you in college? 
VALUES:

$1=1^{\text {st }}$ year, $2=2^{\text {nd }}$ year, $3=3^{\text {rd }}$ year, $4=4^{\text {th }}$ year, $5=$ other (Past $4^{\text {th }}$ year),.$=$ missing data.

Q4.

$\mathrm{q} 4=$ What is your major (or intended major)?

VALUES: 1 = "Computer Science", 2 = "Information Technology “, 3 = "Computer Engineering", 4 = "Other", . =Missing data .

Q5.

$\mathrm{q} 5=$ Which of the following best describes your participation in the Flit-Path Scholars Program?

VALUES: $1=$ never heard of the Program, $2=$ considering applying to the Program, $3=$ have applied to the Program, $4=$ currently in the Program, . = missing data. 
Q6. (field plans). "Mark all that apply."

Which of the following options best describe what field(s) you wanted to pursue?

q6ms... = desired field in middle school

q6bhs... = desired field at the beginning of high school

q6ehs... = desired field at the end of high school

$\mathrm{q} 6 \mathrm{col} \ldots=$ desired field at beginning of college

q6cur... = desired field currently

\begin{tabular}{|c|c|c|c|c|c|}
\hline & Middle school & Beginning of HS & End of $H S$ & $\begin{array}{r}\text { Beginning of } \\
\text { college }\end{array}$ & Currently (now) \\
\hline Computer Science & q6mscs & q6bhscs & q6ehscs & q6colcs & q6nowcs \\
\hline Information Technology & q6msit & q6bhsit & q6ehsit & q6colit & q6nowit \\
\hline Computer Engineering & q6msce & q6bhsce & q6ehsce & q6colce & q6nowce \\
\hline Electrical Engineering & q6msee & q6bhsee & q6ehsee & q6colee & q6nowee \\
\hline Mechanical Engineering & q6msme & q6bhsme & q6ehsme & q6colme & q6nowme \\
\hline Other Engineering & q6msoe & q6bhsoe & q6ehsoe & q6coloe & q6nowoe \\
\hline Other Technology-Related Field & q6msot & q6bhsot & q6ehsot & q6colot & q6nowot \\
\hline $\begin{array}{l}\text { Natural Science (e.g. Biology, } \\
\text { Chemistry, Physics, Earth } \\
\text { Science) }\end{array}$ & q6msns & q6bhsns & q6ehsns & q6colns & q6nowns \\
\hline Mathematics & q6msmath & q6bhsmath & q6ehsmath & q6colmath & q6nowmath \\
\hline Medicine/Health & q6msmed & q6bhsmed & q6ehsmed & q6colmed & q6nowmed \\
\hline $\begin{array}{l}\text { Other STEM }^{\dagger} \text {-related Field (e.g. Social } \\
\text { Science, Psychology) }\end{array}$ & q6msos & q6bhsos & q6ehsos & q6colos & q6nowos \\
\hline Business & q6msbus & q6bhsbus & q6ehsbus & q6colbus & q6nowbus \\
\hline $\begin{array}{c}\text { Other Non-STEM }^{\dagger} \text {-related Field (e.g. } \\
\text { English, Music, Law) }\end{array}$ & q6msons & q6bhsons & q6ehsons & q6colons & q6nowons \\
\hline
\end{tabular}

†STEM stands for Science, Technology, Engineering, and Mathematics

VALUES for all variables: $1=$ checked this field, $0=$ did not check this field 
Q7. (Career likelihood)

Please rate the current likelihood of your choosing a career:

\begin{tabular}{|l|l|}
\hline q7cs & Likelihood of choosing computer science \\
\hline q7it & Likelihood of choosing Information Technology \\
\hline q7ce & Likelihood of choosing computer engineering \\
\hline
\end{tabular}

VALUES for all variables (11-point rating scale): $1=$ not at all likely; $11=$ definitely/extremely likely, . = missing.

Q8.

q8 = finishing a bachelor's degree likelihood

How likely is it that you will finish a bachelor's degree in your current major

VALUES for all variables (11-point rating scale): 1 = not at all; $11=$ definitely; missing $=$.

Q9. (Identity)

Rate the following statements as they apply to you

$\mathrm{q} 9 \mathrm{a}=$ To what extent do you see yourself as an exemplary student in computing fields

$\mathrm{q} 9 \mathrm{~b}=$ To what extent does your family see you as an exemplary student in computing fields

$\mathrm{q} 9 \mathrm{c}=$ To what extent do other students see you as an exemplary student in computing fields

q9d = To what extent do your teachers see you as an exemplary student in computing fields

$\mathrm{q} 9 \mathrm{e}=\mathrm{I}$ am confident I can understand computing

$\mathrm{q} 9 \mathrm{f}=$ Others ask me for help with computers

$\mathrm{q} 9 \mathrm{~g}=$ Others ask me for help with software (applications/programs)

$\mathrm{q} 9 \mathrm{~h}=\mathrm{I}$ can do well on computing tasks (e.g. Programming and setting up servers)

q9i $=$ I understand concepts underlying computer processes

$q 9 \mathrm{j}=$ Topics in computing excite my curiosity

$\mathrm{q} 9 \mathrm{k}=$ Computer programming is interesting to me

q91 = I enjoy learning about computing

$\mathrm{q} 9 \mathrm{~m}=\mathrm{I}$ like to know what is going on in computing

VALUES for all variables (5-point rating scale): $1=$ not at all; $5=$ very much so; missing $=$. 
Q10. (Sense of belonging)

With respect to the computing community, to what extent do you...

$\mathrm{q} 10 \mathrm{a}=$ feel like you are part of the community

$\mathrm{q} 10 \mathrm{~b}=$ feel valued and respected

$\mathrm{q} 10 \mathrm{c}=$ feel alone or isolated

$\mathrm{q} 10 \mathrm{~d}=$ feel you can share your thoughts/ideas

$\mathrm{q} 10 \mathrm{e}=$ feel you can be heard

$\mathrm{q} 10 \mathrm{f}=$ feel inadequate as a member

VALUES for all variables (5-point rating scale): $1=$ not at all; $5=$ very much so; missing $=$.

Q11. Which of the following areas are you interested in?

$\mathrm{q} 11 \mathrm{a}=$ Advanced user support

$\mathrm{q} 11 \mathrm{~b}=$ Database development

$\mathrm{q} 11 \mathrm{c}=$ Gaming

$\mathrm{q} 11 \mathrm{~d}=$ Graphics/art

q11e = Hardware/circuitry

$\mathrm{q} 11 \mathrm{f}=$ Networking

$\mathrm{q} 11 \mathrm{~g}=$ Software Programming

$\mathrm{q} 11 \mathrm{~h}=$ Hardware Programming

q11i = Robotics

$\mathrm{q} 11 \mathrm{j}=$ Web development

$\mathrm{q} 11 \mathrm{k}=$ User interface development

$\mathrm{q} 111=$ None of the above

VALUES: $1=$ marked, $0=$ not marked,.$=$ missing

Q12. Which of the following experiences have you had at your institution with respect to computing?

$\mathrm{q} 12 \mathrm{a}=$ Internship

$\mathrm{q} 12 \mathrm{~b}=$ Research experience

$\mathrm{q} 12 \mathrm{c}=$ Job experience

$\mathrm{q} 12 \mathrm{~d}=$ Job offers

$\mathrm{q} 12 \mathrm{e}=$ Tutoring experience, being a Learning Assistant

$\mathrm{q} 12 \mathrm{f}=$ None of the above

VALUES: $1=$ marked, $0=$ not marked,.$=$ missing

Q13. (What is your average GPA in your computing courses? Please indicate your GPA as a decimal (i.e. 3.4, 4.0, etc.))

q13 $=$ GPA in computing courses 
Q14. (What is your average GPA overall? Please indicate your GPA as a decimal (i.e. 3.4, 4.0, etc.))

$q 14=G P A$ overall

Q15. What grade did you receive in your highest high school english course? q15 = English grade

VALUES: $1=" \mathrm{~A}+", 2=" \mathrm{~A}$ “", . , 11="F"; . = missing data.

Q16. What grade did you receive in your highest high school mathematics course?

q16 = Math high school grade

VALUES: $1=" \mathrm{~A}+", 2=" \mathrm{~A}$ ", $, \ldots, 11=$ ="F”; . = missing data.

Q17. What grade did you receive in your highest college/university mathematics course?

q17 = Math college grade

VALUES: 1="A+", 2="A“, $\ldots, 11=" \mathrm{~F} " ;$. . missing data.

Q18. With which racial and ethnic group(s) do you identify?

$\mathrm{q} 18 \mathrm{a}=$ American Indian or Alaska Native

$\mathrm{q} 18 \mathrm{~b}=$ Asian

$\mathrm{q} 18 \mathrm{c}=$ Black or African American

q18d = Hispanic, Latinx, or Spanish origin

$\mathrm{q} 18 \mathrm{e}=$ Middle Eastern or North African

$\mathrm{q} 18 \mathrm{f}=$ Native Hawaiian or Other Pacific Islander

$\mathrm{q} 18 \mathrm{~g}=$ White

$\mathrm{q} 18 \mathrm{~h}=$ Another race or ethnicity not listed above

$\mathrm{q} 18 \mathrm{txt}=$ Another race/text

VALUES: $1=$ marked, $0=$ not marked,.$=$ missing

Q19. How do you describe your gender identity?

$\mathrm{q} 19 \mathrm{a}=$ Female

$\mathrm{q} 19 \mathrm{~b}=$ Male

$\mathrm{q} 19 \mathrm{c}=$ Agender

$\mathrm{q} 19 \mathrm{~d}=$ Transgender

$\mathrm{q} 19 \mathrm{e}=\mathrm{A}$ gender not listed

$\mathrm{q} 19 \mathrm{txt}=\mathrm{A}$ gender not listed/text

VALUES: $1=$ marked, $0=$ not marked,.$=$ missing 
Q20. What was the highest level of education for your parent(s) / guardian(s)? q20genderp1 = Parent's gender 1

q20genderp 2 = Parent's gender 2

Values: $1=$ Female, 2 = Male

$\mathrm{q} 20 \mathrm{a}=$ highest level of education for your parent 1

$\mathrm{q} 20 \mathrm{~b}=$ highest level of education for your parent 2

Values: 1 = Less than high school diploma, $2=$ High school diploma/GED, $3=$ Some college or associate/trade degree, $4=$ Bachelor's degree, $5=$ Master's degree or higher, $6=$ Don't know, . = missing data.

Q21. Who encouraged you towards computing?

$\mathrm{q} 21 \mathrm{a}=$ No one

$\mathrm{q} 21 \mathrm{~b}=$ Friends

$\mathrm{q} 21 \mathrm{c}=$ Parent

$\mathrm{q} 21 \mathrm{~d}=$ Teacher

$\mathrm{q} 21 \mathrm{e}=$ Sibling

q21f $=$ Guidance counselor

$\mathrm{q} 21 \mathrm{~g}=$ Other family member

$\mathrm{q} 21 \mathrm{~h}=$ Other

$\mathrm{q} 21 \mathrm{txt}=$ Other/Text

VALUES: $1=$ marked, $0=$ not marked,.$=$ missing

Q22. How supportive is your home environment towards computing?

q22 = home being supportive

VALUES for all variables (5-point rating scale): $1=$ not at all; $5=$ Extremely supportive; missing $=$.

Q23. How many friends do you have in computing?

q23: Friend in computing

VALUES: 1 = 0, 2 = "1-2", 3 = "3-4", 4 = "5-6", 5 = "7-8", 6 = "9-10", $7=$ "more than 10"; missing $=$.

Q24. How many hours do you work outside the home each week?

q24. Work outside the home each week

Values: $1=0$, 2 = "1-5", $3=$ " $6-10 ", 4=$ " $11-15 ", 5=$ " $16-20 ", 6=$ "More than 20 ", missing $=$. 
Q25. Which of the following apply to your day-to-day life? Mark all that apply q25a: Caring for a child (e.g. sibling, your own child)

q25b: Caring for an adult (e.g. grandparent)

q25c: Personal recurring health problem (not including common illnesses like a cold or flu)

q25d: Other

q25e: None of the above

q25txt: Other/text

VALUES: $1=$ marked, $0=$ not marked,.$=$ missing 


\title{
Appendix B: Code
}

\section{Article 1 R code:}

\author{
library $(\operatorname{readxl})$ \\ library(car) \\ library(psych)
}

\#factor analysis for identity

\#Internal consistency

write.csv(flitpath17, file = "FlitpathMerged11_17.csv")

flitpathq9 <-

as.data.frame(cbind(flitpath17\$q9a,flitpath17\$q9b,flitpath17\$q9c,flitpath17\$q9d) )

alpha(flitpathq9)

\#Factor Analysis for identity

flitpathq9_10<-

as.data.frame(cbind(flitpath17\$q9a,flitpath17\$q9b,flitpath17\$q9c,flitpath17\$q9d,f litpath17\$q9f,flitpath17\$q9g,flitpath17\$q9h,flitpath17\$q9i,flitpath17\$q9j,flitpath 17\$q9k,flitpath17\$q91,flitpath17\$q9m,flitpath17\$q10a,flitpath17\$q10b,flitpath17 \$q10d,flitpath17\$q10e))

flitpathq9_10 <- na.omit(flitpathq9_10)

library(nFactors)

ev <- eigen(cor(flitpathq9_10)) \# get eigenvalues

ap <- parallel(subject=nrow(flitpathq9_10),var=ncol(flitpathq9_10), rep $=100$, cent $=.05)$

$\mathrm{nS}<-\mathrm{nScree}(\mathrm{x}=\mathrm{ev} \$$ values, aparallel=ap\$eigen\$qevpea $)$

plotnScree $(\mathrm{nS})$

$\operatorname{print}($ factanal(flitpathq9_10,4,rotation="promax"), digits=2, cutoff=0.3, sort=T)

\#Factor Analysis for identity

library(readr)

library(readxl)

library(car) 


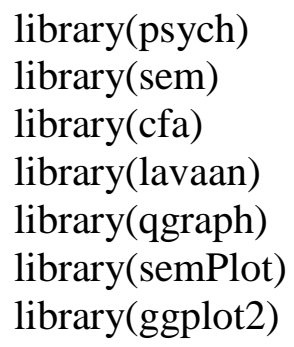

\#Creating the dataframe of questions to use in the CFA

model $2<-$ as.data.frame(cbind(flitpath $17 \$ q 7 \mathrm{cs}$

,flitpath17\$q9a,flitpath17\$q9c,flitpath17\$q9d

,flitpath17\$q9h,flitpath17\$q9i

,flitpath17\$q9j,flitpath17\$q91,flitpath17\$q9m

,flitpath17\$q10a,flitpath17\$q10b))

model2<- na.omit(model2)

\#Lavaan method for CFA (Measurement Model)

summary(model2)

describe(model2)

comID.model <- 'comper $=\sim$ V1

recognition $=\sim \mathrm{V} 2+\mathrm{V} 3+\mathrm{V} 4$

competence $=\sim \mathrm{V} 5+\mathrm{V} 6$

interest $=\sim \mathrm{V} 7+\mathrm{V} 8+\mathrm{V} 9$

belong $=\sim \mathrm{V} 10+\mathrm{V} 11$ ' 
\#fit <- cfa(comID.model, data=model2, se="none")

\#summary(fit, fit.measures=TRUE)

fit <- cfa(comID.model, data=model2, std.lv=TRUE)

summary(fit, fit.measures $=$ TRUE, standardized $=\mathrm{T}$ )

\#summary(fit, standardized=TRUE, fit.measures=TRUE, rsquare=TRUE)

fitMeasures(fit)

modindices(fit)

parameterEstimates(fit,standardized $=\mathrm{T}$ )

\#Item reliability which is the square of standardize factor loading lavInspect(fit, what="r2")

semPaths(fit, color $=$ list $($ lat $=\operatorname{rgb}(245,253,118$, maxColorValue $=255)$, $\operatorname{man}=\operatorname{rgb}(155,253,175, \max$ ColorValue $=255)), \operatorname{mar}=\mathrm{c}(10,5$,

$10,5))$

\footnotetext{
model $3<-$ 'comper $=\sim \mathrm{V} 1$

recognition $=\sim \mathrm{V} 2+\mathrm{V} 3+\mathrm{V} 4$

competence $=\sim \mathrm{V} 5+\mathrm{V} 6$

interest $=\sim \mathrm{V} 7+\mathrm{V} 8+\mathrm{V} 9$

belong $=\sim \mathrm{V} 10+\mathrm{V} 11$

\# regressions

comper $\sim$ interest+competence

interest $\sim$ recognition

interest $\sim$ competence

\#interest belong

competence $\sim$ belong

\#competence $\sim$ interest

\#recognition interest

\#belong interest

\#competence belong

\#recognition belong

\# factor covariances
} 
competence $\sim \sim$ recognition

recognition $\sim \sim$ belong

interest $\sim$ belong

\#competence $\sim$ interest

fit $1<-\operatorname{sem}(\operatorname{model} 3$, data=model2)

summary (fit1, standardized $=\mathrm{T}$ )

fitMeasures(fit1)

modindices(fit1)

parameterEstimates(fit1)

semPaths $($ fit 1, color $=\operatorname{list}(1 \mathrm{lat}=\operatorname{rgb}(245,253,118, \max$ ColorValue $=255)$,

$\operatorname{man}=\operatorname{rgb}(155,253,175$, maxColorValue $=255)), \operatorname{mar}=\mathrm{c}(10$,

5,10

Article 2 R code:

Male vs Female

Senior vs Freshman

\#multiple sem for all 4 groups - organized

\#open file manually "FlitpathMerged11_17 - Copy.rda"

library(readr)

library(readxl)

library(car)

library(psych)

library(sem)

library(cfa)

library(lavaan)

library(qgraph)

library(semPlot)

library(ggplot2)

\#Grouping variable (male VS female)

flitpath17\$q19a_r <-recode(flitpath17\$q19a, "1=2;else=0")

table(flitpath17\$q19a_r) 
flitpath17\$q19b_r <- recode(flitpath17\$q19b, "1=1;else=0")

table(flitpath17\$q19b_r)

flitpath17\$q19ab <- flitpath17\$q19a_r + flitpath17\$q19b_r

table(flitpath17\$q19ab)

flitpath17\$q19ab <- recode(flitpath17\$q19ab, "0=NA;2=2;1=1;3=NA") table(flitpath17\$q19ab)

\#Running the model

model $2<-$ as.data.frame(cbind(flitpath $17 \$ \mathrm{q} 7 \mathrm{cs}$

,flitpath17\$q9a,flitpath17\$q9c,flitpath17\$q9d

,flitpath17\$q9h,flitpath17\$q9i

,flitpath17\$q9j,flitpath17\$q91,flitpath17\$q9m

,flitpath17\$q10a,flitpath17\$q10b,flitpath17\$q19ab))

model $2<-$ na.omit(model2)

\#SEM

\#new5d

\#Interest and competence are directly connected

model $3<-$ 'comper $=\sim \mathrm{V} 1$

recognition $=\sim \mathrm{V} 2+\mathrm{V} 3+\mathrm{V} 4$

competence $=\sim \mathrm{V} 5+\mathrm{V} 6$

interest $=\sim \mathrm{V} 7+\mathrm{V} 8+\mathrm{V} 9$

belong $=\sim \mathrm{V} 10+\mathrm{V} 11$

\# regressions

comper interest+competence

interest $\sim$ recognition+competence

competence $\sim$ belong

\# factor covariances

competence $\sim \sim$ recognition

recognition $\sim \sim$ belong

interest $\sim$ belong

fit1 <- sem(model3, data=model2, group="V12")

summary(fit1, standardized=T)

fitMeasures(fit1)

modindices(fit1)

parameterEstimates(fit1) 


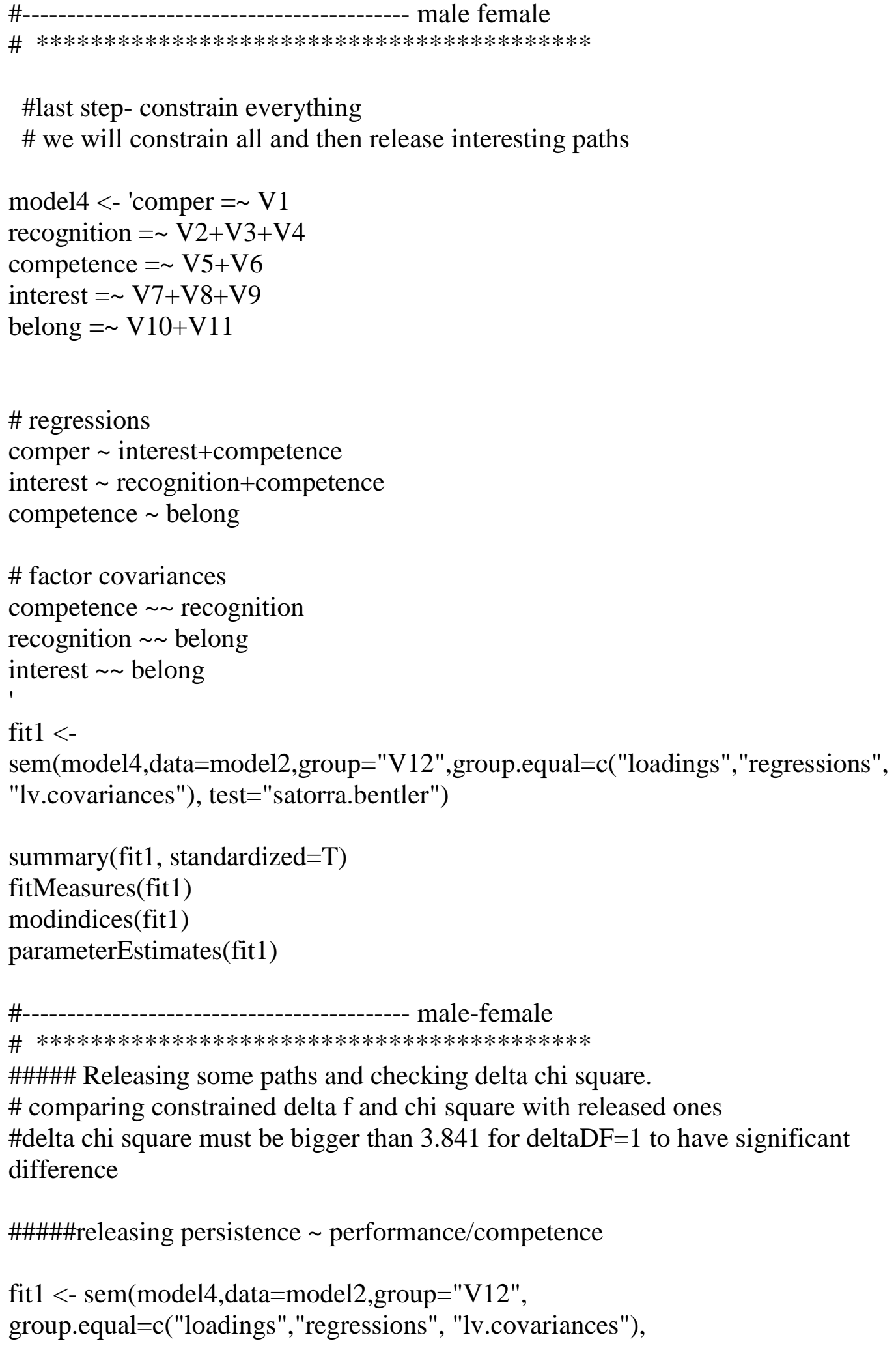

\#\#\#\#\# Releasing some paths and checking delta chi square.

\# comparing constrained delta $\mathrm{f}$ and chi square with released ones \#delta chi square must be bigger than 3.841 for deltaDF=1 to have significant difference

\#\#\#\#\#releasing persistence $~$ performance/competence

fit $1<-$ sem(model4,data=model2,group="V12", group.equal=c("loadings","regressions", "lv.covariances"), 
competence") )

$$
\text { test="satorra.bentler", group.partial=c("comper }
$$

summary(fit1, standardized $=\mathrm{T}$ )

fitMeasures(fit1)

modindices(fit1)

parameterEstimates(fit1)

\#\#\#\#\#\#\# release interest $\sim$ recognition

fit $1<-\operatorname{sem}($ model4, data=model2, group="V12",

group.equal=c("loadings","regressions", "lv.covariances"),

recognition") )

test="satorra.bentler", group.partial=c("interest

summary(fit1, standardized $=\mathrm{T}$ )

fitMeasures(fit1)

modindices(fit1)

parameterEstimates(fit1)

\#\#\#\#\#\#\#\#release both-

fit $1<-\operatorname{sem}($ model4,data=model2, group="V12",

group.equal=c("loadings","regressions", "lv.covariances"),

test="satorra.bentler", group.partial=c("comper

competence", "interest $~$ recognition") )

summary(fit1, standardized $=\mathrm{T}$ )

fitMeasures(fit1)

modindices(fit1)

parameterEstimates(fit1)

\#\#\#\#\#\#\# NEW - release comper interest

fit $1<-$ sem(model4,data=model2,group="V12",

group.equal=c("loadings","regressions", "lv.covariances"), test="satorra.bentler", group.partial=c("comper $\sim$ interest") $)$

summary(fit1, standardized $=\mathrm{T}$ )

fitMeasures(fit1)

modindices(fit1)

parameterEstimates(fit1)

\#\#\#\#\#\#\# NEW - release both comper $\sim$ interest va comper $\sim$ competence 
fit $1<-$ sem(model4, data=model2, group="V12", group.equal=c("loadings","regressions", "lv.covariances"), test="satorra.bentler", group.partial=c("comper interest", "comper competence") )

summary(fit1, standardized $=\mathrm{T}$ )

fitMeasures(fit1)

modindices(fit1)

parameterEstimates(fit1)

\#\#\#\#\#\#\# NEW - release interest recognition

fit $1<-$ sem(model4,data=model2,group="V12",

group.equal=c("loadings","regressions", "lv.covariances"), test="satorra.bentler", group.partial=c("interest $\sim$ recognition") )

summary(fit1, standardized $=\mathrm{T}$ )

fitMeasures(fit1)

modindices(fit1)

parameterEstimates(fit1)

\#\#\#\#\#\#\# NEW - release competence $\sim$ belong

fit $1<-\operatorname{sem}($ model4,data=model2, group="V12",

group.equal=c("loadings","regressions", "lv.covariances"), test="satorra.bentler", group.partial=c("competence $\sim$ belong") )

summary(fit1, standardized=T)

fitMeasures(fit1)

modindices(fit1)

parameterEstimates(fit1)

\#\#\#\#\#\#\# NEW - release interest $~$ recognition

fit $1<-\operatorname{sem}($ model4, data=model2, group="V12",

group.equal=c("loadings","regressions", "lv.covariances"),

test="satorra.bentler", group.partial=c("interest $\sim$ recognition , competence

belong") )

summary(fit1, standardized $=\mathrm{T})$

fitMeasures(fit1)

modindices(fit1)

parameterEstimates(fit1) 
$\# * * * * * * * * * * * * * * * *$ (freshmen 6 vs senior 7)

\# $* * * * * * * * * * * * * * * *$

\#Grouping variable -multiplesem(freshmen 6 vs senior 7)

table(flitpath17\$q3)

flitpath17\$q3_r <-recode(flitpath17\$q3, "1=6;2=NA;3=NA;4=7;5=7;else=NA") table(flitpath17\$q3_r)

\#Running the model

model $2<-$ as.data.frame(cbind(flitpath $17 \$ \mathrm{q} 7 \mathrm{cs}$

,flitpath17\$q9a,flitpath17\$q9c,flitpath17\$q9d

,flitpath17\$q9h,flitpath17\$q9i

,flitpath17\$q9j,flitpath17\$q91,flitpath17\$q9m

model $2<-$ na.omit $(\operatorname{model} 2)$

\#SEM

\#new5d

\#Interest and competence are directly connected

model $3<-$ 'comper $=\sim \mathrm{V} 1$

recognition $=\sim \mathrm{V} 2+\mathrm{V} 3+\mathrm{V} 4$

competence $=\sim \mathrm{V} 5+\mathrm{V} 6$

interest $=\sim \mathrm{V} 7+\mathrm{V} 8+\mathrm{V} 9$

belong $=\sim \mathrm{V} 10+\mathrm{V} 11$

\# regressions

comper $\sim$ interest+competence

interest $\sim$ recognition+competence

competence $\sim$ belong

\# factor covariances

competence $\sim \sim$ recognition

recognition belong

interest $\sim$ belong

fit1 <- sem(model3,data=model2,group="V12")

summary(fit1, standardized $=\mathrm{T}$ ) 
fitMeasures(fit1)

modindices(fit1)

parameterEstimates(fit1)

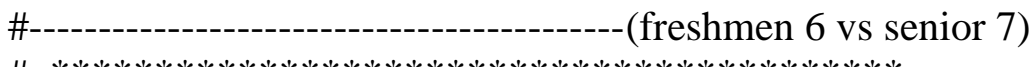

\# $* * * * * * * * * * * * * * * * * * * * * * * * * * * * * * * * * * * * * * * * *$

\#last step- constrain everything

\#last step- constrain everything

\#last step- constrain everything

\# we will constarin all and then release interesting paths

model $4<-$ 'comper $=\sim \mathrm{V} 1$

recognition $=\sim \mathrm{V} 2+\mathrm{V} 3+\mathrm{V} 4$

competence $=\sim \mathrm{V} 5+\mathrm{V} 6$

interest $=\sim \mathrm{V} 7+\mathrm{V} 8+\mathrm{V} 9$

belong $=\sim \mathrm{V} 10+\mathrm{V} 11$

\# regressions

comper interest+competence

interest $\sim$ recognition+competence

competence $\sim$ belong

\# factor covariances

competence $\sim \sim$ recognition

recognition $\sim$ belong

interest $\sim$ belong

model4 \#for test

\#fit1 <- sem(model4,data=model2,group="V12", group.equal=c("loadings"))

\#fit1 <- sem(model4,data=model2,group="V12",

group.equal=c("loadings", "'regressions"))

\#fit1 <- sem(model4,data=model2,group="V12",

group.equal=c("loadings","regressions", "lv.covariances"))

fit $1<-$

sem(model4,data=model2,group="V12",group.equal=c("loadings","regressions",

"lv.covariances"), test="satorra.bentler")

summary(fit1, standardized=T) 
fitMeasures(fit1)

modindices(fit1)

parameterEstimates(fit1)

\# $\#$ \#*****************************************

\#\#\#\# Releasing some paths and checking delta chi square.

\#delta chi square must be bigger than 3.841 for deltaDF=1 to have significant difference

\#\#\#\#\#releasing persistence $~$ performance/competence

fit $1<-$ sem(model4,data=model2, group="V12", group.equal=c("loadings","regressions", "lv.covariances"), test="satorra.bentler", group.partial=c("comper competence") )

summary(fit 1, standardized $=\mathrm{T}$ )

fitMeasures(fit1)

modindices(fit1)

parameterEstimates(fit1)

\#\#\#\#\#\#\# release interest $\sim$ recognition

fit $1<-\operatorname{sem}($ model4,data=model2, group="V12",

group.equal=c("loadings","regressions", "lv.covariances"), test="satorra.bentler", group.partial=c("interest $\sim$ recognition") )

summary(fit1, standardized $=\mathrm{T})$

fitMeasures(fit1)

modindices(fit1)

parameterEstimates(fit1)

\#\#\#\#\#\#\#\#release both- bigger have impact at the same time?

fit1 <- sem(mode14,data=model2, group="V12", group.equal=c("loadings","regressions", "lv.covariances"), test="satorra.bentler", group.partial=c("comper competence", "interest recognition") )

summary (fit 1 , standardized $=\mathrm{T})$

fitMeasures(fit1)

modindices(fit1)

parameterEstimates(fit1) 
\#\#\#\#\#\#\# NEW - release comper $\sim$ interest

fit $1<-$ sem(model4,data=model2,group="V12",

group.equal=c("loadings","regressions", "lv.covariances"), test="satorra.bentler", group.partial=c("comper $\sim$ interest") )

summary(fit1, standardized $=\mathrm{T}$ )

fitMeasures(fit1)

modindices(fit1)

parameterEstimates(fit1)

\#\#\#\#\#\#\# NEW - release both comper interest va comper $\sim$ competence

fit $1<-\operatorname{sem}($ model4,data=model2, group="V12",

group.equal=c("loadings","regressions", "lv.covariances"), test="satorra.bentler", group.partial=c("comper interest", "comper competence") )

summary(fit1, standardized $=\mathrm{T}$ )

fitMeasures(fit1)

modindices(fit1)

parameterEstimates(fit1)

\#\#\#\#\#\#\# NEW - release interest $~$ recognition

fit1 <- sem(model4,data=model2, group="V12",

group.equal=c("loadings","regressions", "lv.covariances"),

test="satorra.bentler", group.partial=c("interest $\sim$ recognition") )

summary(fit1, standardized $=\mathrm{T}$ )

fitMeasures(fit1)

modindices(fit1)

parameterEstimates(fit1)

\#\#\#\#\#\#\# NEW - release competence $\sim$ belong

fit $1<-\operatorname{sem}($ model4,data=model2,group="V12",

group.equal=c("loadings","regressions", "lv.covariances"), test="satorra.bentler", group.partial=c("competence $\sim$ belong") )

summary(fit1, standardized $=\mathrm{T}$ )

fitMeasures(fit1)

modindices(fit1)

parameterEstimates(fit1) 
\#\#\#\#\#\#\# NEW - release interest $~$ recognition

fit1 <- sem(model4,data=model2, group="V12",

group.equal=c("loadings","regressions", "lv.covariances"),

test="satorra.bentler", group.partial=c("interest $\sim$ recognition , competence

belong") )

summary(fit1, standardized $=\mathrm{T})$

fitMeasures(fit1)

modindices(fit1)

parameterEstimates(fit1)

\section{Article 3 R code}

Time series

\#import

library(readr)

library(readxl)

FlitpathMerged11_17_cleaned_ts <-read.csv("FlitpathMerged11_17-cleaned ts.csv")

FLITPATHMerged_1_2019_cleaned_ts <-read.csv("FLITPATHMerged-1-2019

- cleaned ts.csv")

\#merge vertically 2017-2019

flitpath_ts <- merge(FlitpathMerged11_17_cleaned_ts,

FLITPATHMerged_1_2019_cleaned_ts,by="q1")

\#summary(flitpath_ts\$q3.y)

\#describe(flitpath_ts\$q3.y)

\#summary(flitpath_ts)

\#write.csv(flitpath_ts, "flitpath_ts 150 to check.csv")

\#table(flitpath_ts1\$q3.y)

\#flitpath_ts <-read_csv("flitpath_ts.csv") 
\#for time series

\#Factor Analysis for identity with q7 only CS (career), without q8 (persistence liklihood) with some of the $9(\mathrm{acd} / \mathrm{hi} / \mathrm{jklm})$ AND some of the 10(ab) (this fit cfc worked)

library(readr)

library $(\operatorname{readxl})$

library(car)

library(psych)

library(sem)

library(cfa)

library(lavaan)

library(qgraph)

library(semPlot)

library(ggplot2)

\# flitpath_ts\$q7cs -old removed

flitpathq <- as.data.frame(cbind(

flitpath_ts\$q9a.x,flitpath_ts\$q9c.x,flitpath_ts\$q9d.x

,flitpath_ts\$q9h.x,flitpath_ts\$q9i.x

,flitpath_ts\$q9j.x,flitpath_ts\$q91.x,flitpath_ts\$q9m.x

,flitpath_ts\$q10a.x,flitpath_ts\$q10b.x

,flitpath_ts\$q7cs.y

,flitpath_ts\$q9a.y,flitpath_ts\$q9c.y,flitpath_ts\$q9d.y

,flitpath_ts\$q9h.y,flitpath_ts\$q9i.y

,flitpath_ts\$q9j.y,flitpath_ts\$q91.y,flitpath_ts\$q9m.y

,flitpath_ts\$q10a.y,flitpath_ts\$q10b.y))

flitpathq <- na.omit(flitpathq)

\#write.csv(flitpathq, "flitpathq 150 to check.csv")

library(nFactors)

ev <- eigen(cor(flitpathq)) \# get eigenvalues

ap <- parallel(subject=nrow(flitpathq), var=ncol(flitpathq),

rep $=100$, cent $=.05)$

$\mathrm{nS}<-\mathrm{nScree}(\mathrm{x}=\mathrm{ev} \$$ values, aparallel=ap\$eigen\$qevpea $)$

plotnScree $(\mathrm{nS})$

$\operatorname{print}($ factanal(flitpathq, 8 ,rotation="promax"), digits=2, sort=T) 
\#Creating the dataframe of questions to use in the CFA

\# flitpath_ts\$q7cs -old removed

model $2<-$ as.data.frame(cbind(

flitpath_ts\$q9a.x,flitpath_ts\$q9c.x,flitpath_ts\$q9d.x

,flitpath_ts\$q9h.x,flitpath_ts\$q9i.x

,flitpath_ts\$q9j.x,flitpath_ts\$q91.x,flitpath_ts\$q9m.x

,flitpath_ts\$q10a.x,flitpath_ts\$q10b.x

,flitpath_ts\$q7cs.y

,flitpath_ts\$q9a.y,flitpath_ts\$q9c.y,flitpath_ts\$q9d.y

,flitpath_ts\$q9h.y,flitpath_ts\$q9i.y

,flitpath_ts\$q9j.y,flitpath_ts\$q91.y,flitpath_ts\$q9m.y

,flitpath_ts\$q10a.y,flitpath_ts\$q10b.y))

model2<- na.omit(model2)

\#Lavaan method for CFA (Measurement Model)

summary(model2)

describe(model2)

$\# /$ check

comID.model <- '

\#T1 = recognition+competence+interest + belong

$\#$ T2 = recognitionnew +competencenew+interestnew+belongnew

recognition $=\sim \mathrm{V} 1+\mathrm{V} 2+\mathrm{V} 3$

competence $=\sim \mathrm{V} 4+\mathrm{V} 5$

interest $=\sim \mathrm{V} 6+\mathrm{V} 7+\mathrm{V} 8$

belong $=\sim \mathrm{V} 9+\mathrm{V} 10$

compernew $=\sim \mathrm{V} 11$

recognitionnew $=\sim \mathrm{V} 12+\mathrm{V} 13+\mathrm{V} 14$

competencenew $=\sim \mathrm{V} 15+\mathrm{V} 16$

interestnew $=\sim \mathrm{V} 17+\mathrm{V} 18+\mathrm{V} 19$

belongnew $=\sim \mathrm{V} 20+\mathrm{V} 21$

\#T1 T2

\#no impact

\#competence $\sim$ competencenew

\#recognition recognitionnew

\#interest interestnew 


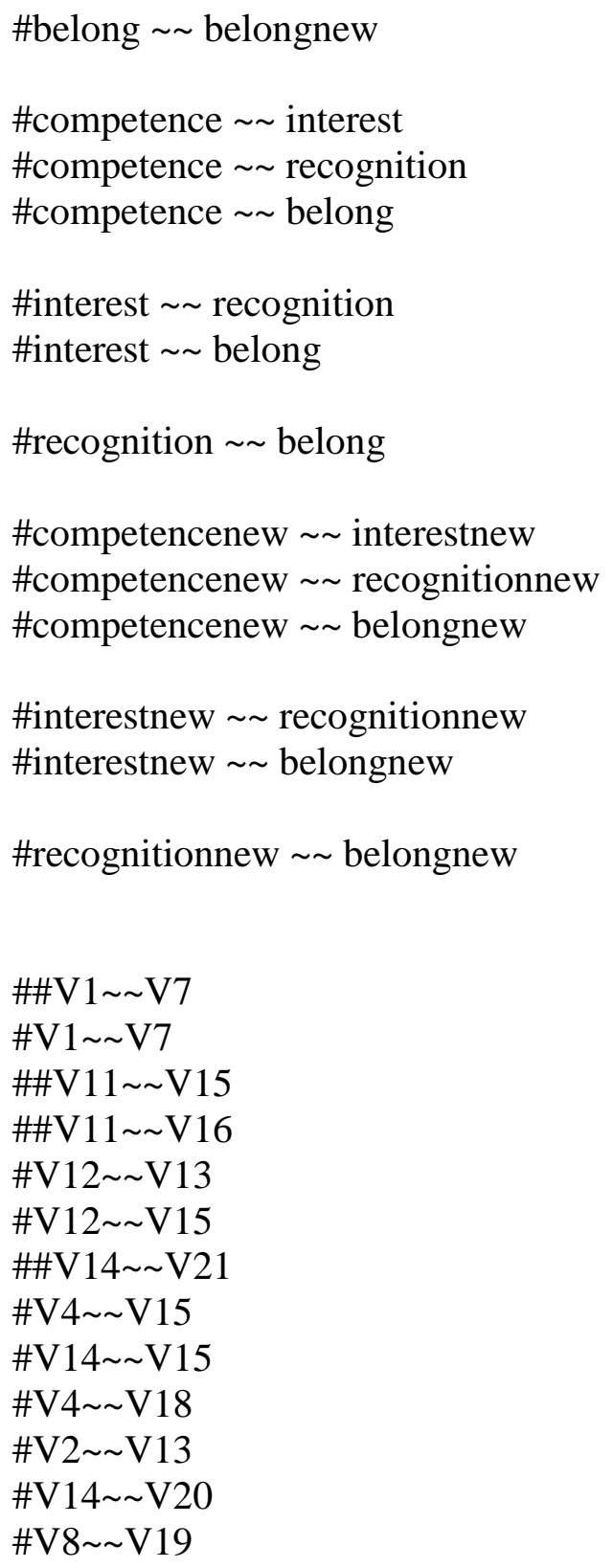




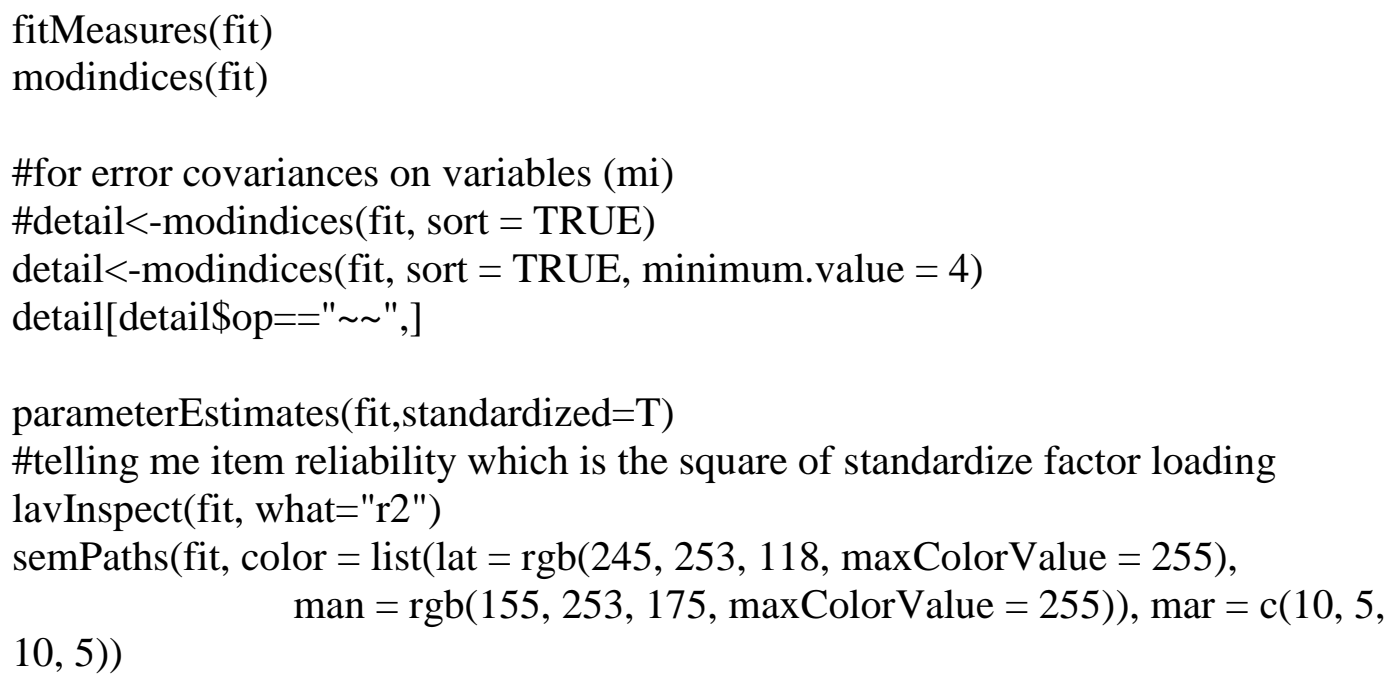

fit $1<-\operatorname{sem}($ model3, data=model2)

summary(fit1, standardized=T)

fitMeasures(fit1) 
modindices(fit1)

detail $<$-modindices(fit, sort $=$ TRUE, minimum.value $=4$ )

detail[detail\$op==" ",]

parameterEstimates(fit1)

semPaths(fit 1, color $=\operatorname{list}(\operatorname{lat}=\operatorname{rgb}(245,253,118$, maxColorValue $=255)$,

$\operatorname{man}=\operatorname{rgb}(155,253,175$, maxColorValue $=255)), \operatorname{mar}=\mathrm{c}(10$,

5,10

$\# * * * * * * * * * *$

\#sem layer to layer

-Final

\# 2 (new layer+old layer)

\#***********

model $3<-$ '

recognition $=\sim \mathrm{V} 1+\mathrm{V} 2+\mathrm{V} 3$

competence $=\sim \mathrm{V} 4+\mathrm{V} 5$

interest $=\sim \mathrm{V} 6+\mathrm{V} 7+\mathrm{V} 8$

belong $=\sim \mathrm{V} 9+\mathrm{V} 10$

compernew $=\sim \mathrm{V} 11$

recognitionnew $=\sim \mathrm{V} 12+\mathrm{V} 13+\mathrm{V} 14$

competencenew $=\sim \mathrm{V} 15+\mathrm{V} 16$

interestnew $=\sim \mathrm{V} 17+\mathrm{V} 18+\mathrm{V} 19$

belongnew $=\sim \mathrm{V} 20+\mathrm{V} 21$

\# regressions

compernew $\sim$ interestnew

interestnew $\sim$ competencenew

interestnew $\sim$ interest

competencenew $\sim$ competence

recognitionnew $\sim$ recognition

belongnew $\sim$ belong

interestnew $\sim$ competence

\#competencenew $\sim$ competence

\#recognitionnew competence

belongnew $\sim$ interest

\# factor covariances

competencenew recognitionnew 
competencenew belongnew

recognitionnew $\sim \sim$ belongnew

fit $1<-\operatorname{sem}(\operatorname{model} 3$, data=model 2$)$

summary(fit1, standardized=T)

fitMeasures(fit1)

modindices(fit1)

detail<-modindices(fit, sort $=$ TRUE, minimum.value $=4$ )

detail[detail\$op==" ",]

parameterEstimates(fit1)

semPaths $($ fit 1, color $=\operatorname{list}(1 a t=\operatorname{rgb}(245,253,118$, maxColorValue $=255)$,

$\operatorname{man}=\operatorname{rgb}(155,253,175$, maxColorValue $=255))$, $\operatorname{mar}=\mathrm{c}(10$,

$5,10,5))$

\#qgraph.lavaan(fit1)

\#ggplot2(fit1)

\#http://davidakenny.net/cm/fit.htm

$\# * * * * * * * * * *$

Time series result:

\begin{tabular}{|c|c|c|c|c|c|c|c|c|}
\hline 168 & compernew & $=\sim$ & v7 & 1.294 & 0.041 & 0.041 & 0.054 & \\
\hline $16 \varsigma$ & compernew & $=\sim$ & V8 & 0.358 & 0.029 & 29 & & \\
\hline 17 & compernew & $=\sim$ & v9 & & 0.100 & 100 & U & \\
\hline 17. & compernew & $=\sim$ & v10 & & -0 & -0 . & & \\
\hline 7 & compernew & $=\sim$ & V12 & & 0.103 & 0. & & \\
\hline 17 & compernew & $=\sim$ & v13 & & 0.0 & & & \\
\hline 17 & compernew & $=\sim$ & V14 & & -0 & -0 . & -0 . & \\
\hline 17 & com & $=\sim$ & V15 & & 0 . & & & \\
\hline & comp & $=\sim$ & V16 & & -0 . & -0 . & -0 & \\
\hline 7 & compernew & $=\sim$ & V17 & & 0.8 & 0 . & & \\
\hline & compernew & $=\sim$ & V18 & & -0 . & -0 . & & \\
\hline & comp & $=\sim$ & V19 & & -0. & -0 . & -0 & \\
\hline & com & $=\sim$ & V20 & & & & & \\
\hline & comp & $=\sim$ & V21 & & -0 . & -0 . & -0 & -0 \\
\hline & recognitionnew & $=\sim$ & v1 & & 0.0 & 0. & & \\
\hline & recognitionnew & $=\sim$ & V2 & & 0.053 & $0 .(1-2)-1$ & & \\
\hline & recognitionnew & $=\sim$ & v3 & & -0 . & -0 . & -0 & \\
\hline & recognitionnew & $=\sim$ & V4 & & 0. & & & \\
\hline & recognit & $=\sim$ & V5 & & $-0 .(2-x)$ & -0 . & -0 & \\
\hline & recognitio & $=\sim$ & v6 & & & & & \\
\hline & recognit & $=\sim$ & v7 & & -0.0 & -0.0 & -0 . & \\
\hline & & & V8 & & 0.024 & 0.024 & $U$. & \\
\hline
\end{tabular}




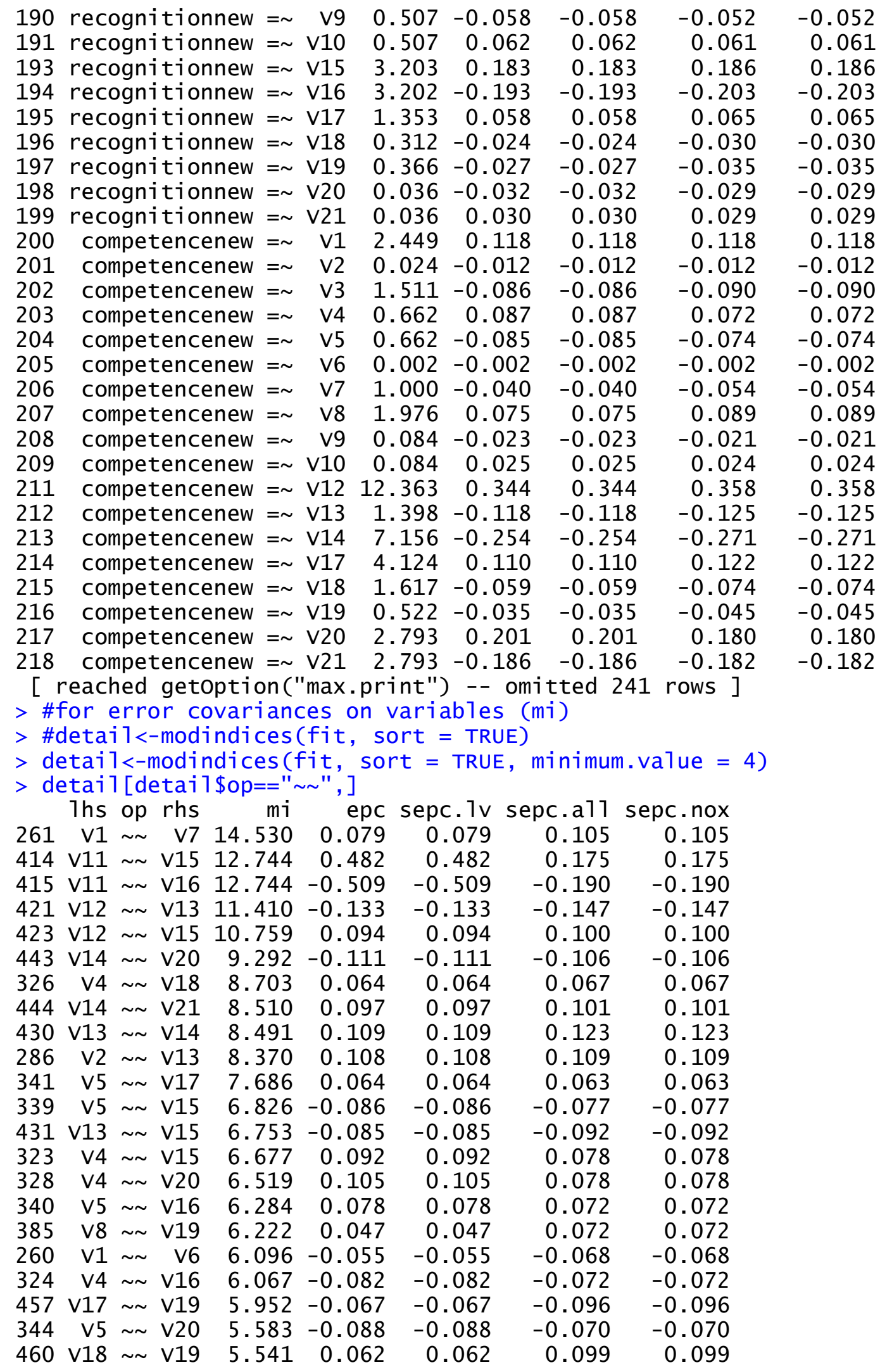




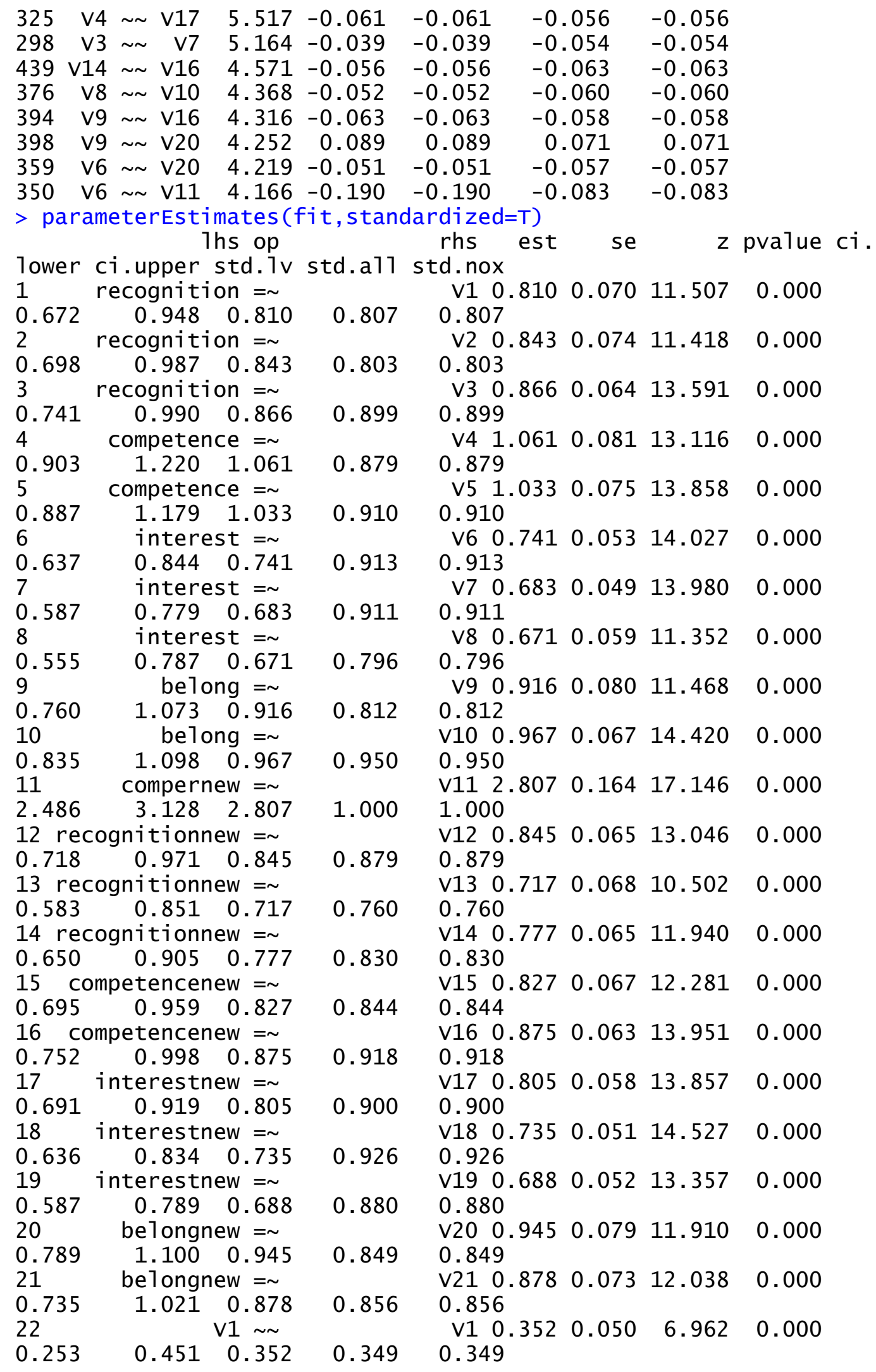




\begin{tabular}{|c|c|c|c|c|c|c|}
\hline 3 & V2 $\sim \sim$ & & v2 0.392 & 0.056 & 7.011 & .000 \\
\hline.$^{282}$ & $\begin{array}{ll}0.501 & 0.392 \\
& \\
& 0 . \sim \sim \sim\end{array}$ & 0.356 & $\begin{array}{l}0.356 \\
\mathrm{~V} 30\end{array}$ & 0.036 & $\begin{array}{ll}4 & 924\end{array}$ & 0.000 \\
\hline 107 & $0.249 \quad 0.178$ & .192 & 0.192 & & & \\
\hline & V4 & & 33 & 0.060 & 5.586 & 0.000 \\
\hline 16 & $0.450 \quad 0.333$ & .228 & 0.228 & & & \\
\hline & V5 & & v5 0.220 & 0.050 & 4.411 & 0.000 \\
\hline & $0.318 \quad 0.220$ & .171 & 0.171 & & & \\
\hline & V6 & & V6 0.109 & 0.024 & 4.621 & 0.000 \\
\hline 63 & $0.155 \quad 0.109$ & .166 & 0.166 & & & \\
\hline & V7 & & V7 0.095 & 0.020 & 4.698 & 0.000 \\
\hline 5 & $0.135 \quad 0.095$ & .169 & 0.169 & & & \\
\hline & V8 & & V8 0. & 0.036 & 7.336 & 0.000 \\
\hline & $0.331 \quad 0.261$ & 0.367 & 0.367 & & & \\
\hline & V9 $\sim$ & & 35 & 0.067 & 6.494 & 0.000 \\
\hline 4 & $0.566 \quad 0.435$ & .341 & 0.3 & & & \\
\hline & V10 & & V10 0.100 & 0.050 & 2.003 & 0.045 \\
\hline 02 & $0.198 \quad 0.100$ & .097 & 0.097 & & & \\
\hline & V11 & & 0.000 & 0.000 & NA & NA \\
\hline 00 & $0.000 \quad 0.000$ & 0.000 & & & & \\
\hline & V12 $\sim \sim$ & & 09 & 40 & .279 & .000 \\
\hline & $\mathrm{V} 13 \sim \sim$ & & V13 0.375 & 0.052 & 7.282 & 0.000 \\
\hline 74 & $0.476 \quad 0.375$ & .422 & 0.422 & & & \\
\hline & V14 & & 0.273 & 0.042 & 6.438 & 0.000 \\
\hline 90 & $0.356 \quad 0.273$ & 0.311 & & & & \\
\hline & V15 & & 0.277 & 0.044 & .308 & 0.000 \\
\hline 91 & $0.363 \quad 0.277$ & .288 & & & & \\
\hline & V16 & & V16 0.142 & 0.037 & 3.824 & 0.000 \\
\hline 9 & $0.215 \quad 0.142$ & 0.157 & & & & \\
\hline & V17 & & 0.152 & 0.026 & 5.844 & 0.000 \\
\hline 101 & $0.203 \quad 0.152$ & .190 & & & & \\
\hline & V18 & & 0.090 & 019 & .807 & 0.000 \\
\hline & $0.127 \quad 0.090$ & .143 & & & & \\
\hline & V19 & & 0.138 & 0.021 & 6.423 & 0.000 \\
\hline 96 & $0.180 \quad 0.138$ & 0.225 & & & & \\
\hline & $\mathrm{V} 20 \sim \sim$ & & 0.345 & 0.070 & 4.947 & 0.000 \\
\hline 08 & $0.482 \quad 0.345$ & 79 & & & & \\
\hline 42 & V21 & & 0.281 & 0.059 & 4.754 & 0.000 \\
\hline 65 & $7 \quad 0.281$ & & 0 . & & & \\
\hline 4 & recognition & ecogni & 1.000 & 0.000 & NA & NA \\
\hline & $0 \quad 1.000$ & 10 & & & & \\
\hline & competence $\sim \sim$ & compet & tence 1.000 & 0.000 & NA & NA \\
\hline & 1.000 & & 1.000 & & & \\
\hline & interest & inte & erest 1.000 & 0.000 & NA & NA \\
\hline & $1.000 \quad 1.000$ & 1.000 & 1.000 & & & \\
\hline 1 & belong & & elong 1.000 & 0.000 & NA & NA \\
\hline & $1.000 \quad 1.000$ & 1000 & & & & \\
\hline 47 & compernew & compe & ernew 1.000 & 0.000 & NA & NA \\
\hline & $00 \quad 1.000$ & 1.0 & 1.000 & & & \\
\hline 48 & onnew & & onnew 1.000 & 0.000 & NA & NA \\
\hline & 01.000 & & & & & \\
\hline 49 & enew & & cenew 1.00 & 000 & NA & NA \\
\hline 00 & 1 & & & & & \\
\hline
\end{tabular}




\begin{tabular}{|c|c|c|c|c|c|c|}
\hline 50 & nterestnew & interes & stnew 1.000 & 0.000 & NA & \\
\hline 1.000 & $1.000 \quad 1.000$ & 1.000 & 1.000 & & & \\
\hline & belongnew & belor & ngnew 1.000 & 0.000 & NA & \\
\hline 00 & 1.000 & 1.000 & 1.000 & & & \\
\hline & recognition & compet & tence 0.721 & 0.051 & 14.142 & 0.0 \\
\hline & 0.721 & 0.721 & 0.721 & & & \\
\hline & tion $\sim$ & inte & erest 0.459 & 0.074 & 6.191 & 0.0 \\
\hline & $4 \quad 0.459$ & 0.459 & 0.459 & & & \\
\hline & ition & $b \in$ & elong 0.778 & 0.045 & 17.448 & .0 \\
\hline 1 & 50.778 & 0.778 & 0.778 & & & \\
\hline 2 & $\begin{array}{l}\text { ition } \sim \sim \\
45 \\
0.178\end{array}$ & $\begin{array}{l}\text { compe } \\
0.178\end{array}$ & $\begin{array}{c}\text { ernew } 0.178 \\
0.178\end{array}$ & 0.085 & 2.099 & 0.036 \\
\hline & tion $\sim 1$ & ecognitic & onnew 0.631 & 061 & 10.273 & .00 \\
\hline & 0.631 & 1 & 31 & & & \\
\hline & tion & competenc & cenew 0.549 & .069 & 7.986 & .00 \\
\hline 14 & 0.549 & .549 & 0.549 & & & \\
\hline 191 & Eion $\sim \sim$ & interes & stnew 0.349 & 0.081 & 4.322 & .0 \\
\hline & ion $\sim$ & belo & 0.493 & 0.076 & 6.486 & .000 \\
\hline 4 & 0.493 & 0.493 & 93 & & & \\
\hline & ence $\sim$ & inte & erest 0.577 & .064 & 9.014 & .0 \\
\hline & 0.577 & 0.577 & 0.577 & & & \\
\hline & $\begin{array}{l}\text { ence } \sim \sim \\
4 \quad 0.676\end{array}$ & $\epsilon$ & elong 0.676 & 0.055 & 12.199 & .00 \\
\hline & ence $\sim$ & compe & ernew 0.215 & 084 & 2.578 & .010 \\
\hline 52 & 0.215 & 0.215 & 15 & & & \\
\hline & ence $\sim \sim^{\prime}$ & ecognitic & onnew 0.445 & 077 & 5.759 & 0.0 \\
\hline & ence $\sim$ & competenc & 0.714 & 052 & 13 & $U$ \\
\hline & 0.714 & 714 & & & & \\
\hline & Eence & interes & stnew 0.343 & .081 & .23 & .000 \\
\hline & 0.343 & & & & & \\
\hline & 1ce $\sim \sim$ & belor & 0.467 & 0.078 & 6.004 & .0 \\
\hline & 0.467 & 0.467 & & & & \\
\hline & erest & & 0.377 & .078 & 4.809 & .06 \\
\hline & 0.377 & 0.377 & 77 & & & \\
\hline & rest $\sim \sim$ & compe & 0.30 & 78 & 867 & \\
\hline & 0.303 & 0.3 & & & & \\
\hline & rest $\sim \sim 1$ & & onn & .084 & 3.807 & .0 \\
\hline & 0.318 & & & & & \\
\hline & interest & competenc & cenew 0.403 & 0.078 & 5.164 & ve \\
\hline & 0.403 & 0.403 & 03 & & & \\
\hline & est $\sim$ & int & stnew 0.532 & 066 & 8.082 & 0.0 \\
\hline & L $\quad 0.532$ & & & & & \\
\hline & rest $\sim \sim$ & b & ngnew 0 . & .080 & 5.060 & 0.000 \\
\hline & 0.406 & 0.40 & & & & \\
\hline & belong & compe & 0.149 & 0.084 & 1.765 & 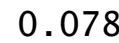 \\
\hline & 0.149 & 0. & 0.149 & & & \\
\hline 74 & ong & ecogr & onne & 0.074 & 6.507 & 0.0 \\
\hline & 0.480 & & & & & \\
\hline & belong & compete & cenew 0 & 0.073 & 6.538 & .000 \\
\hline & 0.479 & & & & & \\
\hline & ng & in & stne & 0.084 & 2.913 & 0.04 > \\
\hline & .41 & & & & & \\
\hline
\end{tabular}




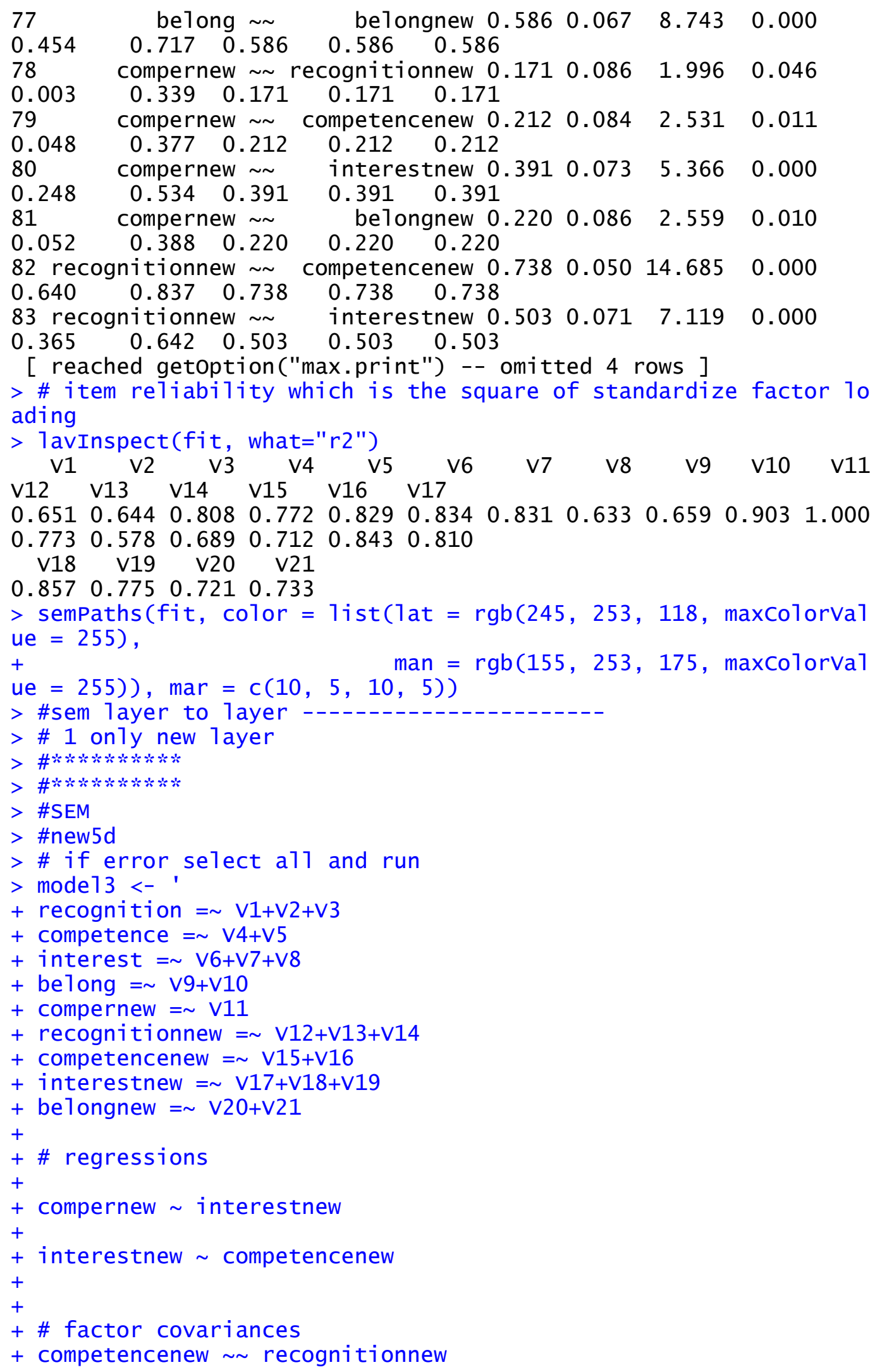


+ competencenew belongnew

+ recognitionnew belongnew

$+$

$>$ fit1 <- sem(mode13, data=mode12)

$>$ summary (fit1, standardized=T)

lavaan (0.5-23.1097) converged normally after 91 iterations

Number of observations

147

Estimator

Minimum Function Test Statistic

Degrees of freedom

P-value (Chi-square)

312.268

167

0.000

Parameter Estimates:

Information

Expected

Standard Errors

standard

Latent Variables:

std.a11

Estimate std.Err z-value $P(>|z|) \quad$ Std.7v recognition = v1

0.807

$\mathrm{V} 2$

0.803

V3

0.899

1.000

0.810

1.041

0.096

10.848

0.000

0.843

1.069

0.086

12.496

0.000

0.866

competence $=\sim$

v4

0.887

1.000

0.954

0.066

14.521

0.000

1.072

0.901

interest $=\sim$

0.907

v6

0.918

V8

1.000

0.936

0.059

15.857

0.796

0.913

0.072

12.601

0.000

0.688

belong =

0.812

1.000

0.950

V10

compernew = v11

1.054

0.086

12.316

0.000

0.917

.000

1.000

$0.086-12.316$

0.966

recognitionnew $=\sim$ v12

0.882

V13

0.757

1.000

0.843

$0.077 \quad 10.913$

0.000

2.807

0.847

0.714 


\begin{tabular}{|c|c|c|c|c|c|}
\hline $\begin{array}{l}\mathrm{V} 14 \\
0.829^{-14}\end{array}$ & 0.916 & 0.073 & 12.550 & 0.000 & 0.776 \\
\hline $\begin{array}{l}\text { competencenew = } \\
\text { V15 } \\
0.851\end{array}$ & 1.000 & & & & 0.835 \\
\hline $\begin{array}{l}\vee 16 \\
0.909\end{array}$ & 1.037 & 0.076 & 13.555 & 0.000 & 0.866 \\
\hline $\begin{array}{l}\text { interestnew = } \\
\text { V17 } \\
0.895\end{array}$ & 1.000 & & & & 0.801 \\
\hline $\begin{array}{l}\mathrm{V} 18 \\
0.933\end{array}$ & 0.925 & 0.054 & 17.260 & 0.000 & 0.741 \\
\hline $\begin{array}{l}\mathrm{v} 19 \\
0.877 \\
\text { belonanew }=\sim\end{array}$ & 0.856 & 0.056 & 15.384 & 0.000 & 0.686 \\
\hline $\begin{array}{l}\text { V20 } \\
0.846\end{array}$ & 1.000 & & & & 0.940 \\
\hline $0.860^{V 21}$ & 0.938 & 0.085 & 10.996 & 0.000 & 0.882 \\
\hline egressio & & & & & \\
\hline $\begin{array}{l}\text { Std.a11 } \\
\quad \text { compernew }\end{array}$ & Estimate & std.Err & z-value & $P(>|z|)$ & std. 1v \\
\hline 0.390 & 1.367 & 0.282 & 4.850 & 0.000 & 0.390 \\
\hline $\begin{array}{l}\text { interestnew } \\
\text { competencenew } \\
0.596\end{array}$ & 0.572 & 0.080 & 7.119 & 0.000 & 0.596 \\
\hline ovariances: & & & & & \\
\hline std.a11 & Estimate & Std.Err & z-value & $P(>|z|)$ & std. $7 v$ \\
\hline $\begin{array}{l}\text { recognitionnew } \\
\text { competencenew } \\
0.751\end{array}$ & .531 & 0.085 & 6.221 & 0.000 & 0.751 \\
\hline $\begin{array}{l}\text { competencenew } \\
\text { belongnew } \\
0.638\end{array}$ & .501 & 0.092 & .439 & 0.000 & 0.638 \\
\hline $\begin{array}{l}\text { recognitionnew } \\
\text { be1ongnew } \\
0.745\end{array}$ & 0.593 & 0.097 & 6.088 & 0.000 & 0.745 \\
\hline $\begin{array}{l}\text { recognition } \sim ~ \\
\text { competence } \\
0.724\end{array}$ & 0.629 & 0.105 & .985 & 0.000 & 0.724 \\
\hline 0.458 & 0.273 & 0.062 & 4.426 & 0.000 & 0.458 \\
\hline $\begin{array}{l}\text { belong } \\
0.778\end{array}$ & 0.578 & 0.097 & 5.934 & 0.000 & 0.778 \\
\hline $0.631^{\text {recognitionnew }}$ & 0.433 & 0.079 & 5.478 & 0.000 & 0.631 \\
\hline $\begin{array}{l}\text { competencenew } \\
0.550\end{array}$ & 0.372 & 0.075 & 4.944 & 0.000 & 0.550 \\
\hline $\begin{array}{l}\text { belongnew } \\
0.493\end{array}$ & 0.375 & 0.084 & 4.478 & 0.000 & 0.493 \\
\hline
\end{tabular}




\begin{tabular}{|c|c|c|c|c|c|}
\hline $\begin{array}{l}\text { competence } \\
\text { interest } \\
573\end{array}$ & 0.452 & 0.084 & 5.366 & 0.000 & 0.573 \\
\hline $\begin{array}{l}0.573 \\
\text { belong } \\
0.679\end{array}$ & 0.667 & 0.117 & 5.701 & 0.000 & 0.679 \\
\hline 0.447 recognitionnew & 0.406 & 0.094 & 4.340 & 0.000 & 0.447 \\
\hline $\begin{array}{l}\text { competencenew } \\
0.707\end{array}$ & 0.633 & 0.105 & 6.008 & 0.000 & 0.707 \\
\hline 0.470 & 0.474 & 0.108 & 4.405 & 0.000 & 0.470 \\
\hline $\begin{array}{l}\text { interest } \sim \\
\text { belong } \\
0.375\end{array}$ & 0.253 & 0.067 & 3.789 & 0.000 & 0.375 \\
\hline $0.317^{\text {recognitionnew }}$ & 0.198 & 0.060 & 3.278 & 0.001 & 0.317 \\
\hline $\begin{array}{l}\text { competencenew } \\
0.431\end{array}$ & 0.265 & 0.062 & 4.262 & 0.000 & 0.431 \\
\hline $\begin{array}{l}\text { belongnew } \\
0.406 \\
\text { belong }\end{array}$ & 0.281 & 0.071 & 3.965 & 0.000 & 0.406 \\
\hline $0.480^{\text {recognitionnew }}$ & 0.373 & 0.083 & 4.505 & 0.000 & 0.480 \\
\hline $\begin{array}{l}\text { competencenew } \\
0.475\end{array}$ & 0.364 & 0.082 & 4.447 & 0.000 & 0.475 \\
\hline $\begin{array}{l}\text { belongnew } \\
0.586\end{array}$ & 0.505 & 0.100 & 5.048 & 0.000 & 0.586 \\
\hline
\end{tabular}

Variances:

Std.a11

0.349

Estimate Std.Err z-value $P(>|z|) \quad$ Std.7v

. $\mathrm{V} 2$

0.356

. $\mathrm{V} 3$

0.192

0.213

. $\mathrm{V} 5$

0.187

0.178

.$v 7$

0.157

$\begin{array}{lllll}0.352 & 0.051 & 6.965 & 0.000 & 0.352\end{array}$

$\begin{array}{lllll}0.392 & 0.056 & 7.013 & 0.000 & 0.392\end{array}$

$\begin{array}{lllll}0.178 & 0.036 & 4.919 & 0.000 & 0.178\end{array}$

$\begin{array}{lllll}0.310 & 0.060 & 5.144 & 0.000 & 0.310\end{array}$

$\begin{array}{lllll}0.241 & 0.052 & 4.624 & 0.000 & 0.241\end{array}$

$\begin{array}{lllll}0.117 & 0.025 & 4.683 & 0.000 & 0.117\end{array}$

$\begin{array}{lllll}0.088 & 0.021 & 4.212 & 0.000 & 0.088\end{array}$

$\begin{array}{lllll}0.261 & 0.036 & 7.286 & 0.000 & 0.261\end{array}$

0.366

v8

0.340

$\begin{array}{lllll}0.434 & 0.067 & 6.479 & 0.000 & 0.434\end{array}$

$\begin{array}{lllll}0.101 & 0.050 & 2.021 & 0.043 & 0.101\end{array}$

0.098

. 11

0.000

0.000

0.000

$\begin{array}{lllll}0.205 & 0.039 & 5.222 & 0.000 & 0.205\end{array}$ 


\begin{tabular}{|c|c|c|c|c|c|}
\hline $\begin{array}{l}. v 13 \\
0.426\end{array}$ & 0.379 & 0.052 & 7.317 & 0.000 & 0.379 \\
\hline 0.313 & 0.275 & 0.042 & 6.475 & 0.000 & 0.275 \\
\hline 0.275 & 0.265 & 0.044 & 6.038 & 0.000 & 0.265 \\
\hline 0.174 & 0.158 & 0.037 & 4.217 & 0.000 & 0.158 \\
\hline $\begin{array}{l}. \mathrm{V} 17 \\
0.198\end{array}$ & 0.159 & 0.027 & 5.908 & 0.000 & 0.159 \\
\hline 0.129 & 0.081 & 0.019 & 4.299 & 0.000 & 0.081 \\
\hline 0.231 & 0.141 & 0.022 & 6.435 & 0.000 & 0.141 \\
\hline $\begin{array}{l}. \mathrm{V} 20 \\
0.285\end{array}$ & 0.353 & 0.070 & 5.033 & 0.000 & 0.353 \\
\hline 0.261 & 0.274 & 0.059 & 4.628 & 0.000 & 0.274 \\
\hline $1.000^{\text {recognition }}$ & 0.656 & 0.114 & 5.752 & 0.000 & 1.000 \\
\hline $\begin{array}{l}\text { competence } \\
1.000\end{array}$ & 1.149 & 0.173 & 6.636 & 0.000 & 1.000 \\
\hline 1.000 & 0.541 & 0.078 & 6.899 & 0.000 & 1.000 \\
\hline $\begin{array}{l}\text { belong } \\
1.000\end{array}$ & 0.840 & 0.146 & 5.738 & 0.000 & 1.000 \\
\hline 0.848 & 6.681 & 0.789 & 8.469 & 0.000 & 0.848 \\
\hline $1.000^{\text {recognitionnew }}$ & 0.717 & 0.109 & 6.555 & 0.000 & 1.000 \\
\hline $\begin{array}{l}\text { competencenew } \\
1.000\end{array}$ & 0.697 & 0.112 & 6.211 & 0.000 & 1.000 \\
\hline $\begin{array}{l}. \text { interestnew } \\
0.645\end{array}$ & 0.413 & 0.064 & 6.429 & 0.000 & 0.645 \\
\hline $\begin{array}{l}\text { belongnew } \\
1.000\end{array}$ & 0.884 & 0.149 & 5.916 & 0.000 & 1.000 \\
\hline $\begin{array}{l}\text { > fitmeasures(fit1) } \\
\text { df } \quad \begin{array}{l}\text { npar } \\
\text { pva1 } \\
\end{array} \\
64.000\end{array}$ & & $\begin{array}{l}\text { fmin } \\
1.062\end{array}$ & & 312 & \\
\hline $\begin{array}{l}167.000 \\
\text { bfi }\end{array}$ & $\begin{array}{l}0.000 \\
1 i\end{array}$ & oaseline.df & & line.pv & \\
\hline $\begin{array}{r}2549.051 \\
n n f i\end{array}$ & $\begin{array}{l}.922 \\
i f j\end{array}$ & $\begin{array}{r}210.000 \\
\mathrm{rfi}\end{array}$ & & & $f i$ \\
\hline $\begin{array}{r}0.922 \\
\mathrm{rni}\end{array}$ & $\begin{array}{l}.939 \\
\text { ic }\end{array}$ & $\begin{array}{r}0.846 \\
\log 1\end{array}$ & unre & ricted. & 77 \\
\hline 6693.831 & 85.218 & -3282.915 & & -312 & 81 \\
\hline
\end{tabular}




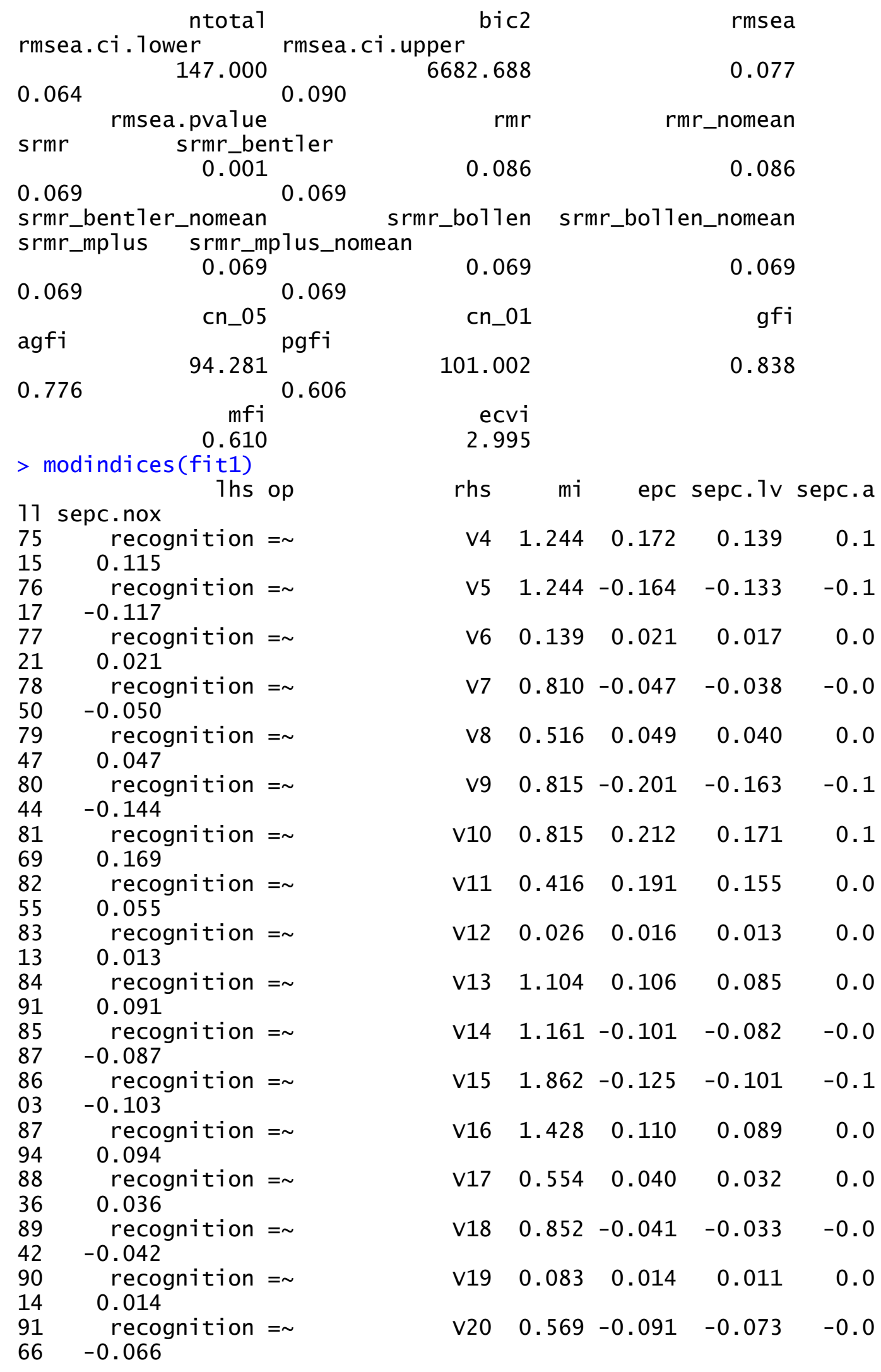




\begin{tabular}{|c|c|c|c|c|c|c|}
\hline $\begin{array}{l}92 \\
67\end{array}$ & $\begin{array}{l}\text { recognition }=\sim \\
0.067\end{array}$ & V21 & 0.569 & 0.085 & 0.069 & 0.0 \\
\hline $\begin{array}{l}93 \\
21\end{array}$ & $\begin{array}{l}\text { competence }=\sim \\
0.221\end{array}$ & V1 & 5.103 & 0.207 & 0.222 & 0.2 \\
\hline 94 & $\begin{array}{l}\text { competence }=\sim \\
-0.101\end{array}$ & v2 & 1.065 & -0.099 & -0.106 & -0.1 \\
\hline $\begin{array}{l}95 \\
05\end{array}$ & $\begin{array}{l}\text { competence }=\sim \\
-0.105\end{array}$ & v3 & 1.191 & -0.094 & -0.101 & -0.1 \\
\hline $\begin{array}{l}96 \\
56\end{array}$ & $\begin{array}{l}\text { competence }=\sim \\
-0.056\end{array}$ & v6 & 0.761 & -0.042 & -0.045 & -0.0 \\
\hline $\begin{array}{l}97 \\
39\end{array}$ & $\begin{array}{l}\text { competence }=\sim \\
-0.039\end{array}$ & v7 & 0.368 & -0.027 & -0.029 & -0.0 \\
\hline $\begin{array}{l}98 \\
40\end{array}$ & $\begin{array}{l}\text { competence }=\sim \\
0.140\end{array}$ & V8 & 3.690 & 0.110 & 0.118 & 0.1 \\
\hline $\begin{array}{l}99 \\
22\end{array}$ & $\begin{array}{l}\text { competence }=\sim \\
0.122\end{array}$ & v9 & 1.422 & 0.129 & 0.138 & 0.1 \\
\hline $\begin{array}{l}100 \\
43\end{array}$ & $\begin{array}{l}\text { competence }=\sim \\
-0.143\end{array}$ & v10 & 1.422 & -0.136 & -0.145 & -0.1 \\
\hline $\begin{array}{l}101 \\
00\end{array}$ & $\begin{array}{l}\text { competence }=\sim \\
0.100\end{array}$ & v11 & 1.234 & 0.261 & 0.280 & 0.1 \\
\hline $\begin{array}{l}102 \\
15\end{array}$ & $\begin{array}{l}\text { competence }=\sim \\
0.115\end{array}$ & v12 & 2.805 & 0.103 & 0.111 & 0.1 \\
\hline $\begin{array}{l}103 \\
06\end{array}$ & $\begin{array}{l}\text { competence }=\sim \\
0.006\end{array}$ & v13 & 0.006 & 0.005 & 0.005 & 0.0 \\
\hline $\begin{array}{l}104 \\
29\end{array}$ & $\begin{array}{l}\text { competence }=\sim \\
-0.129\end{array}$ & V14 & 3.458 & -0.112 & -0.121 & -0.1 \\
\hline $\begin{array}{l}105 \\
41\end{array}$ & $\begin{array}{l}\text { competence }=\sim \\
-0.141\end{array}$ & V15 & 2.353 & -0.129 & -0.139 & -0.1 \\
\hline $\begin{array}{l}106 \\
94\end{array}$ & $\begin{array}{l}\text { competence }=\sim \\
0.194\end{array}$ & v16 & 4.115 & 0.172 & 0.185 & 0.1 \\
\hline $\begin{array}{l}107 \\
87\end{array}$ & $\begin{array}{l}\text { competence }=\sim \\
0.087\end{array}$ & v17 & 2.915 & 0.073 & 0.078 & 0.0 \\
\hline $\begin{array}{l}108 \\
80\end{array}$ & $\begin{array}{l}\text { competence }=\sim \\
-0.080\end{array}$ & V18 & 2.809 & -0.060 & -0.064 & -0.0 \\
\hline $\begin{array}{l}109 \\
34\end{array}$ & $\begin{array}{l}\text { competence }=\sim \\
-0.034\end{array}$ & V19 & 0.415 & -0.025 & -0.027 & -0.0 \\
\hline $\begin{array}{l}110 \\
27\end{array}$ & $\begin{array}{l}\text { competence }=\sim \\
0.027\end{array}$ & V20 & 0.108 & 0.028 & 0.030 & 0.0 \\
\hline $\begin{array}{l}111 \\
27\end{array}$ & $\begin{array}{l}\text { competence }=\sim \\
-0.027\end{array}$ & V21 & 0.108 & -0.026 & -0.028 & 0.0 \\
\hline $\begin{array}{l}112 \\
69\end{array}$ & $\begin{array}{l}\text { interest }=\sim ~ \\
0.169\end{array}$ & v1 & 6.251 & 0.231 & 0.170 & 0.1 \\
\hline $\begin{array}{l}113 \\
39\end{array}$ & $0_{0.039}^{\text {interest }=\sim ~}$ & V2 & 0.335 & 0.056 & 0.041 & 0.0 \\
\hline $\begin{array}{l}114 \\
71\end{array}$ & $\begin{array}{l}\text { interest }=\sim ~ \\
-0.171\end{array}$ & v3 & 6.976 & -0.224 & -0.165 & -0.1 \\
\hline $\begin{array}{l}115 \\
95\end{array}$ & $\begin{array}{l}\text { interest }=\sim \\
-0.195\end{array}$ & V4 & 7.004 & -0.320 & -0.235 & -0.1 \\
\hline $\begin{array}{l}116 \\
98\end{array}$ & $\begin{array}{l}\text { interest }=\sim ~ \\
0.198\end{array}$ & V5 & 7.004 & 0.305 & 0.225 & 0.1 \\
\hline $\begin{array}{l}117 \\
41\end{array}$ & $\begin{array}{l}\text { interest }=\sim \\
0.141\end{array}$ & v9 & 4.947 & 0.216 & 0.159 & 0.1 \\
\hline $\begin{array}{l}118 \\
65\end{array}$ & ${ }_{-0.165}^{\text {interest }}=$ & V10 & 4.947 & -0.228 & -0.168 & -0.1 \\
\hline
\end{tabular}




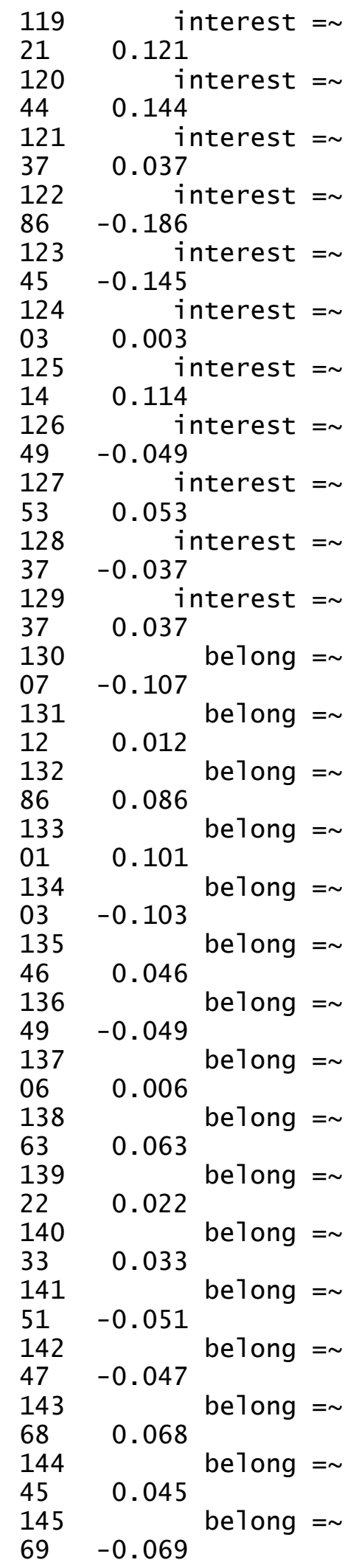

\begin{tabular}{|c|c|c|c|c|}
\hline 11 & .149 & 0.463 & 0.340 & 0 \\
\hline 12 & 5.498 & 0.188 & 0.139 & 0 \\
\hline 13 & 0.300 & 0.047 & 0.0 & \\
\hline 14 & 8.953 & -0.237 & -0.174 & - \\
\hline 15 & 5.088 & -0.194 & -0.142 & -0 \\
\hline 16 & 0.002 & 0.003 & 0.002 & \\
\hline 17 & 6.054 & 0.139 & 0.102 & \\
\hline 18 & 1.323 & -0.053 & -0.039 & - \\
\hline 19 & 1.202 & 0.057 & 0.042 & 0. \\
\hline V20 & 0.249 & -0.056 & -0.041 & -0 \\
\hline 21 & 0.249 & 0.052 & 0.038 & \\
\hline V1 & 0.916 & -0.117 & -0.107 & -0 \\
\hline v2 & 0.011 & 0.013 & 0.012 & \\
\hline v3 & 0.589 & 0.090 & 0.083 & 0. \\
\hline V4 & 1.251 & 0.133 & 0.122 & \\
\hline V5 & 1.251 & -0.127 & -0.117 & -0 . \\
\hline v6 & 0.770 & 0.041 & 0.037 & \\
\hline v7 & 0.882 & -0.040 & -0.037 & -0 \\
\hline V8 & 0.011 & 0.006 & 0.005 & \\
\hline V11 & 0.568 & 0.192 & 0 . & \\
\hline v12 & 0.106 & 0.024 & 0.022 & \\
\hline v13 & 0.196 & 0.034 & 0.031 & \\
\hline v1 & 0.532 & -0.052 & -0.048 & v \\
\hline V15 & 0.479 & -0.050 & -0.046 & -0 \\
\hline v1 & 0.954 & 0.071 & 0.065 & \\
\hline $\mathrm{v} 1$ & 0.931 & 0.044 & 0.040 & \\
\hline 1 & 521 & 0.060 & -0.055 & -0 \\
\hline
\end{tabular}

$\begin{array}{lllll}\text { V11 } & 2.149 & 0.463 & 0.340 & 0.1\end{array}$

$\begin{array}{lllll}\text { V12 } & 5.498 & 0.188 & 0.139 & 0.1\end{array}$

$\begin{array}{lllll}\text { v13 } & 0.300 & 0.047 & 0.034 & 0.0\end{array}$

$\begin{array}{lllll}\text { V14 } & 8.953 & -0.237 & -0.174 & -0.1\end{array}$

$\begin{array}{lllll}\text { V15 } & 5.088 & -0.194 & -0.142 & -0.1\end{array}$

$\begin{array}{lllll}\text { V16 } & 0.002 & 0.003 & 0.002 & 0.0\end{array}$

$\begin{array}{lllll}\text { V17 } & 6.054 & 0.139 & 0.102 & 0.1\end{array}$

$\begin{array}{lllll}\text { V18 } & 1.323 & -0.053 & -0.039 & -0.0\end{array}$

$\begin{array}{lllll}\text { V19 } & 1.202 & 0.057 & 0.042 & 0.0\end{array}$

$\begin{array}{lllll}\text { V20 } & 0.249 & -0.056 & -0.041 & -0.0\end{array}$

$\begin{array}{lllll}\text { V21 } & 0.249 & 0.052 & 0.038 & 0.0\end{array}$

$\begin{array}{lllll}\text { V1 } & 0.916 & -0.117 & -0.107 & -0.1\end{array}$

$\begin{array}{lllll}\text { V2 } & 0.011 & 0.013 & 0.012 & 0.0\end{array}$

$\begin{array}{lllll}\text { V4 } & 1.251 & 0.133 & 0.122 & 0.1\end{array}$

$\begin{array}{lllll}\text { V5 } & 1.251 & -0.127 & -0.117 & -0.1\end{array}$

$\begin{array}{lllll}\text { V6 } & 0.770 & 0.041 & 0.037 & 0.0\end{array}$

$\begin{array}{lllll}\text { v7 } & 0.882 & -0.040 & -0.037 & -0.0\end{array}$

$\begin{array}{lllll}\text { V8 } & 0.011 & 0.006 & 0.005 & 0.0\end{array}$

$\begin{array}{lllll}\mathrm{V} 11 & 0.568 & 0.192 & 0.176 & 0.0\end{array}$

$\begin{array}{lllll}\mathrm{v} 12 & 0.106 & 0.024 & 0.022 & 0.0\end{array}$

$\begin{array}{lllll}\text { v13 } & 0.196 & 0.034 & 0.031 & 0.0\end{array}$

$\begin{array}{lllll}\mathrm{V} 14 & 0.532 & -0.052 & -0.048 & -0.0\end{array}$

$\begin{array}{lllll}\mathrm{V} 15 & 0.479 & -0.050 & -0.046 & -0.0\end{array}$

$\begin{array}{lllll}\mathrm{v} 16 & 0.954 & 0.071 & 0.065 & 0.0\end{array}$

$\begin{array}{lllll}\text { v17 } & 0.931 & 0.044 & 0.040 & 0.0\end{array}$

$\begin{array}{lllll}\mathrm{v} 18 & 2.521 & -0.060 & -0.055 & -0.0\end{array}$ 


\begin{tabular}{|c|c|c|c|c|c|c|c|}
\hline 146 & belong & $=\sim$ & V19 & 0.093 & 0.013 & 0.012 & 0.0 \\
\hline $\begin{array}{l}15 \\
147\end{array}$ & 0.015 belong & $=\sim$ & V20 & 0.397 & -0.070 & -0.064 & -0.0 \\
\hline $\begin{array}{l}58 \\
148\end{array}$ & -0.058 belong & $=\sim$ & V21 & 0.397 & 0.066 & 0.060 & 0.0 \\
\hline 59 & 0.059 & & & & & & \\
\hline $\begin{array}{l}149 \\
53\end{array}$ & $\begin{array}{l}\text { compernew } \\
0.053\end{array}$ & $=\sim$ & V1 & 0.955 & 0.019 & 0.053 & 0.0 \\
\hline $\begin{array}{l}150 \\
24\end{array}$ & $\begin{array}{l}\text { Compernew } \\
0.024\end{array}$ & $=\sim$ & V2 & 0.191 & 0.009 & 0.025 & 0.0 \\
\hline $\begin{array}{l}151 \\
43\end{array}$ & $\begin{array}{l}\text { compernew } \\
-0.043\end{array}$ & $=\sim$ & v3 & 0.872 & -0.015 & -0.042 & -0.0 \\
\hline $\begin{array}{l}152 \\
63\end{array}$ & $\begin{array}{l}\text { compernew } \\
0.063\end{array}$ & $=\sim$ & V4 & 1.812 & 0.027 & 0.077 & 0.0 \\
\hline $\begin{array}{l}153 \\
64\end{array}$ & $\begin{array}{l}\text { compernew } \\
-0.064\end{array}$ & $=\sim$ & V5 & 1.923 & -0.026 & -0.073 & -0.0 \\
\hline $\begin{array}{l}154 \\
31\end{array}$ & $\begin{array}{l}\text { compernew } \\
-0.031\end{array}$ & $=\sim$ & V6 & 0.523 & -0.009 & -0.026 & -0.0 \\
\hline $\begin{array}{l}155 \\
70\end{array}$ & $\begin{array}{l}\text { compernew } \\
0.070\end{array}$ & $=\sim$ & v7 & 2.655 & 0.019 & 0.052 & 0.0 \\
\hline $\begin{array}{l}156 \\
46\end{array}$ & $\begin{array}{l}\text { compernew } \\
0.046\end{array}$ & $=\sim$ & V8 & 0.717 & 0.014 & 0.038 & 0.0 \\
\hline $\begin{array}{l}157 \\
81\end{array}$ & $\begin{array}{l}\text { compernew } \\
0.081\end{array}$ & $=\sim$ & v9 & 2.419 & 0.033 & 0.092 & 0.0 \\
\hline $\begin{array}{l}158 \\
59\end{array}$ & $\begin{array}{l}\text { compernew } \\
-0.059\end{array}$ & $=\sim$ & v10 & 1.727 & -0.022 & -0.060 & -0.0 \\
\hline $\begin{array}{l}159 \\
73\end{array}$ & $\begin{array}{l}\text { compernew } \\
0.073\end{array}$ & $=\sim$ & v12 & 2.271 & 0.025 & 0.071 & 0.0 \\
\hline $\begin{array}{l}160 \\
36\end{array}$ & $\begin{array}{l}\text { compernew } \\
0.036\end{array}$ & $=\sim$ & v13 & 0.370 & 0.012 & 0.034 & 0.0 \\
\hline $\begin{array}{l}161 \\
39\end{array}$ & $\begin{array}{l}\text { compernew } \\
-0.139\end{array}$ & $=\sim$ & V14 & 6.865 & -0.046 & -0.130 & -0.1 \\
\hline $\begin{array}{l}162 \\
14\end{array}$ & $\begin{array}{l}\text { compernew } \\
0.114\end{array}$ & $=\sim$ & V15 & 4.914 & 0.040 & 0.112 & 0.1 \\
\hline $\begin{array}{l}163 \\
28\end{array}$ & $\begin{array}{l}\text { compernew } \\
-0.128\end{array}$ & $=\sim$ & V16 & 7.228 & -0.043 & -0.122 & -0.1 \\
\hline $\begin{array}{l}164 \\
24\end{array}$ & $\begin{array}{l}\text { compernew } \\
0.024\end{array}$ & $=\sim$ & v17 & 0.249 & 0.008 & 0.021 & 0.0 \\
\hline $\begin{array}{l}165 \\
19\end{array}$ & $\begin{array}{l}\text { compernew } \\
-0.019\end{array}$ & $=\sim$ & V18 & 0.185 & -0.005 & -0.015 & -0.0 \\
\hline $\begin{array}{l}166 \\
02\end{array}$ & $\begin{array}{l}\text { compernew } \\
-0.002\end{array}$ & $=\sim$ & V19 & 0.001 & 0.000 & -0.001 & -0.0 \\
\hline $\begin{array}{l}167 \\
91\end{array}$ & $\begin{array}{l}\text { compernew } \\
0.091\end{array}$ & $=\sim$ & V20 & 2.804 & 0.036 & 0.101 & 0.0 \\
\hline $\begin{array}{l}168 \\
52\end{array}$ & $\begin{array}{l}\text { compernew } \\
-0.052\end{array}$ & $=\sim$ & V21 & 0.940 & -0.019 & -0.053 & -0.0 \\
\hline $\begin{array}{l}169 \\
63\end{array}$ & $\begin{array}{l}\text { recognitionnew } \\
0.063\end{array}$ & $=\sim$ & $\mathrm{V} 1$ & 0.603 & 0.075 & 0.063 & 0.0 \\
\hline $\begin{array}{l}170 \\
50\end{array}$ & $\begin{array}{l}\text { recognitionnew } \\
0.050\end{array}$ & $=\sim$ & V2 & 0.380 & 0.062 & 0.053 & 0.0 \\
\hline $\begin{array}{l}171 \\
93\end{array}$ & $\begin{array}{l}\text { recognitionnew } \\
-0.093\end{array}$ & $=\sim$ & v3 & 1.434 & -0.106 & -0.090 & -0.0 \\
\hline $\begin{array}{l}172 \\
45\end{array}$ & $\begin{array}{l}\text { recognitionnew } \\
\quad 0.045\end{array}$ & $=\sim$ & V4 & 0.440 & 0.064 & 0.054 & 0.0 \\
\hline
\end{tabular}




\begin{tabular}{|c|c|c|c|c|c|c|c|}
\hline $\begin{array}{l}173 \\
46\end{array}$ & recognitionnew & $=\sim$ & V5 & 0.440 & -0.061 & -0.052 & -0.0 \\
\hline $\begin{array}{l}174 \\
47\end{array}$ & $\begin{array}{l}\text { recognitionnew } \\
0.047\end{array}$ & $=\sim$ & v6 & 0.852 & 0.045 & 0.038 & 0.0 \\
\hline $\begin{array}{l}175 \\
65\end{array}$ & $\begin{array}{l}\text { recognitionnew } \\
-0.065\end{array}$ & $=\sim$ & v7 & 1.602 & -0.057 & -0.048 & -0.0 \\
\hline $\begin{array}{l}176 \\
30\end{array}$ & $\begin{array}{l}\text { recognitionnew } \\
0.030\end{array}$ & $=\sim$ & V8 & 0.243 & 0.030 & 0.025 & 0.0 \\
\hline $\begin{array}{l}177 \\
51\end{array}$ & $\begin{array}{l}\text { recognitionnew } \\
-0.051\end{array}$ & $=\sim$ & v9 & 0.493 & -0.068 & -0.058 & -0.0 \\
\hline $\begin{array}{l}178 \\
60\end{array}$ & $\begin{array}{l}\text { recognitionnew } \\
0.060\end{array}$ & $=\sim$ & v10 & 0.493 & 0.072 & 0.061 & 0.0 \\
\hline $\begin{array}{l}179 \\
21\end{array}$ & $\begin{array}{l}\text { recognitionnew } \\
-0.021\end{array}$ & $=\sim$ & v11 & 0.054 & -0.071 & -0.060 & -0.0 \\
\hline $\begin{array}{l}180 \\
31\end{array}$ & $\begin{array}{l}\text { recognitionnew } \\
0.131\end{array}$ & $=\sim$ & V15 & 1.526 & 0.152 & 0.129 & 0.1 \\
\hline $\begin{array}{l}181 \\
17\end{array}$ & $\begin{array}{l}\text { recognitionnew } \\
-0.217\end{array}$ & $=\sim$ & v16 & 3.837 & -0.244 & -0.207 & -0.2 \\
\hline $\begin{array}{l}182 \\
74\end{array}$ & $\begin{array}{l}\text { recognitionnew } \\
0.074\end{array}$ & $=\sim$ & v17 & 1.989 & 0.078 & 0.066 & 0.0 \\
\hline $\begin{array}{l}183 \\
21\end{array}$ & $\begin{array}{l}\text { recognitionnew } \\
-0.021\end{array}$ & $=\sim$ & V18 & 0.185 & -0.020 & -0.017 & -0.0 \\
\hline $\begin{array}{l}184 \\
15\end{array}$ & $\begin{array}{l}\text { recognitionnew } \\
-0.015\end{array}$ & $=\sim$ & V19 & 0.079 & -0.014 & -0.012 & -0.0 \\
\hline $\begin{array}{l}185 \\
06\end{array}$ & $\begin{array}{l}\text { recognitionnew } \\
0.006\end{array}$ & $=\sim$ & V20 & 0.002 & 0.008 & 0.007 & 0.0 \\
\hline $\begin{array}{l}186 \\
06\end{array}$ & $\begin{array}{l}\text { recognitionnew } \\
-0.006\end{array}$ & $=\sim$ & V21 & 0.002 & -0.008 & -0.007 & -0.0 \\
\hline $\begin{array}{l}187 \\
24\end{array}$ & $\begin{array}{l}\text { competencenew } \\
0.124\end{array}$ & $=\sim$ & V1 & 2.692 & 0.149 & 0.125 & 0.1 \\
\hline $\begin{array}{l}188 \\
06\end{array}$ & $\begin{array}{l}\text { competencenew } \\
-0.006\end{array}$ & $=\sim$ & V2 & 0.005 & -0.007 & -0.006 & -0.0 \\
\hline $\begin{array}{l}189 \\
00\end{array}$ & $\begin{array}{l}\text { competencenew } \\
-0.100\end{array}$ & $=\sim$ & v3 & 1.861 & -0.115 & -0.096 & -0.1 \\
\hline $\begin{array}{l}190 \\
44\end{array}$ & $\begin{array}{l}\text { competencenew } \\
0.044\end{array}$ & $=\sim$ & V4 & 0.228 & 0.064 & 0.053 & 0.0 \\
\hline $\begin{array}{l}191 \\
45\end{array}$ & $\begin{array}{l}\text { competencenew } \\
-0.045\end{array}$ & $=\sim$ & V5 & 0.228 & -0.061 & -0.051 & -0.0 \\
\hline $\begin{array}{l}192 \\
05\end{array}$ & $\begin{array}{l}\text { competencenew } \\
0.005\end{array}$ & $=\sim$ & V6 & 0.009 & 0.005 & 0.004 & 0.0 \\
\hline $\begin{array}{l}193 \\
62\end{array}$ & $\begin{array}{l}\text { competencenew } \\
-0.062\end{array}$ & $=\sim$ & v7 & 1.255 & -0.055 & -0.046 & -0.0 \\
\hline $\begin{array}{l}194 \\
90\end{array}$ & $\begin{array}{l}\text { competencenew } \\
0.090\end{array}$ & $=\sim$ & V8 & 1.926 & 0.091 & 0.076 & 0.0 \\
\hline $\begin{array}{l}195 \\
10\end{array}$ & $\begin{array}{l}\text { competencenew } \\
-0.010\end{array}$ & $=\sim$ & v9 & 0.018 & -0.013 & -0.011 & -0.0 \\
\hline $\begin{array}{l}196 \\
11\end{array}$ & $\begin{array}{l}\text { competencenew } \\
0.011\end{array}$ & $=\sim$ & v10 & 0.018 & 0.014 & 0.012 & 0.0 \\
\hline $\begin{array}{l}197 \\
02\end{array}$ & $\begin{array}{l}\text { competencenew } \\
0.002\end{array}$ & $=\sim$ & v11 & 0.000 & 0.005 & 0.004 & 0.0 \\
\hline $\begin{array}{l}198 \\
89\end{array}$ & $\begin{array}{l}\text { competencenew } \\
0.389\end{array}$ & $=\sim$ & v12 & 13.605 & 0.447 & 0.373 & 0 \\
\hline $\begin{array}{l}199 \\
34 \\
{[r}\end{array}$ & $\begin{array}{l}\text { competencenew } \\
-0.134 \\
\text { reached getoptic }\end{array}$ & $\begin{array}{l}=\sim \\
\text { on (") }\end{array}$ & v13 & 1.502 & -0.152 & -0.127 & -0.1 \\
\hline
\end{tabular}




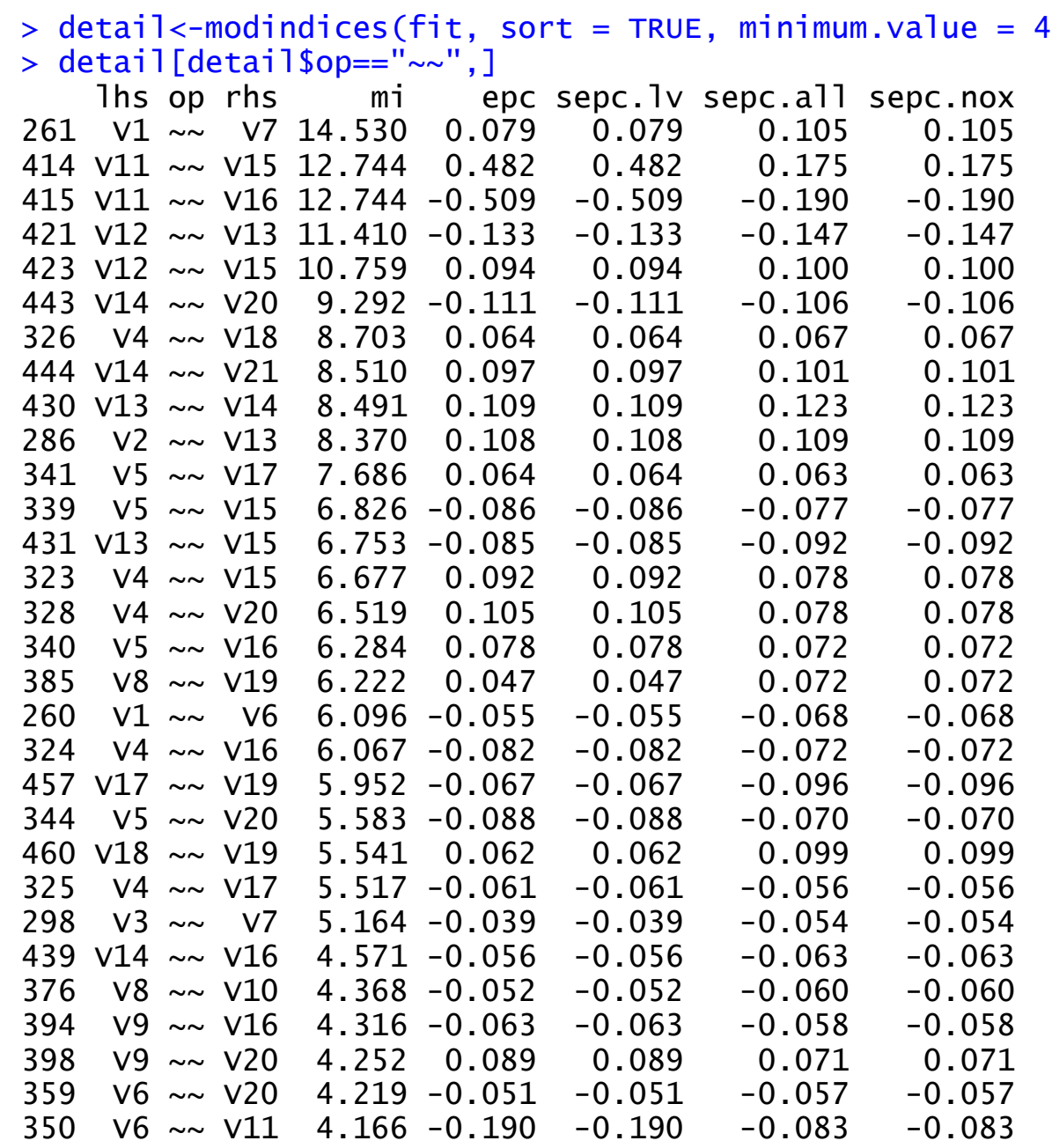

$>$ parameterEstimates (fit1)

\begin{tabular}{|c|c|c|c|c|c|c|c|c|c|}
\hline & 1hs & op & rhs & est & se & z & pvalue & ci.lower & ci.upper \\
\hline 1 & recognition & $=\sim$ & V1 & 1.000 & 0.000 & NA & NA & 1.000 & 1.000 \\
\hline 2 & recognition & $=\sim$ & V2 & 1.041 & 0.096 & 10.848 & 0.000 & 0.853 & 1.229 \\
\hline 3 & recognition & $=\sim$ & V3 & 1.069 & 0.086 & 12.496 & 0.000 & 0.902 & 1.237 \\
\hline 4 & competence & $=\sim$ & V4 & 1.000 & 0.000 & NA & NA & 1.000 & 1.000 \\
\hline 5 & competence & $=\sim$ & V5 & 0.954 & 0.066 & 14.521 & 0.000 & 0.825 & 1.083 \\
\hline 6 & interest & $=\sim$ & v6 & 1.000 & 0.000 & NA & NA & 1.000 & 1.000 \\
\hline 7 & interest & $=\sim$ & v7 & 0.936 & 0.059 & 15.857 & 0.000 & 0.820 & 1.051 \\
\hline 8 & interest & $=\sim$ & V8 & 0.913 & 0.072 & 12.601 & 0.000 & 0.771 & 1.055 \\
\hline 9 & belong & $=\sim$ & v9 & 1.000 & 0.000 & NA & NA & 1.000 & 1.000 \\
\hline 10 & belong & $=\sim$ & v10 & 1.054 & 0.086 & 12.316 & 0.000 & 0.886 & 1.222 \\
\hline 11 & compernew & $=\sim$ & v11 & 1.000 & 0.000 & NA & NA & 1.000 & 1.000 \\
\hline 12 & recognitionnew & $=\sim$ & v12 & 1.000 & 0.000 & NA & NA & 1.000 & 1.000 \\
\hline 13 & recognitionnew & $=\sim$ & v13 & 0.843 & 0.077 & 10.913 & 0.000 & 0.692 & 0.994 \\
\hline 14 & recognitionnew & $=\sim$ & V14 & 0.916 & 0.073 & 12.550 & 0.000 & 0.773 & 1.059 \\
\hline 15 & competencenew & $=\sim$ & V15 & 1.000 & 0.000 & NA & NA & 1.000 & 1.000 \\
\hline 16 & competencenew & $=\sim$ & V16 & 1.037 & 0.076 & 13.555 & 0.000 & 0.887 & 1.187 \\
\hline 17 & interestnew & $=\sim$ & V17 & 1.000 & 0.000 & NA & NA & 1.000 & 1.000 \\
\hline 18 & interestnew & $=\sim$ & V18 & 0.925 & 0.054 & 17.260 & 0.000 & 0.820 & 1.031 \\
\hline 19 & interestnew & $=\sim$ & V19 & 0.856 & 0.056 & 15.384 & 0.000 & 0.747 & 0.965 \\
\hline 20 & belongnew & $=\sim$ & V20 & 1.000 & 0.000 & NA & NA & 1.000 & 1.000 \\
\hline
\end{tabular}




\begin{tabular}{|c|c|c|c|c|c|c|c|c|c|}
\hline 21 & belongnew & $=\sim$ & V21 & 0.938 & 0.085 & 10.996 & 0.000 & 0.771 & 1.105 \\
\hline 22 & compernew & $\sim$ & interestnew & 1.367 & 0.282 & 4.850 & 0.000 & 0.814 & 1.919 \\
\hline 23 & interestnew & $\sim$ & competencenew & 0.572 & 0.080 & 7.119 & 0.000 & 0.414 & 0.729 \\
\hline 24 & recognitionnew & $\sim \sim$ & competencenew & 0.531 & 0.085 & 6.221 & 0.000 & 0.364 & 0.699 \\
\hline 25 & competencenew & $\sim \sim$ & belongnew & 0.501 & 0.092 & 5.439 & 0.000 & 0.320 & 0.681 \\
\hline 26 & recognitionnew & $\sim \sim$ & belongnew & 0.593 & 0.097 & 6.088 & 0.000 & 0.402 & 0.785 \\
\hline 27 & V1 & $\sim \sim$ & v1 & 0.352 & 0.051 & 6.965 & 0.000 & 0.253 & 0.451 \\
\hline 28 & $\mathrm{~V} 2$ & $\sim \sim$ & V2 & 0.392 & 0.056 & 7.013 & 0.000 & 0.282 & 0.502 \\
\hline 9 & V3 & $\sim \sim$ & v3 & 0.178 & 0.036 & 4.919 & 0.000 & 0.107 & 0.249 \\
\hline 30 & V4 & $\sim \sim$ & V4 & 0.310 & 0.060 & 5.144 & 0.000 & 0.192 & 0.428 \\
\hline 31 & V5 & $\sim \sim$ & V5 & 0.241 & 0.052 & 4.624 & 0.000 & 0.139 & 0.343 \\
\hline 32 & v6 & $\sim \sim$ & v6 & 0.117 & 0.025 & 4.683 & 0.000 & 0.068 & 0.166 \\
\hline 33 & v7 & $\sim \sim$ & v7 & 0.088 & 0.021 & 4.212 & 0.000 & 0.047 & 0.130 \\
\hline 34 & V8 & $\sim \sim$ & v8 & 0.261 & 0.036 & 7.286 & 0.000 & 0.190 & 0.331 \\
\hline 35 & V9 & $\sim \sim$ & v9 & 0.434 & 0.067 & 6.479 & 0.000 & 0.303 & 0.565 \\
\hline 36 & V10 & $\sim \sim$ & V10 & 0.101 & 0.050 & 2.021 & 0.043 & 0.003 & 0.200 \\
\hline 37 & V11 & $\sim \sim$ & V11 & 0.000 & 0.000 & NA & NA & 0.000 & 0.000 \\
\hline 38 & V12 & $\sim \sim$ & V12 & 0.205 & 0.039 & 5.222 & 0.000 & 0.128 & 0.282 \\
\hline 39 & V13 & $\sim \sim$ & V13 & 0.379 & 0.052 & 7.317 & 0.000 & 0.277 & 0.481 \\
\hline 40 & V14 & $\sim \sim$ & V14 & 0.275 & 0.042 & 6.475 & 0.000 & 0.192 & 0.358 \\
\hline 1 & V15 & $\sim \sim$ & V15 & 0.265 & 0.044 & 6.038 & 0.000 & 0.179 & 0.350 \\
\hline 42 & V16 & $\sim \sim$ & V16 & 0.158 & 0.037 & 4.217 & 0.000 & 0.084 & 0.231 \\
\hline 43 & V17 & $\sim \sim$ & V17 & 0.159 & 0.027 & 5.908 & 0.000 & 0.106 & 0.211 \\
\hline 44 & V18 & $\sim \sim$ & V18 & 0.081 & 0.019 & 4.299 & 0.000 & 0.044 & 0.118 \\
\hline 45 & V19 & $\sim \sim$ & V19 & 0.141 & 0.022 & 6.435 & 0.000 & 0.098 & 0.184 \\
\hline 46 & V20 & $\sim \sim$ & V20 & 0.353 & 0.070 & 5.033 & 0.000 & 0.215 & 0.490 \\
\hline 47 & V21 & $\sim \sim$ & V21 & 0.274 & 0.059 & 4.628 & 0.000 & 0.158 & 0.390 \\
\hline 48 & recognition & $\sim \sim$ & recognition & 0.656 & 0.114 & 5.752 & 0.000 & 0.432 & 0.879 \\
\hline 49 & competence & $\sim \sim$ & competence & 1.149 & 0.173 & 6.636 & 0.000 & 0.810 & 1.489 \\
\hline 50 & interest & $\sim \sim$ & interest & 0.541 & 0.078 & 6.899 & 0.000 & 0.387 & 0.695 \\
\hline 51 & belong & $\sim \sim$ & belong & 0.840 & 0.146 & 5.738 & 0.000 & 0.553 & 1.127 \\
\hline 52 & compernew & $\sim \sim$ & compernew & 6.681 & 0.789 & 8.469 & 0.000 & 5.135 & 8.227 \\
\hline 53 & recognitionnew & $\sim \sim$ & recognitionnew & 0.717 & 0.109 & 6.555 & 0.000 & 0.503 & 0.932 \\
\hline 54 & competencenew & $\sim \sim$ & competencenew & 0.697 & 0.112 & 6.211 & 0.000 & 0.477 & 0.917 \\
\hline 55 & interestnew & $\sim \sim$ & interestnew & 0.413 & 0.064 & 6.429 & 0.000 & 0.287 & 0.540 \\
\hline 56 & belongnew & $\sim \sim$ & belongnew & 0.884 & 0.149 & 5.916 & 0.000 & 0.591 & 1.177 \\
\hline 57 & recognition & $\sim \sim$ & competence & 0.629 & 0.105 & 5.985 & 0.000 & 0.423 & 0.834 \\
\hline 58 & recognition & $\sim \sim$ & interest & 0.273 & 0.062 & 4.426 & 0.000 & 0.152 & 0.393 \\
\hline 59 & recognition & $\sim \sim$ & belong & 0.578 & 0.097 & 5.934 & 0.000 & 0.387 & 0.768 \\
\hline 60 & recognition & $\sim \sim$ & recognitionnew & 0.433 & 0.079 & 5.478 & 0.000 & 0.278 & 0.588 \\
\hline 61 & recognition & $\sim \sim$ & competencenew & 0.372 & 0.075 & 4.944 & 0.000 & 0.225 & 0.520 \\
\hline 62 & recognition & $\sim \sim$ & belongnew & 0.375 & 0.084 & 4.478 & 0.000 & 0.211 & 0.540 \\
\hline 63 & competence & $\sim \sim$ & interest & 0.452 & 0.084 & 5.366 & 0.000 & 0.287 & 0.617 \\
\hline 64 & competence & $\sim \sim$ & belong & 0.667 & 0.117 & 5.701 & 0.000 & 0.438 & 0.896 \\
\hline 65 & competence & $\sim \sim$ & recognitionnew & 0.406 & 0.094 & 4.340 & 0.000 & 0.223 & 0.589 \\
\hline 66 & competence & $\sim \sim$ & competencenew & 0.633 & 0.105 & 6.008 & 0.000 & 0.427 & 0.840 \\
\hline 67 & competence & $\sim \sim$ & belongnew & 0.474 & 0.108 & 4.405 & 0.000 & 0.263 & 0.685 \\
\hline 68 & interest & $\sim \sim$ & belong & 0.253 & 0.067 & 3.789 & 0.000 & 0.122 & 0.384 \\
\hline 69 & interest & $\sim \sim$ & recognitionnew & 0.198 & 0.060 & 3.278 & 0.001 & 0.079 & 0.316 \\
\hline 70 & interest & $\sim \sim$ & competencenew & 0.265 & 0.062 & 4.262 & 0.000 & 0.143 & 0.387 \\
\hline 71 & interest & $\sim \sim$ & belongnew & 0.281 & 0.071 & 3.965 & 0.000 & 0.142 & 0.419 \\
\hline 72 & belong & $\sim \sim$ & recognitionnew & 0.373 & 0.083 & 4.505 & 0.000 & 0.211 & 0.535 \\
\hline 73 & belong & $\sim \sim$ & competencenew & 0.364 & 0.082 & 4.447 & 0.000 & 0.203 & 0.524 \\
\hline 74 & belong & $\sim \sim$ & belongnew & 0.505 & 0.100 & 5.048 & 0.000 & 0.309 & 0.702 \\
\hline
\end{tabular}




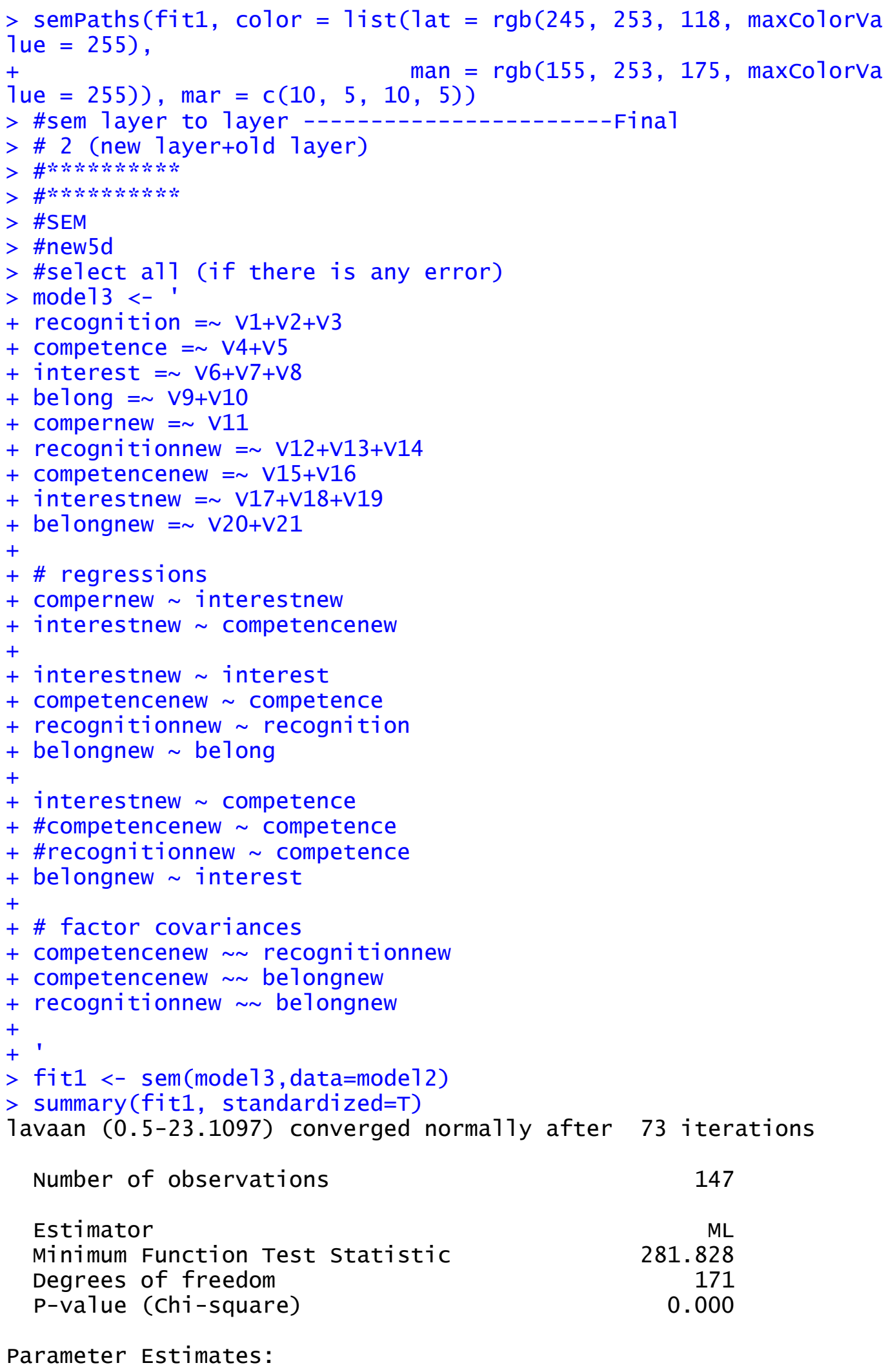

Parameter Estimates: 


\section{Information \\ Standard Errors}

Latent Variables:

recognition $=\sim$

v1

V2

V3

competence $=\sim$

V4

V5

interest $=\sim$

v6

V7

V8

belong =

v9

V10

compernew $=\sim$

v11

recognitionnew $=\sim$

v12

V13

V14

competencenew $=\sim$

V15

v16

interestnew $=\sim$

v17

V18

v19

belongnew =

v20

V21
Estimate Std.Err $z$-value $P(>|z|)$ Std.1v Std.a11

$$
1.000
$$

1.040

1.066

1.000

0.971

1.000

0.918

0.903

1.000

1.061

1.000

1.000

0.852

0.926

1.000

1.044

1.000

0.911

0.853

$0.096 \quad 10.853$

$0.085 \quad 12.483$

0.000

0.810

0.807

Expected

Standard 


\begin{tabular}{|c|c|c|c|c|c|c|}
\hline . recognitionnew & Estimate & Std.Err & z-value & $P(>|z|)$ & std. 1v & std.a11 \\
\hline . competencenew & 0.283 & 0.051 & 5.580 & 0.000 & 0.742 & 0.742 \\
\hline . competencenew & & & & & & \\
\hline $\begin{array}{l}\text {.belongnew } \\
\text {. recognitionnew }\end{array}$ & 0.235 & 0.054 & 4.373 & 0.000 & 0.545 & 0.545 \\
\hline $\begin{array}{l}\text { belongnew } \\
\text { recognition } \sim\end{array}$ & 0.346 & 0.064 & 5.434 & 0.000 & 0.712 & 0.712 \\
\hline competence & 0.623 & 0.104 & 5.998 & 0.000 & 0.724 & 0.724 \\
\hline interest & 0.282 & 0.062 & 4.539 & 0.000 & 0.469 & 0.469 \\
\hline belong & 0.575 & 0.097 & 5.952 & 0.000 & 0.777 & 0.777 \\
\hline competence & & & & & & \\
\hline interest & 0.451 & 0.084 & 5.382 & 0.000 & 0.571 & 0.571 \\
\hline belong & 0.654 & 0.115 & 5.682 & 0.000 & 0.673 & 0.673 \\
\hline $\begin{array}{c}\text { interest } \sim ~ \\
\text { belong }\end{array}$ & 0.255 & 0.067 & 3.810 & 0.000 & 0.376 & 0.376 \\
\hline . compernen & & & & & & \\
\hline . recognitionnew & -0.026 & 0.131 & -0.197 & 0.844 & -0.015 & -0.015 \\
\hline .belongnew & 0.079 & 0.167 & 0.470 & 0.638 & 0.041 & 0.041 \\
\hline
\end{tabular}

Variances:

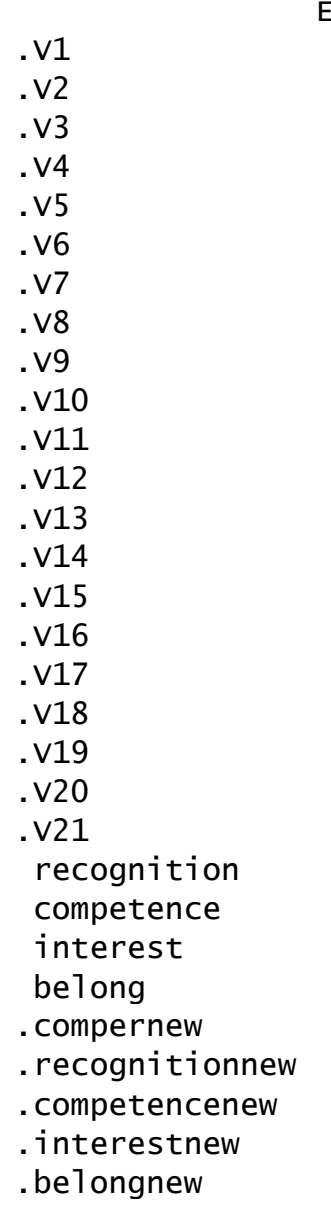

$\begin{array}{rrrrrr}\text { Estimate } & \text { Std.Err } & \text { z-value } & \text { P }(>|z|) & \text { Std. } \mid \mathbf{v} & \text { Std.a11 } \\ 0.351 & 0.050 & 6.956 & 0.000 & 0.351 & 0.348 \\ 0.392 & 0.056 & 7.011 & 0.000 & 0.392 & 0.356 \\ 0.181 & 0.036 & 5.034 & 0.000 & 0.181 & 0.195 \\ 0.329 & 0.060 & 5.493 & 0.000 & 0.329 & 0.226 \\ 0.221 & 0.050 & 4.435 & 0.000 & 0.221 & 0.171 \\ 0.107 & 0.024 & 4.537 & 0.000 & 0.107 & 0.162 \\ 0.097 & 0.020 & 4.773 & 0.000 & 0.097 & 0.173 \\ 0.262 & 0.036 & 7.345 & 0.000 & 0.262 & 0.368 \\ 0.439 & 0.067 & 6.554 & 0.000 & 0.439 & 0.344 \\ 0.095 & 0.049 & 1.955 & 0.051 & 0.095 & 0.092 \\ 0.000 & & & & 0.000 & 0.000 \\ 0.213 & 0.040 & 5.344 & 0.000 & 0.213 & 0.235 \\ 0.374 & 0.051 & 7.266 & 0.000 & 0.374 & 0.426 \\ 0.269 & 0.042 & 6.377 & 0.000 & 0.269 & 0.311 \\ 0.268 & 0.044 & 6.152 & 0.000 & 0.268 & 0.280 \\ 0.151 & 0.037 & 4.132 & 0.000 & 0.151 & 0.167 \\ 0.150 & 0.026 & 5.791 & 0.000 & 0.150 & 0.188 \\ 0.091 & 0.019 & 4.844 & 0.000 & 0.091 & 0.145 \\ 0.139 & 0.022 & 6.435 & 0.000 & 0.139 & 0.227 \\ 0.350 & 0.070 & 4.998 & 0.000 & 0.350 & 0.285 \\ 0.277 & 0.059 & 4.675 & 0.000 & 0.277 & 0.265 \\ 0.656 & 0.114 & 5.758 & 0.000 & 1.000 & 1.000 \\ 1.130 & 0.172 & 6.567 & 0.000 & 1.000 & 1.000 \\ 0.551 & 0.078 & 7.039 & 0.000 & 1.000 & 1.000 \\ 0.835 & 0.146 & 5.719 & 0.000 & 1.000 & 1.000 \\ 6.665 & 0.787 & 8.467 & 0.000 & 0.847 & 0.847 \\ 0.429 & 0.074 & 5.805 & 0.000 & 0.619 & 0.619 \\ 0.339 & 0.063 & 5.387 & 0.000 & 0.492 & 0.492 \\ 0.300 & 0.052 & 5.764 & 0.000 & 0.463 & 0.463 \\ 0.550 & 0.102 & 5.388 & 0.000 & 0.627 & 0.627\end{array}$

$>$ fitmeasures(fit1) 


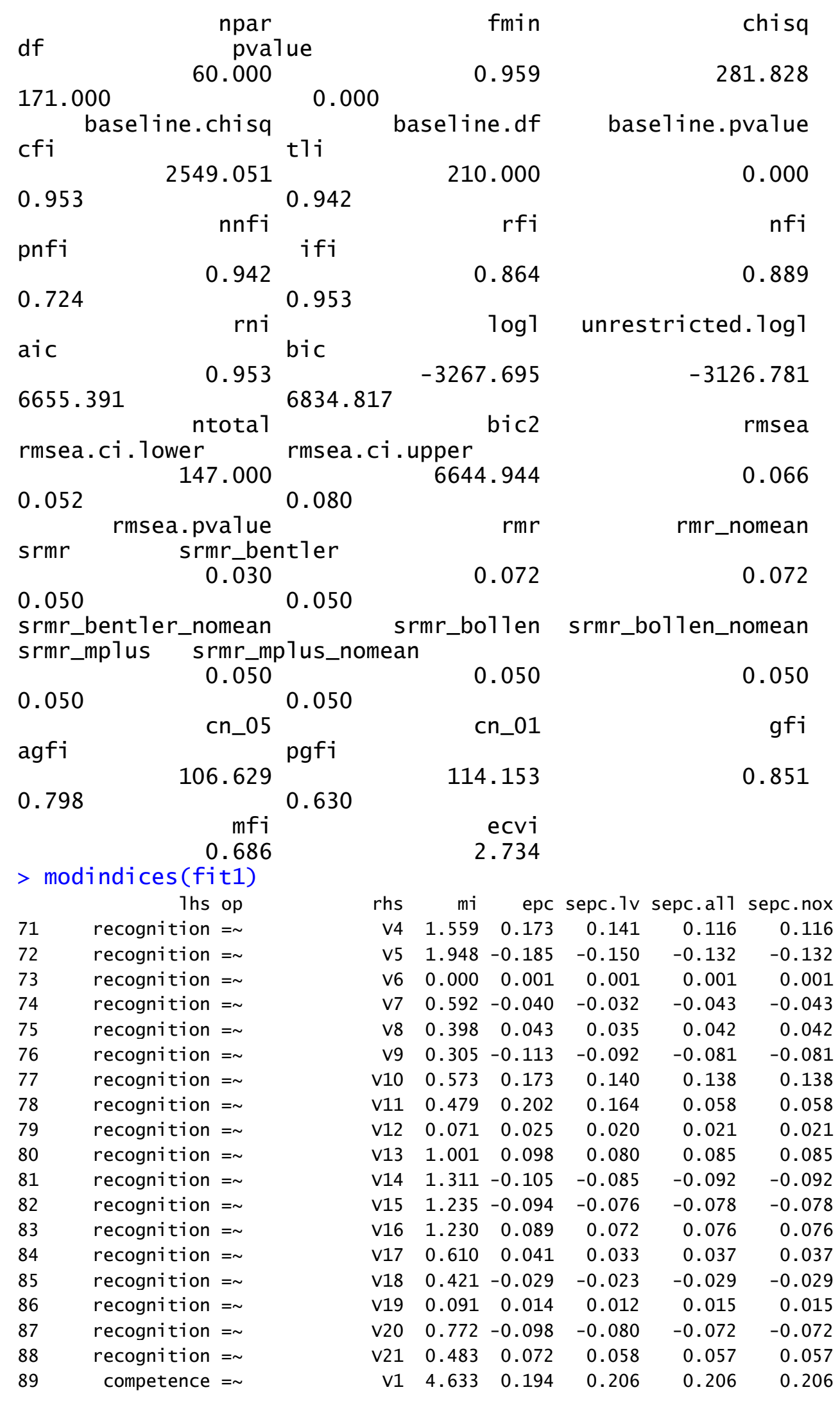




\begin{tabular}{|c|c|}
\hline 90 & competence $=\sim$ \\
\hline 91 & competence $=\sim$ \\
\hline 92 & competence $=\sim$ \\
\hline 3 & competence $=\sim$ \\
\hline 94 & competence $=\sim$ \\
\hline 5 & competence $=\sim$ \\
\hline 96 & competence $=\sim$ \\
\hline 7 & competence $=\sim$ \\
\hline 98 & competence $=\sim$ \\
\hline 9 & competence $=\sim$ \\
\hline 100 & competence $=\sim$ \\
\hline 01 & competence $=\sim$ \\
\hline 102 & competence $=\sim$ \\
\hline 03 & competence $=\sim$ \\
\hline 104 & competence $=\sim$ \\
\hline 05 & competence $=\sim$ \\
\hline 106 & competence $=\sim$ \\
\hline 107 & competence $=\sim$ \\
\hline 108 & interest $=\sim$ \\
\hline 09 & interest $=\sim$ \\
\hline 110 & interest $=\sim$ \\
\hline 111 & interest $=\sim$ \\
\hline 112 & interest $=\sim$ \\
\hline 113 & interest $=\sim$ \\
\hline 114 & interest $=\sim$ \\
\hline 115 & interest $=\sim$ \\
\hline 116 & interest $=\sim$ \\
\hline 117 & interest $=\sim$ \\
\hline 118 & interest $=\sim$ \\
\hline 119 & interest $=\sim$ \\
\hline 120 & interest $=\sim$ \\
\hline 121 & interest $=\sim$ \\
\hline 122 & interest $=\sim$ \\
\hline 123 & interest $=\sim$ \\
\hline 124 & interest $=\sim$ \\
\hline 125 & interest $=\sim$ \\
\hline 126 & belong = \\
\hline 127 & belong = \\
\hline 128 & belong = \\
\hline 129 & belong = \\
\hline 130 & belong = \\
\hline 131 & belong = \\
\hline 132 & belong $=\sim$ \\
\hline 133 & belong = \\
\hline 134 & belong $=\sim$ \\
\hline 135 & belong $=\sim$ \\
\hline 136 & belong $=\sim$ \\
\hline 137 & belong $=\sim$ \\
\hline 138 & belong $=\sim$ \\
\hline 139 & belong $=\sim$ \\
\hline 140 & belong = \\
\hline 141 & belong = \\
\hline 142 & belong = \\
\hline 143 & belong = \\
\hline 144 & belong = \\
\hline
\end{tabular}

\begin{tabular}{|c|c|c|c|c|c|}
\hline V2 & 1.169 & -0.102 & -0.109 & -0.104 & .104 \\
\hline v3 & 0.984 & -0.082 & -0.087 & -0.091 & -0.091 \\
\hline v6 & 1.588 & -0.060 & -0.064 & -0.079 & -0.079 \\
\hline v7 & 0.043 & -0.009 & -0.010 & -0.013 & -0.013 \\
\hline v8 & .762 & 0.111 & 0.118 & 0.140 & 0.140 \\
\hline v9 & .369 & 0.122 & 0.129 & 0.115 & 0.115 \\
\hline 10 & 1.466 & -0.131 & -0.139 & -0.137 & -0.137 \\
\hline 11 & .023 & 0.231 & 0.245 & 0.087 & 0.087 \\
\hline 12 & 2.924 & 0.099 & 0.106 & 0.111 & 0.111 \\
\hline 13 & .002 & -0.003 & -0.003 & -0.003 & -0.003 \\
\hline 14 & 3.063 & -0.103 & -0.109 & -0.118 & -0.118 \\
\hline 15 & 2.750 & -0.142 & -0.151 & -0.154 & -0.154 \\
\hline 16 & 2.750 & 0.148 & 0.157 & 0.166 & 0.166 \\
\hline 17 & .361 & 0.076 & 0.081 & 0.090 & 0.090 \\
\hline 18 & 1.949 & -0.050 & -0.053 & -0.066 & -0.066 \\
\hline 19 & 0.415 & -0.024 & -0.026 & -0 . & -0.033 \\
\hline V20 & 0.042 & 0.016 & 0.017 & 0.015 & 0.015 \\
\hline 21 & 0.011 & -0.008 & -0.008 & -0.008 & -0.008 \\
\hline $\mathrm{V} 1$ & 5.081 & 0.205 & 0.152 & 0.151 & 0.151 \\
\hline $\mathrm{V} 2$ & 0.229 & 0.046 & 0.034 & 0.032 & 0.032 \\
\hline v3 & 7.232 & -0.218 & -0.162 & -0.168 & -0.168 \\
\hline V4 & 3.947 & -0.220 & -0.163 & -0.135 & -0.135 \\
\hline V5 & 5.195 & 0.237 & 0.176 & 55 & 0.155 \\
\hline v9 & .392 & 0.222 & 0.165 & 0.146 & 0.146 \\
\hline 10 & 5.392 & -0.236 & -0.175 & 72 & -0.172 \\
\hline 11 & 2.071 & 0.526 & 0.391 & 0.139 & 0.139 \\
\hline 12 & 5.819 & 0.173 & 0.129 & 35 & 0.135 \\
\hline 13 & 0.652 & 0.066 & 0.049 & & 0.052 \\
\hline 14 & 7.145 & -0.197 & -0 & 58 & -0.158 \\
\hline 15 & 2.575 & -0.129 & -0.096 & -0 . & -0.098 \\
\hline v16 & 0.985 & 0.074 & & & 0.058 \\
\hline v17 & 3.276 & 0.121 & 90 & 01 & 0.101 \\
\hline V18 & 5.703 & -0.138 & -0.102 & 29 & -0.129 \\
\hline V19 & 0.146 & 0.023 & 0.017 & 0.022 & 0.022 \\
\hline V20 & 0.254 & -0.055 & -0.041 & -0. & -0.037 \\
\hline V21 & 0.254 & 0.051 & 0.038 & 0.037 & 0.037 \\
\hline $\mathrm{V} 1$ & 0.986 & -0.118 & -0.108 & -0 . & -0.108 \\
\hline V2 & 0.004 & 0.008 & 0.007 & 0.007 & 0.007 \\
\hline v3 & 0.601 & 0.087 & 0.079 & 0 . & 0.082 \\
\hline V4 & 1.807 & 0.145 & 0.132 & 0.110 & 0.110 \\
\hline v5 & 1.459 & -0.123 & -0 & -0 . & -0.099 \\
\hline v6 & 0.428 & 0.030 & 0.027 & 34 & 0.034 \\
\hline V7 & 0.659 & -0.034 & -0. & -0 . & -0.042 \\
\hline V8 & 0.001 & 0.002 & 0.002 & 02 & 0.002 \\
\hline V11 & 0.496 & 0.177 & 0. & 0 & 0.058 \\
\hline v12 & 0.191 & 0.030 & 0.027 & 29 & 0.029 \\
\hline v13 & 0.142 & 0.028 & 0. & 28 & 0.028 \\
\hline V14 & 0.554 & -0.051 & -0.047 & 51 & -0.051 \\
\hline 15 & 0.614 & -0.054 & -0.050 & -0.051 & -0.051 \\
\hline V16 & 0.316 & 0.036 & 0.033 & 0.035 & 0.035 \\
\hline v17 & 1.079 & 0.046 & 0.042 & 0.047 & 0.047 \\
\hline V18 & 1.518 & -0.047 & -0.043 & -0.054 & -0.054 \\
\hline 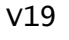 & 0.135 & 0.015 & 0.014 & 0.018 & 0.018 \\
\hline V20 & 0.473 & -0.077 & -0.070 & -0.063 & -0.063 \\
\hline V21 & 0.473 & 0.072 & 0.065 & 0.064 & 0.064 \\
\hline
\end{tabular}




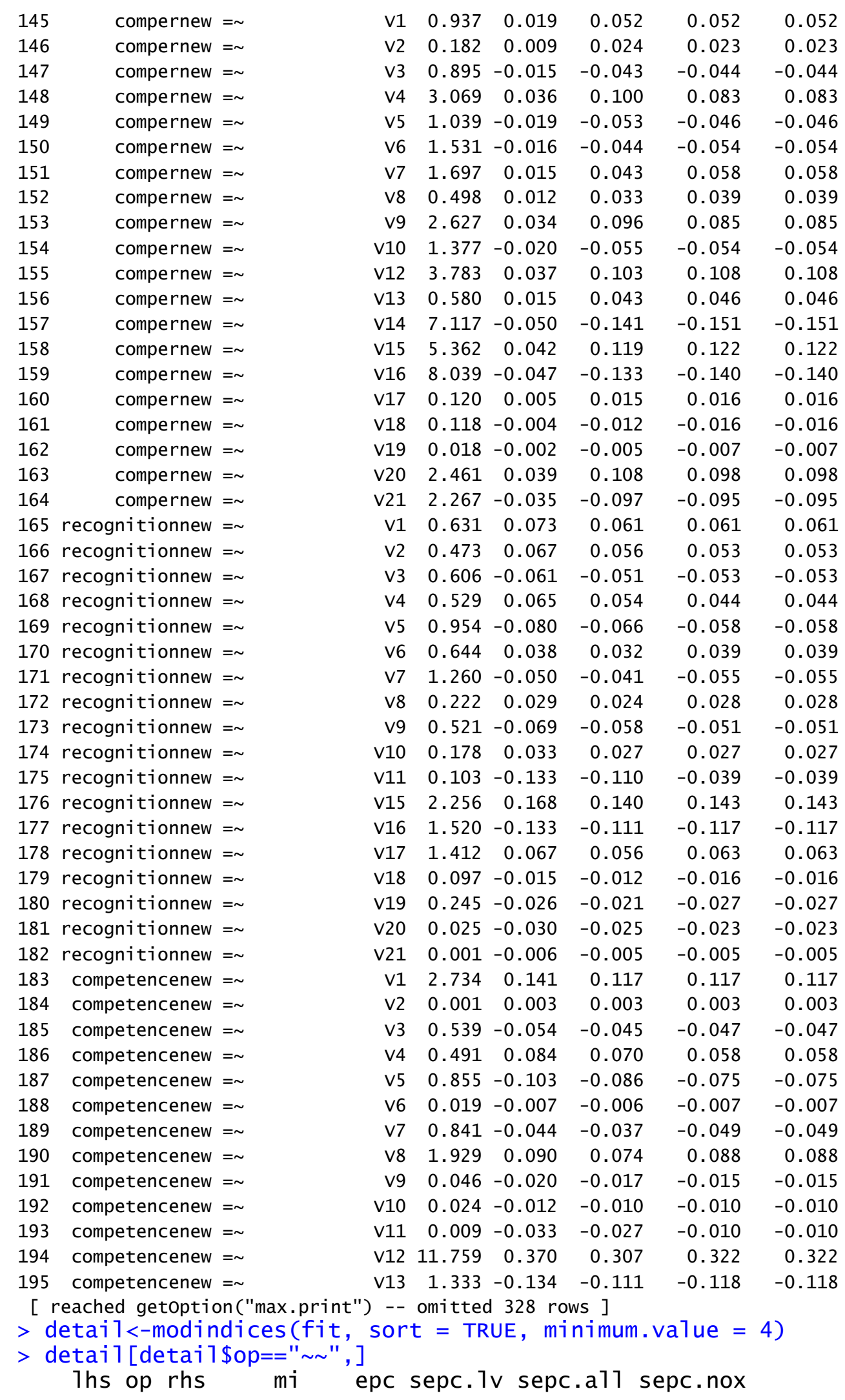




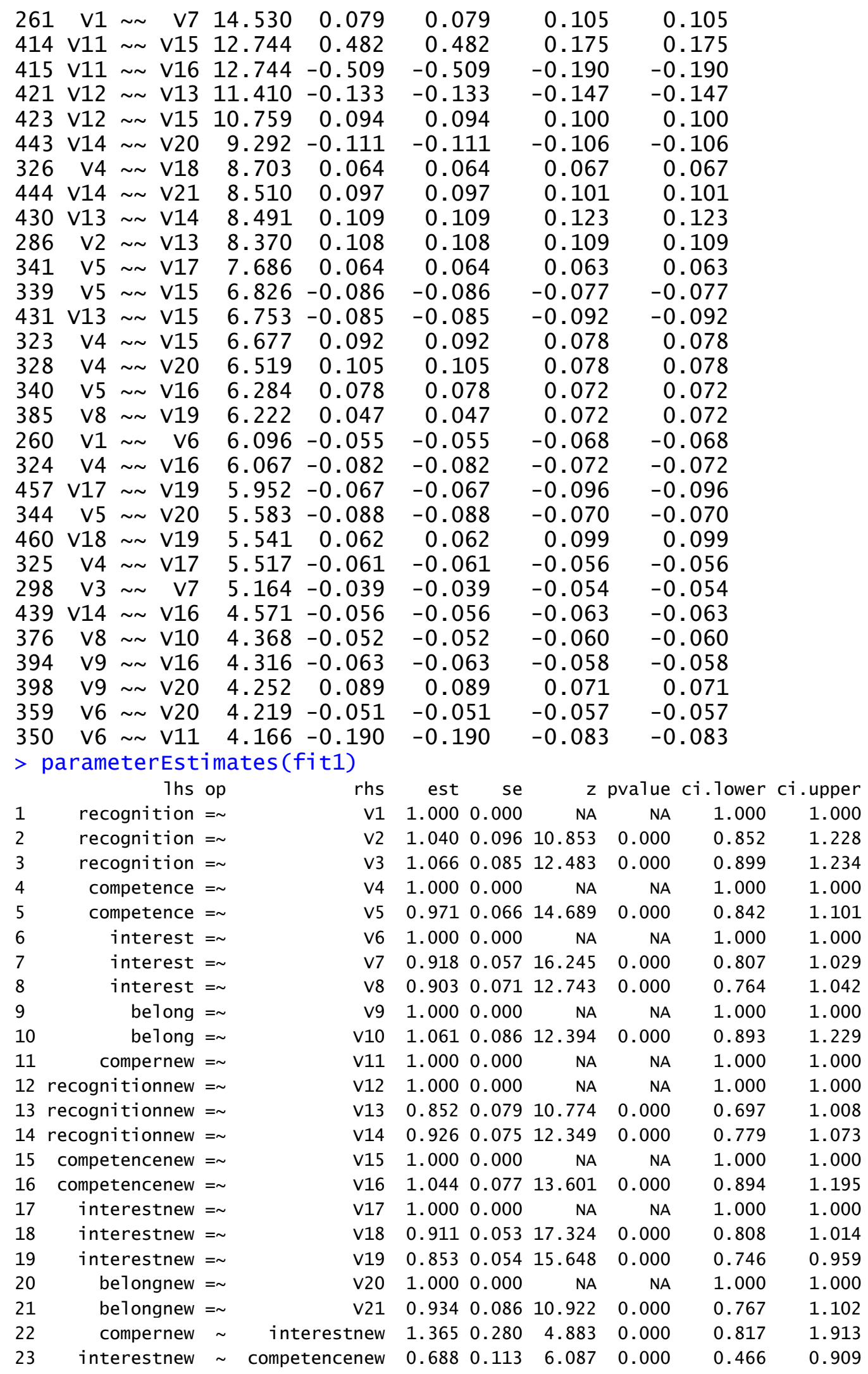




\begin{tabular}{|c|c|c|c|c|c|c|c|c|c|}
\hline 24 & interestnew & $\sim$ & interest & 0.541 & 0.096 & 5.611 & 0.000 & 0.352 & 0.730 \\
\hline 25 & competencenew & $\sim$ & competence & 0.556 & 0.062 & 8.949 & 0.000 & 0.434 & 0.678 \\
\hline 6 & recognitionnew & $\sim$ & recognition & 0.634 & 0.084 & 7.530 & 0.000 & 0.469 & 0.799 \\
\hline 7 & belongnew & $\sim$ & belong & 0.519 & 0.088 & 5.917 & 0.000 & 0.347 & 0.691 \\
\hline 8 & interestnew & $\sim$ & competence & -0.334 & 0.094 & -3.542 & 0.000 & -0.519 & -0.149 \\
\hline & belongnew & $\sim$ & interest & 0.253 & 0.093 & 2.721 & 0.007 & 0.071 & 0.435 \\
\hline 0 & recognitionnew & $\sim \sim$ & competencenew & 0.283 & 0.051 & 5.580 & 0.000 & 0.184 & 0.382 \\
\hline & competencenew & $\sim \sim$ & belongnew & 0.235 & 0.054 & 4.373 & 0.000 & 0.130 & 0.341 \\
\hline 2 & recognitionnew & $\sim \sim$ & belongnew & 0.346 & 0.064 & 5.434 & 0.000 & 0.221 & 0.470 \\
\hline & $\mathrm{v} 1$ & $\sim \sim$ & v1 & 0.351 & 0.050 & 6.956 & 0.000 & 0.252 & 0.450 \\
\hline 4 & v2 & $\sim \sim$ & V2 & 0.392 & 0.056 & 7.011 & 0.000 & 0.282 & 0.502 \\
\hline & v3 & $\sim \sim$ & v3 & 0.181 & 0.036 & 5.034 & 0.000 & 0.111 & 0.252 \\
\hline & V4 & $\sim \sim$ & V4 & 0.329 & 0.060 & 5.493 & 0.000 & 0.212 & 0.447 \\
\hline & V5 & $\sim \sim$ & V5 & 0.221 & 0.050 & 4.435 & 0.000 & 0.123 & 0.318 \\
\hline & v6 & $\sim \sim$ & v6 & 0.107 & 0.024 & 4.537 & 0.000 & 0.061 & 0.153 \\
\hline & v7 & $\sim \sim$ & v7 & 0.097 & 0.020 & 4.773 & 0.000 & 0.057 & 137 \\
\hline 0 & v8 & $\sim \sim$ & v8 & 0.262 & 0.036 & 7.345 & 0.000 & 0.192 & 0.332 \\
\hline & v9 & $\sim \sim$ & v9 & 0.439 & 0.067 & 6.554 & 0.000 & 0.308 & 0.570 \\
\hline 2 & V10 & $\sim \sim$ & v10 & 0.095 & 0.049 & 1.955 & 0.051 & 0.000 & 0.190 \\
\hline & V11 & $\sim \sim$ & V11 & 0.000 & 0.000 & NA & NA & 0.000 & 0.000 \\
\hline & v12 & $\sim \sim$ & V12 & 0.213 & 0.040 & 5.344 & 0.000 & 0.135 & 0.292 \\
\hline & v13 & $\sim \sim$ & v13 & 0.374 & 0.051 & 7.266 & 0.000 & 0.273 & 0.474 \\
\hline 6 & V14 & $\sim \sim$ & V14 & 0.269 & 0.042 & 6.377 & 0.000 & 0.186 & 0.351 \\
\hline & V15 & $\sim \sim$ & V15 & 0.268 & 0.044 & 6.152 & 0.000 & 0.183 & 0.354 \\
\hline 48 & V16 & $\sim \sim$ & V16 & 0.151 & 0.037 & 4.132 & 0.000 & 0.079 & 0.223 \\
\hline 9 & v17 & $\sim \sim$ & v17 & 0.150 & 0.026 & 5.791 & 0.000 & 0.099 & .201 \\
\hline 50 & V18 & $\sim \sim$ & V18 & 0.091 & 0.019 & 4.844 & 0.000 & 0.054 & 0.128 \\
\hline 51 & V19 & $\sim \sim$ & V19 & 39 & 0.022 & 6.435 & 0.000 & & 181 \\
\hline 52 & V20 & $\sim \sim$ & V20 & 0.350 & 0.070 & 4.998 & 0.000 & 0.213 & 0.487 \\
\hline 53 & V21 & $\sim \sim$ & V21 & 0.277 & 0.059 & 4.675 & 0.000 & 0.161 & 393 \\
\hline 54 & recognition & $\sim \sim$ & recognition & 0.656 & 0.114 & 5.758 & 0. & 0.433 & 0.880 \\
\hline 55 & tence & $\sim \sim$ & competence & 1.130 & 0.172 & 6.567 & 0.000 & 0.793 & 1.468 \\
\hline 56 & interest & $\sim \sim$ & interest & 0.551 & 0.078 & 7.039 & 0.000 & 0.398 & 0.705 \\
\hline 57 & belong & $\sim \sim$ & belong & 0.835 & 0.146 & 5.719 & 0.000 & 0.549 & 1.122 \\
\hline 58 & compernew & $\sim \sim$ & compernew & 6.665 & 0.787 & 8.467 & 0.000 & 5.122 & 8.208 \\
\hline 59 & recognitionnew & $\sim \sim$ & recognitionnew & 0.429 & 0.074 & 5.805 & 0.000 & 0.284 & 0.574 \\
\hline 60 & competencenew & $\sim \sim$ & competencenew & 0.339 & 0.063 & 5.387 & 0.000 & 0.216 & 0.462 \\
\hline 61 & interestnew & $\sim \sim$ & interestnew & 0.300 & 0.052 & 5.764 & 0.000 & 0.198 & 0.402 \\
\hline 62 & belongnew & $\sim \sim$ & belongnew & 0.550 & 0.102 & 5.388 & 0.000 & 0.350 & 0.750 \\
\hline 63 & recognition & $\sim \sim$ & competence & 0.623 & 0.104 & 5.998 & 0.000 & 0.420 & 0.827 \\
\hline 64 & recognition & $\sim \sim$ & interest & 0.282 & 0.062 & 4.539 & 0.000 & 0.160 & 0.404 \\
\hline 65 & recognition & $\sim \sim$ & belong & 0.575 & 0.097 & 5.952 & 0.000 & 0.386 & 0.765 \\
\hline 66 & competence & $\sim \sim$ & interest & 0.451 & 0.084 & 5.382 & 0.000 & 0.287 & 0.615 \\
\hline 67 & competence & $\sim \sim$ & belong & 0.654 & 0.115 & 5.682 & 0.000 & 0.428 & 0.879 \\
\hline 68 & interest & $\sim \sim$ & belong & 0.255 & 0.067 & 3.810 & 0.000 & 0.124 & 0.387 \\
\hline 69 & compernew & $\sim \sim$ & recognitionnew & -0.026 & 0.131 & -0.197 & 0.844 & -0.282 & 0.231 \\
\hline 70 & compernew & $\sim \sim$ & belongnew & 0.079 & 0.167 & 0.470 & 0.638 & -0.249 & 0.406 \\
\hline
\end{tabular}


VITA

\section{MOHSEN TAHERI}

Born, Iran

2004-2009

BSc Computer Science

Azad University

Isfahan, Iran

2010-2014

MSc Computer Science

Azad University

Isfahan, Iran

$2014-2020$

Doctoral Candidate

Florida International University

Miami, Florida

\section{PUBLICATIONS AND PRESENTATIONS}

Taheri, M., Ross, M., Hazari, Z., Weiss, M., Georgiopoulos, M., Christensen, K., ... \& Chari, D. (2018, October). A Structural Equation Model Analysis of Computing Identity Sub-Constructs and Student Academic Persistence. In 2018 IEEE Frontiers in Education Conference (FIE) (pp. 1-7). IEEE.

Taheri, M., Ross, M., Hazari, Z., Weiss, W., Georgiopoulos, M., Christensen, K., ... \& Chari, D. (2019, January). Exploring Computing Identity and Persistence Across Multiple Groups Us-ing Structural Equation Modeling. In American Society for Engineering Education (ASEE) Conference Proceedings.

Under review: ACM TOCE (Journal)

Taheri, M., Ross, M., Hazari, Z., Weiss, W., Georgiopoulos, M., Christensen, K., ... \& Chari, D. Understanding Computing Persistence and Identity Through Structural Equation Modeling with Time Series Data 